
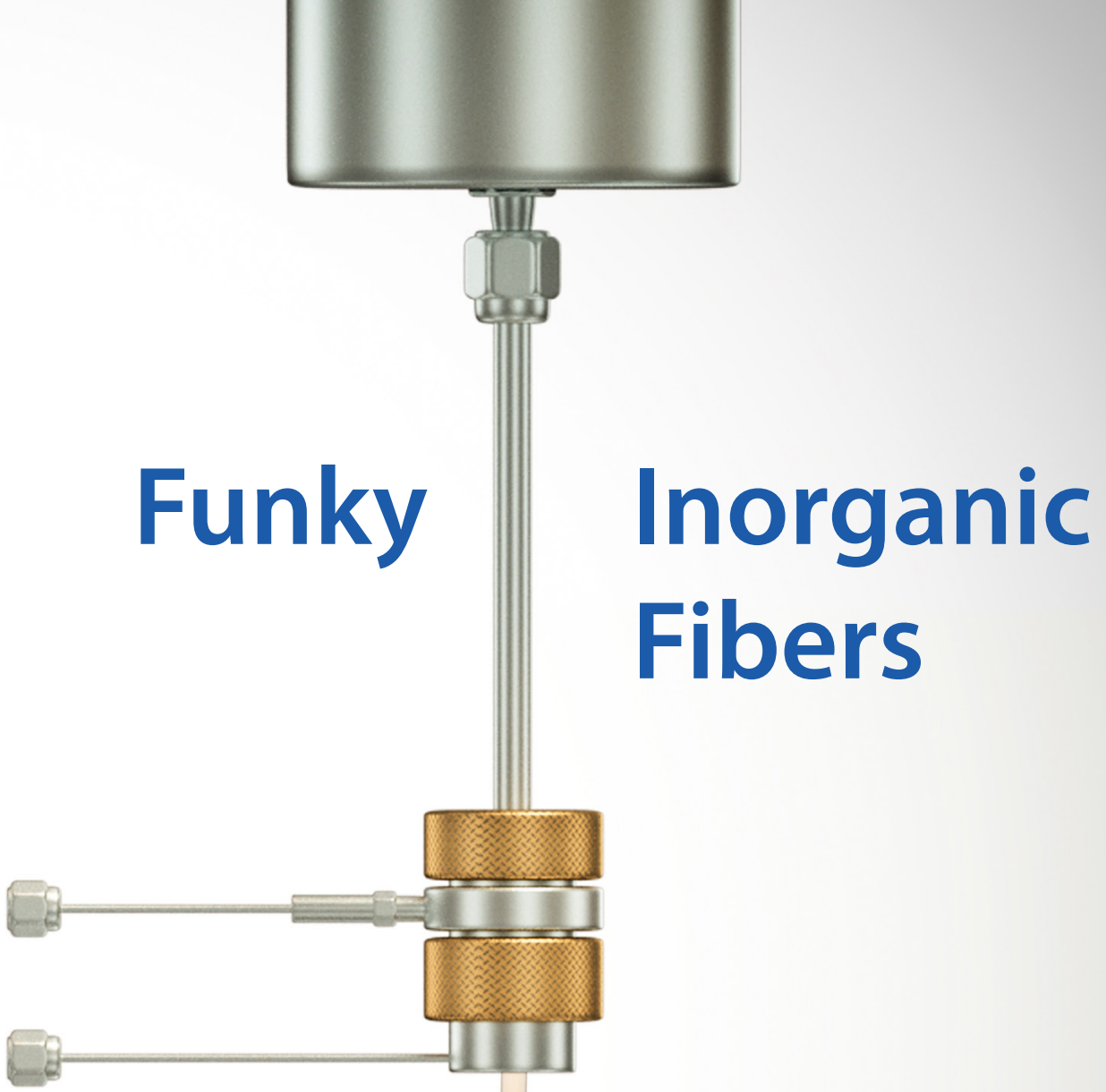


\section{Funky Inorganic Fibers}

Patrick de Wit 


\section{Promotiecomissie}

prof. dr. ir. J.W.M Hilgenkamp (Voorzitter) Universiteit Twente

prof. dr. ir. N. E. Benes (Promotor) Universiteit Twente

prof. dr. ir. A. Nijmeijer (Promotor) Universiteit Twente

prof. dr. ing. M. Wessling

RWTH Aachen

dr. A. Buekenhout

VITO

dr. F. Gallucci

prof. dr. ir. L. Lefferts

prof. dr. G. Mul

Technische Universiteit Eindhoven

Universiteit Twente

Universiteit Twente

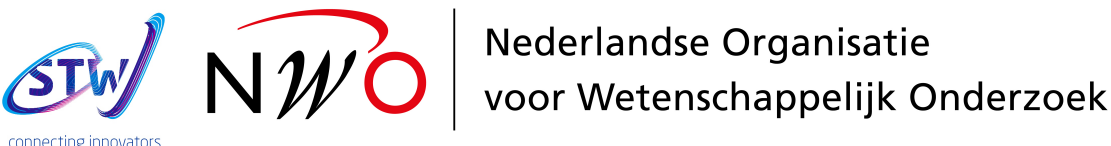

This work is part of the research program IFF with project number 12543, which is (partly) financed by the Netherlands Organisation for Scientific Research (NWO).

Funky Inorganic Fibers

ISBN: $\quad$ 978-90-365-4327-9

DOI: $\quad 10.3990 / 1.9789036543279$

URL: $\quad$ https://dx.doi.org/10.3990/1.9789036543279/

Print: $\quad$ Gildeprint

(C) Patrick de Wit, Enschede, The Netherlands

(C) Cover design by Somersault18:24 


\section{FUNKY INORGANIC FIBERS}

\section{PROEFSCHRIFT}

ter verkrijging van

de graad van doctor aan de Universiteit Twente, op gezag van de rector magnificus, prof. dr. T.T.M. Palstra, volgens besluit van het College voor Promoties, in het openbaar te verdedigen op 30 juni 2017 om 16:45 uur

door

\section{Patrick de Wit} geboren op 30 juni 1988 te Dordrecht, Nederland 
Dit proefschrift is goedgekeurd door de promotoren prof. dr. ir. N. E. Benes (promotor) prof. dr. ir. A. Nijmeijer (promotor) 


\section{Table of Contents}

Table of Contents 5

$\begin{array}{ll}\text { Summary } & 9\end{array}$

$\begin{array}{ll}\text { Samenvatting } & 13\end{array}$

1 Introduction to inorganic porous hollow fibers $\quad 17$

1.1 Inorganic porous hollow fibers . . . . . . . . . . . . . . . . 18

1.2 Fabrication methods . . . . . . . . . . . . . . . . . 19

1.3 Thermal treatment . . . . . . . . . . . . . . . . 25

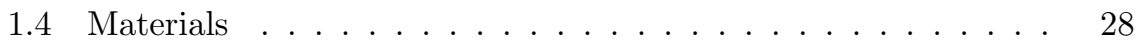

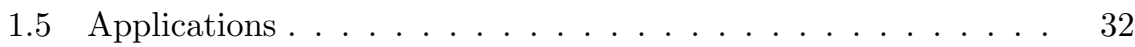

1.6 Scope of this thesis . . . . . . . . . . . . . . . . . 33

1.7 Thesis outline . . . . . . . . . . . . . . . . . 35

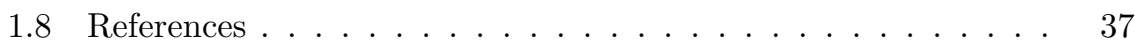

2 Highly permeable and mechanically robust silicon carbide $\begin{array}{ll}\text { hollow fiber membranes } & 47\end{array}$

2.1 Introduction . . . . . . . . . . . . . . . . . . . 49

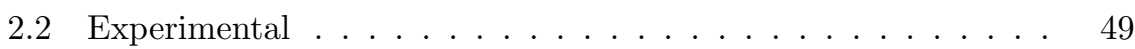

2.3 Results and discussion . . . . . . . . . . . . . . . . 53

2.4 Conclusion ...................... 63

2.5 Acknowledgments . . . . . . . . . . . . . . . 63

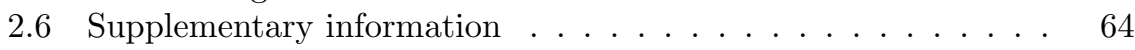

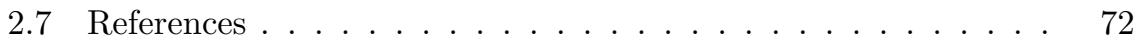


3 Synthesis of porous inorganic hollow fibers without harmful solvents

3.1 Introduction . . . . . . . . . . . . . . . . . . 79

3.2 Experimental . . . . . . . . . . . . . . . . . 80

3.3 Results and discussion . . . . . . . . . . . . . . . . . . . . 82

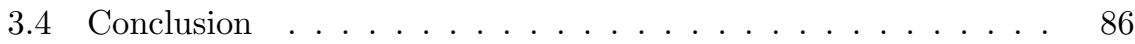

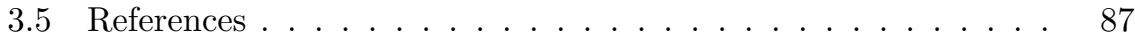

4 Sustainable route to inorganic porous hollow fibers with su$\begin{array}{ll}\text { perior properties } & 91\end{array}$

4.1 Introduction . . . . . . . . . . . . . . . . . 93

4.2 Experimental . . . . . . . . . . . . . . . . . . 95

4.3 Results and discussion . . . . . . . . . . . . . . . . 98

4.4 Conclusion . . . . . . . . . . . . . . . . . . . 107

4.5 Supplementary information . . . . . . . . . . . . . . 108

4.6 References . . . . . . . . . . . . . . . . . 109

5 The mechanical strength of inorganic porous hollow fibers: $\begin{array}{ll}\text { The effect of measurement method } & 115\end{array}$

5.1 Introduction . . . . . . . . . . . . . . . . . 117

5.2 Theoretical background ................. . . . 117

5.3 Experimental . . . . . . . . . . . . . . . . . . 123

5.4 Results and discussion . . . . . . . . . . . . . . . 126

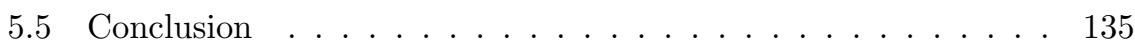

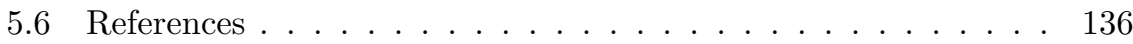

6 The mechanical strength of inorganic porous hollow fibers: $\begin{array}{ll}\text { A comparison between production methods } & 141\end{array}$

6.1 Introduction . . . . . . . . . . . . . . . . . . . 143

6.2 Experimental . . . . . . . . . . . . . . . . . 144

6.3 Data analysis . . . . . . . . . . . . . . . . . 146

6.4 Results and discussion . . . . . . . . . . . . . . . . . . 147

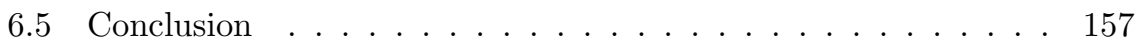

6.6 References ........................... 158 
7 Tunable permeability and selectivity: Heatable ceramic membranes with thermo-responsive microgel coating 163

7.1 Introduction . . . . . . . . . . . . . . . . . . . . 165

7.2 Experimental . . . . . . . . . . . . . . . 167

7.3 Results and discussion . . . . . . . . . . . . . . . 170

7.4 Conclusion . . . . . . . . . . . . . . . . . . . 179

7.5 Acknowledgements . . . . . . . . . . . . . . . . 180

7.6 References . . . . . . . . . . . . . . . . . . . 181

8 Inorganic porous hollow fibers as support material for thin layers by interfacial polymerization $\quad \mathbf{1 8 5}$

8.1 Introduction . . . . . . . . . . . . . . . . 187

8.2 Experimental . . . . . . . . . . . . . . . . . . . . 188

8.3 Results and discussion . . . . . . . . . . . . . . . . . . . 191

8.4 Conclusion . . . . . . . . . . . . . . . . . 196

8.5 References . . . . . . . . . . . . . . . . . . . . 197

9 Reflections and perspectives $\quad 201$

9.1 Reflections . . . . . . . . . . . . . . . . . . . . 203

9.2 Perspectives . . . . . . . . . . . . . . . . . . . . . 208

9.3 References . . . . . . . . . . . . . . . . . . . . 224

$\begin{array}{ll}\text { Dankwoord } & 229\end{array}$

$\begin{array}{ll}\text { Curriculum Vitae } & 233\end{array}$

$\begin{array}{ll}\text { List of publications } & 235\end{array}$ 



\section{Summary}

Inorganic porous hollow fibers are interesting for various applications that could benefit from a high surface-area-to-volume ratio, such as membranes, catalysts, electrodes, or a combination of these.

The introduction in chapter 1 starts with an overview of conceivable materials and applications for inorganic porous hollow fibers, followed by a brief account of the major methods that are currently used to fabricate such fibers. Particular emphasis is given to the dry-wet spinning of polymer/solvent/particle mixtures into a coagulation bath. Next, it discusses the intricacies of the thermal treatment that the spun fibers undergo to remove the polymeric binder and to sinter the inorganic particles together. Finally, the chapter provides the scope and outline of the thesis.

Chapter 2 describes a production method for the fabrication of silicon carbide (SiC) hollow fibers by non-solvent induced phase separation. This method produces fibers with sufficient mechanical strength after thermal treatment at temperatures of $1500{ }^{\circ} \mathrm{C}$ in argon. The fibers still contain a substantial amount of residual carbon that can be removed with additional thermal treatment at temperatures in the range of $1790-2075^{\circ} \mathrm{C}$. Removal of the residual carbon results in a loss of mechanical strength. Only at extreme temperatures of $2075^{\circ} \mathrm{C}$, the $\mathrm{SiC}$ particles sinter sufficiently together to obtain a mechanically robust silicon carbide fiber. The fibers showed a 4-point bending strength of $30-40 \mathrm{MPa}$, together with extremely high clean water fluxes of $50000 \mathrm{~L} \mathrm{~m}^{-2} \mathrm{~h}^{-1} \mathrm{bar}^{-1}$. These silicon carbide fibers can be used directly as a microfiltration membrane, or as a membrane support. 
Chapter 3 describes a production method for inorganic porous hollow fibers that circumvents the use of organic solvents, such as N-methylpyrrolidone or dimethyl sulfoxide. The method is based on ionic cross-linking of a sodium alginate polymer in order to arrest the inorganic particles. This cross-linking is carried out using multivalent cations such as $\mathrm{Ca}^{2+}, \mathrm{Mg}^{2+}, \mathrm{Cu}^{2+}$ and $\mathrm{Al}^{3+}$ that are supplied from the gelation bath. In contrast to non-solvent induced phase separation, ionic cross-linking circumvents the formation of a polymerlean phase and the associated large macrovoids in the fiber wall. In addition, the introduced multivalent ion persists in the fiber after thermal treatment, allowing the facile incorporation of functional metal oxides on the pore surface of the fiber.

Chapter 4 presents a modification of the ionic cross-linking that is discussed in chapter 3 . Here, the multivalent cations are added directly to the spinning mixture in the form of an insoluble carbonate salt. This mixture is then spun into an acidic gelation bath, where the low $\mathrm{pH}$ triggers the dissociation of the carbonate into multivalent cations and carbon dioxide. The multivalent ions cross-link the alginate, thereby consolidating the 3D structure. Adequate gelation requires a sufficiently low $\mathrm{pH}$ of the acid bath and a sufficient buffering capacity of the acid. In order to facilitate proper cross-linking, it is crucial that the acid has a conjugated base with limited propensity for complexing the cations. Lactic and acidic acid are shown to be suitable acids for this method. The fibers prepared via this method show outstanding properties, such as high mechanical strength, a homogeneous morphology, and a sharp distribution of narrow pores.

Chapter 5 discusses the effect of different measurement geometries on the measured mechanical strength of $\mathrm{Al}_{2} \mathrm{O}_{3}$ porous hollow fibers. The value obtained for the mechanical strength depends strongly on the measurement method; values from 3-point bending tests are systematically lower as compared to values from 4-point bending tests. The specimen size also influences the measured value; a larger span size systematically results in lower strength values. A statistical analysis of the strength data has been conducted to attain the failure probability of the fibers. It is found that fibers prepared using phase inversion do not necessarily follow the Weibull model and other models (e.g., normal or log-normal) have to be considered. In particular for systems design it is important that the statistical representation of the strength distribution is accurate. An inappropriate distribution may predict the wrong design strength, potentially resulting in premature failure. 
Chapter 6 continues on the statistics associated with the mechanical strength of inorganic porous hollow fibers. It investigates the effect of production methods, and the resultant micro structures, on the mechanical strength using a standardized 4-point bending test. Fibers were prepared using non-solvent induced phase separation (NIPS), internal, and external bio-ionic gelation (BIGI and BIG-E). Fibers prepared using BIG-I seem to have a larger bending strength compared to fibers prepared using NIPS or BIG-E, yet have a larger scatter in their strength data. This greater strength originates from better stacking of the inorganic particles, caused by the low $\mathrm{pH}$ used during their fabrication. The low $\mathrm{pH}$ results in a surface charge of the particles facilitating a more homogenous stacking. To predict failure behavior, statistical models are fitted to the measured strength data. All production methods result in fibers of which the strength distribution appears to follows a Weibull model, in which failure occurs at the weakest-link. The BIG-I fibers have a large scatter in their strength data, which is likely due to surface deformations present in the fiber wall that act as a weak link. If the strength data is re-analyzed with the surface-deformed fibers excluded, the BIG-I fibers no longer follow the Weibull model but start to follow a normal distribution. This shows that BIG-I based fibers have great potential with respect to their mechanical strength. At this moment, their strength is limited by deformations that occur during production, contrary to NIPS fibers where inherent macrovoids and less ideal stacking of the particles cause the weakness.

Chapter 7 discusses the use of electrically conductive silicon carbide-carbon fibers to adjust membrane selectivity and permeability. On the surface of this fiber, thermo-responsive poly ( $N$-vinylcaprolactam) (P-VCL) microgels have been immobilized. The permeability and selectivity of the membrane can be adjusted by controlling the applied electrical power to the membrane. The thermo-responsiveness is reversible and stable in all the conducted experiments. No change in permeability over time is observed, indicating inconsiderable microgel loss. Also during backwash the permeability remains constant. The hydraulic resistance of the membrane is affected by the hydrodynamic radius of the microgel. Electrical heating of the membrane is found to be $14 \%$ more energy efficient compared to heating of the whole feed stream, when operating in crossflow conditions. 
Chapter 8 outlines the prerequisites in order to use inorganic porous hollow fibers as a support material for thin films prepared by interfacial polymerization. By modification of the surface with multiple inorganic repair layers, a (poly)amide layer is prepared on the outside of the fiber. Defect free films are only obtained when the fiber is coated with $\gamma$-alumina, which increases the amount of hydroxyl-groups on the surface and provides a large volume of small pores for the aqueous phase. The hydroxyl groups allow for covalent attachment of the film to the ceramic substrate. In the fabrication process, the vertical drying step after immersion in the aqueous phase is identified to be critical for obtaining a high quality layer. Inadequate drying (locally) results in excess of the aqueous phase on the outer wall of the fiber, causing film formation to occur at a distance from the ceramic fiber and preventing the hydroxyl groups to participate in the polymerization. The prepared fibers showed acceptable clean water fluxes $\left(2-4 \mathrm{~L} \mathrm{~m}^{-2} \mathrm{~h}^{-1} \mathrm{bar}^{-1}\right)$ and good retention of Rose Bengal dye $\left(1017 \mathrm{~g} \mathrm{~mol}^{-1}\right)$.

The final chapter 9 reflects on the main findings of this thesis and attempts to put the results in perspective. The chapter also suggests possible routes for further research, focusing on functional fibers and the application thereof. 


\section{Samenvatting}

Poreuze anorganische holle vezels zijn interresant in toepassingen waar een groot oppervlakte per volume eenheid is vereist, zoals membraantechnologie, katalyse, elektrodes of een combinatie hiervan.

Het inleidende hoofdstuk 1 geeft een overicht van mogelijke materialen en toepassingen van anorganise poreuze holle vezels. Het geeft uitleg over de, op dit moment, belangrijkste fabrikagemethodes om deze vezels te maken. Hierbij wordt specifiek ingegaan op het 'dry-wet' spinnen van vezels, gemaakt van standaard mengsels van polymeer/oplosmiddel/anorganische deeltjes. Daarnaast wordt de thermische behandeling om het polymeer te verwijderen en de anorganische deeltjes aan elkaar te sinteren behandeld, gevolgd door een kort overzicht van mogelijke toepassingen van deze vezels. Het hoofdstuk wordt afgesloten door een uiteenzetting over het doel van dit proefschrift.

In hoofdstuk 2 word een productiemethode voor silicium carbide ( $\mathrm{SiC}$ ) holle vezels beschreven waarin gebruik wordt gemaakt van fasescheiding. Uit deze methode worden vezels met voldoende mechanische sterkte verkregen na een thermische behandeling op $1500{ }^{\circ} \mathrm{C}$ in een argon atmosfeer. De resulterende vezels bevatten nog een significante hoeveelheid achtergebleven koolstof. Om dit te verwijderen is een thermische behandeling rond $1790-2075{ }^{\circ} \mathrm{C}$ vereist. Echter sinteren de $\mathrm{SiC}$ deeltjes alleen bij een extreme temperatuur van $2075^{\circ} \mathrm{C}$ voldoende aan elkaar om een mechanisch robuuste vezel te verkrijgen. Deze techniek levert vezels op met een 4-punts buigsterkte van 30-40 MPa op en een extreem hoge schoonwaterpermeabiliteit van $50000 \mathrm{~L} \mathrm{~m}^{-2} \mathrm{~h}^{-1} \mathrm{bar}^{-1}$. Deze silicium carbide vezels kunnen direct toegepast worden als microfiltratiemembraan of als membraandrager voor andere scheidingen. 
Hoofdstuk 3 beschrijft een productiemethode voor anorganische poreuze holle vezels die het gebruik van organische oplosmiddelen zoals $\mathrm{N}$-methylpyrrolidon of dimethylsulfoxide overbodig maakt. De werkwijze is gebaseerd ionische verknoping van natrium-alginaat polymeer om de anorganische deeltjes te consolideren in een vezelstructuur. De verknoping wordt uitgevoerd door multivalente kationen zoals $\mathrm{Ca}^{2+} \mathrm{Mg}^{2+}, \mathrm{Cu}^{2+}$ en $\mathrm{Al}^{3+}$, welke worden aangeleverd vanuit het gelatiebad. Door het gebruik van ionische verknoping zijn er geen grote 'macrovoids' aanwezig in de vezelwand, die daardoor symmetrisch is. De multivalente ionen blijven bovendien na de thermische behandeling als oxide aanwezig in de vezel, waardoor op eenvoudige wijze functionele metaaloxiden aan het porieoppervlak van de vezel kunnen worden toegevoegd.

In hoofdstuk 4 wordt een modificatie van de ionische verknoping gepresenteerd. Hier worden de multivalente kationen direct toegevoegd aan het alginaat/deeltjes mengsel, in de vorm van een onoplosbaar carbonaat. Het mengsel wordt bij deze techniek gesponnen in een zuur gelatiebad, waarbij de lage $\mathrm{pH}$ leidt tot de dissociatie van het carbonaat in de multivalente kationen en kooldioxide. De multivalente ionen verknopen het alginaat, waarbij de 3Dstructuur vastgezet wordt. De gelering vereist een voldoende lage $\mathrm{pH}$ van het zuurbad en buffercapaciteit van het zuur. Verder is het cruciaal dat het zuur een geconjugeerde base heeft met beperkte neiging tot complexeren van de kationen. Melkzuur en azijnzuur zijn hiervoor erg geschikt en vezels bereid hiermee laten uitstekende eigenschappen zien. De bereidde vezels vertonen een hoge mechanische sterkte, een homogene morfologie en een scherpe verdeling van nauwe poriën.

Hoofdstuk 5 bespreekt het effect van verschillende meetgeometrien op de gemeten mechanische sterkte van $\mathrm{Al}_{2} \mathrm{O}_{3}$ poreuze holle vezels. De mechanische sterkte is sterk afhankelijk van de meetmethode, zo blijken waardes verkregen met een 3-punts buigtest systematisch lager te zijn in vergelijking tot waardes verkregen door 4-punts buigtest. Het hoofdstuk benoemt ook het effect van specimenlengte tijdens deze buigproeven; een grotere overspanning resulteert in lagere sterktes. De met de verschillende methodes verkregen resultaten zijn statistisch geanalyseerd om de faalkans van de vezels te beschrijven. Tijdens deze analyse is gebleken dat vezels die bereid zijn met fasescheiding niet noodzakelijkerwijs een Weibull verdeling volgen, maar dat ook andere verdelingen zoals de normale of log-normale verdeling moeten worden overwogen. Een foutieve aanname over de verdeling zou kunnen leiden tot verkeerde ontwerpparameters, met voortijdig falen als gevolg. 
Hoofdstuk 6 gaat verder in op de statistiek achter de mechanische sterkte van anorganische poreuze holle vezels. Het beschrijft het effect van de productiemethode, en resultante microstructuur, op de mechanische sterkte, bepaald met behulp van een gestandaardiseerde 4-punts buigtest. Hiervoor werden vezels bereid met faseinversie (NIPS), interne- en externe bio-ionische gelering (BIG-I en BIG-E). Vezels bereid met behulp van de BIG-I methode lijken een hogere buigsterkte te hebben in vergelijking met vezels bereid via NIPS of BIGE, maar hebben een grote spreiding. De hogere sterkte komt vermoedelijk door de betere stapeling van de anorganische deeltjes, onder invloed van de lage $\mathrm{pH}$ tijdens de productie. Om faalgedrag te voorspellen zijn statistische modellen gefit op de gemeten sterkte-data. Hieruit bleek dat alle productiemethoden resulteren in vezels waarvan de sterkte een Weibull verdeling volgt, waarin falen optreedt bij de zwakste schakel. Vezels bereid door de BIG-I methode hebben een grotere spreiding in vergelijking met vezels gemaakt met de NIPS methode. Dit komt door vervormingen in de wand van de vezel, die als een zwakke schakel optreden. Als de sterkte opnieuw word geanalyseerd, met uitsluiting van de vervormde vezels, dan volgen de BIG-I vezels geen Weibull verdeling meer maar een normale verdeling. Dit toont aan dat op BIG-I gebaseerde vezels een groot potentieel hebben met betrekking tot hun mechanische sterkte. Op dit moment is de sterkte beperkt door vervormingen die optreden tijdens de productie, en niet door de inherente macrovoids of minder goede stapeling van de anorganische deeltjes, wat wel het geval is voor de NIPS vezels.

Hoofdstuk 7 bespreekt het gebruik van elektrisch geleidende siliciumcarbidekoolstofvezels om membraan- selectiviteit en permeabiliteit aan te passen. Op het oppervlak van de vezel werden warmtegevoelige poly $(N$-vinylcaprolactam $)$ (P-VCL) microgels geïmmobiliseerd. Door aanpassing van de elektrische stroom door het membraan kan de permeabiliteit en selectiviteit van het membraan kan worden aangepast. De microgel coating blijft gedurende dit proces stabiel, wat blijkt uit de onverandere permeabiliteit over tijd. Zelfs tijdens meerdere terugspoel-cycli blijft de permeabiliteit constant. De warmte reactie blijft bovendien omkeerbaar. De hydraulische weerstand van het membraan gedraagt zich volgens de hydrodynamische straal van de microgel, die op zichzelf een functie is van de temperatuur. De elektrische verwarming van het membraan is energie efficiënter vergeleken met het opwarmen van de gehele voedingsstroom onder cross-flow condities en levert een besparing van $14 \%$. 
Hoofdstuk 8 bespreekt de voorwaarden om dunne poly(amide) films op anorganische vezels te maken door grensvlakpolymerisatie. Door modificatie van het oppervlak met meerdere anorganische reparatielagen kan een poly(amide) film bereid worden op de buitenzijde van de vezel. Om defectvrije films te verkrijgen moet de vezel bekleed worden met $\gamma$-alumina, die de hoeveelheid hydroxylgroepen aan het oppervlak vergroot en zorgt voor een voldoende porievolume voor de waterige reactiefase. De hydroxylgroepen zorgen voor een covalente binding tussen de film en het keramische substraat. De verticale droogstap, na onderdompeling in de waterige reactantoplossing, is cruciaal voor het verkrijgen van een laag van hoge kwaliteit. Onvoldoende droging resulteert in plekken met een overmaat aan reactantoplossing, met als resultaat dat de film zich op een afstand van de wand zal vormen. Hierdoor kunnen de hydroxylgroepen van de vezelwand niet participeren in de polymerisatie. De uiteindelijk gefabriceerde vezels laten een goede schoonwaterpermeatie $\left(2-4 \mathrm{~L} \mathrm{~m}^{-2} \mathrm{~h}^{-1} \mathrm{bar}^{-1}\right)$ zien en hebben een retentie hoger dan $99 \%$ voor kleurstof met een molmasse van $1017 \mathrm{~g} \mathrm{~mol}^{-1}$.

Het laatste hoofdstuk 9 kijkt terug op de belangrijkste resultaten die in dit proefschrift worden behandeld en probeert deze resultaten in een breder perspectief te plaatsen. Daarop aanvullend worden suggesties gedaan voor verder onderzoek ten aanzien van functionele vezels. 
Chapter 1

\section{Introduction to inorganic porous hollow fibers}




\subsection{Inorganic porous hollow fibers}

Hollow fibers are defined as a capillary with an inside diameter larger than $25 \mu \mathrm{m}$ and an outside diameter smaller than $1 \mathrm{~mm}$ [1]. Due to their small radial dimensions, hollow fibers allow for a very large surface-to-volume ratio $\left(2000 \mathrm{~m}^{-1}\right.$ to $\left.16000 \mathrm{~m}^{-1}\right)$.

Polymeric hollow fibers were first reported in the 1960s and are omnipresent today [2]. Major applications of polymeric fibers are in medical devices, in water reclamation, or in gas separation $[1,3]$. To illustrate the scale and maturity of this technology, over 1 million hemodialysis membrane modules are produced on a daily basis, and each of these modules holds over a kilometer of hollow fiber [4].

Inorganic hollow fibers potentially outperform their polymeric counterparts in terms of thermal and chemical stability. The first inorganic $\mathrm{Al}_{2} \mathrm{O}_{3}$ hollow fibers have been reported in 1991 by Okubo et al.[5]. Today, hollow fibers consisting of a variety of inorganic materials are made with radial dimension down to $<0.25 \mathrm{~mm}[6,7]$. The broad variety in materials and dimensions is illustrated in Figure 1.1.

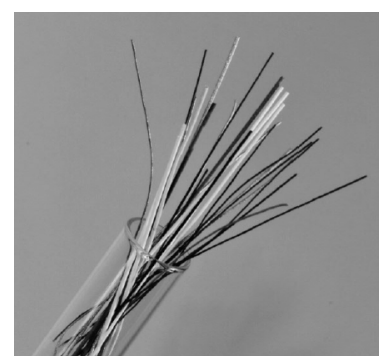

Figure 1.1: A test tube showing a variety of inorganic porous hollow fibers, including stainless steel, alumina, nickel, YSZ and $\mathrm{SiC}$

One of the major envisioned applications of inorganic fibers is their use as membrane, given that inorganic porous hollow fibers have several advantages over polymeric hollow fibers. For example, inorganic fibers have excellent chemical and thermal stability which allows for a larger operating window in membrane separations; examples include gas separation at high temperature [8], under corrosive environments $[9,10]$, or high pressure [11]. The unique properties of the inorganic fibers also allows for different applications, such as the use as catalyst support $[12,13]$, as gas diffusing electrode [14] or microreactor [15-17] 
Despite their potential, these fibers are limited available on a commercial scale, which might be attributed to their expensive and time consuming production method. Widespread industrial application is not only limited due to availability, but also due to challenges with the mechanical strength of the fibers, with fiber sealing, and with multi-fiber module design and construction.

\subsection{Fabrication methods}

Several processes for making single layer inorganic hollow fibers have been reported in literature, including extrusion [7, 18], wet and dry-wet spinning [5, 19-22], and template methods [23, 24]. All of these methods consist of the generalized 4-step production process that is schematically outlined in Figure 1.2. In the first two steps the a so-called "green" hollow fiber is prepared. In the first step an inorganic particle loaded mixture or paste is forced to take on the shape of a hollow fiber. In the second step this geometry is consolidated. The result is a hollow fiber loaded with inorganic particles. In the subsequent steps three and four, all but the inorganic particles are removed by increasing the temperature, followed by sintering of the inorganic particles at even higher temperatures.
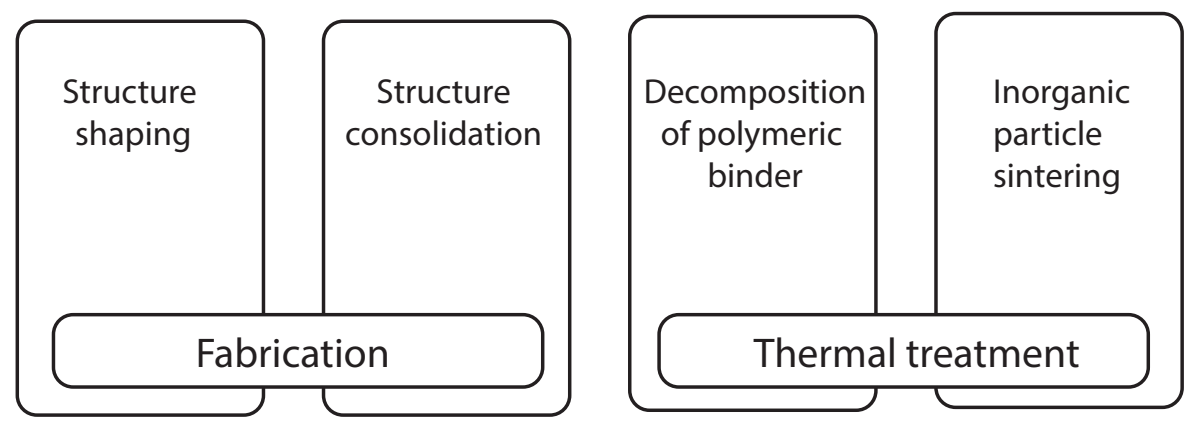

Figure 1.2: Schematic representation of the steps present in the fabrication process of inorganic porous hollow fibers. 


\subsubsection{Extrusion}

During extrusion, a mixture of inorganic particles, binder and additives such as dispersant, plasticizer or pore formers is extruded through an extruder head to form a fiber. Most extruder heads consist of a tip through which a bore-former is co-extruded and an annulus through which the mixture is extruded, resulting in a green body with a cylindrical and hollow shape. During thermal treatment, the binder and additives are removed and the inorganic particles are sintered together [25]. Usually, relatively high particle loadings are utilized, resulting in little shrinkage upon removal of the binder. As a result, the porosity is often low which can be increased by the addition of pore formers [26]. These pore formers are removed in a later stage, and upon removal additional pores are created. Removal is mostly done by thermal treatment or acid leaching. The extrusion-derived hollow fibers generally have a relatively large outer diameter (>1 mm), large pore size, and a symmetric wall structure [7, 18, 26, 27]. A post treatment involving surface modification or coating is usually required to reduce the pore size.

\subsubsection{Spinning}

Spinning is in many ways comparable to extrusion, including the use of a tipin-orifice spinneret to force a particle containing mixture into a hollow fiber shape. In spinning, the inorganic particles are dispersed into a liquid polymer solution or in a melted polymer. As the polymer exits the spinneret, it solidifies into a hollow fiber by non-solvent induced phase separation (wet and dry-wet spinning), by cross-linking (UV, ionic), or by cooling down (melt spinning). In order to keep the fiber hollow, a second phase is introduced via the tip of the spinneret, which can be air in the case of melt spinning, or a non-solvent in the case of non-solvent induced phase separation. During solidification of the structure a front passes through the fiber wall, which often results in a a-symmetric structure [28].

Figure 1.3A shows a schematic representation of a dry-wet spinning setup. A mixture of polymer and solvent is pressurized in a feed vessel and pressed through the spinneret. Here, the bore-liquid is introduced to keep the fiber hollow. Figure 1.3B shows the detail of the spinneret, in which the tip and annulus are clearly visible. After the mixture exits the spinneret it travels through an air gap, where a fraction of the solvent may evaporate vausing the outside of the fiber to solidify. In the coagulation bath the mixture further solidifies. In this step, the cross-sectional morphology of the green fiber is final. 


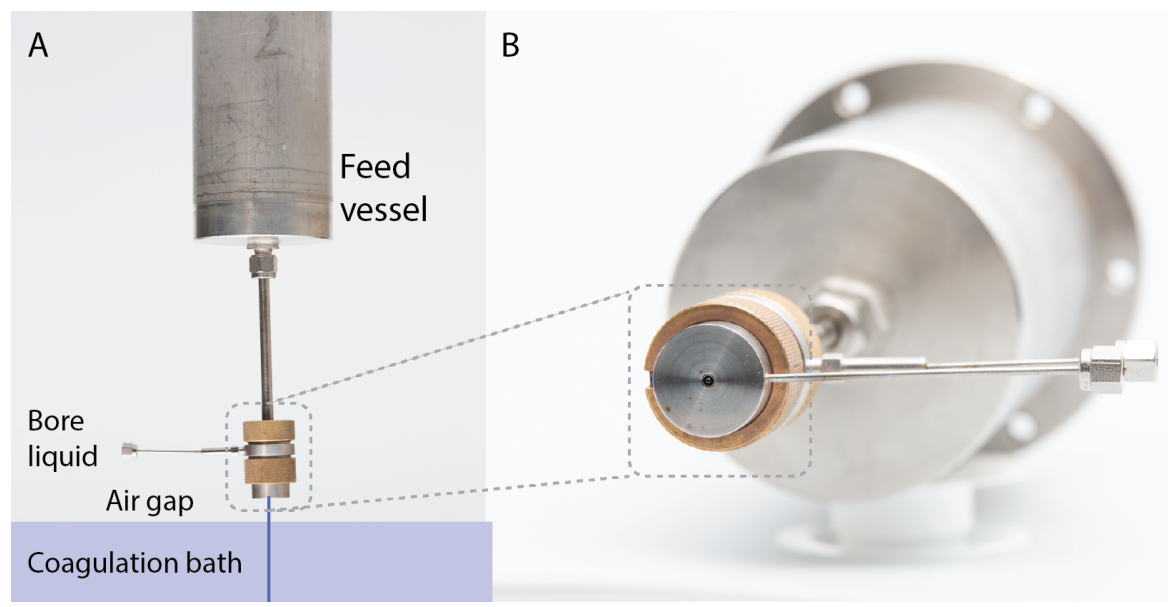

Figure 1.3: A schematic representation of a dry-wet spinning setup (A) and a detailed photograph of a spinneret (B)

Spinning also allows the fabrication of multi-layered systems, by using a spinneret with additional annular openings. The use of multi-layer spinnerets for inorganic fibers comprising an inner and outer layer has been reported by de Jong et al. [29]. The extra annular openings can also be used to introduce different (non-)solvents, such as ethanol or glycerol, to delay the phase inversion process of the outer region region of the fiber. This approach is also used for polymeric hollow fibers to allow localized reactions in the outer region [30, 31].

\subsubsection{Structure consolidation}

After forcing the inorganic particle loaded mixture to take on the shape of a hollow fiber, it requires a step to, temporarily, consolidate its shape before a thermal treatment can be given. Various methods are used to consolidate a structure, that are not limited to hollow fibers. Techniques such as UV crosslinking of a photopolymer [32], ionic cross-linking of a hydrogel [33-35] or freeze drying $[36,37]$ were successfully modified by the addition of inorganic particles, followed by a thermal treatment to obtain an inorganic structure. One of the most used techniques to consolidate the structure is based on phase inversion of a polymer/solvent mixture by means of a non-solvent $[1,38]$. 


\section{Non-solvent induced phase separation}

During non-solvent induced phase separation (NIPS), a polymer dissolved in a suitable solvent is put into contact with a non-solvent. Upon contact with the non-solvent, phase separation results in the formation of two phases, one containing predominantly polymer, whereas the other contains mostly solvent and non-solvent. A wide range of polymer structures can be obtained via phase separation. The finally obtained structure depends on the thermodynamics as well as the kinetics of phase separation.

This process has been extensively studied for the formation of polymeric membranes $[1,38,39]$. Figure 1.4 shows the phase diagram for a typical membrane forming system based on non-solvent induced phase separation. The system is based on three components; a polymer, a solvent, and a non-solvent, that is miscible with the solvent but not with the polymer. The corners of the ternary diagram represent pure components and the sides represent binary mixtures of the two components connected.

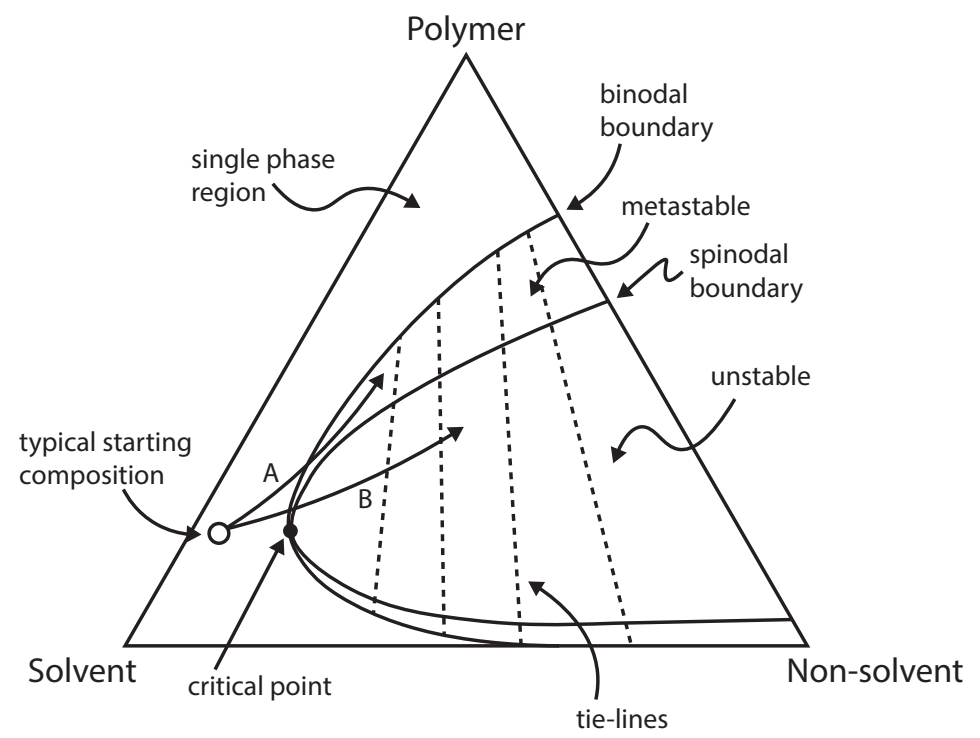

Figure 1.4: Ternary phase diagram of a simple membrane forming system of a polymer, solvent and a non-solvent. A and B indicate two possible paths through which phase separation can occur. 


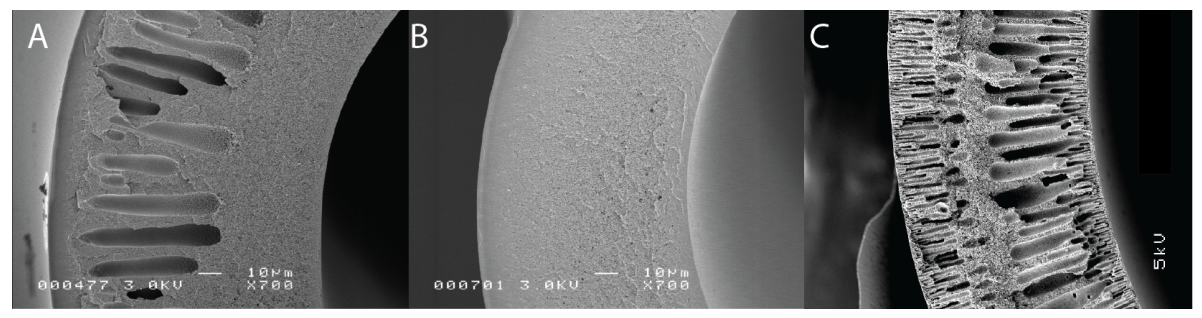

Figure 1.5: Scanning electron micrographs of polymeric fiber walls with a) large macrovoids, b) sponge like structures, c) asymmetrical structure containing regions with macrovoids and sponge like structures.

The binodal boundary divides the phase diagram into a single-phase region, where the three components are miscible in all compositions, and a two-phase region, where the system separates into two phases. The compositions of the two different phases are connected by tie-lines. After phase separation, the polymer-rich phase forms the solid part of the membrane, whereas the polymerlean phase forms the macro voids and pores. The two-phase region can be further divided into a metastable region and an unstable region.

The metastable region is situated between the binodal and spinodal boundaries. In this metastable region phase separation is thermodynamically favored but the system is stable against small concentration fluctuations. Within this region, phase separation proceeds via nucleation and growth of one of the phases (path A, Figure 1.4). In the spinodal region all compositions are unstable and the phase transition is characterized by a fast and uniform separation of the two phases (path B, Figure 1.4).

The exact path through the phase diagram is much more complicated and is influenced by many factors, such as the spinning dope composition, the type of non-solvent used or the spinning parameters. These factors strongly determine the final morphology of the fiber, and a vast amount of structures can be obtained. Figure 1.5 shows some typical structures that can be obtained with non-solvent induced phase separation.

For membrane applications often an a-symmetrical structure is desired, with a sponge-like or dense structure on the outside of the fiber, and a more open structure with macro voids on the lumen side of the fiber wall. By altering the composition and spinning conditions, the exact morphology of the fiber can be modified [39]. 
Non-solvent induced phase separation can also occur for polymer solutions that contain inorganic particles. The result is a solid polymer structure in which inorganic particles are embedded. During a thermal treatment the polymer is removed and the particles are sintered together. During thermal treatment the initial morphology of the polymer/particle fiber often persists. The addition of particles to the polymer/solvent mixture strongly affects the rheology of the mixture, and adding a large amount of particles often increases the viscosity to such a value that spinning is no longer possible. In addition, the change in rheology also limits the morphological structures that can be obtained by phase-inversion. The highly viscous mixture also limits the choice in spinneret diameter, making it difficult to obtain fibers with small radial dimensions [40]. In order to obtain small radial dimensions, Luiten-Olieman et al. lowered the particle loading of the fibers followed by relaxation of the polymer above the glass transition temperature $T_{g}$. As the polymer relaxes, the macro voids in the structure reduce due to surface driven viscous flow, which results in significant shrinkage of the fiber in radial dimensions. The new structure and low radial dimension persist after sintering, resulting in inoganic fibers with an outer diameter as small as $250 \mu \mathrm{m} \mathrm{[6].}$

In addition to the particle loading, also the particle size and shape strongly affect the rheological properties of the spinning mixture. The particle size directly affects the pore size of the fiber after sintering, and in order to reduce the pore size often smaller particles are used. This results in a higher viscosity of the spinning mixture [41].

One of the first sources that described the use of phase separation to prepare $\mathrm{Al}_{2} \mathrm{O}_{3}$ hollow fibers was by Okubo et al. in 1991. Ever since, various materials and types of inorganic fibers were produced and the majority of the methods and recipes are inspired on the production methods used to produce organic fibers $[39,42-44]$. 


\subsection{Thermal treatment}

All fabrication methods result in "green" fiber that consists of inorganic particles embedded in a matrix of a polymeric binder. In order to convert the green fiber into a inorganic fiber, a thermal treatment step is employed to remove the polymeric binder and to sinter the inorganic particles together to form a rigid fiber.

\subsubsection{Drying}

The majority of fiber production methods result in a polymeric fiber with embedded inorganic particles, immersed in a non-solvent. Removal of the nonsolvent and, if present, any residual solvent is key before further thermal treatment steps can be carried out. For these fibers, the drying rate and resultant stresses are of importance. The drying rate determines the timespan to dry the material and the resultant stresses have a large influence on, for example, the shrinkage or collapse of the fiber [25]. Drying is a complex process that can be divided into four main stages; (1) an initial stage, (2) a constant-rate period (CRP), (3) a first falling-rate period (FRP1), and (4) a second fallingrate period (FRP2). During the initial stage and the constant-rate period, the drying takes place mainly at the surface and the rate is close to that of a free liquid surface. For every unit of liquid that evaporates, the volume of the fiber decreases by one unit volume. This stage of constant evaporation and its accompanied shrinkage lasts until the end of the constant-rate period. By this time the solvent-gas interface recedes into the pores and the first falling-rate period starts. In this period the most of the evaporation still takes place at the surface. During the second falling-rate period the interface is receded so far into the pores that the characteristics of the drying mechanism change [25, 45]. The rate of drying can be altered during the second stage, where the drying is sensitive to external conditions such as flow rate of the gas over the fiber, temperature, or humidity. During this stage, strong capillary forces introduce large stresses in the system that can result in shrinkage or deformation of the fiber, especially when high surface tension liquids such as water are used. To avoid fiber collapse, solvent exchange with a solvent that has a lower surface tension can be used [46-48]. During the fabrication of inorganic porous hollow fibers by dry-wet spinning, drying is generally not the limiting step. After dry-wet spinning, the green fibers are immersed in water and the fiber is dried prior to sintering. In most cases the polymeric/inorganic fiber has sufficient mechanical integrity to overcome the stresses that are introduced during the 
evaporation of water [43]. The majority of the water will be present in the bore and in the large macrovoids, and is therefore easily removed from the fiber. Further drying is carried out as part of the thermal treatment routine. A proper drying strategy is more important when other fabrication methods are used, such as ionic cross-linking of a hydrogel [49-51]. In this case the system has a much higher water content, as these gels can incorporate large amounts of water in their network. As a result, after the first falling-rate period, the amount of residual water is much higher and further removal of water at elevated temperature results in significant shrinkage of the fiber [33].

\subsubsection{Glass transition}

The glass-liquid transition is the reversible transition in amorphous materials (or in amorphous regions within semicrystalline materials) from a hard and relatively brittle "glassy" state into a viscous or rubbery state as the temperature is increased. Below the glass transition temperature $\left(T_{g}\right)$, polymer chains have limited mobility. Above the $T_{g}$, the polymer chains have a significant higher mobility, and relaxations tend to be much faster. The $T_{g}$ of a polymer can have a strong influence on the properties of the polymer. One of the most relevant changes for the fabrication of inorganic porous hollow fibers is the reduction of the polymer's viscosity above the $T_{g}$.

The dynamics of surface energy driven viscous polymer flow can allow the reduction of macrovoid volume, which results in a substantial shrinkage of the fiber. The extent of viscous deformation is strongly related to the rheology of the particle loaded polymer mixture. Therefore it depends largely on the concentration and nature of the inorganic particles. This effect is used by Luiten-Olieman et al., who adjusted the particle loading and rheology of the mixture to fabricate fibers with small radial dimensions by controlled shrinkage at temperatures around the $T_{g}[6]$.

\subsubsection{Polymer decomposition}

Polymer decomposition is an extremely broad term including all irreversible polymer degradation processes that involve a loss of weight from the material. During polymer decomposition, the polymer is removed as vapor by heating at ambient pressure in an oxidizing or non-oxidizing atmosphere, or under a partial vacuum. The decomposition of the polymer is influenced by both chemical and physical factors. Chemically, the specific polymer used and the atmosphere determine the decomposition temperature, pathway and decomposition prod- 
ucts. Physically, the decomposition is controlled by heat transfer into the fiber and mass transport of the decomposition products out of the body [25].

The selection of a suitable polymer is governed by multiple factors. To maintain structural integrity it is preferred that the polymer burnout occurs gradually and that the decomposition of the polymer is not be completed before initial neck formation between the particles is obtained (see section 1.3.4). In addition, decomposition should not take place in a region where the polymer or its decomposition products (e.g. carbon [52] or sulfur [53]) can react with the inorganic particles $[52,54]$. The decomposition process can be influenced by the selection of a suitable polymer and atmosphere in which the decomposition occurs [55].

\subsubsection{Sintering}

Sintering is a high-temperature densification process occurring in inorganic materials. The atoms in the materials diffuse across the boundaries of the particles, fusing the particles together and creating one solid piece. For inorganic fibers, this converts the loose particles, stacked in a certain orientation, into a rigid inorganic fiber. This process is mainly limited by the low diffusion rate of the atoms at low temperatures. To create sufficiently high diffusion rates, a temperature of $\approx 2 / 3 T_{\text {melt }}$ is typically required.

Sintering can be considered to occur in three stages: the initial stage starts when the atoms achieve sufficient mobility. As a result of this mobility neck formation between the particles occurs, with only a limited densification of the sample. In the intermediate stage the pore radii shrink, which results in further densification of the sample. A percolative pathway remains present along the particles. In the final stage, the sample further densifies leaving only single pores with no percolative pathway [25].

During the sintering of inorganic porous hollow fibers, one has to balance the mechanisms involved in the first and second stage in order to obtain the desired pore size associated with only neck formation, but also the further densification of the second stage in order to obtain mechanical strength. This is different for fibers that require a non-porous layer, such a perovskites [56].

Pores are commonly present at the point where multiple particles are in contact, and are typically found to be $1 / 3$ th of the size of the initial starting particles. Depending on the exact sintering mechanism and conditions, these pores can either grow or shrink. Pore growth is often the result of a process where larger particles grow on the expense of the smaller particles, resulting in a larger average pore size as compared to the starting material. This mechanism can 
also be employed to enhance the sintering of difficult to sinter materials, such as silicon carbide [57]. Pore shrinkage is the result of intermediate stage sintering, in which the sample densifies and shrinks at the expense of porosity [25].

The degree of sintering of inorganic porous fibers can be tuned by sintering temperature, time, or a combination thereof. Insufficient sintering results in a relatively weak fiber with a low mechanical strength, whereas over-sintering often reduces porosity and pore size up to a state where an almost dense fiber is obtained. Depending on the desired properties, the sintering conditions can be altered.

\subsubsection{Volatilization and inorganic reactions}

During sintering, some inorganic components can have a non-negligible vapor pressure. For most materials used to prepare inorganic fibers, a relatively low sintering temperature is sufficient to fabricate a fiber with sufficient mechanical strength. One of the exceptions is the sintering of silicon carbide, where temperatures in the range of 2000 to $2200^{\circ} \mathrm{C}$ are used. These temperatures are well above the melting point of silica $\left(1700^{\circ} \mathrm{C}\right)$, which result in a strong increase in $\mathrm{SiO}_{2}$ vapor pressure [58]. In addition, at these very high temperatures solidstate reactions can also be present. For example, during the sintering of $\mathrm{SiC}$, excess carbon is removed from the fiber's structure by a solid-state reaction between carbon and silica [59].

\subsection{Materials}

This paragraph gives an overview of the materials used to fabricate inorganic porous hollow fibers.

\subsubsection{Metal oxides}

Metal oxides are a class of materials that are extensively investigated in the field of hollow fibers, mainly due to their good thermal and chemical stability and the ease of fabrication. The incorporation of oxides allows the use of oxidative environments during thermal treatment, resulting in complete removal of polymeric binders and additives.

The majority of research was done on $\mathrm{Al}_{2} \mathrm{O}_{3}$ hollow fibers, utilizing a polymer/solvent system based on poly(ethersulfon)(PES), $N$-Methyl-2-pyrrolidone (NMP), and various polymeric additives [19]. Liu et al. investigated the effect of inorganic particle size distribution and the sintering temperatures on the 
final resulting fibers. Many systematic studies have focused on the effects of spinning mixture composition and process conditions on the final morphology of the inorganic fiber $[5-7,20,40]$. Most of these $\mathrm{Al}_{2} \mathrm{O}_{3}$ fibers were directly used as ultrafiltration (UF) or as microfiltration (MF) membrane, or were used as membrane support for other functional layers.

Yttria stabilized zirconia (YSZ) has been used as material because it is the most common electrolyte material in solid oxide fuel cells (SOFCs), and because of its better chemical stability in alkali environments as compared to alumina [6, 60-62]. Fibers were prepared based on the common PES/NMP polymer/solvent system and thermal treatment was carried out in air which facilitates the full removal of the polymer at approximately $800^{\circ} \mathrm{C}$ and subsequent sintering at temperatures of $1200^{\circ} \mathrm{C}$ to $1590^{\circ} \mathrm{C}$ [62]. In addition, zirconia fibers were prepared without yttria stabilization by a template method [17, 23]. Titanium dioxide $\mathrm{TiO}_{2}$ is widely investigated for its photocatalytic activity. Poly(etherimide) (PEI) and NMP were used to prepare $\mathrm{TiO}_{2}$-loaded hollow fibers with an outer diameter of $2 \mathrm{~mm}$. These fibers were subsequently sintered in the range of $700{ }^{\circ} \mathrm{C}$ to $1400{ }^{\circ} \mathrm{C}$ to obtain a $\mathrm{TiO}_{2}$ hollow fiber [63]. This production method was later adapted to facilitate the fabrication of multi-bore $\mathrm{TiO}_{2}$ fibers $[63,64]$.

\subsubsection{Metals}

Porous metal fibers receive increasing attention due to their desirable properties, such as their electrical conductivity, processability, and mechanical properties such as ductile behavior. One of the main challenges of sintering porous metals is the complete removal of the polymer without the use of oxidative environments, such as air. Careful selection of the thermal treatment conditions can not only prevent oxidation of the metal particles, but can also prevent the formation of other unwanted species, such as nitrides (nitrogen environment) or carbides (residual carbon).

Porous stainless steel is commonly used as a membrane support, for example for $\mathrm{Pd}$ membranes used in $\mathrm{H}_{2}$ separation [11]. This, together with the improved mechanical properties of a metallic fiber, drives the research into stainless steel fibers. Stainless steel fibers often suffer from the formation of chromium carbides when thermally treated under a protective atmosphere, such as nitrogen or argon. The formation of these chromium carbides is undesirable as the chromium is a key component in the corrosion protection of the steel [65]. Due to incomplete removal of the polymer, residual carbon is present at temperatures $\left(500^{\circ} \mathrm{C}\right.$ to $\left.600{ }^{\circ} \mathrm{C}\right)$ where these carbides can form, which significantly 
reduces the corrosion resistance of the steel [66-69]. Reducing the amount of polymer used [67], or selecting a polymer which a suitable decomposition temperature might solve this problem [55, 68].

Nickel is considered to be a possible alternative for the more expensive palladium membranes for hydrogen separation. This particular application requires the fabrication of dense nickel fibers. By altering the sintering conditions, both dense and porous nickel hollow fibers could be fabricated [70]. For these fibers the decomposition of the poyler occurs in air, to allow lower temperatures $\left(450{ }^{\circ} \mathrm{C}\right)$, and subsequently the final sintering othe nickel is done in an argon atmosphere. At temperatures in excess of $900{ }^{\circ} \mathrm{C}$, liquid phase sintering occurs and the particles fuse together to form a continuous, gas tight nickel fiber.

Titanium is used as electrode material in for example redox flow batteries [71].Such systems benefit from the large surface area to volume ratio that the fibers offer. The high reactivity of the titanium complicates the fabrication of porous hollow fibers. Especially at elevated temperatures titanium readiliy reactis with a variety of organic and inorganic compounds. By sintering titanium fibers at 700 to $1350{ }^{\circ} \mathrm{C}$ under argon, followed by electrochemical oxidation at a anodic current of $0.2 \mathrm{~A}$, pure titanium fibers were prepared. This multiple-step thermal treatment indicates that oxidation of the titanium particles is still one of the main challenges [72].

\subsubsection{Other}

In addition to traditional metal-oxide ceramics, also other inorganic materials are investigated. Perovskite fibers are often investigated for their excellent oxygen transport characteristics, and scale up of these materials into a hollow fiber geometry would be a large step towards industrial application [73]. Perovskite materials are very sensitive to sulfur impurities, limiting the amount of polymers that can be used. In addition, in order to fabricate defect free perovskite fibers, no percolative porous pathway can be present after sintering [74].

Perovskite fibers have been prepared out of $\mathrm{Ba}_{0.5} \mathrm{Sr}_{0.5} \mathrm{Co}_{0.8} \mathrm{Fe}_{0.2} \mathrm{O}_{3-\delta}(\mathrm{BSCF})$. This is one of the most studied materials because it can allow high oxygen fluxes. Fibers have been obtained from spinning mixtures based based on NMP and various sulfur free polymers, such as low density polyethene (LDPE), polyethylene terephthalate $(\mathrm{PET})$, polyurethane $(\mathrm{PU})$ and polyetherimide (PEI). After sintering at $1190^{\circ} \mathrm{C}$ for $4 \mathrm{~h}$, fibers with suitable properties for oxygen permeation have been obtained [53]. 
$\mathrm{La}_{0.6} \mathrm{Sr}_{0.4} \mathrm{Co}_{0.2} \mathrm{Fe}_{0.8} \mathrm{O}_{3-\delta}$ (LSCF), exhibits lower oxygen fluxes but has better mechanical and chemical stability. Dense fibers have been prepared from spinning mixtures based on DMSO and cellulose acetate, followed by a two step thermal treatment; macro voids were removed by keeping the fibers above the $T_{g}\left(200^{\circ} \mathrm{C}\right)$ for $4 \mathrm{~h}$, and further sintering has been carried out at temperatures ranging from $1250{ }^{\circ} \mathrm{C}$ to $1350{ }^{\circ} \mathrm{C}[75]$.

In addition to perovskites, non-metal oxide ceramics such as silicon nitride $\left(\mathrm{Si}_{3} \mathrm{~N}_{4}\right)$ have been investigated. For example, in membrane distillation $\mathrm{Si}_{3} \mathrm{~N}_{4}$ ceramics are considered to be among the promising materials due to their excellent resistance to oxidation, corrosion and thermal shock [76]. Zhang et al. have used a system based on NMP and poly(ethersulfone) in which the starting ceramic powders $\left(\alpha-\mathrm{Si}_{3} \mathrm{~N}_{4}, \mathrm{Al}_{2} \mathrm{O}_{3}\right.$ and $\left.\mathrm{Y}_{2} \mathrm{O}_{3}\right)$ were dispersed. The metal oxides acted as a sintering aid and promoted grain growth of rod-like $\mathrm{Si}_{2} \mathrm{~N}_{4}$ grains. They were subsequently sintered at $1700^{\circ} \mathrm{C}$ for $4 \mathrm{~h}$ in a graphite furnace, under a nitrogen atmosphere $[7,76]$. In order to lower the thermal conductivity of the $\mathrm{Si}_{3} \mathrm{~N}_{4}$ fibers, $\beta$-Sialon $\left(\mathrm{Si}_{6-z} \mathrm{Al}_{\mathrm{z}} \mathrm{O}_{\mathrm{z}} \mathrm{N}_{8-z}, z=1-4\right)$ fibers were prepared. The lower thermal conductivity meets one of the requirements of membrane distillation [77]. The multi-step thermal treatments indicate that fabrication of non-oxide ceramics can be difficult, as sintering of these materials is not straightforward.

Carbon hollow fibers are considered an interesting class of materials, for example as catalyst support [78]. Carbon fibers are prepared mainly by pyrolysis of different polymeric fibers. The polymers usually investigated are poly(vinylidene chloride), cellulose, polyacrylonitrile (PAN), phenolic resins, and polyimides [79] [80].

Structuring carbon hollow fibers is critical to their further advancement as a membrane. Numerous approaches have been investigated to manipulate carbon nanotubes (CNTs) into macroscopic aligned CNT membranes. Carbon nanotube (CNT) fibers have been prepared by spinning a mixture of CNT'S dispersed in poly(vinylbutyral) and DMF. After calcination at $600{ }^{\circ} \mathrm{C}$ for $1 \mathrm{~h}$ in argon, free-standing CNT hollow fiber membranes have been obtained that show a high porosity, clean water flux, and pore sizes in the region of $100 \mathrm{~nm}$ [81].

Depending on the material used, the fabrication process requires optimization. In general, fabricating fibers by dry-wet spinning or extrusion is fairly straightforward, and often a generic approach can be used [6]. Thermal treatment of these materials is often the limiting step, for instance when extreme temperatures, inert or reactive gas atmospheres, or sintering aids are required. 


\subsection{Applications}

Thin inorganic porous hollow fibers are used for a wide range of applications, mostly for their excellent mass-transfer properties combined with the high surface-to-volume ratio. Traditionally, inorganic porous hollow fibers have been used as membrane (supports), depending on the specific pore size of the fiber. A wide range of membrane applications is envisioned, such as for example water desalination [76], membrane distillation [82, 83], pervaporation [83-87], water treatment [88, 89], membrane extraction [90, 91], organic solvent nanofiltration $[10,84]$, microfiltration $[19,60,63,67,92-94]$, gas separation $[27,73-75,80,93,95-97]$ or as a membrane bio reactor $[17,98]$.

Additionally, fibers have been used as a catalyst support by deposition of a catalyst on the fiber's surface [12]. For example, an oxygen selective perovskite fiber has been modified by deposition of a Ni-based catalyst on the outer surface for the partial oxidation of methane [73]. A different approach has been used by Maneerung et al., who modified a $\mathrm{Al}_{2} \mathrm{O}_{3}$ fiber by deposition of a $\mathrm{Ni}$ based catalyst on the outer surface of the fiber and a dense $\mathrm{Pd}$ layer on the inner surface of the fiber, for the production of hydrogen from methane [95]. In addition to catalyst deposition, $\mathrm{TiO}_{2}$ fibers have been used for water treatment where the photo catalytic activity of the $\mathrm{TiO}_{2}$ fiber aids removal of fouling from the membrane surface $[63,64]$.

The combination of catalysis and separation is further extended to hollow fiber micro reactors in which both reaction and separation take place in a small volume. One example is the use of an $\mathrm{Al}_{2} \mathrm{O}_{3}$ fiber modified with a $\mathrm{Cu} / \mathrm{Zn} / \mathrm{GaOX}$ catalyst for methanol steam reforming. The micro reactor results in high purity $\mathrm{CO}_{\mathrm{x}}$ free $\mathrm{H}_{2}$ in a single reaction step, working at significantly lower temperature and using less amount of catalyst as compared to a conventional fixed bed reactor [16]. A second example includes the use of a modified $\mathrm{Al}_{2} \mathrm{O}_{3}$ fiber by hydrophobization and $\mathrm{Pd}$ coating for catalytic hydrogenation of nitrite $\left(\mathrm{NO}_{2}\right)$ ions in an aqueous environment [15]. Zirconia fibers have been used as microbial cell reactor for the growth of $E$. Coli, where the fiber is used as growth substrate and as a barrier against particle contamination. In addition, the porous nature of the fiber allows for in-situ removal of generated by-products. This enhances the growth of these bacteria [17].

Electrically conductive fibers can also be used as electrode in various applications. For example, fibers out of carbon nanotubes (CNT's) have been used as both anode and cathode to enhance the selectivity in gold nanoparticles separation, where the applied potential enhances electrostatic interactions between these particles and the membrane wall [81]. Ni-YSZ fibers have been used as 
anode material for the production of a solid oxide fuel cell (SOFC). The Ni-YSZ fiber was coated with an YSZ electrolyte layer followed by a LSM-YSZ cathode layer and showed acceptable power densities [99]. Porous titanium fibers have been prepared for use as a tubular membrane-electrode assembly (MEA) in a fuel cell, or as electrode in a tubular redox flow battery [72]. Catalysis has also been combined with the use as an electrode and gas diffuser for the electro-chemical conversion of $\mathrm{CO}_{2}$ into $\mathrm{CO}$ using porous copper hollow fibers, with exceptionally high Faradaic efficiencies [14].

\subsection{Scope of this thesis}

The first inorganic porous hollow fibers have been reported in 1991, and have been studied ever since. Several challenges are identified such as the availability of the fibers that are not metal oxides, the fabrication of fibers with a sufficiently small pore size, the use of an organic solvent during the production of these fibers and the sealing and potting of these fibers for multi-fiber systems.

\subsubsection{New materials}

As discussed before, fibers are prepared using a wide range of materials, yet some applications could benefit from fibers made from a specific material. The fabrication of silicon carbide hollow fibers is useful for extreme environments such as high temperature gas separation or liquid permeation where there is an increased risk of fouling [100, 101]. Metallic fibers are produced sporadically and are limited to stainless steel/iron [66-68], nickel [6, 70] and titanium [72]. Expanding this array with, for example, catalytically active metals, such as aluminium, copper, or zinc could open up new applications in the field of electro-catalysis or reactive separations.

\subsubsection{Multi-layer systems}

As a direct result from the production method of inorganic porous hollow fibers it is difficult to obtain fibers with a very small pore size directly. Albeit effort has been made to prepare dual-layer fibers directly, these fibers suffer from a lack of mechanical strength or delamination of layers [29]. Post-fabrication modifications are often done on fibers in order to lower the molecular weight cutoff, for example by coating with one or more polymeric layers. This hampers the application under harsh conditions, as these polymeric layers often lower the thermal or chemical stability of the system [84]. 
Some hybrid organic-inorganic separation layers with high thermal and chemical resistance were reported recently [102], and expanding these chemistries to a hollow fiber geometry would allow for a combination of outstanding properties; a separation layer with a high thermal and chemical resistance on a ceramic support with a high surface-to-volume ratio. To our knowledge, direct interfacial polymerization on an inorganic porous hollow fiber has not been carried out.

\subsubsection{Polymer/Solvent systems}

A major drawback in the fabrication of hollow fibers using phase separation based methods is the use of organic solvents.These organic solvents are costly, environmentally malignant or toxic [103]. Attempts have been made to replace these polymer/solvent systems with more environmentally benign systems, but only with limited success. Substituting the current solvent/polymer systems for an aqueous based system would significantly lower the environmental footprint of inorganic porous hollow fibers, and potentially lower production costs of these fibers. Frequently used systems are based on the use of the polymer polyethersulfon (PES) dissolved in $N$-Methyl-2-pyrrolidone (NMP) [20]. One of the drawbacks of using a polysulfon is that it contains sulfur atoms that may persist in the final inorganic fiber. Various sulfur-free polymers have been investigated, such as PS, PMMA, PE, PU and PEI [6, 8, 53] with limited success. These polymers indeed prevent the presence of sulfur but still require an organic solvent such as NMP or dimethyl sulfoxide (DMSO) to be dissolved.

\subsubsection{Mechanical strength}

The mechanical strength of inorganic porous hollow fibers has often been investigated. It is one of the key parameters that defines the fibers usability; fibers with insufficient mechanical integrity would be impossible to handle, and cannot be incorporated into a module. As for all brittle ceramics, it is impossible to describe the mechanical features of these fibers with one single number [104]. Measuring a small amount of fibers and reporting an average mechanical strength would disregard the underlying statistical strength distributions. Systems designed using only the average strength are likely to exhibit premature failure [105].

In order to properly assess the mechanical strength of inorganic hollow fibers, one should measure a large amount of samples in order to determine the underlying distribution. To determine the distribution, sample set sizes of 100 
or more samples are required. For mere quantification and comparison smaller sample set sizes can be acceptable [106]. To the best of my knowledge, no extensive or systematic study of these mechanical properties of inorganic porous hollow fibers is presented in the open literature.

\subsubsection{Module design}

In order to facilitate industrial application of inorganic fibers, fabrication of multi-fiber modules is required. Sealing and potting for polymeric fibers is often considered to be straightforward; one simply uses a low-viscosity glue to seal a bundle of fibers into a module. Many modules are produced annually this way, for example for kidney-dialysis where imperfect sealing would be disastrous [3].

Inorganic fibers have high thermal and chemical resistance, and so should have the module that encloses them. Most polymer based glues are unstable under these demanding conditions, and suffer from thermal decomposition, swelling, plasticization, or dissolution. Ceramic bonding or glass sealing are often used for inorganic membranes [107-109], but these are not suitable for sealing a bundle of closely packed fibers.

Sealing multiple inorganic fibers into a bundle also affects their mechanical integrity, as the brittle nature of these fibers complicates the construction of a module in which fibers are closely packed. Small stresses in radial direction might already result in the failure of one single fiber, rendering the module useless.

\subsection{Thesis outline}

In chapter 2 the fabrication of silicon carbide hollow fiber membrane discussed. sintering of these fibers requires requires temperatures in excess of $1800{ }^{\circ} \mathrm{C}$ in order to obtain sufficiently strong fibers that can be used in an industrial application.

Chapter 3 discusses a method that circumvents the use of potentially harmful organic solvents during the production of hollow fiber membranes, by using a water soluble sodium alginate salt. Upon contact with a solution containing divalent cations, these alginate form a gel which allows the formation of 3D structures. By adding inorganic particles and subsequent thermal treatment this technique is used to fabricate inorganic porous hollow fibers.

Chapter 4 presents an alternative method based on sodium alginate crosslinking for the production of inorganic porous hollow fibers. An insoluble carbon- 
ate salt is added to the spinning mixture to act as the cation source. During spinning the mixture is put in contact with an acid, liberating the multivalent cation from the carbonate and allowing crosslinking of the alginate gel. This method produces very well defined fibers with an excellent stacking of the inorganic particles.

In chapter 5 the effect of measurement method, geometry and sample set size on the bending strength of inorganic porous hollow fibers discussed. The chapter gives guidance on what a suitable measurement geometry is in order to assess the mechanical strength of hollow fibers. By measuring large sample sets, the underlying statistical models are investigated that are the bases for ceramic component design. In addition, in this chapter the effect of sample set size is discussed.

In chapter 6 a comparison is provided for the mechanical strength of fibers prepared using three different production methods: non-solvent induced phase separation, bio-ionic gelation with internal multivalent cation supply, and bioionic gelation with an external ion source. This chapter builds on the method and analysis method explained in Chapter 5

Chapter 7 discusses the use of electrically conductive silicon carbide fibers as membrane support for thermally responsive microgels. By applying a current to the membrane, the silicon carbide fiber is heated above the volume phase transition temperature of the microgel, which alters the size of the microgel. By manipulating the temperature, thus the size of the microgel, the permeability and selectivity of the membrane can be altered.

Chapter 8 discusses the use of inorganic porous hollow fibers as a substrate for the fabrication of organic solvent resistant nanofiltration membranes prepared using interfacial polymerization (IP). The chapter specifically discusses the surface modifications required to allow good adhesion of the IP layer onto the inorganic fiber.

In chapter 9 the results obtained in this thesis are discussed and the main challenges that keep inorganic porous hollow fibers from widespread application are discussed. This is followed by some perspectives for future work. 


\subsection{References}

[1] R. W. Baker, Membrane Technology and Applications, 2012.

[2] H. K. Lonsdale, The growth of membrane technology, J. Memb. Sci. 10 (1982) 81-181.

[3] I. Moch, Hollow-Fiber Membranes, in: Kirk-Othmer Encycl. Chem. Technol., John Wiley \& Sons, Inc., 2000.

[4] M. Mulder, Basic principles of membrane technology, Kluwer Academic Publisher, second edi edition, 1996.

[5] T. Okubo, K. Haruta, K. Kusakabe, S. Morooka, H. Anzai, S. Akiyama, Preparation of a sol-gel derived thin membrane on a porous ceramic hollow fiber by the filtration technique, J. Memb. Sci. 59 (1991) 73-80.

[6] M. W. J. Luiten-Olieman, M. J. T. Raaijmakers, L. Winnubst, T. C. Bor, M. Wessling, A. Nijmeijer, N. E. Benes, Towards a generic method for inorganic porous hollow fibers preparation with shrinkage-controlled small radial dimensions, applied to $\mathrm{Al}_{2} \mathrm{O}_{3}, \mathrm{Ni}, \mathrm{SiC}$, stainless steel, and YSZ, J. Memb. Sci. 407-408 (2012) 155-163.

[7] J. Smid, C. G. Avci, V. Günay, R. A. Terpstra, J. P. G. M. Van Eijk, Preparation and characterization of microporous ceramic hollow fibre membranes, J. Memb. Sci. 112 (1996) 85-90.

[8] C. Buysse, a. Kovalevsky, F. Snijkers, A. Buekenhoudt, S. Mullens, J. Luyten, J. Kretzschmar, S. Lenaerts, Development, performance and stability of sulfur-free, macrovoid-free BSCF capillaries for high temperature oxygen separation from air, J. Memb. Sci. 372 (2011) 239-248.

[9] C. Guizard, A. Ayral, A. Julbe, Potentiality of organic solvents filtration with ceramic membranes. A comparison with polymer membranes, Desalination 147 (2002) 275-280.

[10] S. Dutczak, M. Luiten-Olieman, H. Zwijnenberg, L. Bolhuis-Versteeg, L. Winnubst, M. Hempenius, N. Benes, M. Wessling, D. Stamatialis, Composite capillary membrane for solvent resistant nanofiltration, J. Memb. Sci. 372 (2011) 182-190. 
[11] P. P. Mardilovich, Y. She, Y. H. Ma, M.-H. Rei, Defect-free palladium membranes on porous stainless-steel support, AIChE J. 44 (1998) 310322 .

[12] X. Tan, K. Li, Inorganic hollow fibre membranes in catalytic processing, Curr. Opin. Chem. Eng. 1 (2011) 69-76.

[13] X. Xu, W. Yang, J. Liu, L. Lin, N. Stroh, H. Brunner, Synthesis of NaA zeolite membrane on a ceramic hollow fiber, J. Memb. Sci. 229 (2004) $81-85$.

[14] R. Kas, K. K. Hummadi, R. Kortlever, P. de Wit, A. Milbrat, M. W. J. Luiten-Olieman, N. E. Benes, M. T. M. Koper, G. Mul, Threedimensional porous hollow fibre copper electrodes for efficient and highrate electrochemical carbon dioxide reduction, Nat. Commun. 7 (2016) 10748.

[15] H. C. Aran, J. K. Chinthaginjala, R. Groote, T. Roelofs, L. Lefferts, M. Wessling, R. G. H. Lammertink, Porous ceramic mesoreactors: A new approach for gas-liquid contacting in multiphase microreaction technology, Chem. Eng. J. 169 (2011) 239-246.

[16] F. R. Garcia-Garcia, S. C. Tsang, K. Li, Hollow fibre based reactors for an enhanced $\mathrm{H}_{2}$ production by methanol steam reforming, J. Memb. Sci. 455 (2014) 92-102.

[17] L. Liu, S. Liu, X. Tan, Zirconia microbial hollow fibre bioreactor for Escherichia coli culture, Ceram. Int. 36 (2010) 2087-2093.

[18] R. A. Terpstra, P. G. M. Van Eijk, F. K. Feenstra, Method for the production of ceramic hollow fibres, United States Pat. US 5707584 A (1998) 38-41.

[19] X. Tan, S. Liu, K. Li, Preparation and characterization of inorganic hollow fiber membranes, J. Memb. Sci. 188 (2001) 87-95.

[20] S. Liu, K. Li, R. Hughes, Preparation of porous aluminium oxide $\left(\mathrm{Al}_{2} \mathrm{O}_{3}\right)$ hollow fibre membranes by a combined phase-inversion and sintering method, Ceram. Int. 29 (2003) 875-881.

[21] K. Lee, Y. Kim, Asymmetric hollow inorganic membranes, Key Eng. Mater. 61 (1991) 17-22. 
[22] J. Luyten, W. Adriansens, I. Genné, J. Cooymans, R. Leysen, Spinning of ceramic fibers with a special structure for membrane applications, Ceram. Trans. 83 (1998) 415-423.

[23] L. Xu, K. L. Hian, Zirconia hollow fiber: Preparation, characterization, and microextraction application, Anal. Chem. 79 (2007) 5241-5248.

[24] K. S. Jang, H. J. Kim, J. R. Johnson, W. G. Kim, W. J. Koros, C. W. Jones, S. Nair, Modified mesoporous silica gas separation membranes on polymeric hollow fibers, Chem. Mater. 23 (2011) 3025-3028.

[25] M. N. Rahaman, Ceramic processing, Taylor \& Francis Group, 2007.

[26] X. L. Pan, N. Stroh, H. Brunner, G. X. Xiong, S. S. Sheng, Pd/ceramic hollow fibers for $\mathrm{H}_{2}$ separation, Sep. Purif. Technol. 32 (2003) 265-270.

[27] X. L. Pan, N. Stroh, H. Brunner, G. X. Xiong, S. S. Sheng, Deposition of sol-gel derived membranes on $\gamma-\mathrm{Al}_{2} \mathrm{O}_{3}$ hollow fibers by a vacuum-assisted dip-coating process, J. Memb. Sci. 226 (2003) 111-118.

[28] W. Albrecht, K. Kneifel, T. Weigel, R. Hilke, R. Just, M. Schossig, K. Ebert, A. Lendlein, Preparation of highly asymmetric hollow fiber membranes from poly(ether imide) by a modified dry-wet phase inversion technique using a triple spinneret, J. Memb. Sci. 262 (2005) 69-80.

[29] J. de Jong, N. Benes, G. Koops, M. Wessling, Towards single step production of multi-layer inorganic hollow fibers, J. Memb. Sci. 239 (2004) 265-269.

[30] S. Dutczak, C. Tanardi, K. Kopeć, M. Wessling, D. Stamatialis, "Chemistry in a spinneret" to fabricate hollow fibers for organic solvent filtration, Sep. Purif. Technol. 86 (2012) 183-189.

[31] N. Awanis Hashim, F. Liu, M. R. Moghareh Abed, K. Li, Chemistry in spinning solutions: Surface modification of PVDF membranes during phase inversion, J. Memb. Sci. 415-416 (2012) 399-411.

[32] B. C. Gross, J. L. Erkal, S. Y. Lockwood, C. Chen, D. M. Spence, Evaluation of 3D printing and its potential impact on biotechnology and the chemical sciences, Anal. Chem. 86 (2014) 3240-3253.

[33] A. S. Hoffman, Hydrogels for biomedical applications, Adv. Drug Deliv. Rev. 64 (2012) 18-23. 
[34] C. K. Kuo, P. X. Ma, Ionically crosslinked alginate hydrogels as scaffolds for tissue engineering: Part 1. Structure, gelation rate and mechanical properties, Biomaterials 22 (2001) 511-521.

[35] Z. P. Xie, X. Wang, Y. Jia, Y. Huang, Ceramic forming based on gelation principle and process of sodium alginate, Mater. Lett. 57 (2003) 16351641.

[36] H. Mori, K. Aotani, N. Sano, H. Tamon, Synthesis of a hierarchically micro-macroporous structured zeolite monolith by ice-templating, J. Mater. Chem. 21 (2011) 5677.

[37] J. Zheng, L. Winnubst, S. Fang, D. Salamon, Manipulation of Sintering Behavior by Initial Freeze Pressing an Aqueous Alumina Suspension, Adv. Eng. Mater. 13 (2011) 77-81.

[38] H. Strathmann, K. Kock, The formation mechanism of phase inversion membranes, Desalination 21 (1977) 241-255.

[39] P. S. T. Machado, A. C. Habert, C. P. Borges, Membrane formation mechanism based on precipitation kinetics and membrane morphology: flat and hollow fiber polysulfone membranes, J. Memb. Sci. 155 (1999) $171-183$.

[40] B. Kingsbury, K. Li, A morphological study of ceramic hollow fibre membranes, J. Memb. Sci. 328 (2009) 134-140.

[41] C. C. Wei, O. Y. Chen, Y. Liu, K. Li, Ceramic asymmetric hollow fibre membranes: One step fabrication process, J. Memb. Sci. 320 (2008) 191-197.

[42] Y. Liu, G. H. Koops, H. Strathmann, Characterization of morphology controlled polyethersulfone hollow fiber membranes by the addition of polyethylene glycol to the dope and bore liquid solution, J. Memb. Sci. 223 (2003) 187-199.

[43] I. M. Wienk, F. H. A. Olde Scholtenhuis, T. van den Boomgaard, C. A. Smolders, Spinning of hollow fiber ultrafiltration membranes from a polymer blend, J. Memb. Sci. 106 (1995) 233-243.

[44] S. Veríssimo, K.-V. Peinemann, J. Bordado, New composite hollow fiber membrane for nanofiltration, Desalination 184 (2005) 1-11. 
[45] D. A. Brosnan, G. C. Robinson, Introduction to Drying of Ceramics, Wiley-American Ceramic Society, 2003.

[46] P. Manos, Membrane drying process, 1978.

[47] R. Wang, L. Shi, C. Y. Tang, S. Chou, C. Qiu, A. G. Fane, Characterization of novel forward osmosis hollow fiber membranes, J. Memb. Sci. 355 (2010) 158-167.

[48] K. Y. Wang, T. S. Chung, M. Gryta, Hydrophobic PVDF hollow fiber membranes with narrow pore size distribution and ultra-thin skin for the fresh water production through membrane distillation, Chem. Eng. Sci. 63 (2008) 2587-2594.

[49] T. Andersen, J. E. Melvik, O. Gåserød, E. Alsberg, B. E. Christensen, Ionically gelled alginate foams: Physical properties controlled by type, amount and source of gelling ions, Carbohydr. Polym. 99 (2014) 249-256.

[50] R. Vreeker, L. Li, Y. Fang, I. Appelqvist, E. Mendes, Drying and rehydration of calcium alginate gels, Food Biophys. 3 (2008) 361-369.

[51] Q. Xiao, X. Gu, S. Tan, Drying process of sodium alginate films studied by two-dimensional correlation ATR-FTIR spectroscopy, Food Chem. 164 (2014) 179-184.

[52] Z. Wu, R. Faiz, T. Li, B. F. Kingsbury, K. Li, A controlled sintering process for more permeable ceramic hollow fibre membranes, J. Memb. Sci. 446 (2013) 286-293.

[53] A. Leo, S. Smart, S. Liu, J. C. Diniz da Costa, High performance perovskite hollow fibres for oxygen separation, J. Memb. Sci. 368 (2011) 64-68.

[54] E. J. Kappert, Firing Membranes, Phd thesis, University of Twente, 2015.

[55] M. W. Luiten-Olieman, Inorganic porous hollow fiber membranes, Phd thesis, University of Twente, 2012.

[56] D. D. Athayde, D. F. Souza, A. M. Silva, D. Vasconcelos, E. H. Nunes, J. C. Diniz da Costa, W. L. Vasconcelos, Review of perovskite ceramic synthesis and membrane preparation methods, Ceram. Int. 42 (2016) $6555-6571$. 
[57] A. Noviyanto, D.-H. Yoon, Metal oxide additives for the sintering of silicon carbide: Reactivity and densification, Curr. Appl. Phys. 13 (2013) $287-292$.

[58] J. Marchi, J. Bressiani, A. Bressiani, Densification studies of silicon carbide-based ceramics with yttria, silica and alumina as sintering additives, Mater. Res. 4 (2001) 231-236.

[59] F. van Dijen, E. Mayer, Liquid phase sintering of silicon carbide, J. Eur. Ceram. Soc. 16 (1996) 413-420.

[60] X. Zhang, B. Lin, Y. Ling, Y. Dong, D. Fang, G. Meng, X. Liu, Highly permeable porous YSZ hollow fiber membrane prepared using ethanol as external coagulant, J. Alloys Compd. 494 (2010) 366-371.

[61] W. Yin, B. Meng, X. Meng, X. Tan, Highly asymmetric yttria stabilized zirconia hollow fibre membranes, J. Alloys Compd. 476 (2009) 566-570.

[62] L. Liu, X. Tan, S. Liu, Yttria Stabilized Zirconia Hollow Fiber Membranes, J. Am. Ceram. Soc. 89 (2006) 1156-1159.

[63] X. Zhang, D. K. Wang, D. R. S. Lopez, J. C. Diniz da Costa, Fabrication of nanostructured $\mathrm{TiO}_{2}$ hollow fiber photocatalytic membrane and application for wastewater treatment, Chem. Eng. J. 236 (2014) 314-322.

[64] T. Zhao, Z. Liu, K. Nakata, S. Nishimoto, T. Murakami, Y. Zhao, L. Jiang, A. Fujishima, Multichannel $\mathrm{TiO}_{2}$ hollow fibers with enhanced photocatalytic activity, J. Mater. Chem. 20 (2010) 5095.

[65] T. M. Devine, The mechanism of sensitization of austenitic stainless steel, Corros. Sci. 30 (1990) 135-151.

[66] M. Luiten-Olieman, L. Winnubst, A. Nijmeijer, M. Wessling, N. E. Benes, Porous stainless steel hollow fiber membranes via dry-wet spinning, J. Memb. Sci. 370 (2011) 124-130.

[67] B. Michielsen, H. Chen, M. Jacobs, V. Middelkoop, S. Mullens, I. Thijs, A. Buekenhoudt, F. Snijkers, Preparation of porous stainless steel hollow fibers by robotic fiber deposition, J. Memb. Sci. 437 (2013) 17-24.

[68] D. R. Schmeda-Lopez, S. Smart, E. H. Nunes, D. Vasconcelos, W. L. Vasconcelos, M. Bram, W. a. Meulenberg, J. C. Diniz da Costa, Stainless steel hollow fibres: Sintering, morphology and mechanical properties, Sep. Purif. Technol. (2015). 
[69] H. Li, J. Song, X. Tan, Y. Jin, S. Liu, Preparation of spiral porous stainless steel hollow fiber membranes by a modified phase inversionsintering technique, J. Memb. Sci. 489 (2015) 292-298.

[70] B. Meng, X. Tan, X. Meng, S. Qiao, S. Liu, Porous and dense Ni hollow fibre membranes, J. Alloys Compd. 470 (2009) 461-464.

[71] S. Chandrabose Raghu, M. Ulaganathan, T. M. Lim, M. Skyllas Kazacos, Electrochemical behaviour of titanium/iridium(IV) oxide: Tantalum pentoxide and graphite for application in vanadium redox flow battery, J. Power Sources 238 (2013) 103-108.

[72] O. David, Y. Gendel, M. Wessling, Tubular macro-porous titanium membranes, J. Memb. Sci. 461 (2014) 139-145.

[73] H. Wang, A. Feldhoff, J. Caro, T. Schiestel, S. Werth, Oxygen selective ceramic hollow fiber membranes for partial oxidation of methane, AIChE J. 55 (2009) 2657-2664.

[74] X. Tan, Y. Liu, K. Li, Mixed conducting ceramic hollow-fiber membranes for air separation, AIChE J. 51 (2005) 1991-2000.

[75] V. Middelkoop, H. Chen, B. Michielsen, M. Jacobs, G. Syvertsen-Wiig, M. Mertens, A. Buekenhoudt, F. Snijkers, Development and characterisation of dense lanthanum-based perovskite oxygen-separation capillary membranes for high-temperature applications, J. Memb. Sci. 468 (2014) $250-258$.

[76] J.-W. Zhang, H. Fang, J.-W. Wang, L.-Y. Hao, X. Xu, C.-S. Chen, Preparation and characterization of silicon nitride hollow fiber membranes for seawater desalination, J. Memb. Sci. 450 (2014) 197-206.

[77] J.-W. Wang, L. Li, J.-W. Zhang, X. Xu, C.-S. Chen, $\beta$-Sialon ceramic hollow fiber membranes with high strength and low thermal conductivity for membrane distillation, J. Eur. Ceram. Soc. 36 (2015) 59-65.

[78] J. A. Díaz, M. Calvo-Serrano, A. R. de la Osa, A. M. García-Minguillán, A. Romero, a. Giroir-Fendler, J. L. Valverde, $\beta$-silicon carbide as a catalyst support in the Fischer-Tropsch synthesis: Influence of the modification of the support by a pore agent and acidic treatment, Appl. Catal. A Gen. 475 (2014) 82-89. 
[79] E. Barbosa-Coutinho, V. M. M. Salim, C. P. Borges, Preparation of carbon hollow fiber membranes by pyrolysis of polyetherimide, Carbon N. Y. 41 (2003) 1707-1714.

[80] A. F. Ismail, L. I. B. David, A review on the latest development of carbon membranes for gas separation, J. Memb. Sci. 193 (2001) 1-18.

[81] G. Wei, S. Chen, X. Fan, X. Quan, H. Yu, Carbon nanotube hollow fiber membranes: High-throughput fabrication, structural control and electrochemically improved selectivity, J. Memb. Sci. 493 (2015) 97-105.

[82] S. Shukla, Membrane destillation with porous metal hollow fibers for the concentration of thermo-sensitive solutions, Ph.D. thesis, 2014.

[83] S. Shukla, N. Benes, I. Vankelecom, J. Méricq, M. Belleville, N. Hengl, J. S. Marcano, Sweep gas membrane distillation in a membrane contactor with metallic hollow-fibers, J. Memb. Sci. 493 (2015) 167-178.

[84] Z. Dong, G. Liu, S. Liu, Z. Liu, W. Jin, High performance ceramic hollow fiber supported PDMS composite pervaporation membrane for bio-butanol recovery, J. Memb. Sci. 450 (2014) 38-47.

[85] D. Hua, Y. Kang Ong, P. Wang, T. S. Chung, Thin-film composite tribore hollow fiber (TFC TbHF) membranes for isopropanol dehydration by pervaporation, J. Memb. Sci. 471 (2014) 155-167.

[86] S. Liu, W. Teo, X. Tan, K. Li, Preparation of PDMS - $\mathrm{Al}_{2} \mathrm{O}_{3}$ composite hollow fibre membranes for VOC recovery from waste gas streams, Sep. Purif. Technol. 46 (2005) 110-117.

[87] G. Liu, W. Wei, W. Jin, N. Xu, Polymer/Ceramic Composite Membranes and Their Application in Pervaporation Process, Chinese J. Chem. Eng. 20 (2012) 62-70.

[88] M. Lee, Z. Wu, R. Wang, K. Li, Micro-structured alumina hollow fibre membranes: Potential applications in wastewater treatment, J. Memb. Sci. 461 (2014) 39-48.

[89] M. Ebrahimi, S. Kerker, S. Daume, M. Geile, F. Ehlen, I. Unger, S. Schütz, P. Czermak, Innovative ceramic hollow fiber membranes for recycling/reuse of oilfield produced water, Desalin. Water Treat. (2014) $1-14$. 
[90] K. Hylton, S. Mitra, A microfluidic hollow fiber membrane extractor for arsenic(V) detection, Anal. Chim. Acta 607 (2008) 45-49.

[91] X. Yu, L. An, J. Yang, S.-T. Tu, J. Yan, CO2 capture using a superhydrophobic ceramic membrane contactor, J. Memb. Sci. 496 (2015) 1-12.

[92] X. Zhang, D. Fang, B. Lin, Y. Dong, G. Meng, X. Liu, Asymmetric porous cordierite hollow fiber membrane for microfiltration, J. Alloys Compd. 487 (2009) 631-638.

[93] L. Jiansheng, W. Lianjun, H. Yanxia, L. Xiaodong, S. Xiuyun, Preparation and characterization of $\mathrm{Al}_{2} \mathrm{O}_{3}$ hollow fiber membranes, J. Memb. Sci. 256 (2005) 1-6.

[94] N. Wung, S. M. Acott, D. Tosh, M. J. Ellis, Hollow fibre membrane bioreactors for tissue engineering applications, Biotechnol. Lett. (2014) $2357-2366$.

[95] T. Maneerung, K. Hidajat, S. Kawi, Triple-layer catalytic hollow fiber membrane reactor for hydrogen production, J. Memb. Sci. 514 (2016) $1-14$.

[96] R. Faiz, M. Fallanza, I. Ortiz, K. Li, Separation of Olefin/Paraffin Gas Mixtures Using Ceramic Hollow Fiber Membrane Contactors, Ind. Eng. Chem. Res. 52 (2013) 7918-7929.

[97] X. Tan, N. Liu, B. Meng, S. Liu, Morphology control of the perovskite hollow fibre membranes for oxygen separation using different bore fluids, J. Memb. Sci. 378 (2011) 308-318.

[98] K. P. Katuri, C. M. Werner, R. J. Jimenez-sandoval, W. Chen, S. Jeon, B. E. Logan, Z. Lai, G. L. Amy, P. E. Saikaly, A Novel Anaerobic Electrochemical Membrane Bioreactor (AnEMBR) with Conductive Hollowfiber Membrane for Treatment of Low-Organic Strength Solutions, Environ. Sci. Technol. 48 (2014) 12833-12841.

[99] C. Yang, W. Li, S. Zhang, L. Bi, R. Peng, C. Chen, W. Liu, Fabrication and characterization of an anode-supported hollow fiber SOFC, J. Power Sources 187 (2009) 90-92.

[100] B. Hofs, J. Ogier, D. Vries, E. F. Beerendonk, E. R. Cornelissen, Comparison of ceramic and polymeric membrane permeability and fouling using surface water, Sep. Purif. Technol. 79 (2011) 365-374. 
[101] V. Suwanmethanond, E. Goo, P. K. T. Liu, G. Johnston, M. Sahimi, T. T. Tsotsis, Porous silicon carbide sintered substrates for high-temperature membranes, Ind. Eng. Chem. Res. 39 (2000) 3264-3271.

[102] M. J. T. Raaijmakers, M. A. Hempenius, P. M. Schön, G. J. Vancso, A. Nijmeijer, M. Wessling, N. E. Benes, Sieving of hot gases by hypercross-linked nanoscale-hybrid membranes., J. Am. Chem. Soc. 136 (2014) $330-5$.

[103] L. A. Malley, G. L. Kennedy, G. S. Elliott, T. W. Slone, W. Mellert, K. Deckardt, K. Kuttler, B. Hildebrand, M. I. Banton, R. J. Parod, J. C. Griffiths, Chronic toxicity and oncogenicity of N-methylpyrrolidone (NMP) in rats and mice by dietary administration, Drug Chem. Toxicol. 24 (2001) 315-338.

[104] W. Weibull, A statistical distribution function of wide applicability, J. Appl. Mech. 18 (1951) 293-297.

[105] C. Lu, A reassessment of the strength distributions of advanced ceramics, J. Aust. Ceram. Soc. 44 (2008) 38-41.

[106] S. Nohut, Influence of sample size on strength distribution of advanced ceramics, Ceram. Int. 40 (2014) 4285-4295.

[107] A. Nijmeijer, Hydrogen-selective Silica Membranes for Use in Membrane Steam Reforming, Ph.D. thesis, 1999.

[108] X. Qi, F. T. Akin, Y. S. Lin, Ceramic-glass composite high temperature seals for dense ionic-conducting ceramic membranes, J. Memb. Sci. 193 (2001) 185-193.

[109] S. T. Reed, R. G. Stone, T. M. Nenoff, D. E. Trudell, S. G. Thoma, Gas impermeable glaze for sealing porous ceramic surfaces, 2004. 


\section{Chapter 2}

\section{Highly permeable and mechanically robust silicon carbide hollow fiber membranes}

This chapter is adapted from:

P. de Wit, E.J. Kappert, T. Lohaus, M. Wessling, A. Nijmeijer, N.E. Benes, Highly permeable and mechanically robust silicon carbide hollow fiber membranes, J. Membr. Sci., 475, pp. 480-487, doi: 10.1016/j.memsci.2014.10.045 

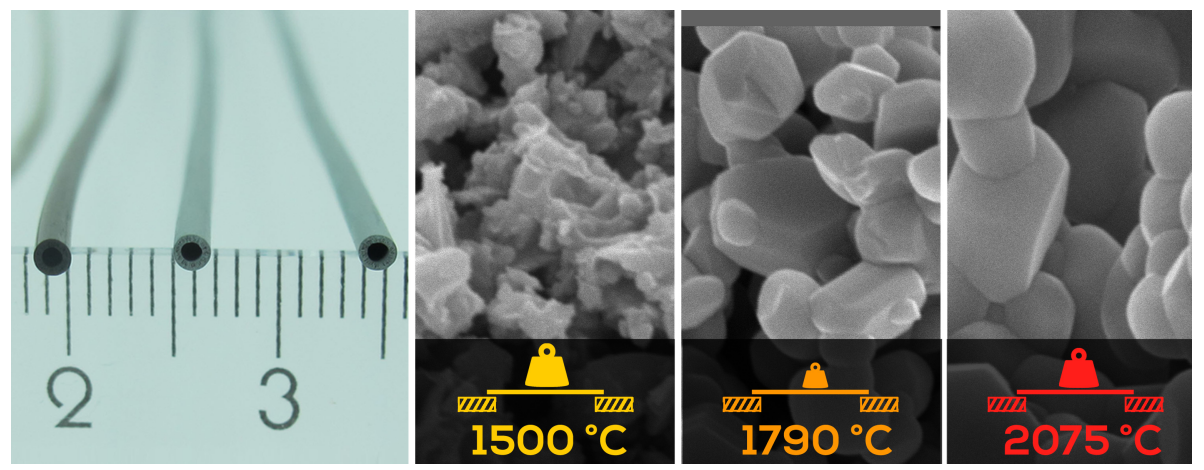

\begin{abstract}
Silicon carbide ( $\mathrm{SiC}$ ) membranes have shown large potential for applications in water treatment. Being able to make these membranes in a hollow fiber geometry allows for higher surface-to-volume ratios. In this study, we present a thermal treatment procedure that is tuned to produce porous silicon carbide hollow fiber membranes with sufficient mechanical strength. Thermal treatments up to $1500{ }^{\circ} \mathrm{C}$ in either nitrogen or argon resulted in relatively strong fibers, that were still contaminated with residual carbon from the polymer binder. After treatment at a higher temperature of $1790^{\circ} \mathrm{C}$, the mechanical strength had decreased as a result of carbon removal, but after treatments at even higher temperature of $2075^{\circ} \mathrm{C}$ the SiC-particles sinter together, resulting in fibers with mechanical strengths of $30 \mathrm{MPa}$ to $40 \mathrm{MPa}$ and exceptionally high water permeabilities of $50000 \mathrm{~L} \mathrm{~m}^{-2} \mathrm{~h}^{-1}$ bar $^{-1}$. Combined with the unique chemical and thermal resistance of silicon carbide, these properties make the fibers suitable microfiltration membranes or as a membrane support for application under demanding conditions.
\end{abstract}




\section{$2.1 \quad$ Introduction}

The outstanding mechanical integrity and chemical stability of silicon carbide has resulted in its use in various applications in which the material has to resist harsh conditions, such as diesel particulate filters [1], catalyst carriers [2], and sensors that are used at extreme pHs [3]. Whereas silicon carbide membranes also have been proposed for gas separation [4-8], the application of silicon carbide membranes for liquid applications has received little attention in literature. In 2011, Hofs et al demonstrated the superb fouling resistance of silicon carbide membranes in the treatment of surface water [9]. Several companies claimed that this low-fouling behaviour extents to the harsh conditions of oil/water separations [10-12]. Until now, silicon carbide membranes have been limited to flat [13], tubular $[4,14]$ and multichannel [5] geometries. All these geometries have a comparatively low surface-to-volume ratio in comparison with hollow fibers. The synthesis of inorganic hollow fibers has seen increasing attention during the last decade [15-18], but the few silicon carbide fibers that have been produced showed an undesirable pore structure [19, 20] or poor mechanical stability [21]. In this chapter, we developed a procedure for the fabrication of mechanically robust, porous silicon carbide hollow fibers via dry-wet spinning. The paper elaborates on the effects of the thermal treatment on the structure and properties of the obtained fibers, demonstrating that a felicitous thermal treatment is of key importance for the successful synthesis of highly permeable and mechanically robust silicon carbide hollow fibers.

\section{$2.2 \quad$ Experimental}

\subsubsection{Materials}

$\alpha$-Silicon carbide powders with a mean size of 0.4 and $0.6 \mu \mathrm{m}$ were supplied by Liqtech International AS (Denmark). Polyethersulfone (PES, Ultrason ${ }^{\circledR}$ E 6020 P, BASF), N-methyl-2-pyrrolidone (NMP, <99.5\%, Sigma Aldrich) and de-ionized water ( $>18.2 \mathrm{M} \Omega \mathrm{cm}^{-1}$, Milli-Q Advantage A10, Millipore) were used for dry-wet spinning. Prior to use, PES was dried overnight at $80^{\circ} \mathrm{C}$; all other chemicals were used as received. Sintering was carried out in argon (4.5) or nitrogen (2.8) gas atmosphere (Praxair). 
Table 2.1: Spinning conditions

\begin{tabular}{ll}
\hline Condition & Value \\
\hline Bore Liquid & $\mathrm{H}_{2} \mathrm{O}$ \\
Coagulation bath & $\mathrm{H}_{2} \mathrm{O}$ \\
Extrusion pressure & $2 \mathrm{bar}$ \\
Air gap & $3 \mathrm{~cm}$ \\
Bore liquid flow rate & $7 \mathrm{~mL}$ min $^{-1}$ \\
Diameter spinneret & $\mathrm{OD} / \mathrm{ID}=2.0 \mathrm{~mm} / 0.8 \mathrm{~mm}$ \\
\hline
\end{tabular}

\subsubsection{Dry-wet spinning}

The spinning dope composition was based on prior work [22]. Silicon carbide powders were mixed in a 1:5 weight ratio $(0.4: 0.6 \mu \mathrm{m})$, added to NMP and treated ultrasonically for $30 \mathrm{~min}$. PES was added in multiple steps to this mixture, allowing the PES to dissolve before the next amount was added. The resulting spinning mixture was composed of $36 \mathrm{wt} \%$ of $\mathrm{SiC}, 50 \mathrm{wt} \%$ of NMP and $14 \mathrm{wt} \%$ of PES. After stirring overnight, vacuum was applied for $30 \mathrm{~min}$ and the mixture was left overnight to degas.

For the dry-wet spinning, the mixture was forced through a spinneret by pressuring a stainless-steel vessel with nitrogen. The spinning conditions are given in Table 2.1; full details on the spinning setup can be found elsewhere [21]. After spinning, the fibers were stretched $\left(1 \mathrm{~cm} \mathrm{~m}^{-1}\right)$ and dried prior to sintering.

\subsubsection{Thermal treatment}

Thermal treatments up to $1500^{\circ} \mathrm{C}$ were carried out in a STF $16 / 610$ tubular furnace (Carbolite) equipped with an alumina working tube. Samples were loaded in $\mathrm{SiC}$ crucibles and thermally treated according to the programs given in Table 2.2. Prior to sintering, the system was evacuated and refilled with either argon or nitrogen three times, followed by sintering under a sweep flow of $100 \mathrm{~mL} \mathrm{~min}{ }^{-1}$.

High-temperature sintering $\left(1500^{\circ} \mathrm{C}\right.$ to $\left.2075{ }^{\circ} \mathrm{C}\right)$ was carried out at Liqtech Industries $\mathrm{A} / \mathrm{S}$, Denmark, where the fibers were co-sintered with a running production batch. All high-temperature sintering was carried out under argon; prior to shipping for high-temperature sintering, the samples were pre-sintered at $1500^{\circ} \mathrm{C}$ for $2 \mathrm{~h}$ in argon. Fiber mass $(m)$, length $(l)$ and diameter $(d)$ were 
Table 2.2: Overview of the used sintering programs. For all experiments, a $5{ }^{\circ} \mathrm{C} \min ^{-1}$ heating rate was employed.

\begin{tabular}{lll}
\hline Name & Sintering & Atmosphere \\
\hline $300-\mathrm{N}_{2}$ & 1 h at $300^{\circ} \mathrm{C}$ & Nitrogen \\
$1000-\mathrm{N}_{2}$ & 1 h at $300^{\circ} \mathrm{C}, 3$ h at $1000^{\circ} \mathrm{C}$ & \\
$1500-\mathrm{N}_{2}$ & $1 \mathrm{~h}$ at $300^{\circ} \mathrm{C}, 3 \mathrm{~h}$ at $1500^{\circ} \mathrm{C}$ & \\
& & \\
$300-\mathrm{Ar}$ & $1 \mathrm{~h}$ at $300^{\circ} \mathrm{C}$ & Argon \\
$1000-\mathrm{Ar}$ & $1 \mathrm{~h}$ at $300^{\circ} \mathrm{C}, 3 \mathrm{~h}$ at $1000^{\circ} \mathrm{C}$ & \\
$1500-\mathrm{Ar}$ & $1 \mathrm{~h}$ at $300^{\circ} \mathrm{C}, 3 \mathrm{~h}$ at $1500^{\circ} \mathrm{C}$ & \\
$1790-\mathrm{Ar}^{*}$ & $6 \mathrm{~h}$ at $1790^{\circ} \mathrm{C}$ & \\
$2075-\mathrm{Ar}^{*}$ & $0.75 \mathrm{~h}$ at $2075{ }^{\circ} \mathrm{C}$ & \\
\hline
\end{tabular}

* Sample sintered at Liqtech, Denmark. Samples were pre-sintered according to program 1500-Ar.

determined per fiber prior to and after thermal treatment to allow for paired comparison.

\subsubsection{Characterization}

\section{SEM-EDS}

The cross section morphology, the wall thickness and semi-quantitative elemental analysis of green and sintered fibers were obtained with a JSM-6010LA scanning electron microscope equipped with an energy dispersive spectrometer (Jeol). To obtain a clean fracture, the green compacts were soaked in liquid nitrogen before fracturing. The samples were gold-sputtered (13 $\mathrm{mA}, 3 \mathrm{~min})$ before SEM photos were taken. The EDS spectra were obtained from a crosssection of the non-sputtered fibers in low-vacuum mode.

\section{TGA-MS}

Thermogravimetric analysis (TGA) was performed on a STA 449 F3 Jupiter ${ }^{\circledR}$ (Netzch) fitted with a TG-only sample holder. Measurements were performed under $70 \mathrm{~mL} \mathrm{~min}^{-1}$ argon at a heating rate of $20^{\circ} \mathrm{C} \mathrm{min}^{-1}$ from room temperature to $1500{ }^{\circ} \mathrm{C}$. Temperature correction by melting standard and a blank cor- 
rection with an empty cup were carried out prior to the measurements. Small fragments of dried fibers were used as sample and their mass was determined externally.

Gases evolving during the thermogravimetric analysis were transferred to a mass spectrometer (MS, QMS 403 D Aëolos ${ }^{\circledR}$, Netzsch) by a glass capillary. TGA and MS start times were synchronized; no correction was applied for the time offset caused by the transfer line time (estimated $<30 \mathrm{~s}$, systematic offset). First, a bar graph scan for $m / z=1-100$ amu was performed to determine the evolving $m / z$-numbers (data not included here). The detected $m / z$-numbers $(2,12,14-18,20,26-30,32,36,38,40,44,48-52,56,60-61,64,67-68)$ were selected and recorded more accurately in multiple-ion-detection mode, with a dwell of $0.5 \mathrm{~s}$ per $\mathrm{m} / z$-value and a resolution of 50 .

\section{Clean water permeation}

The clean water flux was measured using an OSMO Inspector 2 (Convergence, Netherlands). Experiments were carried out in dead-end mode under constant flux operation with three different flux settings for each fiber. Custom-made single-fiber modules were used made out of Plexiglass tubing and sealed with PUR435/PUR-N 2-component glue (Intercol, Germany).

The permeate flow $\Phi_{v}\left(\mathrm{~L} \mathrm{~h}^{-1}\right)$ was recorded as a function of the transmembrane pressure. The pressure drop over the fiber is assumed to be negligible. The permeability was calculated using eq. 2.1 , where $A$ is the effective membrane area.

$$
\Pi=\frac{\Phi_{v}}{\left(p_{\text {feed }}-p_{\text {permeate }}\right) \cdot A}
$$

\section{Conductivity}

Electrical conductivity was measured using a home-build 4-probe conductivity meter. Current was applied at the outer probes that were $7 \mathrm{~cm}$ apart; the voltage drop was measured with two inner probes $3 \mathrm{~cm}$ apart. Measurements were performed at room temperature on three different spots at each fiber.

\section{Mercury intrusion porosimetry}

The volume of mercury intruded was measured as function of the pressure using a Poremaster PM-33-14 (Quantachrome ${ }^{\circledR}$ ). The helium density was measured using an AccuPyc II 1340 gas displacement analyzer (Micromeritics). Pressure 
$p$ and volume mercury intruded $V_{\mathrm{Hg}}$ were recorded and data processing was performed using Matlab ${ }^{\circledR}[23]$. The pore diameter corresponding to a certain pressure is calculated using Washburn's equation [24]. The volume based pore size distribution is calculated via eq. 2.2.

$$
D_{v}(r)=\frac{d V_{\mathrm{Hg}}}{d p}\left|\frac{p^{2}}{2 \gamma \cos \theta}\right|
$$

The porosity is computed by combining apparent density measured using helium $\rho_{\mathrm{He}}$ and mercury $\rho_{\mathrm{Hg}}$ and calculated using equation 2.3 .

$$
\varepsilon=100\left[1-\frac{\rho_{\mathrm{Hg}}}{\rho_{\mathrm{He}}}\right]
$$

\section{Mechanical strength}

Mechanical testing (4-point bending test) was carried out according to ASTM C1161-02 [25] using a 5564A mechanical testing bench (Instron). Sintered fibers were cut to a length of $5 \mathrm{~cm}$, and tested with a crosshead speed of $2 \mathrm{~mm} \mathrm{~min}^{-1}$ at room temperature. The force and deflection curves were measured and subsequently the bending strength for sample $j$ was calculated using

$$
\sigma_{j}=\frac{16 F_{j} K d_{o, j}}{\pi\left(d_{o, j}^{4}-d_{i, j}^{4}\right)}
$$

where $F_{j}$ is the force at fracture, $K$ half the difference between outer and inner span $(5 \mathrm{~mm})$ and $d_{i, j}$ and $d_{o, j}$ are the inner and outer diameter of the hollow fiber $j$ at its fracture site. The error in the calculated bending strength was estimated using $\Delta F= \pm 0.5 \%, \Delta d_{i}=\Delta d_{o}=20 \mu \mathrm{m}$ and $\Delta K=50 \mu \mathrm{m}$. For each fiber a minimum of 20 measurements were taken and the obtained bending strengths were fitted by a Weibull cumulative probability function, where the characteristic strength $\sigma_{\theta}$ and the shape parameter $m_{\text {shape }}$ are used as fitting parameters.

\subsection{Results and discussion}

Figure 2.1 provides a set of pictures that show the fiber morphology before and after thermal treatments at various temperatures. Figure $2.1 \mathrm{~B}$ and $2.1 \mathrm{C}$ display the fiber morphology of green hollow fibers after drying. The via drywet spinning prepared fiber consists of a PES network that is loaded with 


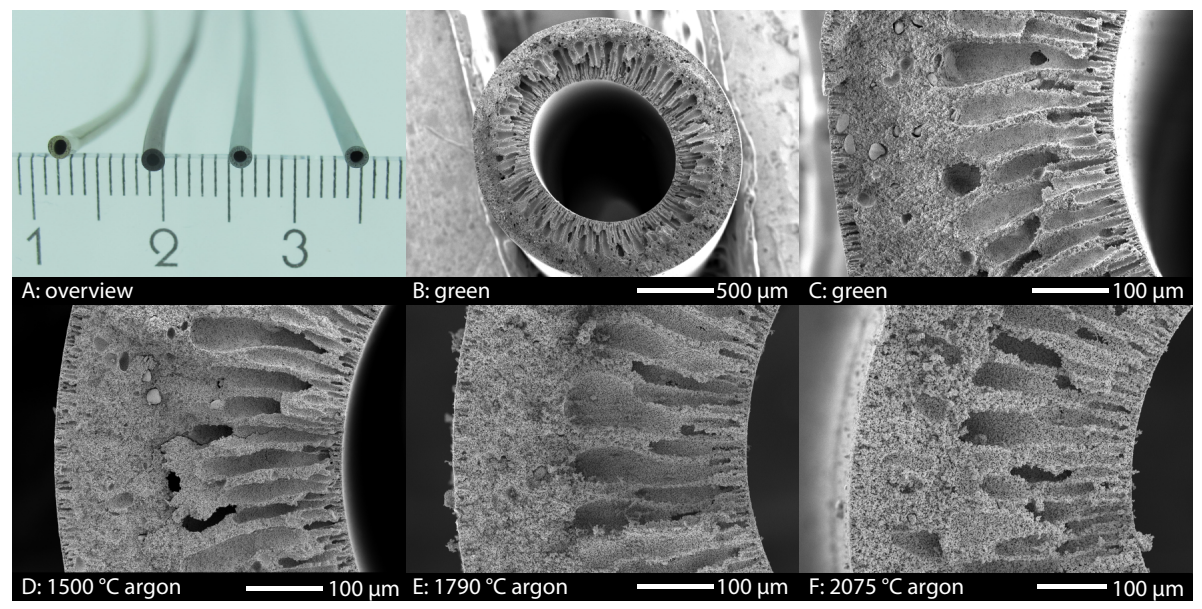

Figure 2.1: Photo of, from left to right, a green, sintered at $1500{ }^{\circ} \mathrm{C}$, sintered at $1790{ }^{\circ} \mathrm{C}$, sintered fiber $2075^{\circ} \mathrm{C}(\mathrm{A})$, and cross-sectional images of a green (B), a green (C), 1500-Ar (D), 1790-Ar (E) and 2075-Ar (F) sintered fibers.

silicon carbide particles and has an asymmetric structure with finger-like voids at the lumen side and a sponge-like outer layer. Such a morphology is typical for inorganic fibers $[15,26]$. Figure 2.1C shows the presence of $10 \mu \mathrm{msized}$ particles dispersed throughout the fiber. A close-up of these particles (not shown here) indicated that the grains are presumably aggregates/agglomerates of smaller silicon carbide grains.

Figure 2.1D-F show that sintering at temperatures of $1500^{\circ} \mathrm{C}$ to $2075^{\circ} \mathrm{C}$ has no apparent effect on the morphology of the silicon carbide fibers. The fingerlike voids and sponge-like structure are both preserved. However, at temperatures in excess of $1790{ }^{\circ} \mathrm{C}$, the sponge-like layer develops into a more open structure, in which the individual grains are clearly visible (see Figure 2.4 for close-up SEM images). The minor changes in morphology also reflected in the small changes in the radial dimensions between the green and the sintered fibers. Prior to sintering, the dried fibers had an outer diameter of $1.78 \mathrm{~mm}$ $\pm 0.02 \mathrm{~mm}$. The level of shrinkage in radial $\left(d_{\text {sintered }} / d_{\text {green }}\right)$ and longitudinal $\left(l_{\text {sintered }} / l_{\text {green }}\right)$ directions as a result of sintering at $2075^{\circ} \mathrm{C}$ was limited to less than $5 \%$ and $8 \%$, respectively. No difference was observed between sintering in argon or nitrogen atmospheres. 

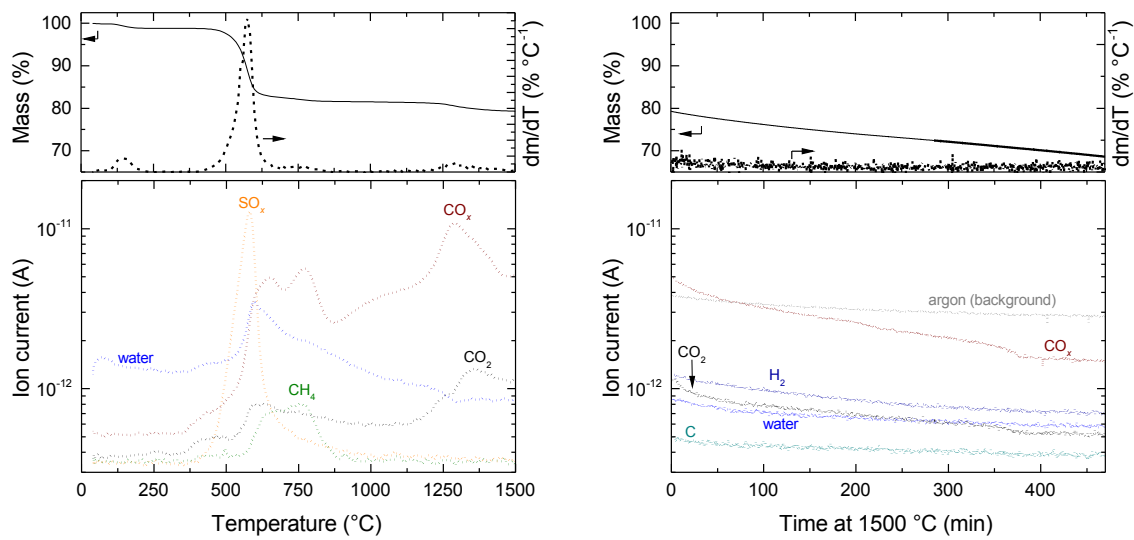

Figure 2.2: TGA-MS data of the thermal processing of SiC hollow fibers under argon with (A) a heating rate of $20^{\circ} \mathrm{C} / \mathrm{min}$ followed by (B) a $8 \mathrm{~h}$ dwell at $1500^{\circ} \mathrm{C}$.

\subsubsection{Thermal treatment}

The mass loss of the green hollow fibers upon heating and the gases that have concurrently evolved are shown in Figure 2.2 for heating under argon up to $1500^{\circ} \mathrm{C}$ (left panel), and for a consecutive $8 \mathrm{~h}$ dwell at $1500{ }^{\circ} \mathrm{C}$ (right panel). At lower temperatures $\left(25^{\circ} \mathrm{C}\right.$ to $\left.250^{\circ} \mathrm{C}\right)$, minor mass loss is recorded that is accompanied by the release of water. This mass loss is attributed to the further drying of the $\mathrm{SiC}$ fibers. A second mass loss step is recorded at intermediate temperatures $\left(450{ }^{\circ} \mathrm{C}\right.$ to $\left.650{ }^{\circ} \mathrm{C}\right)$, where $\mathrm{SO}_{2}, \mathrm{CO}, \mathrm{CO}_{2}$ and water are the main gases emitted, followed by a minor mass loss concurring with release of methane, $\mathrm{CO}$ and $\mathrm{CO}_{2}$ at $750{ }^{\circ} \mathrm{C}$. This observed decomposition process matches closely to the reported decomposition of PES under an argon atmosphere [27-29], indicating that the presence of the silicon carbide has had no (apparent) effect on the decomposition of the PES.

Further mass loss is recorded at temperatures exceeding $1150{ }^{\circ} \mathrm{C}$. This mass loss continues up to $1500^{\circ} \mathrm{C}$ and persists for a full $8 \mathrm{~h}$ dwell period at this temperature. Mainly $\mathrm{CO}$ and $\mathrm{CO}_{2}$ evolve during this step. As the reaction atmosphere is free of oxygen, the formation of $\mathrm{CO}$ and $\mathrm{CO}_{2}$ is attributed to 

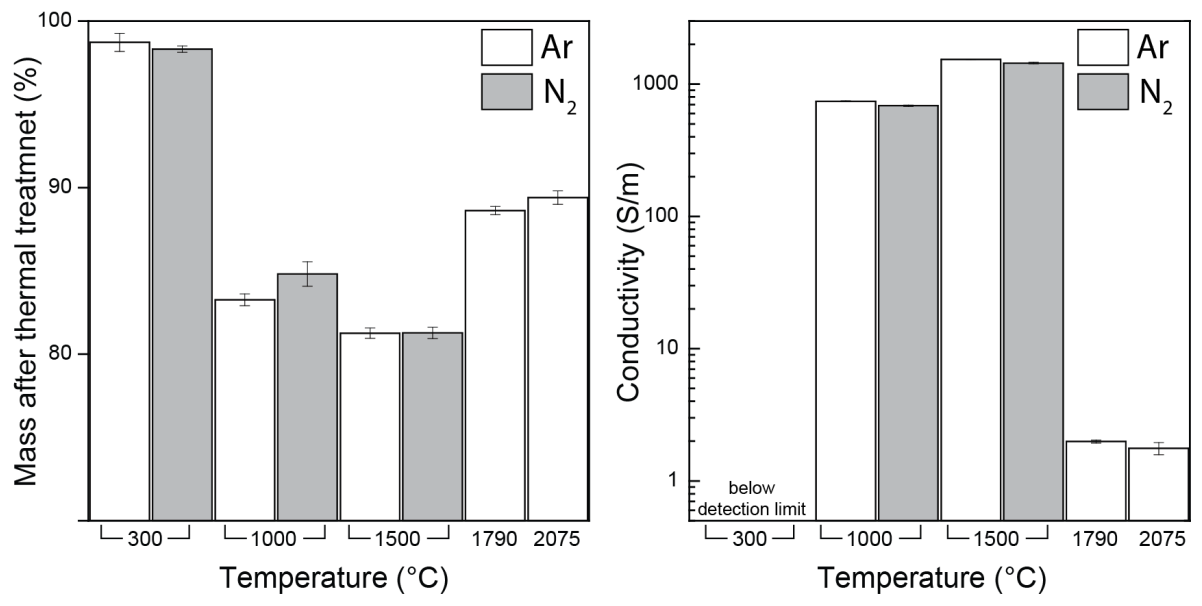

Figure 2.3: (A) Final mass after thermal treatment (with 95\% confidence interval) after sintering at certain temperatures and (B) conductivity after sintering at certain temperature. A full explanation of the thermal treatment steps is given in the text.

the following reaction $[30,31]$ :

$$
\mathrm{SiO}_{2}(\mathrm{~g})+3 \mathrm{C}(\mathrm{s}) \longrightarrow \mathrm{SiC}(\mathrm{s})+2 \mathrm{CO}(\mathrm{g})
$$

The silica originates from impurities in the silicon carbide [32]. The production of $\mathrm{CO}_{2}$ would be the result of only two carbon atoms reacting with the silica. The reaction between silica and silicon carbide is reported to be inhibited at these temperatures in the presence of free carbon [33]. The rate of reaction (2.5) is controlled by the diffusion of $\mathrm{CO}$ through the $\mathrm{SiC}$ fiber wall [31]. Among the main parameters that influence the rate of this process are the porosity, tortuosity and sample thickness of the material. In this respect, the fiber morphology - having a bore and large voids — would result in shorter times required for the thermal treatment than those required for a dense or mesoporous silicon carbide sample.

In Figure 2.3A, the mass of the fibers is shown after thermal treatment in nitrogen or argon. Because of the temperature limitations of the TG-apparatus and tubular furnaces, the temperature treatments at higher temperatures $\left(>1500^{\circ} \mathrm{C}\right)$ were performed in an industrial furnace, in which the fibers are co-fired along 
with the standard production batch. The results obtained up to $1500^{\circ} \mathrm{C}$ are in excellent agreement with the previously discussed TG-experiments. However, at temperatures above $1500{ }^{\circ} \mathrm{C}$, a deviation from the mass loss trend is observed. At these temperatures, the fiber mass increases slowly with increasing sintering temperature. Mass conservation dictates that this increase in mass results from reactions with the atmosphere in the furnace. This cannot be the inert argon gas. It is known that the vapour pressure of silica is non-negligible at these temperatures, and that silica originating from the co-fired samples and/or the furnace can be deposited onto the samples. At the fiber, this silica can then react with the free carbon through reaction (2.5), yielding silicon carbide and carbon monoxide. At these high temperatures, an opposite reaction, in which silicon carbide reacts with the silica can occur as well [32]. The resulting silicon oxide will either be removed in the vapour phase, or disproportionate into silica and silicon at room temperature [34]. To test this hypothesis, the electrical conductivity of the silicon carbon fibers was measured after sintering. The electrical conductivity of amorphous carbon (up to $10^{6} \mathrm{~S} \mathrm{~m}^{-1}$ ) is multiple orders of magnitude higher than that of silicon carbide (down to $10^{-4} \mathrm{~S} \mathrm{~m}^{-1}$ under a nitrogen atmosphere) or voids $[35,36]$. Hence, the deposition of silicon dioxide and the removal of carbon via reaction 2.5 should result in a sharp decline in the conductivity of the fibers. In Figure 2.3B, the electrical conductivity is given for fibers that have been treated under nitrogen or argon at various temperatures. The high electrical conductivity of the samples up to $1500^{\circ} \mathrm{C}$ demonstrates that carbon is present and forms a percolative pathway through the material. Fitting of the data with a Bruggeman Effective Medium Approximation proved to be impossible, which demonstrates that the carbon is not present in the form of spherical inclusions, but more likely forms a film that surrounds the silicon carbide particles. Above $1500^{\circ} \mathrm{C}$, the large drop in conductivity indicates the removal of the carbon from the fibers. To verify the presence of carbon in the 1500-Ar fiber, and the absence of carbon in the 2075Ar fiber, these fibers were measured with TGA under air. The TGA-runs give a clear indication for the presence of $13.5 \mathrm{wt} \%$ residual carbon in the 1500-Ar fiber, and the absence of residual carbon in the 2075-Ar fiber (see Figure 2.8 in the supplementary information). 


\subsubsection{Microstructure of the treated SiC fibers}

\section{Scanning Electron Micrographs}

Figure 2.4 shows the microstructure of the hollow fibers as a function of sintering temperature $1500^{\circ} \mathrm{C}$ to $2400{ }^{\circ} \mathrm{C}$ ). The microstructures of the fibers sintered at $1500^{\circ} \mathrm{C}$ (Figure $2.4 \mathrm{~A}$ and B) reveal submicron silicon carbide particles, still bound together by the residual carbon. No significant sintering has taken place, which is as expected for the comparatively short holding time of $2 \mathrm{~h}$ just above the sintering temperature $\left(T_{\text {Tamman }} \sim 1250^{\circ} \mathrm{C}\right)$. At higher temperatures, sintering is evident from the significant grain growth that is a consequence of Ostwald ripening $\left(1790^{\circ} \mathrm{C}\right.$ in Figure $2.4 \mathrm{C}$ and $2075^{\circ} \mathrm{C}$ in Figure $\left.2.4 \mathrm{D}\right)$. The grains grow from loose grains, smaller than $0.5 \mu \mathrm{m}$ in size, to strongly necked particles of approximately $2 \mu \mathrm{m}$ at $2075^{\circ} \mathrm{C}$, forming an interconnected pore structure with large-sized pores. This degree of grain growth agrees well with reported morphologies of synthesized $\mathrm{SiC}$ substrates at comparable temperatures and without the use sintering additives $[1,4]$.

\section{Pore size distribution}

Figure 2.5 shows the volume-based pore size distribution of fibers sintered under argon. It can be seen that the median pore size increases with increasing sintering temperature. The green fiber shows an apparent median pore size of $125 \mathrm{~nm}$, consisting of both pores in the polymeric matrix and voids between the ceramic particles. After sintering at $1500{ }^{\circ} \mathrm{C}$ many of the smaller pores disappear as the polymer is converted into elemental carbon - leaving only the voids between the ceramic particles. This results in a bell-shaped pore size distribution with a median pore size of $500 \mathrm{~nm}$. Still, a considerable amount of residual carbon is present in this fiber, as a subsequent oxidation step further opens up the pores in the $100 \mathrm{~nm}$ to $500 \mathrm{~nm}$ range.

At higher temperatures $\left(1790{ }^{\circ} \mathrm{C}\right.$ to $\left.2075^{\circ} \mathrm{C}\right)$, strong broadening of the pore size is observed, combined with a shift of the poresize to larger pores $(>1000 \mathrm{~nm})$. The increase in pore size agrees well with the observed increase in particle size (Figure 2.4). The change in pore size does not result in a strong change in the fiber' porosity (Table 2.3), as the porosity indicates there is no significant densification, even at higher sintering temperatures. 


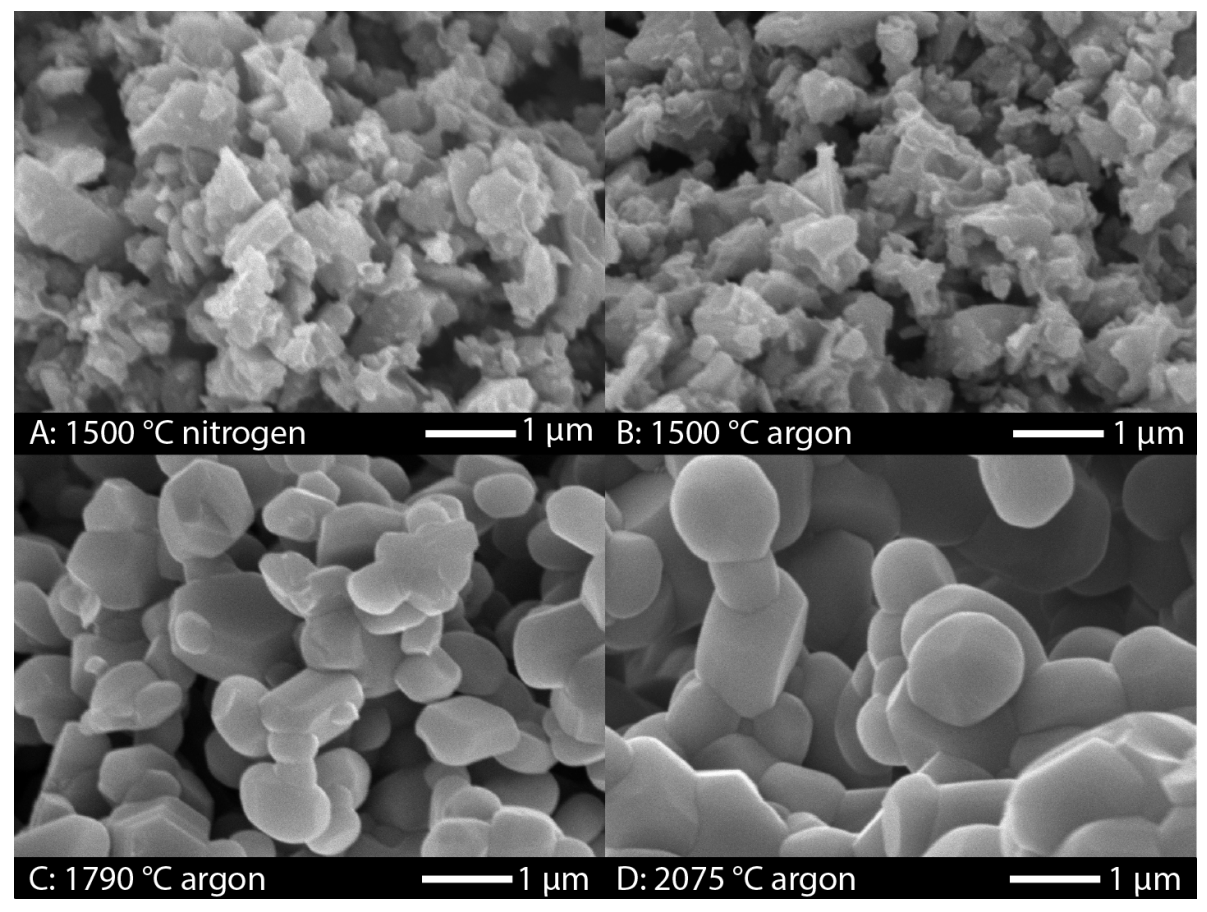

Figure 2.4: Cross section microstructure for sintered silicon carbide fibers. Details about the heat treatment can be found in Table $2.2 .1500{ }^{\circ} \mathrm{C}$ sintered fibers in nitrogen (A) and $\operatorname{argon}(\mathrm{B}) .1790^{\circ} \mathrm{C}(\mathrm{C}), 2075^{\circ} \mathrm{C}(\mathrm{D})$ were sintered in argon atmosphere.

Table 2.3: Porosity for green and sintered fibers, including standard error

\begin{tabular}{ll}
\hline Sample & Porosity \\
\hline Green & $62.8 \pm 9.7 \%$ \\
SiC1500Ar & $64.4 \pm 6.5 \%$ \\
SiC1790Ar & $70.0 \pm 4.7 \%$ \\
SiC2075Ar & $63.5 \pm 4.8 \%$ \\
\hline
\end{tabular}




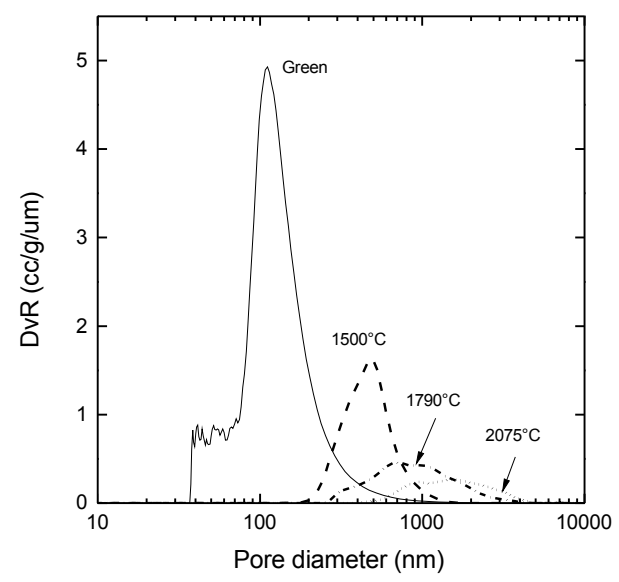

Figure 2.5: Volume-based pore size distribution by mercury intrusion for various sintering temperatures under argon atmosphere.

\subsubsection{Properties}

\section{Mechanical strength}

Figure 2.6A shows the mechanical strength as result of the sintering temperature and sintering atmosphere. The lower and upper error bars indicate a cumulative probability of failure of $5 \%$ and $95 \%$, respectively. Figure 2.6B demonstrates in detail how these values were obtained from a Weibull-fit of the cumulative probability of failure to the bending strength.

From the data, it can be concluded that there is no strong influence of the sintering atmosphere on the characteristic strength for the $1000{ }^{\circ} \mathrm{C}$ sintered sample. A large reduction in the strength is observed between the fibers sintered up to $1500{ }^{\circ} \mathrm{C}$ and at $1790{ }^{\circ} \mathrm{C}$. This loss of strength is attributed to the removal of residual carbon at the higher processing temperatures. As only minor neck formation is present between the silicon carbide particles at these temperatures, the carbon is required to bind together the particles. Although the increasing sintering temperature of $1790{ }^{\circ} \mathrm{C}$ increases the inherent strength of the SiC-network through neck formation, this increased strength is offset by the removal of the carbon. A higher sintering temperature of $2075{ }^{\circ} \mathrm{C}$ resulted 


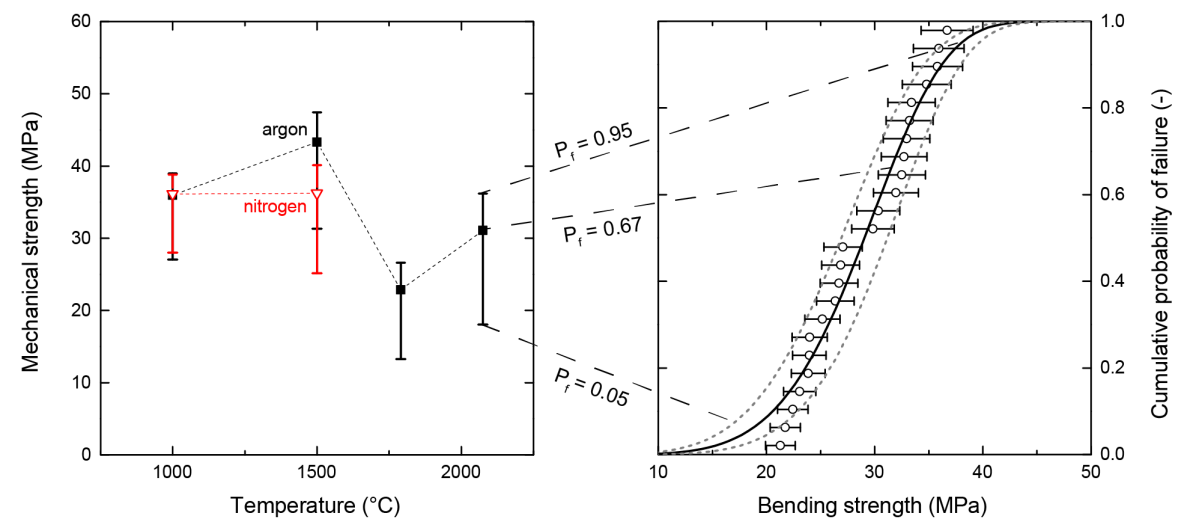

Figure 2.6: Summary of measured mechanical strengths at different temperature and atmosphere. In A), the symbol (square for argon, triangle for nitrogen) denotes the characteristic strength $\left(\sigma_{\theta}\right)$ from Weibull fitting. The lower error bar denotes the strength at which $5 \%$ of the fibers would fail. The upper error bar denotes strength at which $95 \%$ of the fibers would fail. B) shows the weibull cumulative probability function for the 2075-Ar sample, showing the measured mechanical strengths where the error bar denotes measurement error. The solid line is the fit based on the weibull function, whereas the dashed lines represent the $95 \%$ confidence interval of the fit.

in progressive sintering of the silicon carbide particles, leading to an increasing mechanical strength. At first glance the mechanical strength of these silicon carbide fibers appears to be low in comparison with other ceramic hollow fibers [18, 37-39]. These values, however, cannot be directly compared as in the present study the bending strength was obtained via a 4-point bending test. This results in a lower value for the mechanical strength as compared to an often-used 3-point bending test [40]. In addition, assessing the mechanical strength of a ceramic based on small sample numbers requires caution as sample-to-sample differences might introduce large errors. Even though in this study a limited sample size of 24 fibers is used [41-43], this method of testing provides a better insight in the mechanical behaviour of these fibers as compared to other studies. 


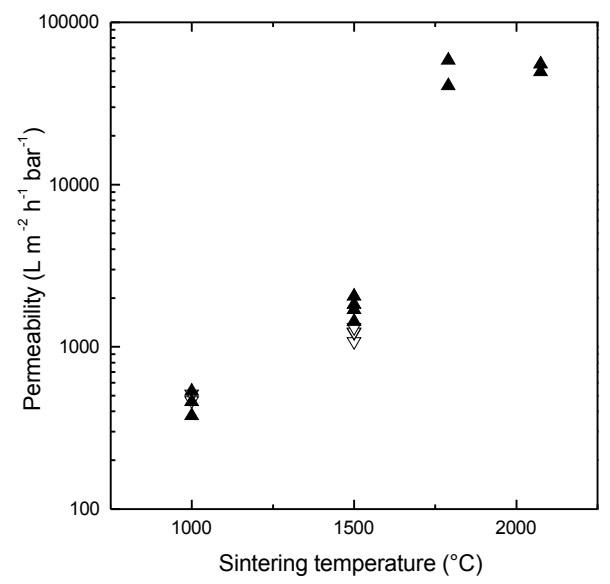

Figure 2.7: Clean water permeability for silicon carbide fibers sintered at various temperatures. The open symbols represent fibers sintered in a nitrogen atmosphere, the closed symbols represent the fibers sintered in an argon atmosphere. Each symbol represents a single fiber.

\section{Clean water permeation}

Figure 2.7 shows the clean water permeability for fibers sintered at various temperatures. The fibers sintered at $1000^{\circ} \mathrm{C}$ show a clean water permeability of approximately $500 \mathrm{~L} \mathrm{~m}^{-2} \mathrm{~h}^{-1} \mathrm{bar}^{-1}$ for both sintering atmospheres. After sintering at $1500{ }^{\circ} \mathrm{C}$ an increase in permeability to values in the order of $1000 \mathrm{~L} \mathrm{~m}^{-2} \mathrm{~h}^{-1}$ bar $^{-1}$ to $1200 \mathrm{~L} \mathrm{~m}^{-2} \mathrm{~h}^{-1}$ bar $^{-1}$ is observed. The sintering atmosphere has little influence on the clean water permeability for these fibers. After high temperature sintering the clean water permeability increases more than tenfold to values in the order of $50000 \mathrm{~L} \mathrm{~m}^{-2} \mathrm{~h}^{-1}$ bar $^{-1}$. Sintering at these high temperatures not only removed the residual carbon but also resulted in larger pores, yielding this increased clean water permeability. The observed clean water permeability of the fibers in this study (pore size $0.5 \mu \mathrm{m}$ to $3 \mu \mathrm{m}$ ) is approximately a factor 50 higher than that reported for alumina (pore size $0.1 \mu \mathrm{m}$ to $1.4 \mu \mathrm{m})[44,45]$, a factor 5 higher than that reported for titanium (pore size $1 \mu \mathrm{m}$ to $3 \mu \mathrm{m}$ ) [39] and a factor 2 higher than that reported for silicon nitride hollow fibers (pore size $0.5 \mu \mathrm{m}$ to $0.9 \mu \mathrm{m}$ ) [37]. Burst pressure 
experiments were conducted up to a transmembrane pressure of 20 bar without rupture of the fiber, further substantiating the mechanical robustness of the fibers.

\subsection{Conclusion}

Porous silicon carbide hollow fiber membranes with outer diameters of $1.8 \mathrm{~mm}$ were successfully prepared by dry-wet spinning, followed by thermal treatment at various temperatures. Tuning of the microstructure by changing the sintering temperature allowed for the optimization of pore size and mechanical strength of the fibers. Although sintering at $1500^{\circ} \mathrm{C}$ yielded mechanically stable fibers, the carbon residue of the polymeric binder effectively blocked the pores of the fiber, resulting in low water fluxes. The carbon binds the SiCparticles together, as is evident from the sharp decrease in mechanical strength when carbon is removed upon heating to $1790^{\circ} \mathrm{C}$. A treatment at temperatures as high as $2075^{\circ} \mathrm{C}$ is required to sufficiently sinter together the silicon carbide particles. The resulting fibers show exceptionally high clean water fluxes in the order of $50000 \mathrm{~L} \mathrm{~m}^{-2} \mathrm{~h}^{-1} \mathrm{bar}^{-1}$ at a differential pressure of 1 bar. With pore sizes in the order of microns, the membranes are directly applicable as a microfiltration membrane, or can be used as a substrate for UF or gas-separation membranes.

\subsection{Acknowledgments}

The authors would like to thank Liqtech International A/S for using their high temperature furnaces. 


\subsection{Supplementary information}

\subsubsection{Residual carbon in high temperature sintered fibers}

To analyze the presence of residual carbon in fibers that were treated under argon, these fibers were analyzed by TGA under air. Under air, residual carbon will be burned out at temperatures between 500 and $700{ }^{\circ} \mathrm{C}$, resulting in a mass loss. This process is easily distinguished from the oxidation of $\mathrm{SiC}$, which takes place and results in a mass increase, due to the substitution of 1 carbon atom by 2 oxygen atoms. Figure 2.8 presents the results for a TGA-run on a 1500-Ar and a 2075-Ar fiber. From the figure, it is clear that the 2075-Ar fiber only shows a mass increase as a result of $\mathrm{SiC}$ oxidation. No burning of carbon was detected. For the 1500-Ar fiber, the presence of a significant amount of residual carbon is clear from the $13.5 \%$ mass loss between 500 and $700{ }^{\circ} \mathrm{C}$.

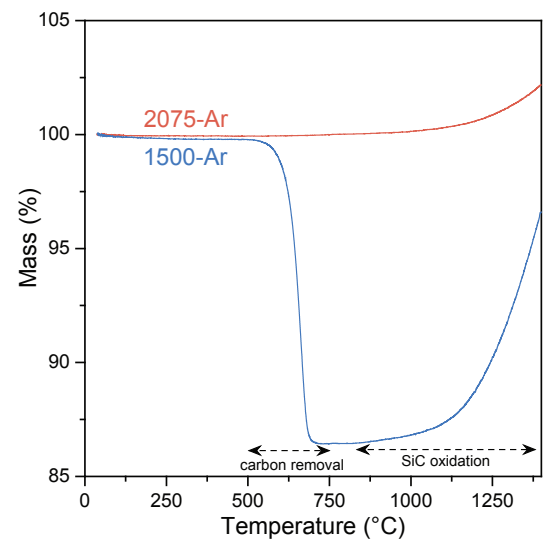

Figure 2.8: TGA-run on a 1500-Ar and a 2075-Ar fiber. Gas atmosphere is synthetic air. 


\subsubsection{Clean water permeation}

Clean water permeation experiments were carried out using a OSMO inspector operated under constant flux settings in which a fiber was measured in a deadend operating mode. The following figures show the flux as function of the transmembrane pressure for various fibers. The symbols in the graphs represent the various fibers measured.

Figure 2.13, 2.15 and 2.14 show the clean water flux versus the transmembrane pressure for silicon carbide fibers prepared under different sintering conditions. Per graph, one sintering condition is give, and the different symbols represent different fibers prepared under identical conditions, as to demonstrate the reproducibility of the fiber preparation. From the slopes of the graphs, the permeability of the fibers was determined, these results are shown in the main article.
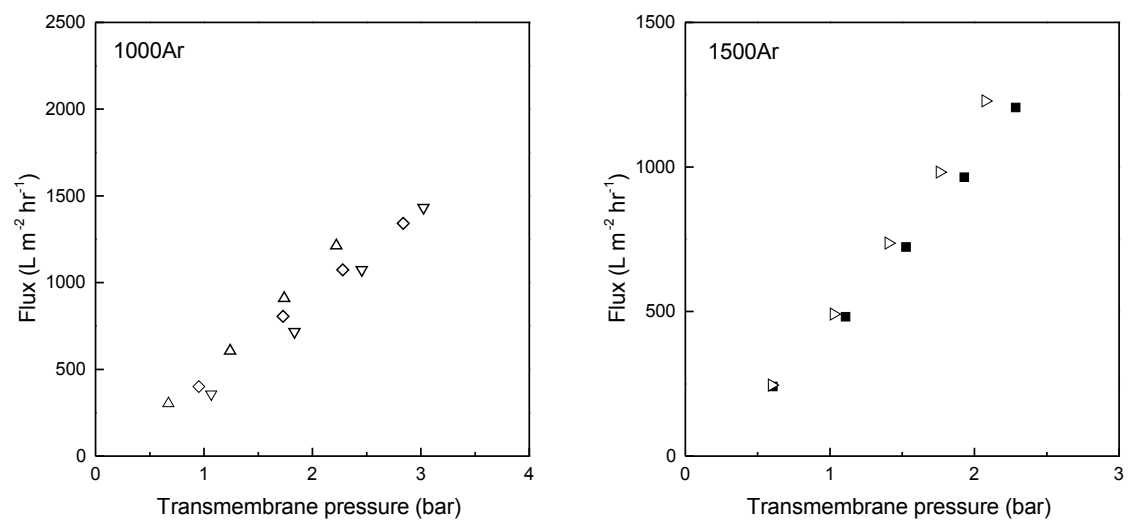

Figure 2.9: 1000-Ar (left) and 1500-Ar (right) clean water permeation data. 

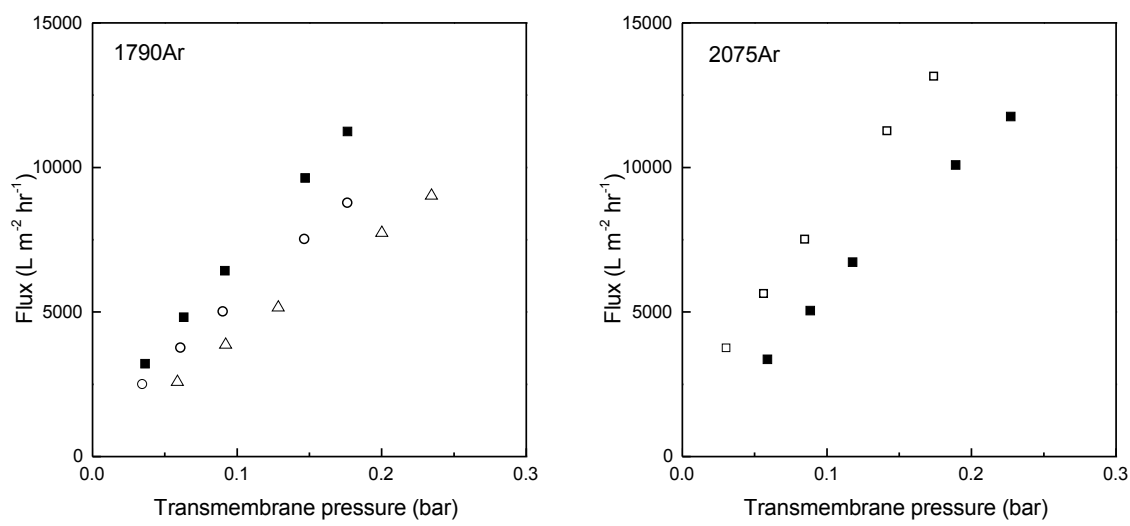

Figure 2.10: 1790-Ar (left) and 2075-Ar (right) clean water permeation data.
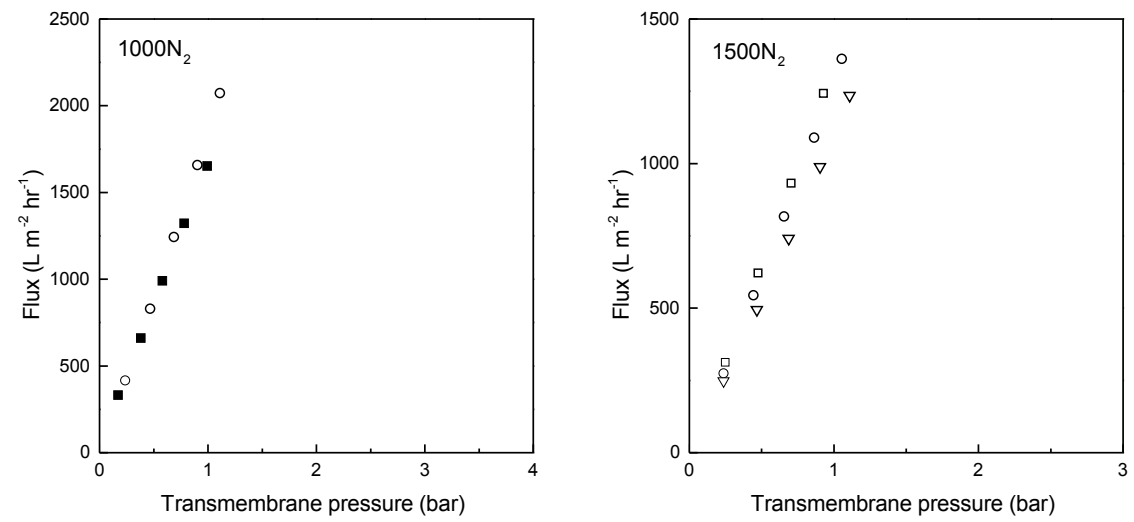

Figure 2.11: 1000-N2 (left) and 1500-N2 (right) clean water permeation data. 


\subsubsection{Filtration experiments}

To proof that the fibers have potential in filtration, a cross flow filtration experiment was performed using a silicon carbide fiber glued (Araldite 2000) into a cross-flow module. A $0.1 \mathrm{wt}-\%$ aqueous solution of AKP-30 particles with 0.05 $\mathrm{M} \mathrm{HNO}_{3}$ was used as the feed. Figure 2.12 (left panel) shows a photograph of the feed, permeate and retentate (left, center and right vial respectively). The absence of turbidity of the permeate solution implies that particles have been retained by the fiber.

The right pane of Figure 2.12 shows the particle size distribution for the feed, permeate and retentate determined using dynamic light scattering (Zetasizer Nano, Malvern) as a qualitative measure of the separation performance. Results clearly show that the larger particles have been retained by the membrane, resulting in a permeate that only contains particles of sizes well below the pore size.
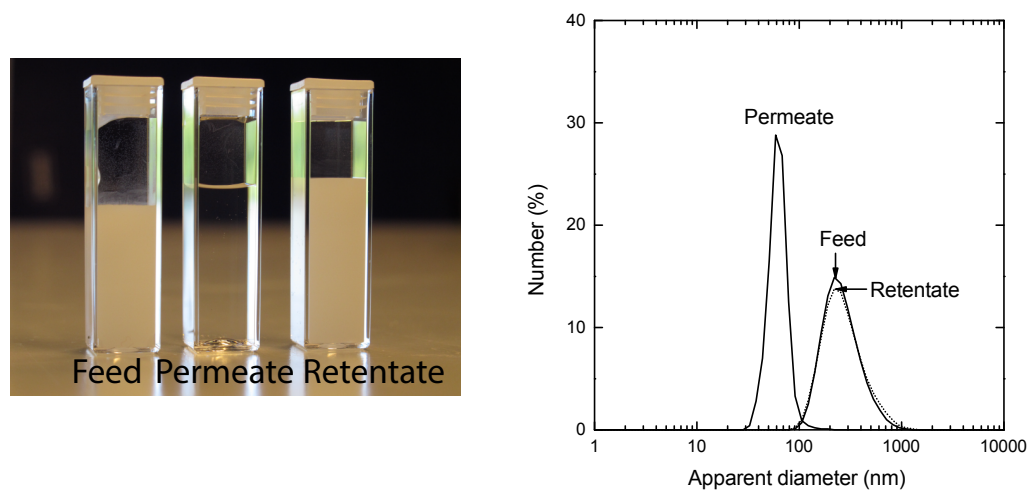

Figure 2.12: Photographs of feed, permeate and retentate (left) and particle size distribution of feed, permeate and retentate obtained with Dynamic Light Scattering (right). 


\subsubsection{Mechanical Strength}

Figures 2.13, 2.14 and 2.15 show the results of a 4-point bending test on fibers prepared under different sintering conditions. Per condition, 25 bending strength measurements were performed. The solid line gives the best cumulative Weibull-fit through the data, and the dashed lines indicate the lower and upper boundaries of the fit. Table 2.4 and 2.5 summarize the data obtained from the figures 2.13 to 2.15 .

The results of ordering and fitting the mechanical strength data is shown in the following figures.
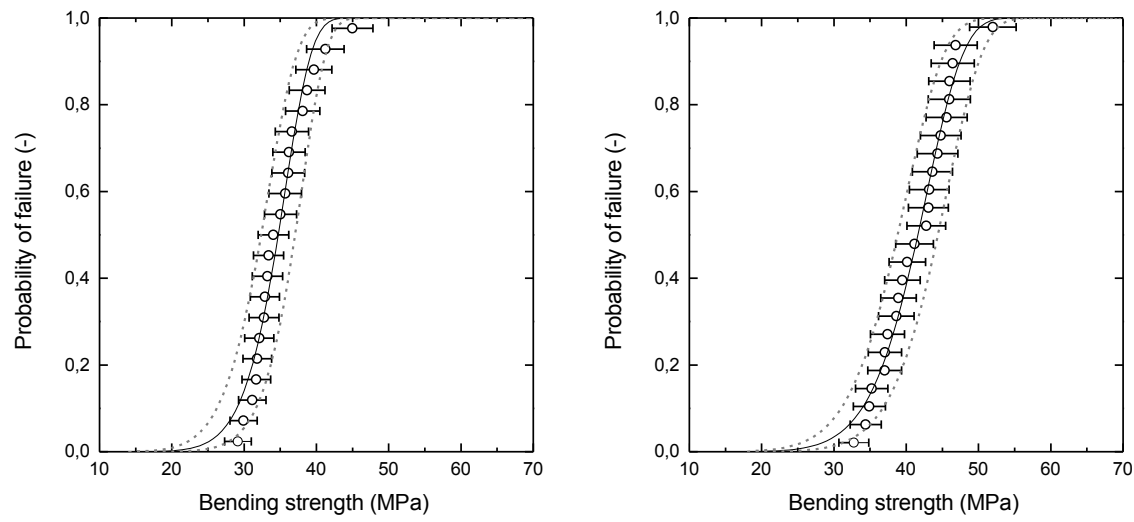

Figure 2.13: 1000-Ar (left) and 1500-Ar (right) mechanical strength data. 

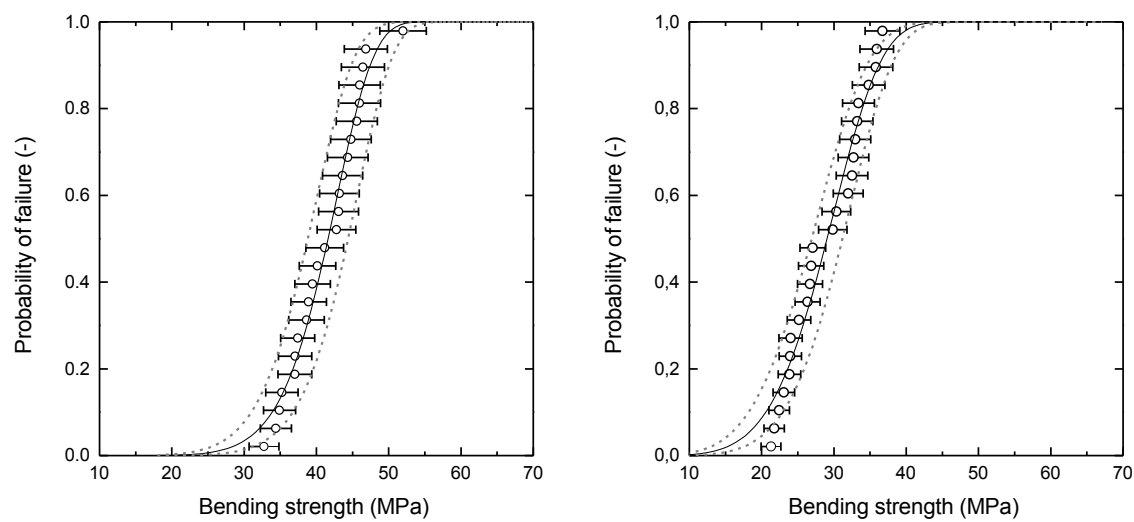

Figure 2.14: 1790-Ar (left) and 2075-Ar (right) mechanical strength data.
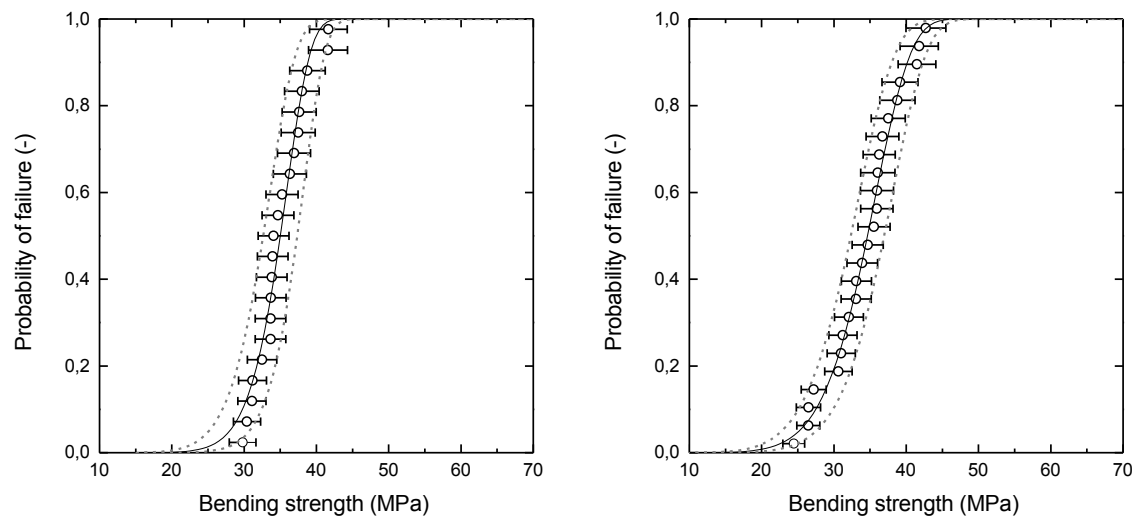

Figure 2.15: 1000-N2 (left) and 1500-N2r (right) mechanical strength data. 


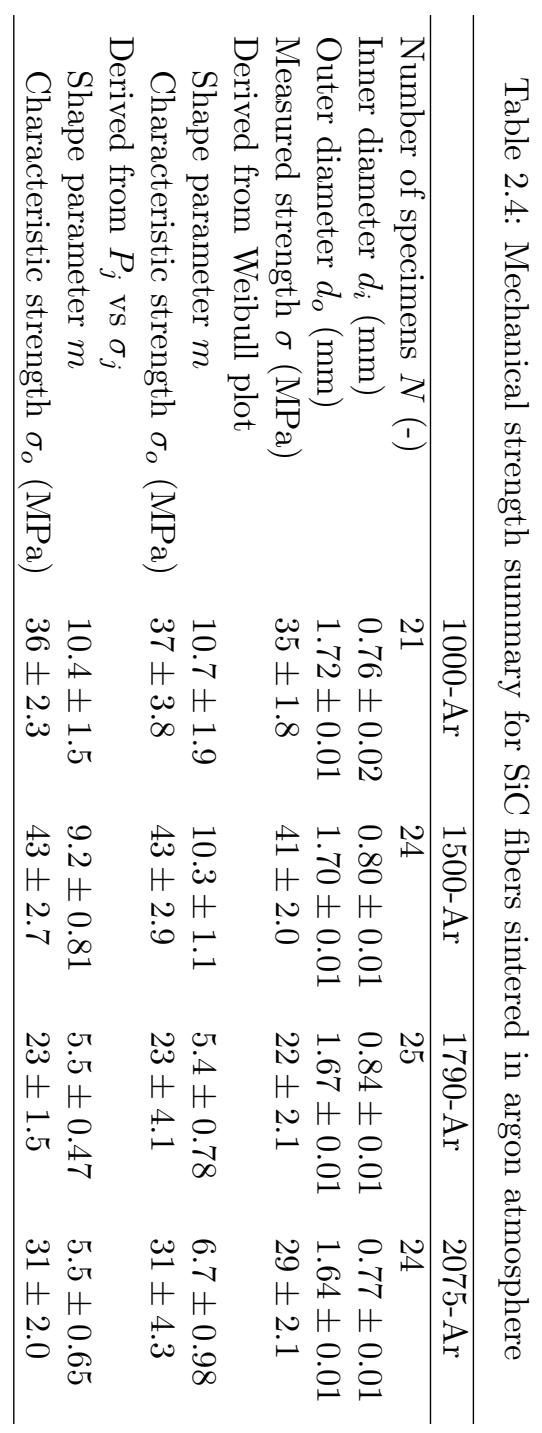




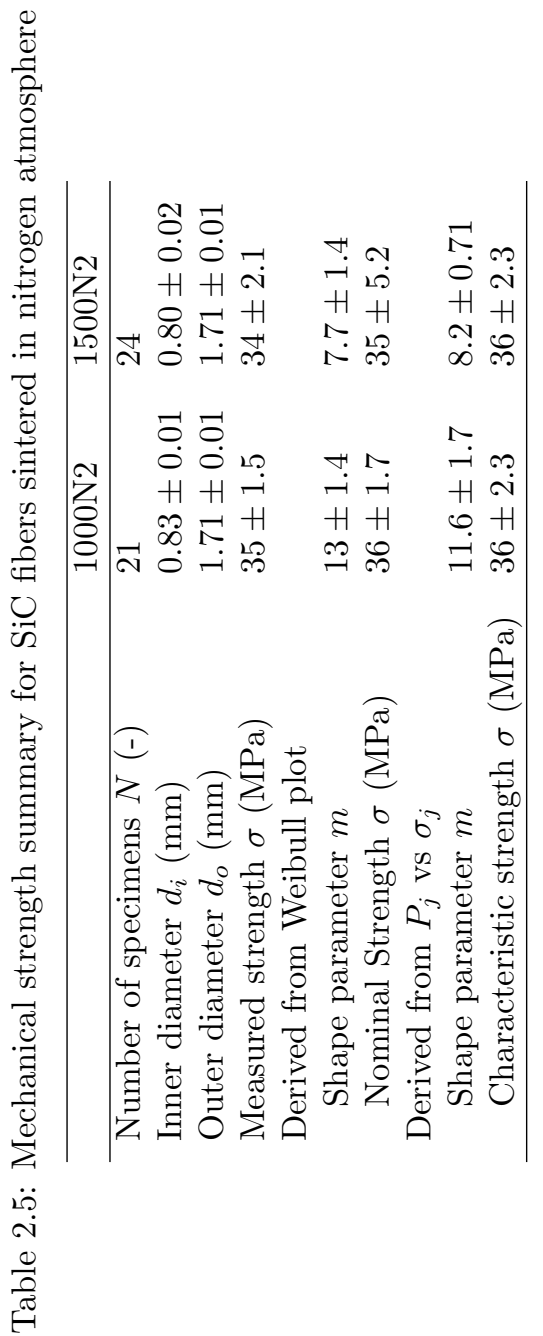




\section{$2.7 \quad$ References}

[1] T. Thomé, M. Capelle, L. Thomé, T. Prenant, M. Néret, Thermal Oxidation of Sintered Silicon Carbide Used for Diesel Particulate Filter Walls, J. Ceram. Sci. Technol. 3 (2012) 89-94.

[2] J. A. Díaz, M. Calvo-Serrano, A. R. de la Osa, A. M. García-Minguillán, A. Romero, A. Giroir-Fendler, J. L. Valverde, $\beta$-silicon carbide as a catalyst support in the fischer-tropsch synthesis: Influence of the modification of the support by a pore agent and acidic treatment, Appl. Catal. A: Gen 475 (2014) 82-89.

[3] M. Rosso, A. Arafat, K. Schroën, M. Giesbers, C. S. Roper, R. Maboudian, H. Zuilhof, Covalent attachment of organic monolayers to silicon carbide surfaces., Langmuir 24 (2008) 4007-12.

[4] V. Suwanmethanond, E. Goo, P. K. T. Liu, G. Johnston, M. Sahimi, T. T. Tsotsis, Porous silicon carbide sintered substrates for high-temperature membranes, Ind. Eng. Chem. Res. 39 (2000) 3264-3271.

[5] W. Deng, X. Yu, M. Sahimi, T. T. Tsotsis, Highly permeable porous silicon carbide support tubes for the preparation of nanoporous inorganic membranes, J. Membr. Sci. 451 (2014) 192-204.

[6] S. Chae, Y. Kim, I. Song, Porosity control of porous silicon carbide ceramics, J. Eur. Ceram. Soc. 29 (2009) 2867-2872.

[7] F. Chen, R. Mourhatch, T. T. Tsotsis, M. Sahimi, Experimental studies and computer simulation of the preparation of nanoporous silicon-carbide membranes by chemical-vapor infiltration/chemical-vapor deposition techniques, Chem. Eng. Sci. 63 (2008) 1460-1470.

[8] B. Elyassi, W. Deng, M. Sahimi, T. T. Tsotsis, On the use of porous and nonporous fillers in the fabrication of silicon carbide membranes, Ind. Eng. Chem. Res. 52 (2013) 10269-10275.

[9] B. Hofs, J. Ogier, D. Vries, E. F. Beerendonk, E. R. Cornelissen, Comparison of ceramic and polymeric membrane permeability and fouling using surface water, Sep. Purif. Technol. 79 (2011) 365-374.

[10] Liqtech, Success for LiqTech ceramic membranes in oil \& gas trial, Filtration Industry Analyst 2012 (2012) 4. 
[11] Veolia Water Solutions and Technology, Veolia adds silicon carbide membranes to its CeraMem range, 2010.

[12] R. Neufert, M. Moeller, A. Bakshi, Dead-end silicon carbide micro-filters for liquid filtration, John Wiley \& Sons, Inc., Hoboken, NJ, USA, pp. $113-125$.

[13] P. Lin, D. Tsai, Preparation and analysis of a silicon carbide composite membrane, J. Am. Ceram. Soc. 72 (1997) 365-372.

[14] M. Facciotti, V. Boffa, G. Magnacca, L. B. Jørgensen, P. K. Kristensen, A. Farsi, K. König, M. L. Christensen, Y. Yue, Deposition of thin ultrafiltration membranes on commercial SiC microfiltration tubes, Ceram. Int. 40 (2014) 3277-3285.

[15] X. Tan, S. Liu, K. Li, Preparation and characterization of inorganic hollow fiber membranes, J. Membr. Sci. 188 (2001) 87-95.

[16] J. de Jong, N. E. Benes, G. H. Koops, M. Wessling, Towards single step production of multi-layer inorganic hollow fibers, J. Membr. Sci. 239 (2004) 265-269.

[17] S. Husain, W. J. Koros, Macrovoids in hybrid organic/inorganic hollow fiber membranes, Ind. Eng. Chem. Res. 48 (2009) 2372-2379.

[18] S. Liu, K. Li, R. Hughes, Preparation of porous aluminium oxide $\left(\mathrm{Al}_{2} \mathrm{O}_{3}\right)$ hollow fibre membranes by a combined phase-inversion and sintering method, Ceram. Int. 29 (2003) 875-881.

[19] R. A. Terpstra, J. P. G. M. van Eijk, F. K. Feenstra, Method for the production of ceramic hollow fibres, US Patent 5,707,584 (1998).

[20] D. Shin, E. Kong, K. Cho, W. Kwon, Y. Kim, S. Kim, J. Hong, D. Riu, Nano-Structure Control of SiC Hollow Fiber Prepared from Polycarbosilane, J. Korean Ceram. Soc. 50 (2013) 301-307.

[21] M. W. J. Luiten-Olieman, M. J. T. Raaijmakers, L. Winnubst, T. C. Bor, M. Wessling, A. Nijmeijer, N. E. Benes, Towards a generic method for inorganic porous hollow fibers preparation with shrinkage-controlled small radial dimensions, applied to $\mathrm{Al}_{2} \mathrm{O}_{3}, \mathrm{Ni}, \mathrm{SiC}$, stainless steel and YSZ, J. Membr. Sci. 407-408 (2012) 155-163. 
[22] M. Luiten-Olieman, L. Winnubst, A. Nijmeijer, M. Wessling, N. E. Benes, Porous stainless steel hollow fiber membranes via dry-wet spinning, J. Membr. Sci. 370 (2011) 124-130.

[23] The MathWorks, MATLAB and Optimization Toolbox, Release 2012b, 2012.

[24] C. León, New perspectives in mercury porosimetry, Adv. Colloid Interface Sci. 66-77 (1998) 341-372.

[25] ASTM C1684-08, Standard test method for flexural strength of advanced ceramics at ambient temperature-cylindrical rod strength, 2002.

[26] B. Kingsbury, K. Li, A morphological study of ceramic hollow fibre membranes, J. Membr. Sci. 328 (2009) 134-140.

[27] Y. Gupta, A. Chakraborty, Thermal and thermooxidative degradation of engineering thermoplastics and life estimation, J. Appl. Polym. Sci. 92 (2004) 1737-1748.

[28] X. Li, H. Shao, H. Bai, M. Huang, W. Zhang, High-resolution thermogravimetry of polyethersulfone chips in four atmospheres, J. Appl. Polym. Sci. 90 (2003) 3631-3637.

[29] L. Perng, Comparison of thermal degradation characteristics of poly(arylene sulfone)s using thermogravimetric analysis/mass spectrometry, J. Appl. Polym. Sci. 81 (2001) 2387-2398.

[30] J. Baird, J. Taylor, Reaction between silica and carbon and the activity of silia in slag solution, Transactions of the Faraday Society 54 (1958) $526-539$.

[31] A. Kaza, M. J. Matthewson, D. Niesz, R. L. Haber, M. A. Rossi, A Model of Gas-Phase Transport During the Initial Stages of Sintering of Silicon Carbide, J. Am. Ceram. Soc. 92 (2009) 2517-2527.

[32] W. Rijswijk, D. Shanefield, Effects of carbon as a sintering aid in silicon carbide, J. Am. Ceram. Soc. 73 (1990) 148-149.

[33] A. Malinge, A. Coupé, Y. Le Petitcorps, R. Pailler, Pressureless sintering of beta silicon carbide nanoparticles, J. Eur. Ceram. Soc. 32 (2012) 4393 4400 . 
[34] W. Hertl, W. Pultz, Disproportination and Vaporization of Solid Silicon Monoxide, J. Am. Ceram. Soc. 50 (1967) 278-381.

[35] M. Morgan, Conduction in amorphous carbon films, Thin Solid Films 7 (1970) 313-323.

[36] S. Prochazka, Sintered dense silicon carbide, US Patent 4,004,934 (1977).

[37] J. Zhang, H. Fang, J. Wang, L. Hao, X. Xu, C. Chen, Preparation and characterization of silicon nitride hollow fiber membranes for seawater desalination, J. Membr. Sci. 450 (2014) 197-206.

[38] X. Zhang, D. K. Wang, D. R. S. Lopez, J. C. Diniz da Costa, Fabrication of nanostructured $\mathrm{TiO}_{2}$ hollow fiber photocatalytic membrane and application for wastewater treatment, Chem. Eng. J. 236 (2014) 314-322.

[39] O. David, Y. Gendel, M. Wessling, Tubular macro-porous titanium membranes, J. Membr. Sci. 461 (2014) 139-145.

[40] J. B. Wachtman, W. Roger Cannon, M. John Matthewson, Mechanical properties of ceramics, John Wiley \& Sons, Inc., Hoboken, NJ, USA, 1st ed edition, 1996.

[41] C. Lu, R. Danzer, F. Fischer, Fracture statistics of brittle materials: Weibull or normal distribution, Physical Review E 65 (2002) 067102.

[42] T. Hoshide, H. Sugiyama, Numerical Analysis of Sample-Size Effect on Strength of Alumina, J. Mater. Eng. Perform. 22 (2012) 1-8.

[43] I. Štubna, P. Šín, A. Trník, L. Vozár, Measuring the flexural strength of ceramics at elevated temperatures-an uncertainty analysis, Meas. Sci. Rev. 14 (2014) 35-40.

[44] M. Lee, Z. Wu, R. Wang, K. Li, Micro-structured alumina hollow fibre membranes: Potential applications in wastewater treatment, J. Membr. Sci. 461 (2014) 39-48.

[45] G. Xu, K. Wang, Z. Zhong, C. Chen, P. A. Webley, H. Wang, SiC nanofiber reinforced porous ceramic hollow fiber membranes, J. Mater. Chem. A 2 (2014) 5841-5846. 



\section{Chapter 3}

\section{Synthesis of porous inorganic hollow fibers without harmful solvents}

This chapter is adapted from:

S. Shukla, P. de Wit, M.W.J. Luiten-Olieman, E.J. Kappert, A. Nijmeijer, N.E. Benes, Synthesis of Porous Inorganic Hollow Fibers without Harmful Solvents, ChemSusChem, 8, pp. 251-254, doi: $10.1002 / \operatorname{cssc} .201402483$ 


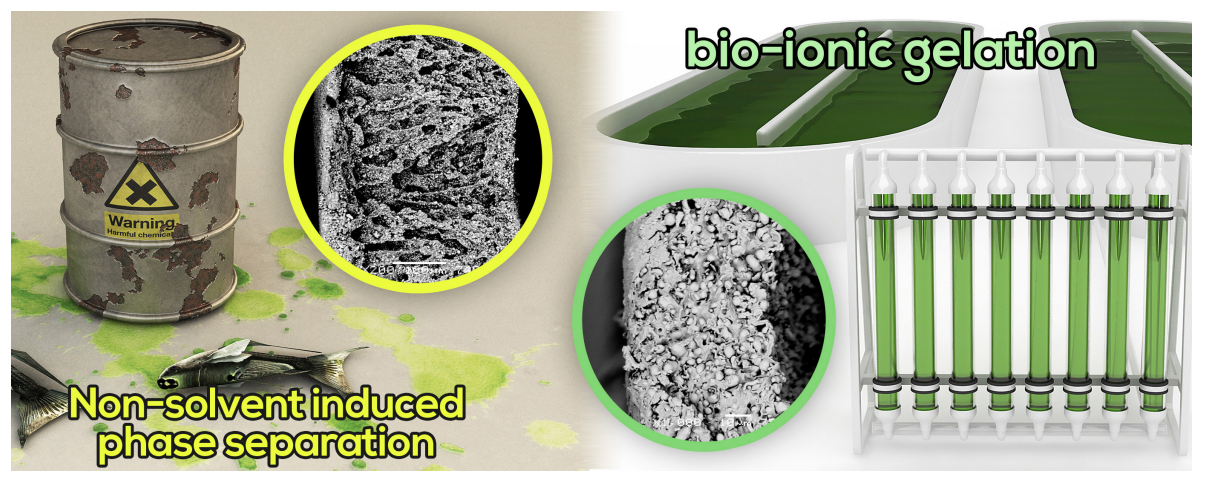

\begin{abstract}
A solvent-free route is presented for the fabrication of porous inorganic hollow fibers with high surface-area-to-volume ratio. The approach is based on bioionic gelation of an aqueous mixture of inorganic particles and sodium alginate during wet spinning. In a subsequent thermal treatment, the bioorganic material is removed and the inorganic particles are sintered together. The method is applicable to the fabrication of various inorganic fibers, including metals and ceramics. The route completely avoids the use of organic solvents, such as N-methyl-2-pyrrolidone, and additives associated with the currently used fiber fabrication methods. In addition, it inherently avoids the manifestation of so-called macro voids and allows the facile incorporation of additional metal oxides in the inorganic hollow fibers.
\end{abstract}




\subsection{Introduction}

Organic hollow fibers provide a high surface-area-to-volume ratio [1] and have found application in, for instance, hemodialysis [2], filtration [3] desalination [4], high-pressure gas separation [5] and microfluidic devices [6]. The high surface area of the fibers results from their small radial dimensions, which are achieved by the dry-wet spinning method. In this method, a polymer solution is pressed through a spinneret and led into a coagulation bath, where a non-solvent causes the polymer solution to separate into a solid polymer-rich phase and a liquid polymer-lean phase. The dimensions and cross-sectional morphology of the resulting fibers can be changed via the composition of the spinning solution and the process conditions [7-9]. This method of production of organic hollow fibers via non-solvent induced phase separation (NIPS) is very mature, as is evident from the combined low cost and high quality of hemodialysis membrane modules. Over 100 million of defect-free hemodialysis modules are marketed annually at a selling price of $15 \$[10]$.

The application landscape of organic hollow fibers is limited by their thermochemical and mechanical stability. In this respect, inorganic materials provide superior resistance to abrasion and thermo-chemical degradation and allow greater usability in corrosive environments and under severe operating conditions [11-13]. In recent years, several inorganic hollow fibers have been synthesized, from materials including alumina [14, 15], yttria-stabilized zirconia16, stainless steel[17], nickel[18], and perovskites[19]. All these fibers have been prepared via a two-step approach. The first step is similar to that of the production of organic hollow fibers and entails dry-wet spinning of a particleloaded polymer solution. In the second step, the organic polymer is burned out and the inorganic particles are sintered together. Recipes for the particleloaded spinning solutions have been inspired by the wealth of knowledge that exists for dry-wet spinning of organic fibers. An example of a typical solution in which the inorganic material is dispersed is polyethersulfone dissolved in N-methyl-2-pyrrolidone. Polyethersulfone is an easily available and relatively cheap polymer that allows the use of water as a non-solvent to induce phase separation. The decomposition temperature of polyethersulfone is sufficiently high to allow some necking of the inorganic particles before the polymer is removed. Other polymers are used as well but all require the use of an organic solvent. Particularly suitable are aprotic solvents, such as dimethyl formamide, N-methyl-2-pyrrolidone and dimethyl acetamide. These solvents dissolve a wide variety of polymers and their spinning solutions readily coagulate upon contact with water. Yet, many of these solvents are toxic, hazardous, 
or environmentally malignant.

In this communication, we present an alternative approach for the synthesis of inorganic hollow fibers. This novel method is based on ionic crosslinking of a biopolymer, here referred to as bio-ionic gelation. The biopolymer is sodium alginate, the sodium salt of the polysaccharide alginic acid that is produced by brown algae and bacteria. It is a linear, unbranched block copolymer consisting of two C-5 epimer uronic acids: 1,4-(b-D)-mannuronic acid (M) and 1,4-(a-L)-guluronic acid $(G)$. When the sodium ions in the polymer are replaced by di- or trivalent cations, the water-soluble alginate forms a stable, water insoluble, three-dimensional gel network[20]. The gel formation involves interaction between the cations and consecutive guluronate residues. Sodium alginates find application in cellular and enzyme encapsulation, photocatalyst immobilization[21], food industries[22] and drug delivery[23].

Bio-ionic gelation has several benefits over NIPS. Firstly, the biopolymer that is used is water soluble, which avoids the use of undesirable organic solvents. Secondly, the viscosity of the spinning solution can be directly regulated via the concentration of the biopolymer, which makes the need for rheology-modifying additives, such as polyvinylpyrrolidone, superfluous. Thirdly, the bio-ionic gelation requires less polymer in comparison with the NIPS process.

Consequently, the resulting fibers contain less organic material, facilitating a more effective thermal treatment. Fourthly, bio-ionic gelation inherently circumvents the creation of so-called macro voids in the hollow fiber structure. In NIPS, such macro voids result from the entrapment of the polymer-lean phase in the fiber during the exchange of non-solvent and solvent. The presence of macro voids is often considered to cause a reduced mechanical strength of the fibers. In bio-ionic gelation, there is no creation of a new phase and consequently a macro void free structure is obtained.

\subsection{Experimental}

\subsubsection{Materials}

AKP30 $\alpha 1$ alumina powder (mean particle size of $0.3 \mu \mathrm{m}$ ) was purchased from Sumitomo Chemicals Co LTD (Japan), alginic acid sodium salt and calcium chloride were purchased from Sigma-Aldrich. Stainless steel powder (316L) with a mean particle size of $4.17 \mu \mathrm{m}$ was purchased from Epson Atmix Corporation (Japan). Deionized water $\left(>18.2 \mathrm{M} \Omega \mathrm{cm}^{-1}\right)$ was obtained using a Milli-Q Advantage A10 system (Millipore). Iron(III) nitrate nonahydrate, magnesium nitrate hexahydrate and chromium nitrate nonahydrate were purchased from 
Table 3.1: Composition of the six different spinning mixtures

\begin{tabular}{lllrl}
\hline Material & Na-alg & $\mathrm{H}_{2} \mathrm{O}$ & Particles & Particles in green fiber \\
\hline $\mathrm{Al}_{2} \mathrm{O}_{3}$ & $5 \mathrm{wt} \%$ & $92.5 \mathrm{wt} \%$ & $2.5 \mathrm{wt} \%$ & $17 \mathrm{vol} \%$ \\
$\mathrm{Al}_{2} \mathrm{O}_{3}$ & $5 \mathrm{wt} \%$ & $87.5 \mathrm{wt} \%$ & $7.5 \mathrm{wt} \%$ & $38 \mathrm{vol} \%$ \\
$\mathrm{Al}_{2} \mathrm{O}_{3}$ & $5 \mathrm{wt} \%$ & $82.5 \mathrm{wt} \%$ & $12.5 \mathrm{wt} \%$ & $50 \mathrm{vol} \%$ \\
$\mathrm{Stainless} \mathrm{steel}$ & $5 \mathrm{wt} \%$ & $90.5 \mathrm{wt} \%$ & $4.5 \mathrm{wt} \%$ & $17 \mathrm{vol} \%$ \\
Stainless steel & $5 \mathrm{wt} \%$ & $81.5 \mathrm{wt} \%$ & $13.5 \mathrm{wt} \%$ & $38 \mathrm{vol} \%$ \\
Stainless steel & $5 \mathrm{wt} \%$ & $72 \mathrm{wt} \%$ & $23 \mathrm{wt} \%$ & $50 \mathrm{vol} \%$ \\
\hline
\end{tabular}

Sigma Aldrich, cobalt nitrate hexahydrate was from obtained from Merck. All the chemicals were used without any further treatment.

\subsubsection{Preparation of mixtures}

Inorganic particles were added to deionized water and the mixture was treated ultrasonically for 30 minutes to break agglomerates of inorganic particles. Sodium alginate powder was added under stirring in three steps, followed by overnight stirring. A small portion of the mixtures was used "as is" for viscosity measurements. Prior to spinning, mixtures were transferred to a stainless steel vessel, degassed by applying vacuum (30 minutes) and left overnight. Table 3.1 shows the spinning mixture compositions used in the study.

\subsubsection{Spinning procedure}

The spinning vessel was pressurized (2 bar, nitrogen) and the mixture was forced through a spinneret with the following dimensions: outer diameter/inner diameter $=2.0 / 0.8 \mathrm{~mm}$. A calcium chloride solution $(10 \mathrm{wt} \%)$ was pumped through the bore of the spinneret at speed of $17 \mathrm{~mL} \mathrm{~min}^{-1}$ and calcium chloride solution of the same composition was used in the gelation bath. The air gap was set at $1 \mathrm{~cm}$. All the spinning experiments were carried out at ambient temperature $\left(20-21^{\circ} \mathrm{C}\right.$. NIPS fibers were prepared following the procedures and recipes that can be found elsewhere [17]. 


\subsubsection{Drying and thermal treatment}

After spinning, the fibers were left in the gelation bath overnight, followed by a brief rinse with deionized water. The fibers were dried and stretched in air overnight. Alumina fibers were dried at $110^{\circ} \mathrm{C}$ for $120 \mathrm{~min}$ to remove excess water (heating rate $5^{\circ} \mathrm{C} \mathrm{min}{ }^{-1}$ ). Thereafter, polymer removal and sintering was carried out at $1500{ }^{\circ} \mathrm{C}$ for 300 minutes (heating rate of $5^{\circ} \mathrm{C} \mathrm{min}{ }^{-1}$ ) and fibers were cooled down at a rate of $10^{\circ} \mathrm{C} \mathrm{min}{ }^{-1}$. Air atmosphere was used for all thermal treatment steps.

In case of stainless steel fibers, no drying step was included, but a polymer removal step was carried out at temperature of $525^{\circ} \mathrm{C}$ at a heating rate of $5^{\circ} \mathrm{C} \mathrm{min}{ }^{-1}$ for 120 minutes, followed by the sintering of stainless steel particles at $1100 \mathrm{C}$ at the rate of $5^{\circ} \mathrm{C} \mathrm{min}{ }^{-1}$ for 60 minutes, followed by cooling at a rate of $10^{\circ} \mathrm{C} \mathrm{min}^{-1}$. Thermal treatment of the stainless steel fibers was carried out in a nitrogen atmosphere to avoid oxidation.

\subsubsection{Analysis}

The morphology, microstructure, composition, and thermal evolution of weight of the samples were investigated by SEM (JEOL JSM 5600LV), XPS (Quantera SXM (scanning XPS microprobe from Physical Electronics), and TGA-DTA (Netzsch STA 449 F3). Water and nitrogen flux measurements were performed in dead-end mode with atmospheric pressure at the permeate side. The flow was determined using a balance (water) or a soap film flow meter (nitrogen). For the flow-to-flux conversion, the fiber diameter was determined per batch using SEM, and considered to be representative for the whole batch.

\subsection{Results and discussion}

Scanning Electron Micrographs (SEM) elucidate the morphology of stainless steel particle loaded fibers that have been prepared by bio-ionic gelation and NIPS prior to sintering (Figure 3.1). The images clearly show the entrapped stainless-steel particles in the polymer matrix, appearing as bright spots in the contrasting polymer materials. The fiber prepared via NIPS (left in Figure 3.11) possesses a cross-sectional morphology with distinct macro voids, whereas the fiber prepared via bio-ionic crosslinking (right in Figure 3.1) exhibits a more homogeneous cross section (picture on right in Figure 3.1). The feasibility of the continuous fabrication of hollow fibers by wet spinning with bio-ionic gelation is further demonstrated in Figure 3.2. On the left side 


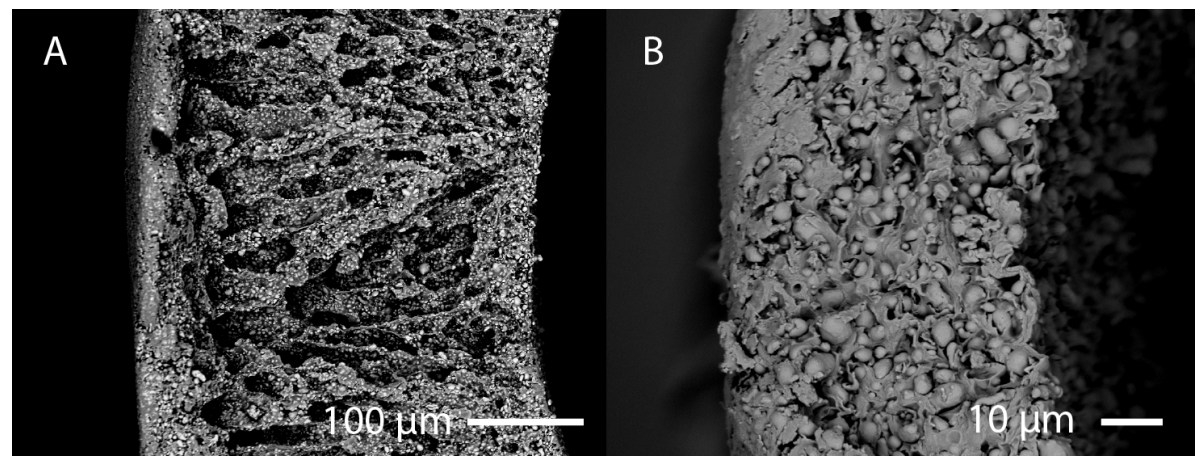

Figure 3.1: Backscattered scanning electron micrographs of polymer hollow fiber loaded with stainless steel particles prior to thermal treatment obtained via phase separation (A) and obtained via bio-ionic gelation (B).

in Figure 3.2, fibers are presented that have been spun with an aqueous sodium alginate solution containing stainless-steel particles (top panels in Figure 3.2) or alumina particles (bottom panels in Figure 3.2). Details of the spinning solution compositions are provided in Table 3.1.

For both types of particles, a round fiber with uniform cross-sectional morphology and an open lumen is obtained. The alumina fiber has a larger diameter and a larger wall thickness in comparison with the stainless-steel fiber. These differences in fiber dimensions are due to the differences in rheology of the two spinning solutions that are caused by the different particle sizes. The alumina particles are smaller, which results in a higher viscosity and a more pronounced shear-thinning behavior of the spinning solution [17].

For both materials, the fiber geometry persists during thermal treatment (right in Figure 3.2), except for a reduction in fiber diameter and in wall thickness due to polymer burnout. These observations demonstrate the feasibility to produce a variety of inorganic hollow fibers via wet spinning and bio-ionic gelation.

Potential applications of the inorganic fibers include (electro)catalysis, microfluidic devices, and membrane separations. For the last application field the fibers can serve either as support for a thin selective film, or for microfiltration of fluids. The fluxes of liquid water and nitrogen gas through various alumina fibers are presented in Figure 3. The fluxes show linear trends with the inside-out pressure difference over the fiber wall. The water flux is measured up to a pressure difference of 20 bar. This substantiates that the fibers 


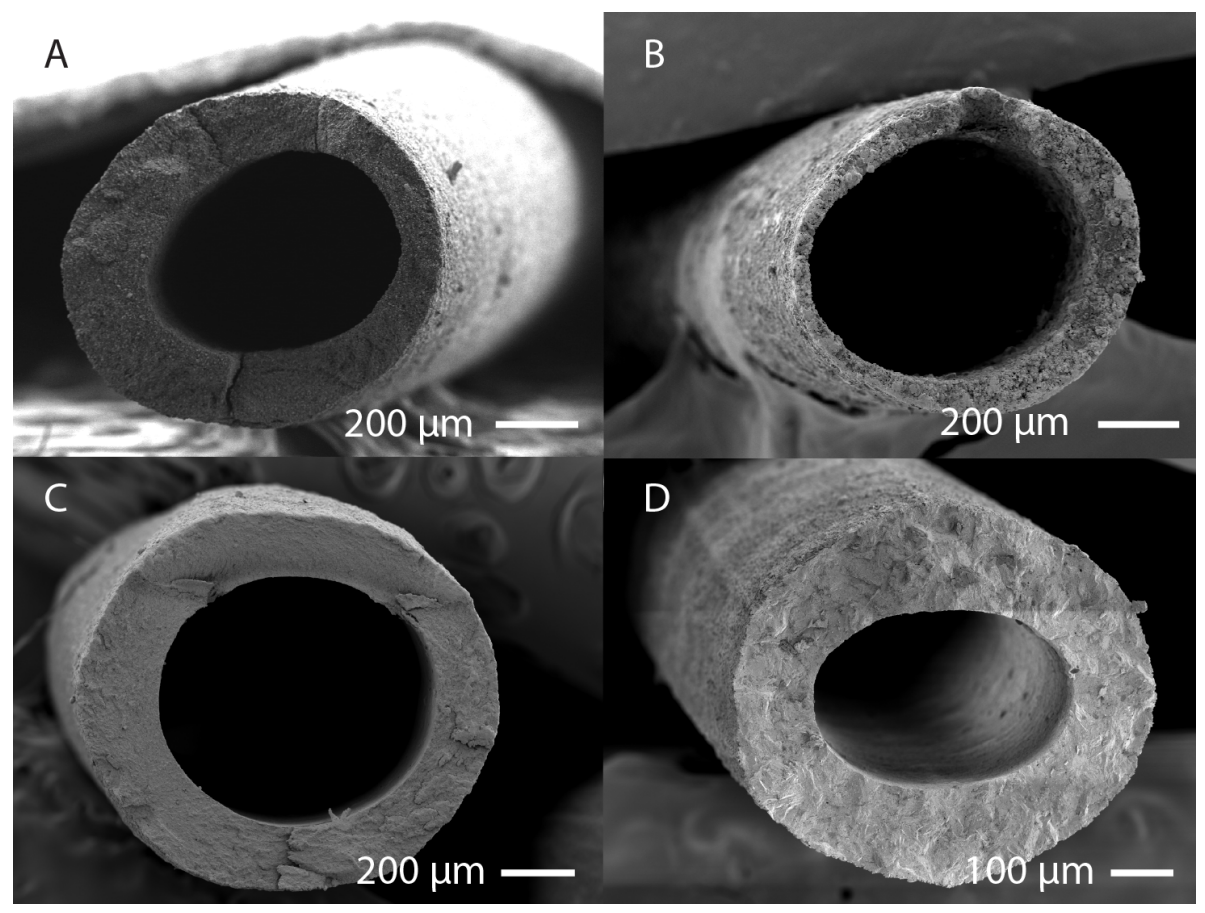

Figure 3.2: Scanning electron micrographs of hollow fibers obtained via bioionic gelation; prior to thermal treatment ( $\mathrm{a}$ and $\mathrm{c}$ ), and sintered ( $\mathrm{b}$ and $\mathrm{d}$ ). The fibers have a $50 \mathrm{vol} . \%$ inorganic particle loading of stainless-steel particles (a and b) or alumina particles (c and d).

can have sufficient strength to withstand this measured pressure difference. The linear trend indicates that in this pressure range the fibers do not suffer severely from mechanical deformation. The variations in flux, when comparing different fibers, can presumably be attributed to lateral variations in the shape and the inside and outside diameters of the fibers.

The alumina fibers are able to separate small particles from an aqueous solution and the size of the particles that can be separated by sieving is directly related to the pore size of the fibers, which in turn is directly determined by the size of the inorganic particles used in the fiber synthesis. The pore sizes of the alumina fibers obtained via bio-ionic gelation and NIPS are similar, in the range 200 to 


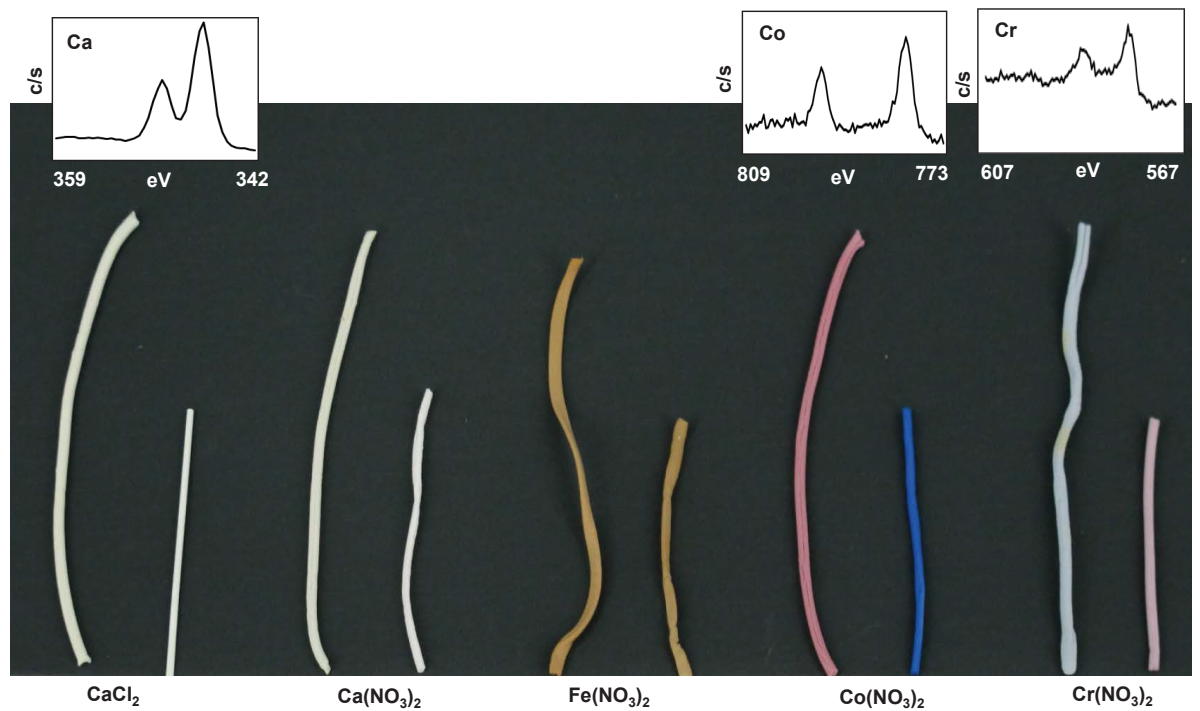

Figure 3.3: Alumina loaded alginate fibers obtained via bio-ionic gelation using various cations, before and after thermal treatment (left and right fibers of pairs, respectively). From left to right: calcium chloride, calcium nitrate, ferric nitrate, cobalt nitrate and chromium nitrate. The insets show XPS spectra.

$300 \mathrm{~nm}$. The pore volume of the fiber obtained by bio-ionic gelation is lower as compared to the NIPS derived fiber, due to the more homogeneous fiber morphology that is inherent to the bio-ionic gelation procedure.

Bio-ionic gelation implicates the introduction of multivalent cations into the inorganic particle loaded biopolymer. During the burnout of the biopolymer, these cations may remain in the fiber, conceivably as an oxide when oxygen is present during thermal treatment. By selecting a cation that is associated with the inorganic particles, for instance $\mathrm{Al}^{3+}$ for alumina particles, the introduction of the cation does not have implications for the final chemical composition of the fiber. When other cations are used for gelation, the fiber (surface) chemistry may be altered.

Figure 3.3 shows alumina fibers obtained by bio-ionic gelation, using different multivalent cations. The different colors of the fibers indicate the presence of the different cations. Before thermal treatment the color of the fiber is resembling that of the ionic solution used for the gelation. 
A solution of $\mathrm{CaCl}_{2}$ or $\mathrm{Ca}\left(\mathrm{NO}_{3}\right)_{2}$ is colorless and the oxide of calcium is white. Before and after sintering the presence of calcium will not be apparent from the color of the fiber, but is confirmed by X-ray Photoelectron Spectroscopy (XPS). For the other fibers colorization persists upon thermal treatment, indicating that cations remain in the fibers. The color changes of the fibers made with cobalt and chromium are manifestations of the change in the oxidation state of these cations. The XPS inserts of the fiber outer surface confirm that cobalt and chromium are indeed present before and after sintering. These results demonstrate that our method allows facile alteration of the surface chemistry of the hollow fibers via the introduction of various elements in the bio-ionic gelation process.

\subsection{Conclusion}

In conclusion, we demonstrate an organic solvent-free method for the fabrication of inorganic porous hollow fibers based on the gelation of a biopolymer. This approach is simple and suitable to fabricate ceramic and metallic hollow fibers and can be extended to different inorganic materials without extensive alterations. 


\subsection{References}

[1] M. Mulder, Basic principles of membrane technology, Springer Science \& Business Media, 1996.

[2] J. Barzin, C. Feng, K. Khulbe, T. Matsuura, S. Madaeni, H. Mirzadeh, Characterization of polyethersulfone hemodialysis membrane by ultrafiltration and atomic force microscopy, J. Membr. Sci. 237 (2004) 77-85.

[3] B. J. Cha, J. M. Yang, Preparation of poly(vinylidene fluoride) hollow fiber membranes for microfiltration using modified tips process, J. Membr. Sci. 291 (2007) 191-198.

[4] A. Figoli, S. Simone, A. Criscuoli, S. AL-Jlil, F. A. Shabouna, H. AlRomaih, E. D. Nicolò, O. Al-Harbi, E. Drioli, Hollow fibers for seawater desalination from blends of pvdf with different molecular weights: Morphology, properties and vmd performance, Polymer 55 (2014) 1296-1306.

[5] C. Ma, W. J. Koros, High-performance ester-crosslinked hollow fiber membranes for natural gas separations, J. Membr. Sci. 428 (2013) 251-259.

[6] K. Hylton, S. Mitra, A microfluidic hollow fiber membrane extractor for arsenic(v) detection, Anal. Chim. Acta 607 (2008) 45-49.

[7] N. A. Hashim, F. Liu, M. M. Abed, K. Li, Chemistry in spinning solutions: Surface modification of pvdf membranes during phase inversion, J. Membr. Sci. 415416 (2012) 399-411.

[8] J. Viguié, T. Savart, P. Duru, J.-C. Rouch, J.-C. Remigy, Characterisation of $3 \mathrm{~d}$ porous macrostructure of hollow fibre membranes using x-ray tomography - effects of some spinning process conditions, J. Membr. Sci. 435 (2013) 11-20.

[9] L. Setiawan, L. Shi, W. B. Krantz, R. Wang, Explorations of delamination and irregular structure in poly(amide-imide)-polyethersulfone dual layer hollow fiber membranes, J. Membr. Sci. 423424 (2012) 73-84.

[10] R. W. Baker, Membrane technology and Applications, Wiley Online Library, 2000.

[11] C. Guizard, A. Ayral, A. Julbe, Potentiality of organic solvents filtration with ceramic membranes. a comparison with polymer membranes, Desalination 147 (2002) 275-280. 
[12] W. Liu, N. Canfield, Development of thin porous metal sheet as microfiltration membrane and inorganic membrane support, J. Membr. Sci. 409410 (2012) 113-126.

[13] T. Wang, Y. Zhang, G. Li, H. Li, Preparation and characterization of alumina hollow fiber membranes, Front. Chem. Eng. China 3 (2009) 265.

[14] B. Wang, Z. Lai, Finger-like voids induced by viscous fingering during phase inversion of alumina/pes/nmp suspensions, J. Membr. Sci. 405406 (2012) 275-283.

[15] B. Kingsbury, K. Li, A morphological study of ceramic hollow fibre membranes, J. Membr. Sci. 328 (2009) 134-140.

[16] C. C. Wei, O. Y. Chen, Y. Liu, K. Li, Ceramic asymmetric hollow fibre membranes - one step fabrication process, J. Membr. Sci. 320 (2008) 191197.

[17] M. W. Luiten-Olieman, L. Winnubst, A. Nijmeijer, M. Wessling, N. E. Benes, Porous stainless steel hollow fiber membranes via dry-wet spinning, J. Membr. Sci. 370 (2011) 124-130.

[18] B. Meng, X. Tan, X. Meng, S. Qiao, S. Liu, Porous and dense ni hollow fibre membranes, J. Alloys Compd. 470 (2009) 461-464.

[19] X. Tan, Y. Liu, K. Li, Preparation of lscf ceramic hollow-fiber membranes for oxygen production by a phase-inversion/sintering technique, Ind. Eng. Chem. Res. 44 (2005) 61-66.

[20] G. T. Grant, E. R. Morris, D. A. Rees, P. J. Smith, D. Thom, Biological interactions between polysaccharides and divalent cations: The egg-box model, FEBS Lett. 32 (1973) 195-198.

[21] S. Papageorgiou, F. Katsaros, E. Favvas, G. E. Romanos, C. Athanasekou, K. Beltsios, O. Tzialla, P. Falaras, Alginate fibers as photocatalyst immobilizing agents applied in hybrid photocatalytic/ultrafiltration water treatment processes, Water Res. 46 (2012) 1858-1872.

[22] C. Soukoulis, L. Yonekura, H.-H. Gan, S. Behboudi-Jobbehdar, C. Parmenter, I. Fisk, Probiotic edible films as a new strategy for developing functional bakery products: The case of pan bread, Food Hydrocolloids 39 (2014) 231-242. 
[23] K. Kesavan, G. Nath, J. K. Pandit, Sodium alginate based mucoadhesive system for gatifloxacin and its in vitro antibacterial activity, Sci. Pharm. 78 (2010) 941. 



\section{Chapter 4}

\section{Sustainable route to inorganic porous hollow fibers with superior properties}

This chapter is adapted from:

H. Qasim Hussein, P. de Wit, E.J. Kappert, N.E. Benes, A sustainable route to inorganic porous hollow fibers with superior properties, Sustainable Chem. Eng., 3 (12), pp. 3454-3460,

doi: 10.1021/acssuschemeng.5b01248 


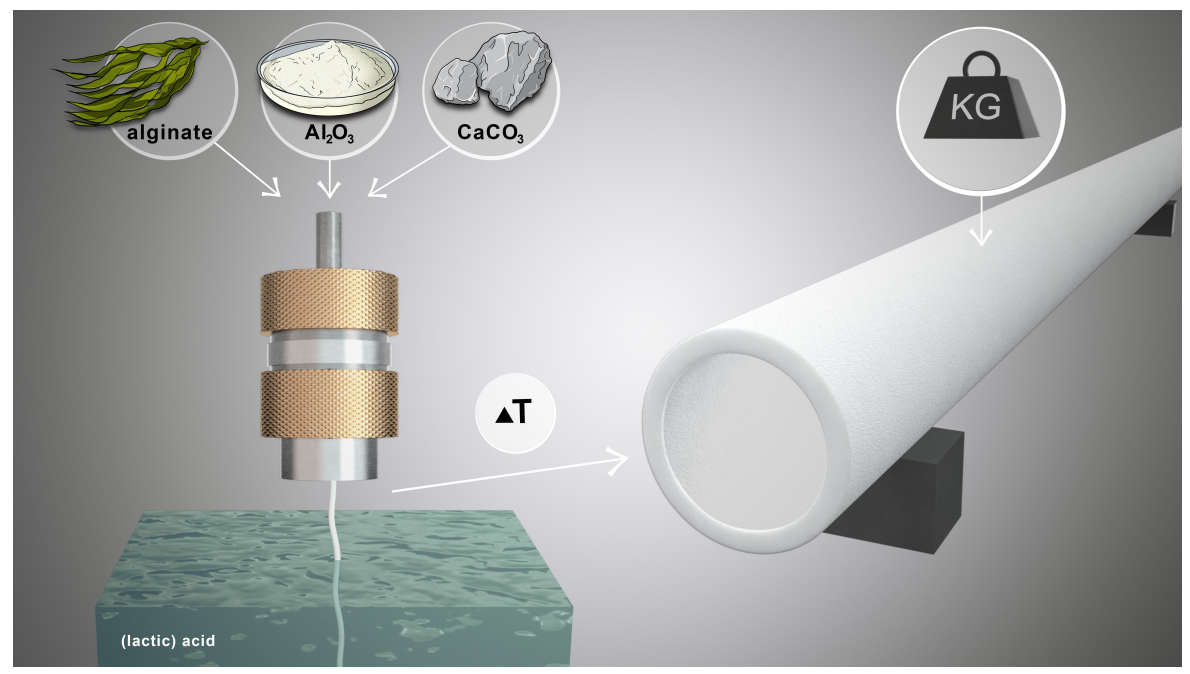

\section{Abstract}

This chapter presents a method for the fabrication of inorganic porous hollow fibers, using ecologically benign feed materials instead of organic solvents and harmful additives. Our method is based on ionic cross-linking of an aqueous mixture of sodium alginate, inorganic particles, and a carbonate. The mixture is spun into an acidic coagulation bath, where the low $\mathrm{pH}$ triggers the dissociation of the carbonate into multivalent cations and carbon dioxide. The multivalent cations cross-link the alginate, thereby consolidating the 3D structure and arresting the inorganic particles. In a subsequent thermal treatment the polymer is removed and the particles are sintered together. Adequate gelation requires a sufficiently low $\mathrm{pH}$ of the acid bath and a sufficing buffering capacity of the acid. In addition, to facilitate thermal treatment, it appears to be crucial that the acid has a conjugated base with limited propensity for complexing cations. The environmentally safe and sustainable lactic acid and acetic acid are shown to be convenient acids. The fibers prepared via our method have outstanding properties, such as high mechanical strength, homogeneous morphology, and sharp distribution of small pores. In addition, they are prepared using sustainable chemicals such as lactic acid and calcium carbonate. 


\subsection{Introduction}

Inorganic porous hollow fibers provide large surface-area-to-volume ratios, due to their small radial dimensions. As a result, these fibers are applied in a vast array of applications, for example, in photocatalysis [1, 2], bio-reactor and sensors [3, 4], gas-liquid contactors [5-7], membranes for demanding separations [8-10], and for combined chemical reaction and molecular separation in harsh environments [11-13]. The small radial dimensions of the fibers are generally achieved by using the dry-wet spinning method, in which a mixture of a polymer, solvent and inorganic particles is spun into a coagulation bath. In the coagulation bath, non-solvent induced phase separation (NIPS) occurs and the inorganic particles are arrested in a polymer matrix. In a subsequent thermal treatment, the polymer is decomposed and the inorganic particles are sintered together. This method is well understood and described in detail for a variety of inorganic particles [14-16]. The major drawback of the NIPS-method is the use of harmful solvents. Typically, aprotic solvents such as dimethyl formamide (DMF), N-methyl-2-pyrrolidone (NMP) or dimethyl acetamide (DMAc) are used, because these dissolve a wide variety of polymers and the obtained spinning solutions coagulate readily upon contact with water. We have recently demonstrated bioionic gelation as a novel solvent-free alternative approach for the fabrication of porous hollow fibers [17]. The concept is based on the solidification of a spinning mixture by the ionic cross-linking of a sodium alginate when it is spun into an aqueous solution containing multivalent cations $\mathrm{M}^{\mathrm{n}+}$, such as $\mathrm{Ca}^{2+}, \mathrm{Ba}^{2+}, \mathrm{Cu}^{2+}$, or $\mathrm{Fe}^{3+}$. The alginate is the sodium salt of the polysaccharide alginic acid that is produced by brown algae and bacteria and is a linear block copolymer consisting of 1,4-( $\beta$-D)-mannuronic acid and 1,4- $(\alpha-\mathrm{L})$-guluronic acid. Upon entering the solution, the multivalent cations diffuse into the spinning mixture and exchange with the sodium ions in the polymer, thereby forming a stable water-insoluble three-dimensional gel network [18]. This concept is depicted in Figure 4.1, top right. During a subsequent thermal treatment the biopolymer is removed and the inorganic particles are sintered together. Introducing the multivalent ions into the alginate from a bath is known to have disadvantages. The gelation rate is hard to control and the concentration gradients of the multivalent ions inside and outside the alginate solution result in an inhomogeneous alginate gel [19-21]. As a result of this, the mechanical integrity of the final fibers can be poor[17]. In addition, in order to maintain stationary spinning conditions a regeneration of relatively large volumes of the $\mathrm{M}^{\mathrm{n}+}$ solution is necessary. In the present paper, we propose a new method for cross-linking fibers that overcomes these limitations, 

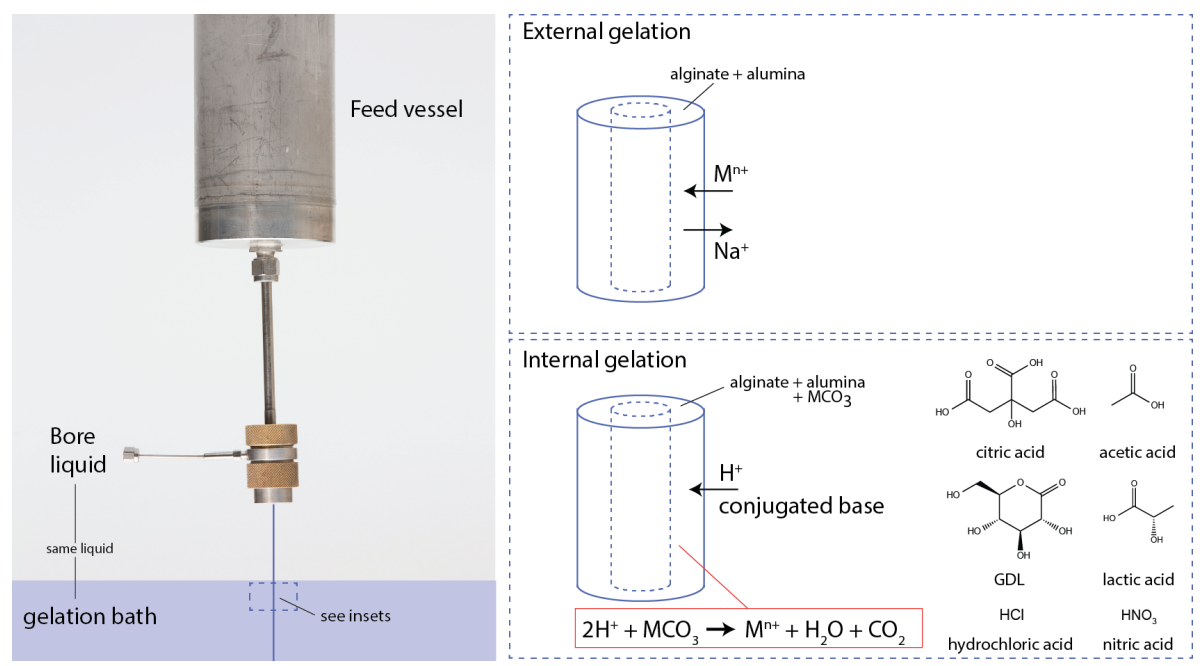

Figure 4.1: Left: setup for dry-wet spinning; right, schematic representation of the concept of external (top right) and internal (bottom right) gelation. The spinning mixture is cross-linked with a solution of $\mathrm{MCl}_{\mathrm{n}}$ in the case of external gelation, whereas in the case of internal gelation the multivalent ion is present as $\mathrm{M}^{\mathrm{n}+}\left(\mathrm{CO}_{3}\right)_{0.5 \mathrm{n}}$ in the spinning mixture, which is in turn liberated upon contact with protons originating from the gelation bath.

by providing the multivalent ions as an inactive, insoluble salt in the spinning mixture in the form of a carbonate. Carbonates have been used in the past for the production of homogenous microspheres [22-24], hydrogels [25-27], and thin films [28-30]. In our case, the mixture is spun into an acidic coagulation bath, where the low $\mathrm{pH}$ triggers the dissociation of the carbonate into $\mathrm{M}^{\mathrm{n}+}$ and carbon dioxide [31]. The multivalent ions then form the ionic crosslinks in the biopolymer. The bottom right part of Figure 4.1 schematically depicts this concept. Gels prepared using the internal supply of multivalent ions are found to be more homogenous as compared to those obtained using the external supply [21].

To demonstrate the versatility of the proposed method, we compare different types of carbonates and different types and concentrations of acids. Conforming to the literature and because it is considered a benign substance, most experiments have been carried out with calcium carbonate. Cobalt carbonate 
and copper carbonate have been used to prove that the method also works for other multivalent ions. The particular focus of the study is on the importance of the buffering properties of the acid and the propensity of its conjugated base to form complexes with cations [32]. Hydrochloric and nitric acid have been selected as strong inorganic acids, with minimal buffering capacity. Acetic acid, citric acid, and lactic acid have been selected as weaker acids, with larger buffering capacities. It should be noted that these acids can be obtained from sustainable sources [33-35]. Glucono-delta-lactone (GDL) was selected as a gluconic acid precursor [36], because the extensive buffering properties in the $\mathrm{CaCO}_{3}$-GDL system have been proven to result in a time-delayed release of calcium ions that produces more homogenous alginate gels [37].

In this chapter, we show that the bio-ionic cross-linking, induced by the carbonateacid reaction, allows for facile and solvent/organic polymer-free fabrication of inorganic porous hollow fiber membranes. The fibers have very thin walls, superior mechanical strengths, and more narrow distributions of smaller pores, as compared to fibers obtained by previous methods.

\subsection{Experimental}

\subsubsection{Chemicals}

Alginic acid sodium salt from brown algae with medium viscosity (SigmaAldrich); calcium carbonate, cobalt carbonate, and copper carbonate (all SigmaAldrich); AKP-30 and AKP-50 $\alpha$ alumina powder with a mean particle size of 0.3 and $0.1 \mu \mathrm{m}$ respectively (Sumitomo Chemicals); and deionized water $\left(>18.2 \mathrm{M} \Omega \mathrm{cm}^{-1}\right.$ ) were used to prepare spinning mixtures. Acetic acid (Merck), citric acid, glucono delta-lactone (GDL), hydrochloric acid, lactic acid, and nitric acid (All from Sigma-Aldrich) were used as proton source.

\subsubsection{Preparation of spinning mixture}

$0.15 \mathrm{~g}$ calcium carbonate was added to $82.5 \mathrm{~g}$ de-ionized water in a two-neck flask followed by mechanical stirring for $10 \mathrm{~min}$. $12.5 \mathrm{~g}$ AKP-30 $\alpha$-alumina was added under continuous stirring and ultrasonic treatment, followed by stirring and ultrasonic treatment for 20 minutes (Branson 1800, 10 min min, $40 \mathrm{kHz}$ ). $5.0 \mathrm{~g}$ sodium alginate was added in three steps to prevent the formation of alginate lumps. The mixture was stirred overnight to obtain a homogeneous slurry. 


\subsubsection{Preparation of fibers}

Non-hollow alumina fibers were prepared by extruding the spinning mixture into solutions of acetic acid, citric acid, GDL, or lactic acid, with a $\mathrm{pH}$ of 1.7, 2,3 , and 4 . For hydrochloric and nitric acid, a $\mathrm{pH}$ of $0.6,1,1.3$, and 2 was used. Upon contact with the acid gelation bath, cross-linking of the alginate occurs. After extrusion, samples were left overnight in the acid gelation bath. The cross-linked fibers were dried at room temperature for $24 \mathrm{~h}$ and were subsequently thermally treated in a STF16/610 tubular furnace (Carbolite) under an airflow of $100 \mathrm{~mL} \mathrm{~min}{ }^{-1}$. Using a heating rate of $5^{\circ} \mathrm{C} \mathrm{min}^{-1}$, the fibers were kept at $110^{\circ} \mathrm{C}$ for $60 \mathrm{~min}$ for drying, followed by further sintering at $1400^{\circ} \mathrm{C}$ for 120 min. Hollow alumina fibers were prepared through a similar procedure by spinning into a lactic acid solution with a $\mathrm{pH}$ of 1.7 . The spinning mixture was pressurized in a stainless steel vessel, degassed for $30 \mathrm{~min}$ and left overnight. Spinning was carried out using a spinneret with dimensions OD/ID=2.0/0.8 $\mathrm{mm}$, using 2 bar nitrogen pressure at ambient temperature. The air gap was $15 \mathrm{~mm}$, and the bore liquid flow rate was $14 \mathrm{~mL} \mathrm{~min}^{-1}$. The bore liquid was taken from the gelation bath, which consists of lactic acid with a $\mathrm{pH}$ of 1.7. After spinning, the fibers were left in the gelation bath overnight, dried, and thermally treated following the procedure described above. In addition, fibers were prepared using NIPS [14] and external gelation [17] as described elsewhere.

\subsubsection{SEM}

Scanning electron micrographs of the cross-section morphology and the wall thickness of green and sintered fibers were obtained with a Zeiss Merlin FESEM or JEOL-JSM6010 scanning electron microscope. To obtain a flat crosssection, the green compacts were soaked in ethanol and submersed in liquid nitrogen before fracturing. No further pretreatment was done on the samples.

\subsubsection{TGA/DTA-MS}

Thermogravimetric analysis combined with differential scanning calorimetry analysis (TGA/DSC) was performed on a STA 449 F3 Jupiter ${ }^{\circledR}$ (Netzch) fitted with a TGA-DSC sample holder. Measurements were performed under a flow of $70 \mathrm{~mL} \mathrm{~min}^{-1}$ synthetic air at a heating rate of $20^{\circ} \mathrm{C} \mathrm{min}^{-1}$ from room temperature to $1000{ }^{\circ} \mathrm{C}$. A temperature correction and sensitivity analysis using melting standards and a blank correction with an empty cup were carried out prior to the measurements. Small fragments of fibers that had been dried 
overnight under vacuum at $50{ }^{\circ} \mathrm{C}$ were used as samples and their mass was determined externally.

\subsubsection{Mechanical Strength}

The mechanical strength of the prepared hollow fibers was measured on a 5564A mechanical testing bench (Instron). Sintered fibers were picked randomly and broken to a length of approximately $5 \mathrm{~cm}$, followed by tested using a 4 point fixture, with an outer span $\left(L_{o}\right)$ of $20 \mathrm{~mm}$ and an inner span $\left(L_{i}\right)$ of $10 \mathrm{~mm}$. The load was measured at constant extension rate $\left(2 \mathrm{~mm} \mathrm{~min}^{-1}\right)$ and the inner and outer diameters of the fiber were measured after fracture, using a digital caliper (Mitutoyo CD-15CPX, $\Delta d \pm 0.02 \mathrm{~mm}$ ). A sample set size of 30 samples was used. The maximum bending strength is computed using Equation 4.1, where $F_{j}$ is the force at fracture for specimen $j, L_{o}$ the distance between the two outer rollers, $K$ is defined by half the distance between the inner and outer span $\left.K=\left(L_{o} L\right) i\right) / 2$, and $d_{o, j}$ and $d_{i, j}$ the outer and inner diameters of specimen $\mathrm{j}$ :

$$
\sigma_{(f, j)}=\frac{16 F_{j} K d_{o, j}}{\pi\left(d_{o, j}^{4}-d_{i, j}^{4}\right)}
$$

\subsubsection{Nitrogen gas permeation}

Single-gas permeation was carried out using nitrogen (Linde Gas, Purity 4.0). Fibers were potted into $1 / 4^{\prime \prime}$ stainless steel tubing and sealed with glue (Epoxy, Araldite 2014) before they were mounted into a stainless steel module. The inside-out nitrogen flow was measured using a soap-film flow meter, while the feed pressure was regulated using a pressure-reducing valve (Genie, 0-10 bar). The permeate side is assumed to be at atmospheric pressure.

\subsubsection{Mercury intrusion}

The volume of mercury intruded was measured as a function of the pressure using a Poremaster PM-33-14 (Quantachrome ${ }^{\circledR}$ ). The pore diameter corresponding to a certain pressure is calculated using Washburns equation from the measured volume mercury intruded $V_{H g}$ versus pressure $P$ using Matlab (Mathworks, R2014b) . The volume based pore size distribution is calculated via equation Equation 4.2.[38]

$$
D_{v}(r)=\frac{d V_{\mathrm{Hg}}}{d p}\left|\frac{p^{2}}{2 \gamma \cos \theta}\right|
$$




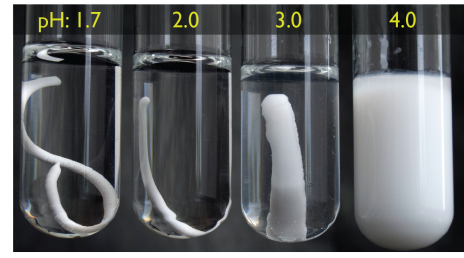

Lactic Acid

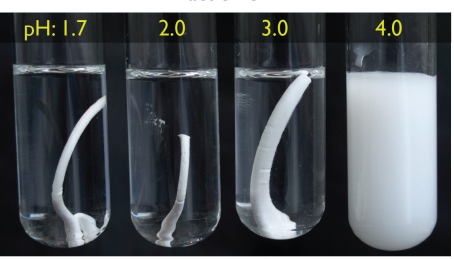

Acetic Acid

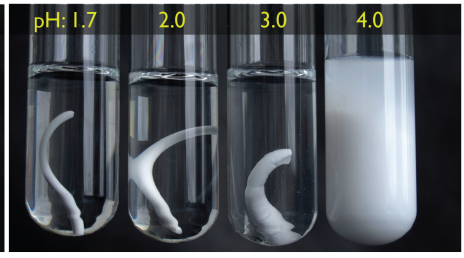

Citric Acid

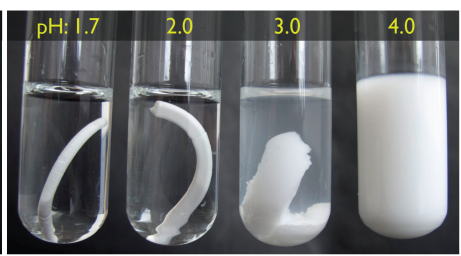

Gluconic acid

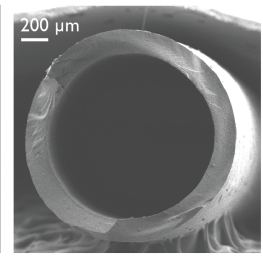

Lactic acid: green fiber

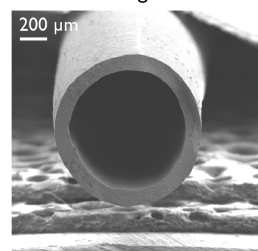

Lactic acid: sintered fiber

Figure 4.2: Left and middle panels: photos of nonhollow fibers obtained from injecting a calcium carbonate/alginate/alumina solution into the different acids at different $\mathrm{pH}$. Right panels: scanning electron micrographs of the green and sintered hollow fiber. Note: the contrast and brightness of the pictures has been adjusted to improve visualization

\subsection{Results and discussion}

\subsubsection{Fiber consolidation}

Figure 4.2 shows the nonhollow fibers that result from injecting a calcium carbonate/alginate/alumina solution from a syringe into the different gelation baths. The characteristics of the gels that are formed and the extent to which the inorganic particles are incorporated show a strong dependency on the $\mathrm{pH}$ of the gelation bath and the acid strength. A maximum critical $\mathrm{pH}$ appears to exist to induce effective gelation. Below this $\mathrm{pH}$, a sufficient amount of calcium is released to form a stable and insoluble network. It should be noted that these critical $\mathrm{pH}$ values are below the pKa values of the sodium alginate building blocks, $\beta$-D)-mannuronic acid (3.38) and $(\alpha-\mathrm{L})$-guluronic (3.65). This implies that the sodium alginate will be partly converted into alginic acid,[39, 40] which is known to form gels that are stabilized by intermolecular hydrogen bonds. This could further aid the cross-linking of the fibers[20]. In the strong mineral acids, $\mathrm{HCl}$ and $\mathrm{HNO}_{3}$, rigid shapes are obtained at $\mathrm{pH}$ values below 
1.3 [41]. At higher $\mathrm{pH}$ values, insufficient protons are available to liberate calcium ions, inhibiting the cross-linking of the fiber. For the strong acids the $\mathrm{pH}$ increases substantially when the sodium alginate mixture is injected in the acid solution. For the weak acids, a $\mathrm{pH}$ of 1.7 is already sufficient to obtain a rigid shape. The buffering properties of the weak acids allow for a continuing release of protons and subsequent calcium release. For the weak acids, the $\mathrm{pH}$ does not show a substantial increase when the sodium alginate mixture is injected in the acid solution. For the weak acids, $\mathrm{pH}$ values in excess of 2 result in only partially cross-linked alginate gels. This lesser extent of crosslinking becomes more pronounced at higher $\mathrm{pH}$ values, until virtually no cross-linking is observed for fibers spun into acids with a $\mathrm{pH}$ of 4 . At a $\mathrm{pH}$ of 3 , rigid structures are obtained for the acetic and lactic acid, whereas the structures for gluconic and citric acid result in a loosely packed gel that lacks mechanical integrity. Using citric and gluconic acid there will be competition between calcium uptake by the alginate and complexation of calcium ions by the conjugated base [23, 42]. Fibers taken from an acid bath, with a pH below the critical value, are flexible and have sufficient mechanical strength for handling. The microstructure of the fibers reveals a dense matrix for the citric and gluconic acid, whereas a more open structure is observed for acetic and lactic acid (See Figure 4.9 in the Supplementary Information for the scanning electron micrographs.) Upon drying, the fibers diameter and flexibility were largely reduced.

\subsubsection{Thermal treatment}

All fibers have been subjected to identical thermal treatment. For the fibers obtained from $\mathrm{HCl}, \mathrm{HNO}_{3}$, acetic acid, or lactic acid and below the critical $\mathrm{pH}$, the thermal treatment resulted in well-shaped and structurally intact fibers. The fibers obtained from citric acid or GDL solutions, however, disintegrated into powder during the thermal treatment. Figure 4.3 shows the results of the TGA/DSC analysis of the dried fibers and powders (TGA/DSC data for $\mathrm{HCl}$ and $\mathrm{HNO}_{3}$ are not shown here but show a similar pattern [41]). Up to $150{ }^{\circ} \mathrm{C}$, the mass loss is below $1 \%$ and can be attributed to the last stages of drying of the fibers. Around $150{ }^{\circ} \mathrm{C}$, the onset of mass loss is found for all fibers, followed by a multi-step, exothermic mass loss. During these steps, the mass loss is significantly higher for citric acid and gluconic acid than that for the other acids. 


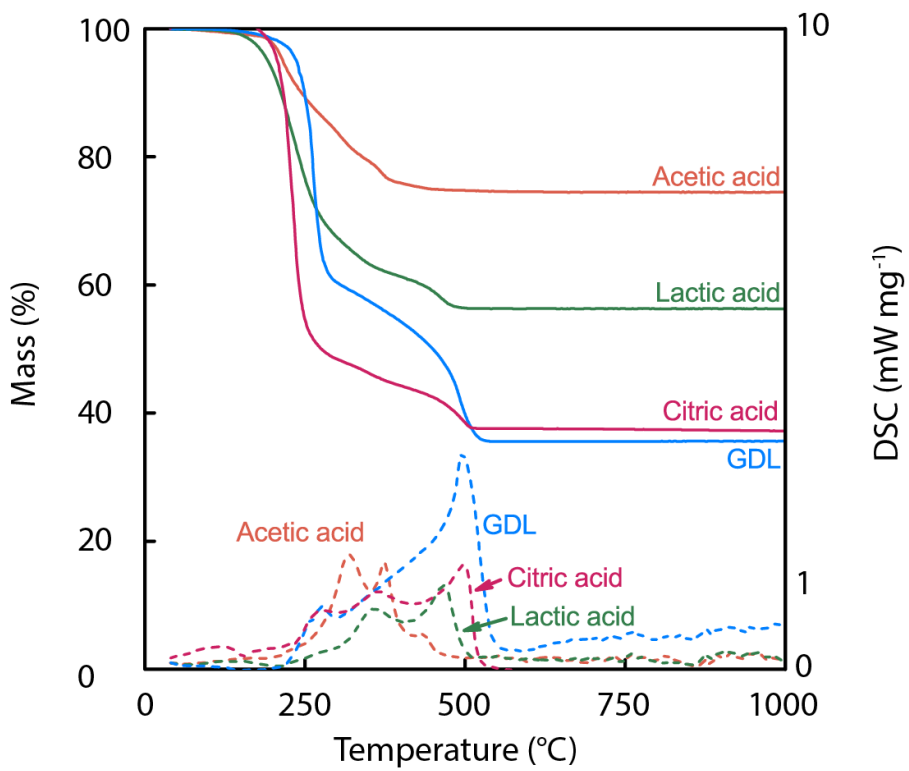

Figure 4.3: TGA (solid lines) and DSC (dashed lines) curves of the cross-linked fibers obtained by spinning into an acid solution with $\mathrm{pH}$ of 1.7 .

For all experiments, the spinning mixture consisted of $28.4 \mathrm{wt} \%$ alginate, 70.8 wt\% alumina, and 0.8 wt $\% \mathrm{CaCO}_{3}$ (on dry basis). For fully dried fibers, a maximum theoretical mass loss of $28.7 \%$ would therefore be expected based on the spinning mixture, assuming that the calcium remains in the fibers in the form of CaO. Only for $\mathrm{HCl}(23.61 \mathrm{wt} \%)$, HNO3 (23.40 wt\%) and acetic acid (25.5 wt\%), the experimental mass loss is lower than the theoretical expectation. For all other acids, the mass losses are higher: $43.6 \mathrm{wt} \%$ for lactic acid, $62.8 \mathrm{wt} \%$ for citric acid and $64.4 \mathrm{wt} \%$ for gluconic acid.

Co-diffusion of the conjugated base to balance the charge of the diffusing protons does not explain the mass difference between theory and experiment, as this would result in a surplus mass loss of $0.4 \%$ (acetic acid), $0.7 \%$ (lactic acid), and $1.9 \%$ (gluconic and citric acid). The adsorption of the acids onto the surface of alumina particles can also explain only a small amount of extra mass, because of the low surface area of the particles[43]. Complexation of $\mathrm{Ca}^{2+}$ or $\mathrm{Na}^{+}$ions, [32] would result in only low extra mass for lactic acid and acetic 
acid, but potentially results in much higher masses for the citric acid and GDL ions. In addition, the complexes formed would be able to hold a significant amount of water that may be released at higher temperatures than normally can be expected [44]. Indeed, SEM micrographs of the green citric acid and GDL fibers (given in Figure 4.9 in the Supplementary Information) suggest the presence of more non-alumina material. The higher water content that these layers may hold, could rationalize the surplus mass $\operatorname{loss}[26,45,46]$. At $250{ }^{\circ} \mathrm{C}$, the alginate starts to decompose[47, 48], inducing a further release of the water as seen in the mass spectrum of the gasses evolving the sample. Indeed, the recorded heat flow is comparatively low, which could be the result of the endothermic contribution water evaporation [41].

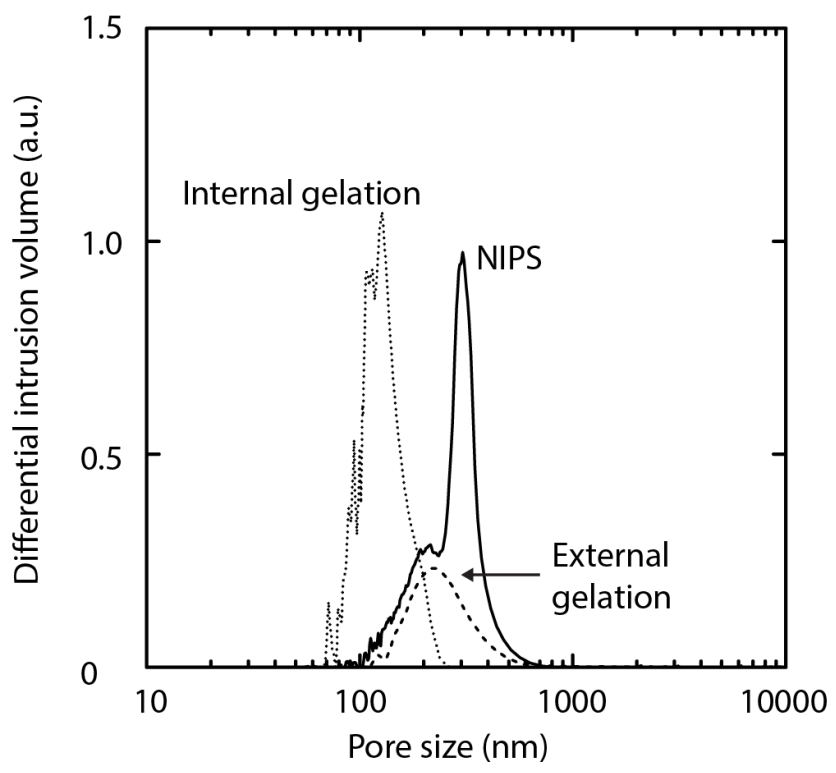

Figure 4.4: Pore size distribution obtained by mercury intrusion for a sintered fiber. Fibers were prepared by internal gelation (lactic acid coagulation bath), by external gelation $\left(\mathrm{CaCl}_{2}\right.$ gelation bath), and by non-solvent induced phase separation. 
Figure 4.4 shows the pore size distribution of fibers prepared via internal gelation, external gelation, and NIPS. The data clearly show that the fiber prepared using internal gelation has smaller pore size as compared to fibers prepared using external gelation or NIPS. Pores in the range of $100 \mathrm{~nm}$ to $200 \mathrm{~nm}$ are observed, which agrees well with the original powder size of approximately $300 \mathrm{~nm}$ and the assumption of dense sphere packing. For fibers prepared using NIPS, it is known that the stacking of the particles is less dense, resulting in larger pore sizes using equivalent starting materials[14] The porosities of the internal, external and NIPS fibers are 29, 16 and 54\% respectively. The combination of spatially uniform and slow gel formation will aid the formation of a homogeneous and dense packed ceramic body. In addition, at the low $\mathrm{pH}$ values the alumina particles have a substantial positive surface charge. It is known that slow settling of charged alumina particles from a suspension allows for obtaining well-defined homogeneous porous structures, with a narrow distribution of small pores[49] and may prevent the formation of agglomerates by electrostatic stabilization[50].

\subsubsection{Performance}

The results for the consolidation and the thermal treatment of the non-hollow fibers indicate that acetic acid and lactic acid are the best choices for the acid bath. These acids have sufficient buffering capacity, are available from sustainable sources, and generate fibers that show limited mass loss during thermal treatment. Given the pungent odor of acetic acid, preference is given to the use of lactic acid.

Thin $(110 \mu \mathrm{m})$, flexible, and defect free hollow fibers were obtained by pressing a $\mathrm{CaCO}_{3}$ /alginate/alumina solution through a spinneret into a lactic acid bath with a $\mathrm{pH}$ of 1.7). The scanning electron micrographs in Figure 4.5 show that homogeneous ceramic bodies are obtained that are virtually free from any large defects that might negatively affect mechanical strength.

Figure 4.6 shows the 4-point bending strengths for 30 of these hollow fibers after sintering. Based on the measured strength values, an empirical cumulative distribution is computed using Kaplan-Meijer estimates [51]. A lot of scatter is present in the mechanical strength data. This scatter does not only originate from the defect distribution, but is presumably also a result of lateral variations in the dimensions and the structure of the fiber. Furthermore, two failure populations can be distinguished, suggesting different failure mechanisms [52]. The presence of different failure populations might indicate distinctive microstructural features of the fibers, for instance the presence of small agglomerates[53]. 


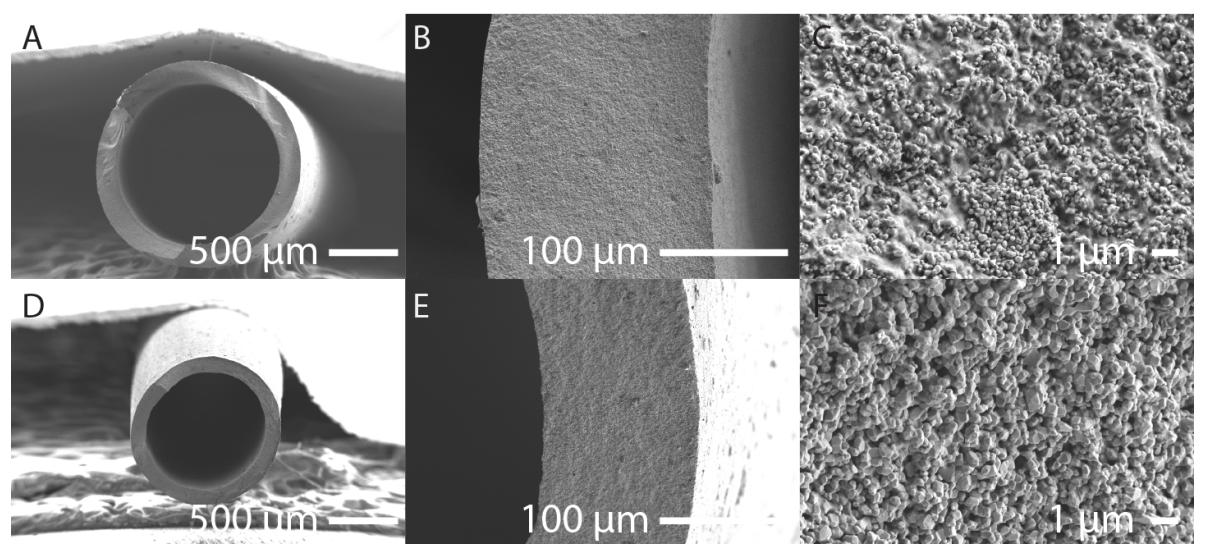

Figure 4.5: Cross-sectional scanning electron micrographs of green (A, B and C) and sintered at $1400 \mathrm{C}$ for $2 \mathrm{hr}(\mathrm{D}, \mathrm{E}$ and $\mathrm{F}$ ) hollow fibers prepared using lactic acid, $\mathrm{pH}$ 1.7. Figures $\mathrm{C}$ and $\mathrm{F}$ show the microstructure of the fiber wall, panel $\mathrm{F}$ clearly shows the removal of the polymer.

The presence of such small agglomerates is not apparent from the scanning electron micrographs.

By fitting the strength data with a normal distribution an average strength of $232.7 \pm 28.5(95 \% \mathrm{CI}) \mathrm{MPa}$ is calculated, with a standard deviation of 77.6 \pm 15.6 (95\% CI) MPa. These mechanical strength values are exceptionally high for $\mathrm{Al}_{2} \mathrm{O}_{3}$ hollow fibers. Typical values reported in literature range from $100 \mathrm{MPa}$ to $150 \mathrm{MPa},[54-57]$ and are generally obtained using a 3-point bending test. A direct comparison between strength numbers is in general not straightforward, because 3-point bending tests systematically result in higher strength values in comparison with 4-point bending tests [58]. This further supports the high mechanical strength of the prepared fibers, which is a direct result of the elimination of the macro-voids that are inherently present in fibers prepared using NIPS, and the controlled homogenous stacking of the alumina particles. Figure 4.7 shows the normalized inside-out nitrogen permeance versus the arithmetic mean pressure inside the fiber wall [14]. Some fiber-to-fiber differences are observed, likely due to slight variations in the wall thickness and diameter over the fiber length. The estimated pore size $d_{p}$ and porosity-tortuosity ratio $\epsilon / \tau$ are in between 179-207 $\mathrm{nm}$ and 0.04-0.09, respectively (assuming cylindrical pores with unimodal pore size distribution). These obtained flow-average 


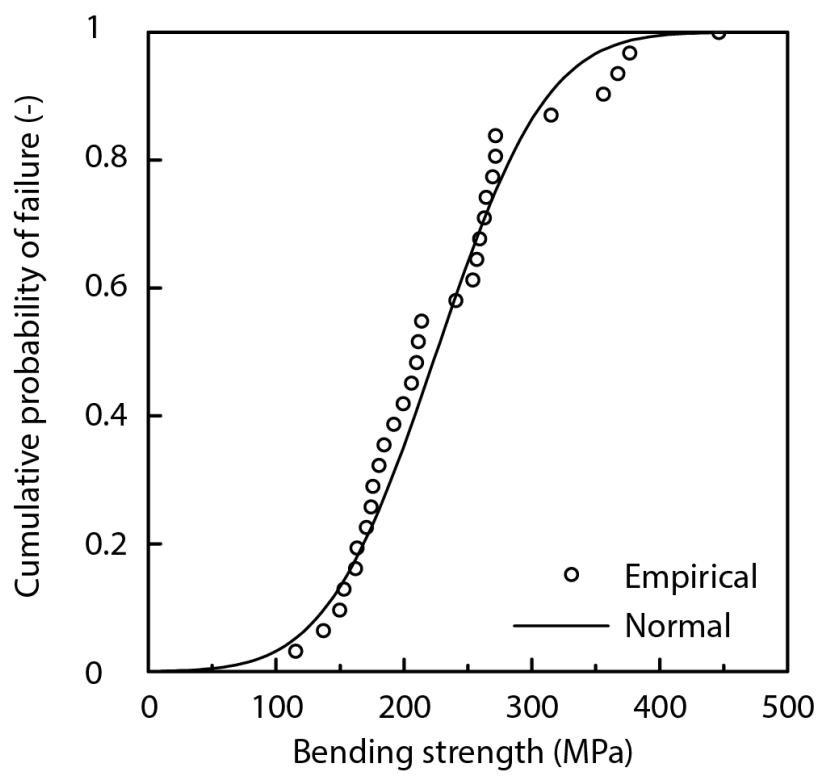

Figure 4.6: Observed mechanical strength of sintered hollow fibers (Lactic acid, $\mathrm{pH}=1.7$, sintered in air for $1400^{\circ} \mathrm{C}, 2 \mathrm{~h}$ ) ranked to their probability of failure. The 30 different fibers are presented as spheres, whereas the solid line represents a normal distribution fitted to this data.

pore sizes are in excellent agreement with the $100 \mathrm{~nm}$ to $200 \mathrm{~nm}$ pore diameter values that were determined by mercury intrusion. The $\epsilon / \tau$ values are slightly lower than those typically obtained in our labs for high quality alumina supports obtained by colloidal filtration of peptized alumina particles, which are $\sim 0.1$. For hollow fibers that are prepared by NIPS, much lower $\epsilon / \tau$ values have been reported. These low values have been rationalized by the less homogeneous microstructure of these fibers, further undermining the assumption of a unimodal pore size distribution in these fibers[14]. Under the assumption of a tortuosity of 3 [59-61], the porosity of the fibers obtained by internal gelation is calculated to be in the range $13-28 \%$, which agrees well with the value of $28.8 \%$ obtained using mercury intrusion. 


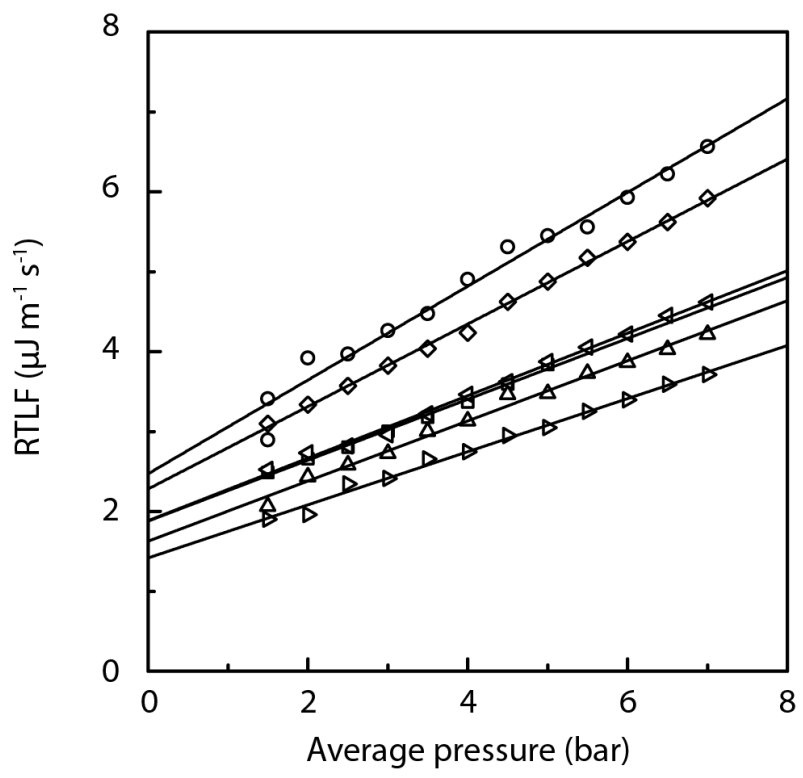

Figure 4.7: Nitrogen permeation for 6 different fibers as function of the average pressure in the fiber wall $\left(P_{m}=\left(P_{\text {feed }}+P_{\text {permeate }}\right) / 2\right)$.

The hollow fibers have various potential applications, including their use as catalyst or membrane support, and their direct use as a microfiltration membrane. The potential of these fibers as a microfiltration membrane is demonstrated by the filtration of an aqueous dispersion of AKP-50 alumina particles with a mean particle size of $100 \mathrm{~nm}$, in dead-end mode. Figure 4.8 shows the feed and permeate dispersions. The apparent difference in the turbidity of the solutions confirms that the particles are retained by the membrane. The particle size distribution of the feed and permeate shows that the peak is shifted significantly towards smaller particle sizes. The fact that only particles smaller than $10 \mathrm{~nm}$ are detected in the permeate shows the ability of the membrane to retain the particles with larger sizes. The size of the particles that can be separated is a direct result of the pore size of the fibers, which can be tuned by either adjusting the particle size of the inorganic starting material or by adjusting the thermal treatment program of the fiber. 


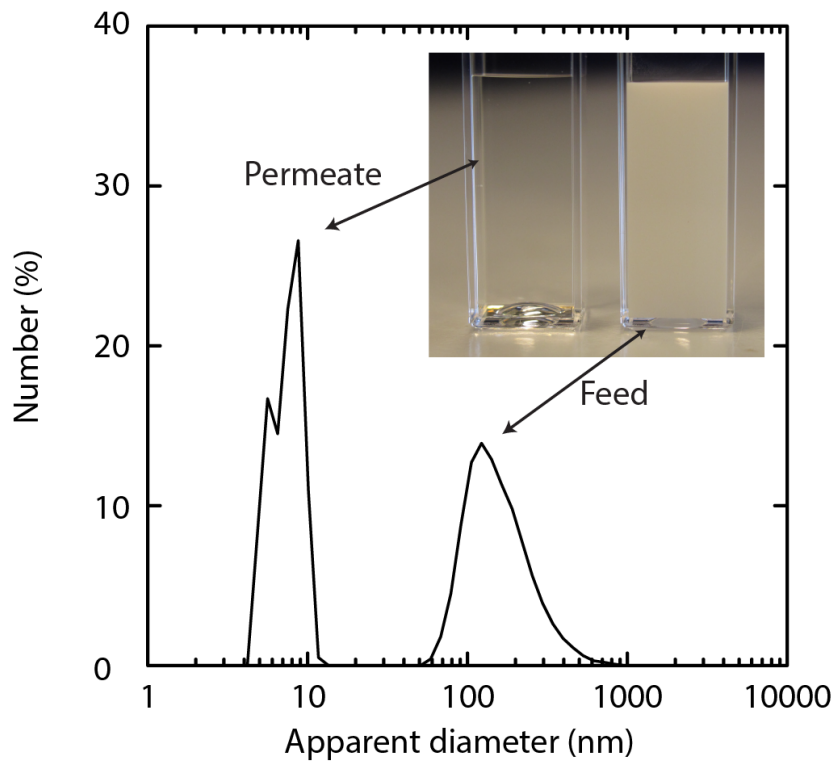

Figure 4.8: Feed (right vial) and permeate (left vial) of a separation experiment with an aqueous feed containing AKP-50 particles $(100 \mathrm{~nm})$. The curve shows the apparent particle diameter of the particles present in the feed and permeate. 


\subsection{Conclusion}

We developed a sustainable route for the fabrication of high performance inorganic porous hollow fibers without the use of harmful solvents and additives. The route is based on pressing an aqueous mixture of a carbonate, a sodium alginate, and inorganic particles through a spinneret into an acid bath. The low $\mathrm{pH}$ triggers the dissociation of the carbonate into multivalent cations and carbon dioxide. The multivalent cations are responsible for cross-linking of the alginate, which in turn arrests the inorganic particles. During a subsequent thermal treatment, the polymer is removed and the particles are sintered together. The acid in the coagulation bath is crucial for successful fiber preparation; not only is a sufficiently low $\mathrm{pH}$ of the acid bath required, it is also critical to select an acid with appropriate buffering capacity, and a conjugated base that has limited propensity to complexation with cations in order to fabricate high quality fibers. By using this method, we are able to prepare alumina hollow fibers with outstanding properties, such as high mechanical strength, homogeneous morphology, and sharp distribution of small pores. These fibers have an extensive application landscape; they can for instance be used directly as a microfiltration membrane, or can be used as catalyst of membrane support material. Our new method substantially reduces the environmental impact of the fiber production process, because it only requires benign chemicals such as sodium alginate, lactic acid, and calcium carbonate that can be obtained from sustainable sources. 


\subsection{Supplementary information}

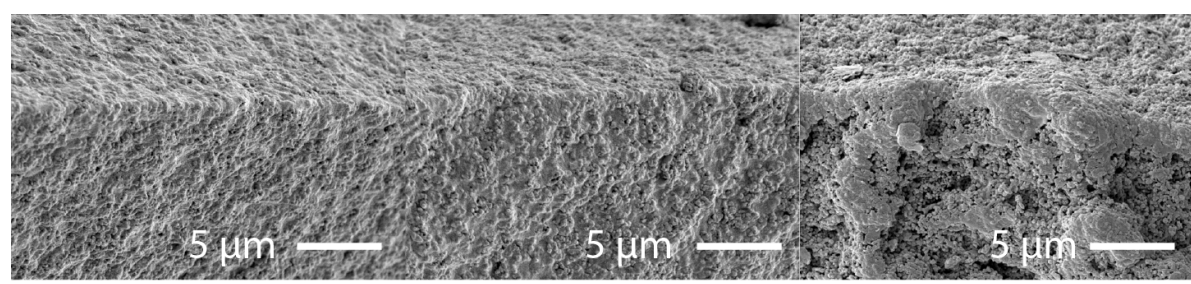

Lactic acid, $\mathrm{pH} 1.7$

$$
\text { Lactic acid, } \mathrm{pH} 2.0
$$

Lactic acid, $\mathrm{pH} 3.0$
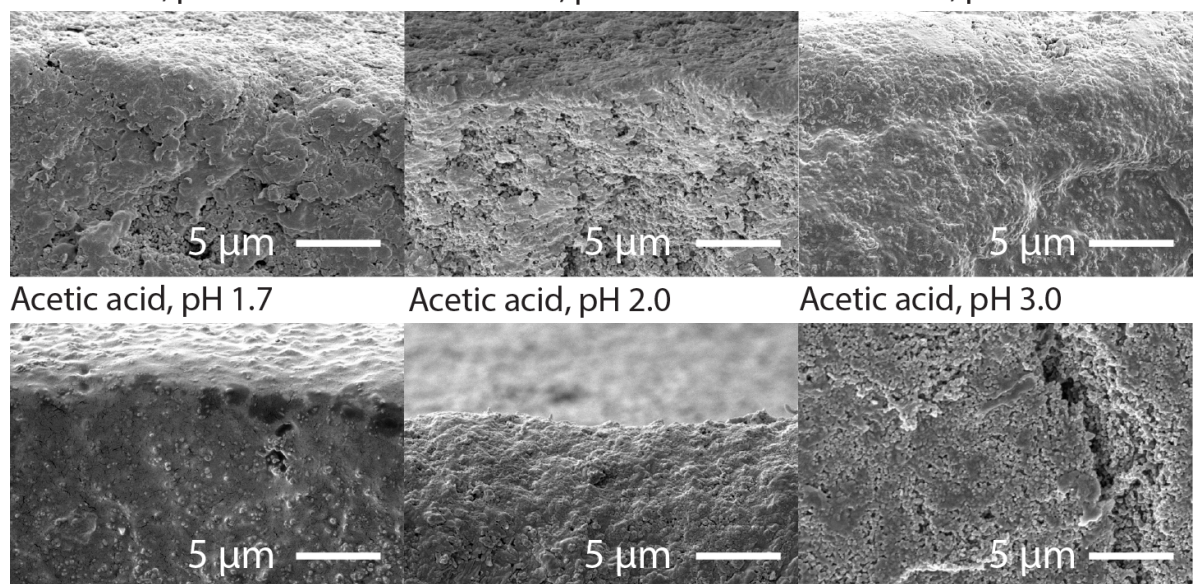

Acetic acid, $\mathrm{pH} 3.0$

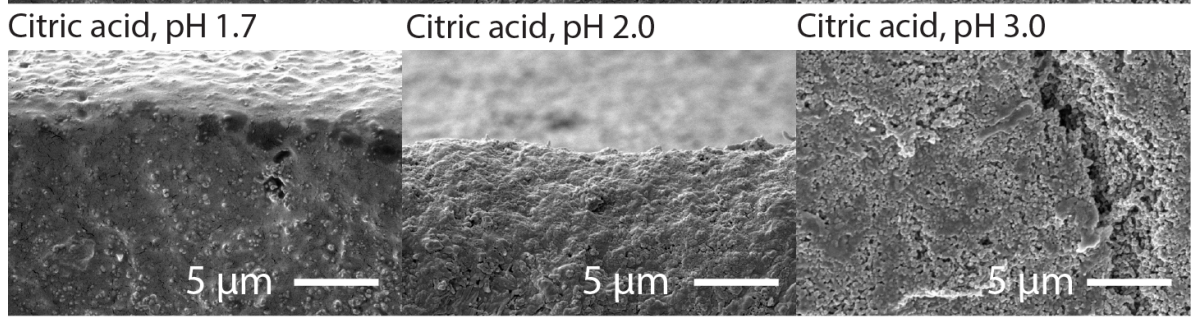

Citric acid, $\mathrm{pH} 1.7$

Citric acid, $\mathrm{pH} 2.0$

Citric acid, $\mathrm{pH} 3.0$

Figure 4.9: Scanning electron micrographs of fracture sites of dense extrudes. Samples were prepared using different pHs and acids. The acid and its concentration is given in the image. All photos are taken after drying of the sample. 


\subsection{References}

[1] X. Zhang, D. K. Wang, D. R. S. Lopez, J. C. Diniz da Costa, Fabrication of nanostructured $\mathrm{TiO}_{2}$ hollow fiber photocatalytic membrane and application for wastewater treatment, Chem. Eng. J 236 (2014) 314-322.

[2] T. Zhao, Z. Liu, K. Nakata, S. Nishimoto, T. Murakami, Y. Zhao, L. Jiang, A. Fujishima, Multichannel $\mathrm{TiO}_{2}$ hollow fibers with enhanced photocatalytic activity, J. Mater. Chem. 20 (2010) 5095-5099.

[3] N. Wung, S. M. Acott, D. Tosh, M. J. Ellis, Hollow fibre membrane bioreactors for tissue engineering applications, Biotechnol. Lett. 36 (2014) $2357-2366$.

[4] K. P. Katuri, C. M. Werner, R. J. Jimenez-sandoval, W. Chen, S. Jeon, B. E. Logan, Z. Lai, G. L. Amy, P. E. Saikaly, A Novel Anaerobic Electrochemical Membrane Bioreactor (AnEMBR) with Conductive Hollow-fiber Membrane for Treatment of Low-Organic Strength Solutions, Environ. Sci. Technol. 48 (2014) 12833-12841.

[5] J. L. Li, B. H. Chen, Review of $\mathrm{CO}_{2}$ absorption using chemical solvents in hollow fiber membrane contactors, Sep. Purif. Technol. 41 (2005) 109-122.

[6] V. Y. Dindore, D. W. F. Brilman, G. F. Versteeg, Hollow fiber membrane contactor as a gas-liquid model contactor, Chem. Eng. Sci. 60 (2005) 467-479.

[7] H. Kreulen, C. Smolders, G. Versteeg, W. van Swaaij, Microporous hollow fibre membrane modules as gas-liquid contactors. Part 1. Physical mass transfer processes, J. Membr. Sci. 78 (1993) 197-216.

[8] S. Dutczak, C. Tanardi, K. Kopeć, M. Wessling, D. Stamatialis, "Chemistry in a spinneret" to fabricate hollow fibers for organic solvent filtration, Sep. Purif. Technol. 86 (2012) 183-189.

[9] O. David, Y. Gendel, M. Wessling, Tubular macro-porous titanium membranes, J. Membr. Sci. 461 (2014) 139-145.

[10] B. Michielsen, H. Chen, M. Jacobs, V. Middelkoop, S. Mullens, I. Thijs, A. Buekenhoudt, F. Snijkers, Preparation of porous stainless steel hollow fibers by robotic fiber deposition, J. Membr. Sci. 437 (2013) 17-24. 
[11] A. Julbe, D. Farrusseng, C. Guizard, Porous ceramic membranes for catalytic reactors - Overview and new ideas, J. Membr. Sci. 181 (2001) 3-20.

[12] H. Wang, A. Feldhoff, J. Caro, T. Schiestel, S. Werth, Oxygen selective ceramic hollow fiber membranes for partial oxidation of methane, AIChE J. 55 (2009) 2657-2664.

[13] C. Buysse, A. Kovalevsky, F. Snijkers, A. Buekenhoudt, S. Mullens, J. Luyten, J. Kretzschmar, S. Lenaerts, Development, performance and stability of sulfur-free, macrovoid-free BSCF capillaries for high temperature oxygen separation from air, J. Membr. Sci. 372 (2011) 239-248.

[14] M. W. J. Luiten-Olieman, M. J. T. Raaijmakers, L. Winnubst, T. C. Bor, M. Wessling, A. Nijmeijer, N. E. Benes, Towards a generic method for inorganic porous hollow fibers preparation with shrinkage-controlled small radial dimensions, applied to $\mathrm{Al}_{2} \mathrm{O}_{3}, \mathrm{Ni}, \mathrm{SiC}$, stainless steel, and YSZ, J. Membr. Sci. 407-408 (2012) 155-163.

[15] S. Husain, W. J. Koros, Macrovoids in Hybrid Organic/Inorganic Hollow Fiber Membranes, Ind. Eng. Chem. Res. 48 (2009) 2372-2379.

[16] X. Tan, S. Liu, K. Li, Preparation and characterization of inorganic hollow fiber membranes, J. Membr. Sci. 188 (2001) 87-95.

[17] S. Shukla, P. de Wit, M. W. J. Luiten-Olieman, E. J. Kappert, A. Nijmeijer, N. E. Benes, Synthesis of Porous Inorganic Hollow Fibers without Harmful Solvents, ChemSusChem 8 (2015) 251-254.

[18] G. T. Grant, E. R. Morris, D. A. Rees, P. J. Smith, D. Thom, Biological interactions between polysaccharides and divalent cations: The egg-box model, FEBS Lett. 32 (1973) 195-198.

[19] G. Skjåk-Bræk, H. Grasdalen, O. Smidsrød, Inhomogeneous polysaccharide ionic gels, Carbohydr. Polym. 10 (1989) 31-54.

[20] K. I. Draget, G. Skjåk-Bræk, B. T. Stokke, Similarities and differences between alginic acid gels and ionically crosslinked alginate gels, Food Hydrocoll. 20 (2006) 170-175.

[21] G. W. Vandenberg, K. De La Noue, Evaluation of protein release from chitosan-alginate microcapsules produced using external or internal gelation., J. Microencapsul. 18 (2001) 433-441. 
[22] L. W. Chan, H. Y. Lee, P. W. S. Heng, Production of alginate microspheres by internal gelation using an emulsification method, Int. J. Pharm. 242 (2002) 259-262.

[23] J. P. Paques, L. M. C. Sagis, C. J. M. van Rijn, E. van der Linden, Nanospheres of alginate prepared through w/o emulsification and internal gelation with nanoparticles of $\mathrm{CaCO}_{3}$, Food Hydrocoll. 40 (2014) 182-188.

[24] X. D. Liu, W. Y. Yu, Y. Zhang, W. M. Xue, W. T. Yu, Y. Xiong, X. J. Ma, Y. Chen, Q. Yuan, Characterization of structure and diffusion behaviour of Ca-alginate beads prepared with external or internal calcium sources., J. Microencapsul. 19 (2002) 775-782.

[25] M. C. Straccia, G. G. d'Ayala, I. Romano, P. Laurienzo, Novel zinc alginate hydrogels prepared by internal setting method with intrinsic antibacterial activity, Carbohydr. Polym. 125 (2015) 103-112.

[26] K. Y. Lee, J. A. Rowley, P. Eiselt, E. M. Moy, K. H. Bouhadir, D. J. Mooney, Controlling mechanical and swelling properties of alginate hydrogels independently by cross-linker type and cross-linking density, Macromolecules 33 (2000) 4291-4294.

[27] M. Golmohamadi, K. J. Wilkinson, Diffusion of ions in a calcium alginate hydrogel-structure is the primary factor controlling diffusion, Carbohydr. Polym. 94 (2013) 82-87.

[28] M. D. Cathell, C. L. Schauer, Structurally colored thin films of $\mathrm{Ca}^{2+}$ cross-linked alginate, Biomacromolecules 8 (2007) 33-41.

[29] A. M. Padoł, G. Maurstad, K. I. Draget, B. T. Stokke, Delaying cluster growth of ionotropic induced alginate gelation by oligoguluronate, Carbohydr. Polym. 133 (2015) 126-134.

[30] K. Kilan, P. Warszyński, Thickness and permeability of multilayers containing alginate cross-linked by calcium ions, Electrochim. Acta 144 (2014) $254-262$.

[31] B. Y. Choi, H. J. Park, S. J. Hwang, J. B. Park, Preparation of alginate beads for floating drug delivery system: Effects of $\mathrm{CO}_{2}$ gas-forming agents, Int. J. Pharm. 239 (2002) 81-91. 
[32] H. Bazin, G. Descotes, A. Bouchu, M. Petit-Ramel, Comparison of calcium complexation of some carboxylic acids derived from D-glucose and D-fructose, Can. J. Chem. 73 (1995) 1338-1347.

[33] S. Lomate, B. Katryniok, F. Dumeignil, S. Paul, High yield lactic acid selective oxidation into acetic acid over a Mo-V-Nb mixed oxide catalyst, Sustain. Chem. Process 3 (2015) 5.

[34] G. S. Dhillon, S. K. Brar, M. Verma, R. D. Tyagi, Utilization of different agro-industrial wastes for sustainable bioproduction of citric acid by Aspergillus niger, Biochem. Eng. J. 54 (2011) 83-92.

[35] M. Morales, P. Y. Dapsens, I. Giovinazzo, J. Witte, C. Mondelli, S. Papadokonstantakis, K. Hungerbuhler, J. Perez-Ramirez, Environmental and economic assessment of lactic acid production from glycerol using cascade bio- and chemocatalysis, Energy. Environ. Sci. 8 (2015) 558-567.

[36] Y. Pocker, E. Green, Hydrolysis of D-glucono- $\delta$-lacone, JACS 78 (1972) 113-119.

[37] C. K. Kuo, P. X. Ma, Ionically crosslinked alginate hydrogels as scaffolds for tissue engineering: Part 1. Structure, gelation rate and mechanical properties, Biomaterials 22 (2001) 511-521.

[38] C. A. León y León, New perspectives in mercury porosimetry, Adv. Colloid Interface Sci. 76-77 (1998) 341-372.

[39] L. W. Chan, H. Y. Lee, P. W. S. Heng, Mechanisms of external and internal gelation and their impact on the functions of alginate as a coat and delivery system, Carbohydr. Polym. 63 (2006) 176-187.

[40] A. Haug, S. Myklestad, B. Larsen, O. Smidsrød, G. Eriksson, R. Blinc, S. Paušak, L. Ehrenberg, J. Dumanović, Correlation between Chemical Structure and Physical Properties of Alginates, Acta Chem. Scand. 21 (1967) 768-778.

[41] H. Qasim Hussein, P. de Wit, E. J. Kappert, N. E. Benes, Sustainable Route to Inorganic Porous Hollow Fibers with Superior Properties, ACS Sustain. Chem. Eng. (2015) acssuschemeng.5b01248.

[42] S. A. Mansour, Thermal decomposition of calcium citrate tetrahydrate, Thermochim. Acta 233 (1994) 243-256. 
[43] P. C. Hidber, T. J. Graule, L. J. Gauckler, Citric Acid - A dispersant for Aquous Alumina Suspensions, J. Am. Chem. Soc. 79 (1996) 1857-67.

[44] D. A. Brosnan, G. C. Robinson, Introduction to Drying of Ceramics, Wiley, 2003.

[45] Y. K. Lee, D. J. Mooney, Alginate: properties and biomedical applications, Prog Polym Sci. 37 (2013) 106-126.

[46] S. K. Bajpai, R. Tankhiwale, Investigation of water uptake behavior and stability of calcium alginate/chitosan bi-polymeric beads: Part-1, React. Func. Polym. 66 (2006) 645-658.

[47] M. J. Zohuriaan, F. Shokrolahi, Thermal studies on natural and modified gums, Polym. Test. 23 (2004) 575-579.

[48] A. Said, R. Hassan, Thermal decomposition of some divalent metal alginate gel compounds, Polym. Degrad. Stab. 39 (1993) 393-397.

[49] N. E. Benes, Mass transport in thin supported silica membranes, Ph.D. thesis, University of Twente, 2000.

[50] P. C. Hidber, T. J. Graule, L. J. Gauckler, Influence of the dispersant structure on properties of electrostatically stabilized aqueous alumina suspensions, J. Eur. Ceram. Soc. 17 (1997) 239-249.

[51] E. L. Kaplan, P. Meier, Nonparametric Estimation from Incomplete Observations, J. Am. Stat. Assoc. 53 (1958) 457-481.

[52] ASTM, C1239-13 Standard Practice for Reporting Uniaxial Strength Data and Estimating Weibull Distribution Parameters for Advanced Ceramics, 2014 .

[53] M. Genet, M. Houmard, S. Eslava, A two-scale Weibull approach to the failure of porous ceramic structures made by robocasting: possibilities and limits, J. Eur. Ceram. Soc. 33 (2013) 679-688.

[54] J.-W. Zhang, H. Fang, J.-W. Wang, L.-Y. Hao, X. Xu, C.-S. Chen, Preparation and characterization of silicon nitride hollow fiber membranes for seawater desalination, J. Membr. Sci. 450 (2014) 197-206.

[55] L. Jiansheng, W. Lianjun, H. Yanxia, L. Xiaodong, S. Xiuyun, Preparation and characterization of $\mathrm{Al}_{2} \mathrm{O}_{3}$ hollow fiber membranes, J. Membr. Sci. 256 (2005) 1-6. 
[56] S. Liu, K. Li, R. Hughes, Preparation of porous aluminium oxide $\left(\mathrm{Al}_{2} \mathrm{O}_{3}\right)$ hollow fibre membranes by a combined phase-inversion and sintering method, Ceram. Int. 29 (2003) 875-881.

[57] Y.-L. E. Fung, H. Wang, Nickel aluminate spinel reinforced ceramic hollow fibre membrane, J. Membr. Sci. 450 (2014) 418-424.

[58] S. A. Rodrigues, J. L. Ferracane, Á. Della Bona, Flexural strength and Weibull analysis of a microhybrid and a nanofill composite evaluated by 3- and 4-point bending tests., Dent. Mater. 24 (2008) 426-31.

[59] M. Mota, A. Teixeira, A. Yelshin, Image analysis of packed beds of spherical particles of different sizes, Sep. Purif. Technol. 15 (1999) 59-68.

[60] S. Khirevich, A. Höltzel, A. Daneyko, A. Seidel-Morgenstern, U. Tallarek, Structure-transport correlation for the diffusive tortuosity of bulk, monodisperse, random sphere packings, J. Chromatogr. A 1218 (2011) 6489-6497.

[61] A. Bertei, B. Nucci, C. Nicolella, Effective transport properties in random packings of spheres and agglomerates, CEt 32 (2013) 1531-1536. 


\section{Chapter 5}

\section{The mechanical strength of inorganic porous hollow fibers: The effect of measurement method}

This chapter is adapted from:

P. de Wit, F. S. van Daalen, N.E. Benes, The mechanical strength of a ceramic porous hollow fiber, 2017, J. Membr. Sci., 524, pp. 721-728, doi: 10.1016/j.memsci.2016.11.047 


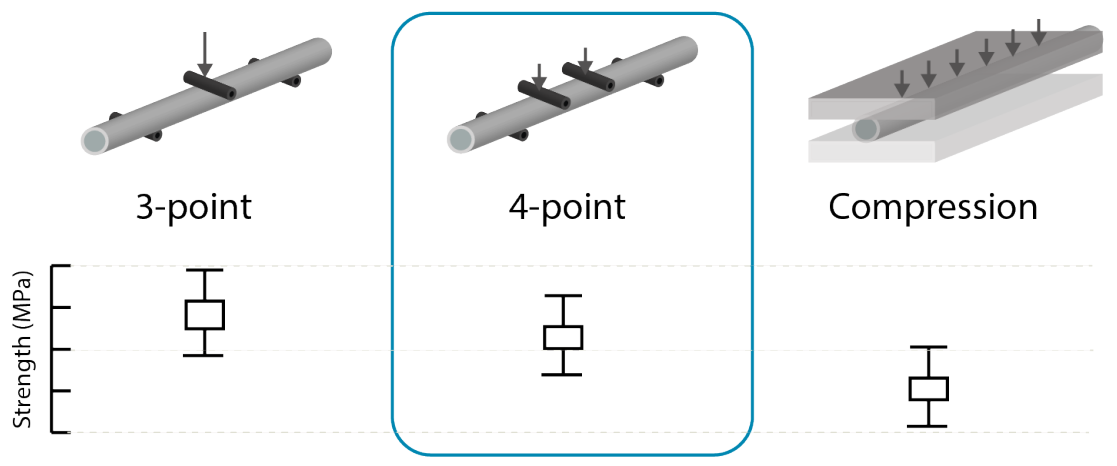

\begin{abstract}
The mechanical strength of inorganic porous hollow fibers is a critical constraint that limits their wide scale application. Various methods, including 3point bending, 4-point bending, and diametrical compression are used for the quantification of the mechanical strength. Here, we show that these methods cannot be used in an interchangeable manner. For large sets of alumina hollow fibers, the parameters describing the cumulative probability of failure functions depend on the type of measurement, i.e., 3 or 4-point, the span size, and the measurement geometry. This implies that reporting data on mechanical properties of inorganic hollow fibers requires that extensive information about the experimental details is provided, and that a direct quantitative comparison between datasets is unjustifiable. The mechanical strength of the alumina hollow fibers tends to follow a normal distribution, or log-normal distribution, instead of the often used Weibull distribution. Monte Carlo simulations demonstrate that, especially at small sample set sizes, it is difficult to accurately determine the shape of the probability distribution. However, detailed knowledge of the type and the shape of this distribution function is essential when mechanical strength values are to be used in further design.
\end{abstract}




\subsection{Introduction}

The mechanical strength of porous inorganic hollow fibers prepared using nonsolvent induced phase inversion (NIPS) is often investigated. A poor mechanical strength affects the large-scale application of these hollow fibers as, for example, microfiltration membrane, catalyst support, or (membrane) microreactor [1]. Many methods are used to assess the mechanical robustness of inorganic fibers; most commonly their flexural or bending strength is determined via a 3-point [2-6] or 4-point bending test [7-10]. Alternatives include burst pressure measurements $[11,12]$ or diametrical compression tests $[13,14]$.

The reported mechanical strength is a direct result of the measurement method and the conditions used. As a result, comparison of strength data presented in literature can be deceptive. In addition to the measurement method, the amount of samples measured and the subsequent statistical analysis are of great importance. The comparison of a 3-point versus a 4-point bending test is described in literature for various applications, like advanced dense ceramics [15-18] and polymers [19], but not for porous inorganic hollow fibers. In this paper, we demonstrate the pronounced influence of the measurement method on the reported strength value, and why it is crucial to not only report the measurement method, but also sample geometry and sample set size to allow comparison of reported strength values. In ceramic reliability engineering, one often assumes a specific probability distribution. Based on the microstructure of a ceramic -being porous or non-porous- different probability distributions are assumed. In traditional non-porous ceramics the Weibull distribution is mostly used, whereas recently the use of the log-normal or normal distributions are proposed for porous ceramics [20]. We demonstrate why detailed knowledge of the probability distribution is relevant for the design of components consisting of porous ceramic hollow fibers.

\subsection{Theoretical background}

\subsubsection{Strength distributions}

The result of fracture testing is usually reported as an average strength or mean strength of the measured stress at failure, of a set of $N$ samples.

$$
\sigma_{i}=\frac{\sum i=1 N \sigma_{i}}{N}
$$


A drawback of the average strength is that it contains no information about the spread of the strength values measured. In ceramics, defects are randomly distributed over the sample and they will vary in position, size, and severity. As a consequence, the strength of a fiber will vary from fiber to fiber, even for apparent identical fibers. As a measure for this spread often the standard deviation of the mechanical strength data is reported. In addition, if a small amount of samples is measured, the average strength might not be a good representation of the real strength number (this effect becomes more severe at lower sample sizes, e.g. $\mathrm{N}<10$ [21]). Therefore, the common interpretation of fracture tests is based on a statistical models that predict a probability of failure. It is often stated the one is required to measure at least 10-30 samples if the statistical model is known $[18,22]$, others propose that a minimum of 150-200 samples is required for an unknown model [21, 23].

The distribution parameters are of utmost importance in the design of components that consist of ceramics. In design, an acceptable probability of failure is selected, and the associated design stress is calculated using the statistical distribution function. Especially the lower tail of the probability distribution strongly affects the design stress [24]. Without appropriate characterization and the use of the correct statistical distribution, the measured strengths cannot be applied in design and might lead to erroneous conclusions. [20, 25-27].

\section{Weibull distribution}

The Weibull distribution [28] is the generally applied distribution for strength characterization of brittle ceramics with little defects. It is based on the socalled weakest link principle. In the majority of dense ceramics, only few defects are present. If the ceramic fails, it is assumed to fail at its weakest defect. The regular formulation of the Weibull distribution, used in measuring the strength of ceramics, is written as:

$$
P(\sigma)=1-\exp \left[-\left(\frac{\sigma}{\sigma_{\theta}}\right)^{m}\right]
$$

where $P(\sigma)$ is the cumulative probability of failure, $\sigma$ the applied stress, $m$ the Weibull modulus a measure for the spread of strength data and $\sigma_{\theta}$ is the characteristic strength. The characteristic strength and estimate of the Weibull modulus are often obtained via maximum likelihood fitting of the measured strength data. The Weibull characteristic strength depends on the test geometry, such type and size; and it is a value specific to a certain test. 
An alternative representation of the probability of failure is the more general equation,

$$
P(\sigma, V)=1-\exp \left[-\int_{V}\left(\frac{\sigma}{\sigma_{0}}\right)^{m} d V\right]
$$

where $P(\sigma, V)$ is the cumulative probability of failure, $V$ is the volume of the component, $\sigma$ is the applied stress, $m$ is the Weibull modulus and $\sigma_{0}$ is the Weibull material scale parameter. If the integration in the above-mentioned equation is carried out the equation reduces to:

$$
P(\sigma)=1-\exp \left[-k V\left(\frac{\sigma}{\sigma_{0}}\right)^{m}\right]
$$

Where $k$ is a dimensionless constant that accounts for test specimen geometry and stress gradients. In general, $k$ is also a function of the estimated Weibull modulus. The product $k V$ is often referred to as the effective volume. Using this effective volume, the characteristic Weibull strength $\sigma_{\theta}$ can be converted into the Weibull material scale parameter using a relation such as

$$
\left(\sigma_{0}\right)_{V}=(k V)^{1 /(m)}\left(\sigma_{\theta}\right)_{V}
$$

This approach is discussed in detail in various references $[22,29,30]$. Calculation of the effective volume of a porous ceramic hollow fiber with its defects, pores, and macrovoids is problematic as the volume under stress is nearly impossible to estimate.

Mechanical strength testing combined with Weibull analysis are broadly standardized for dense ceramics, for example in ASTM C1161 [22] or DIN 843-5 [31]. Most methods recommend to measure at least 30 samples in order to accurately estimate the Weibull modulus and characteristic strength. The Weibull distribution, depending on the weakest link theory with non-interacting defects, is questioned to be suitable for certain ceramic strength data [26, 32-35]. For example Danzer et al. [26] demonstrate that in certain situations a deviation of the Weibull distribution is expected; when the material exhibits a multi-model flaw size distribution (e.g., porosity), when defects interact, when R-curve behavior is observed or when subcritical crack growth is likely [36]. Inorganic porous hollow fibers prepared by non-solvent induced phase inversion (NIPS) have a high defect density with a large range of defects such as pores, large finger like voids and agglomerates. This results in a questionable applicability of the Weibull model and its underlying assumption. Therefore, other models are also evaluated. 


\section{Normal distribution}

The normal distribution is one of the mostly used distributions in sciences for real-valued random variables whose distributions are not known. Therefore, a normal distribution is used to describe the strength of brittle ceramics, in particular when these materials show a roughly symmetrical distribution and when the amount of defects is large [33, 37, 38]. Its parameters $\bar{\sigma}$ and $\alpha$ represent the mean and standard deviation of the distribution. The cumulative probability is given by:

$$
P(\sigma)=\frac{1}{2}\left[1+\operatorname{erf}\left(\frac{\sigma-\bar{\sigma}}{\alpha \sqrt{2}}\right)\right]
$$

\section{Log-normal distribution}

$\mathrm{Lu}$ et al. proposed the log-normal distribution for porous ceramics with high porosity. This assumes that the probability of a flaw being critical depends on a lot of factors such as size, shape and pore-grain interaction [20, 21]. The failure probability can be estimated by $p=\prod p_{i}$, where $p_{i}$ is the failure probability of the $i$-th factor of influence. Via $\ln p=\sum \ln p_{i}$ this results in an overall probability that follows the log-normal distribution [39]. The cumulative probability of a log-normal distribution is:

$$
P(\sigma)=\frac{1}{2}\left[1+\operatorname{erf}\left(\frac{\sigma-\bar{\sigma}}{\alpha \sqrt{2}}\right)\right]
$$

If data is log-normally distributed with parameters $\bar{\sigma}$ and $\alpha$, the logarithm of the data is distributed with the mean $\bar{\sigma}^{*}=\exp \left(\bar{\sigma}+\alpha^{2} / 2\right)$ and multiplicative standard deviation $s^{*}=\exp \left(2 \bar{\sigma}+\alpha^{2}\right)\left[\exp \left(\alpha^{2}\right)-1\right]$. Analog to the additive transformation for the normal distribution $\bar{\sigma} \pm \alpha$, the multiplicative transformation of the lognormal distribution can be expressed as $\bar{\sigma}^{*} \cdot / s^{*}$, where "./" indicates "times or divided" by [39]. 


\subsubsection{Minimum Information Criterion}

The unknown parameters of the proposed distribution functions are obtained by maximum likelihood method. Equation 5.8 shows the likelihood of a probability density function, where $\sigma_{i}$ is the strength of the $i$-th sample, $N$ is the total number of samples, $\mathcal{L}$ is the likelihood, and $f\left(\sigma_{i}\right)$ is the probability density function (pdf) of the proposed distribution [33].

$$
\ln (\mathcal{L})=\sum_{i=1}^{N} \ln f\left(\sigma_{i}\right)
$$

To compare the proposed models, the Akaike information criterion $(A I C)[40]$ is used; which is an estimate for the distance between the true and the estimated distribution, and is defined as:

$$
A I C=-2 \ln (\mathcal{L})+2 k
$$

In which $\ln (\mathcal{L})$ is the maximum $\log$-likelihood for a given model and $k$ is the number of parameters to be fitted. The $A I C$ values allow direct comparison, and a lower value for a certain distribution would indicate that this distribution is more likely, a difference in $A I C$ value larger than 2 is considered statistically significant [21, 41].

\subsubsection{Anderson-Darling Goodness of Fit test}

In addition to the Akaike Information Criterion, an Anderson-Darling goodness of fit test is conducted. The Anderson-Darling test (AD), is one of the most powerful goodness of fit tests $[42,43]$ with critical values for various distributions being available in literature $[44,45]$. The hypothesis regarding the distributional form is rejected at the chosen confidence level $(\alpha=0.05)$ if the test statistic is greater than the critical value.

\subsubsection{Measurement methods}

Various methods and geometries are used to assess the flexural strength of ceramic hollow fiber membranes, all with their own distinct features. In current literature the 3-point and 4-point bending test are used interchangeably, both with various inner and outer span sizes [8, 46-48]. Recently the use of diametric compression tests is reported to assess the strength of inorganic hollow fibers $[13,49]$. The reported strength value depends strongly on the measurement method and span size $[18,22,50]$. 


\section{4-point bending test}

In the 4-point bending test the maximum stress is constant over a relatively large area between the two inner rollers, separated by distance $L_{i n}$. The maximum bending strength is computed using Equation 5.10, where $F_{j}$ is the force at fracture for specimen $j, L_{\text {outer }}$ the distance between the two outer rollers, $K$ being half the distance between the inner and outer roller $\left(K=0.5\left(L_{\text {out }}-L_{i n}\right)\right)$ and $d_{o u t, j}$ and $d_{i n, j}$ the outer and inner diameter of specimen $j$ :

$$
\sigma_{f, j}=\frac{16 F_{j} K d_{o u t, j}}{\pi\left(d_{o u t, j}^{4}-d_{i n, j}^{4}\right)}
$$

\section{3-point bending test}

The 3-point bending test exposes only a very small portion of the fiber to the maximum stress [16]. Therefore, bending strengths obtained via 3 -point bending tests are likely to be larger as compared to ones obtained by means of the 4-point bending tests [19]. The maximum bending strength is computed using Equation 5.11, where $F_{j}$ is the force at fracture for specimen $j, L_{\text {out }}$ the distance between the two outer rollers and $d_{o u t, j}$ and $d_{i n, j}$ the outer and inner diameter of specimen $j$, respectively.

$$
\sigma_{f, j}=\frac{8 F_{j} L_{\text {out }} d_{o u t, j}}{\pi\left(d_{o u t, j}^{4}-d_{i n, j}^{4}\right)}
$$

The major difference between the 3 and 4-point bending test is the location of the maximum bending moment and as a result the maximum stress. In a 4-point bending test a uniform stress profile is observed between the two inner rollers, whilst during a 3-point bending test the stress is concentrated under the loading roller. This influences the area under stress, which might result in a higher chance of observing a defect in the sample. The 3-point bending test has some advantages when compared to the 4-point bending test; it uses a simpler test fixture -minimizing the chance of roller misalignment- and a lower force to break the sample. Nonetheless, the ASTM recommends the 4-point bending test for most characterization purposes, mainly because a larger area is subjected to the maximum stress [18].

\section{Diametrical compression test}

In a diametrical compression test a compressive load is applied by two plates parallel to the axis of the fiber. The expression for the stress distribution is 
derived from the curved beam theory; if a fiber is subjected to a load $F_{j}$ over a length $L_{\text {out }}$, the resultant hoop stress is a sum of the stress components caused by axial and bending load. According to de With [51], the strength can be computed using Equation 5.12 where $F_{j}$ is the force at fracture, $r_{m}$ is the mean radius $\left(d_{o u t, j}+d_{i n, j}\right) / 4$, and $t$ is the wall thickness $\left(d_{o u t, j}-d_{i n, j}\right) / 2$.

$$
\sigma_{f, j}=\frac{2 F_{j} r_{m}\left(6 r_{m}-t\right)}{\pi L_{\text {out }} t^{2}\left(2 r_{m}-t\right)}
$$

Equation 5.12 assumes the fiber is a concentric ring structure and does not account for any eccentricity of the fiber. Although this measurement method is fairly simple to operate, the resultant strength values depend largely on the fibers geometry. De With does not recommend the use of this test, but proposed the use of a modified burst pressure [51-53]. The use of a burst pressure method is considered to be beyond the scope of this paper. For comparison reasons the diametrical compression test is included in this study, as it is recently used in the field of porous inorganic hollow fibers [13].

\section{$5.3 \quad$ Experimental}

\subsubsection{Hollow fiber fabrication}

Alumina hollow fibers were prepared by non-solvent induced phase separation (NIPS) using a mixture of AKP30 $\alpha-\mathrm{Al}_{2} \mathrm{O}_{3}$ powder $\left(\mathrm{Al}_{2} \mathrm{O}_{3}\right.$, particle size of $0.3 \mu \mathrm{m}$, Sumitomo Chemicals Co. LTD. Japan), Polyethersulfone (PES, Ultrason, 6020P, BASF, Germany) and N-methylpyrrolidone (NMP, 99.5 wt\%, Sigma Aldrich, The Netherlands). Polyvinylpyrrolidone $\left(M_{w}\right.$ 1,300,000, Sigma Aldrich, The Netherlands) was used as viscosity enhancer and de-ionized water ( $>18 \mathrm{M} \Omega \mathrm{cm}^{-1}$, Milli-Q Advantage A10, Millipore) was used as non-solvent. Prior to use, PES and AKP-30 were dried overnight at $80{ }^{\circ} \mathrm{C}$; all other chemicals were used as received. Table 5.1 describes the spinning conditions and recipe and fibers were prepared using standard methods [7].

After drying, the fibers were thermally treated under air $\left(100 \mathrm{~mL} \mathrm{~min}^{-1}\right)$ using a tubular furnace (STF16/610, Carbolite). The thermal treatment program consisted of $60 \mathrm{~min}$ at $300^{\circ} \mathrm{C}$ and $120 \mathrm{~min}$ at $1400^{\circ} \mathrm{C}$. A heating and cooling rate of $5^{\circ} \mathrm{C} \mathrm{min}^{-1}$ was used. After thermal treatment, the fibers were cut to the desired length. 

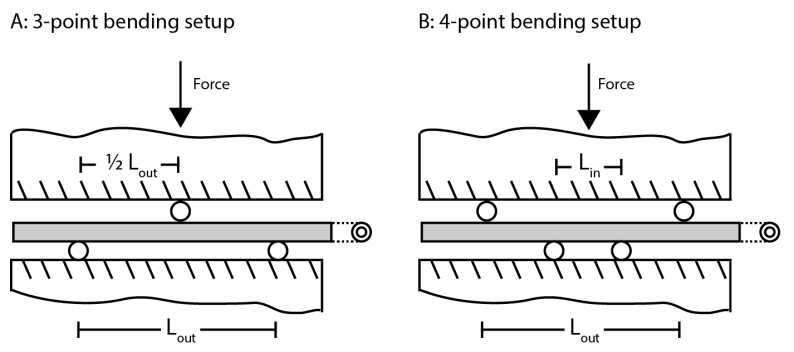

C: Diametrical compression setup

Figure 5.1: Schematic representation of the three different testing geometries. A: 3 -point bending setup, B: 4 -point bending setup $\left(L_{\text {in }}=0.5 L_{\text {out }}\right)$, C: Diametrical compression setup

Table 5.1: Spinning conditions

\begin{tabular}{ll}
\hline Condition & Value \\
\hline PES & $9.40 \%$ \\
NMP & $40.0 \%$ \\
AKP-30 & $48.9 \%$ \\
PVP K-95 & $0.70 \%$ \\
Water & $1.00 \%$ \\
Bore Liquid & $\mathrm{H}_{2} \mathrm{O}$ \\
Coagulation bath & $\mathrm{H}_{2} \mathrm{O}$ \\
Extrusion pressure & $2 \mathrm{bar}$ \\
Air gap & $3 \mathrm{~cm}$ \\
Bore liquid flow rate & $7 \mathrm{~mL} \mathrm{~min}-1$ \\
Diameter spinneret & $\mathrm{OD} / \mathrm{ID}=2.0 \mathrm{~mm} / 0.8 \mathrm{~mm}$ \\
Drying after spinning & $>24 \mathrm{~h}$ \\
\hline
\end{tabular}

\subsubsection{Experimental setup}

The bending strength of the alumina hollow fibers was measured at room temperature $\left(20 \pm 2{ }^{\circ} \mathrm{C}\right)$ and a relative humidity of $40 \% \pm 10 \%$, using a $5564 \mathrm{~A}$ mechanical testing bench (Instron) equipped with a $100 \mathrm{~N}$ load cell. All testing was carried out according to ASTM C1684-08 [18], which has been adapted at the following points: 1) the rollers are not free to move laterally, b) a tube is used instead of a rod, c) the ceramic material is porous. 
Figure 5.1 schematically displays the three different setups used. In order to make a fair comparison $L_{\text {out }}$ was kept constant for both the 3 -point and the 4-point bending tests. For diametrical compression testing, the fibers length was measured prior to each experiment.

A piece of hollow fiber was loaded into the test fixture. The load was measured at constant extension rate $\left(2 \mathrm{~mm} \mathrm{~min}^{-1}\right)$. The inner and outer diameter of the fiber were measured, after fracture, using a digital caliper (Mitutoyo CD15CPX, $\Delta d \pm 0.02 \mathrm{~mm}$ ). All fibers were tested as-fabricated and no surface treatment was carried out on the fibers. Fibers originated from one spinning batch, but from different sintering batches. Fibers were taken randomly from different sintering batches for the various experiments. A sample set size of $N=100$ was used for the $20 \mathrm{~mm}$ outer span size and diametrical compression measurements. For the $40 \mathrm{~mm}$ outer span size experiments, a sample set size of $N=50$ was used. All fiber fragments were collected for post-failure analysis; for various fibers the fracture surface was investigated using SEM. In order to verify the accuracy of inner and outer diameter obtained by the digital caliper, the inner and outer diameter were also estimated from the scanning electron micrographs. Table 5.2 shows the result of this comparison, where it can be seen that the differences in diameters were less than 5 percent.

Table 5.2: Comparison of inner and outer diameter using estimates from scanning electron micrographs and measurements with a digital caliper. Diameters are given in $\mathrm{mm}$

\begin{tabular}{llcccccc}
\hline \multirow{2}{*}{ \# } & \multirow{2}{*}{ Geometry } & \multicolumn{2}{c}{ SEM } & \multicolumn{2}{c}{ Caliper } & \multicolumn{2}{c}{ Difference $^{*}$} \\
& & $d_{\text {in }}$ & $d_{\text {out }}$ & $d_{\text {in }}$ & $d_{\text {out }}$ & $d_{\text {in }}$ & $d_{\text {out }}$ \\
\hline 1 & 4 point 10 $-20 \mathrm{~mm}$ & 0.82 & 1.32 & 0.84 & 1.39 & $-4.99 \%$ & $-2.31 \%$ \\
2 & 4 point 10 $-20 \mathrm{~mm}$ & 0.82 & 1.34 & 0.82 & 1.39 & $-3.83 \%$ & $0.45 \%$ \\
3 & 4 point 20 $-40 \mathrm{~mm}$ & 0.83 & 1.34 & 0.82 & 1.38 & $-3.05 \%$ & $1.44 \%$ \\
4 & 4 point 20 $-40 \mathrm{~mm}$ & 0.84 & 1.36 & 0.81 & 1.39 & $-2.38 \%$ & $3.25 \%$ \\
5 & 3 point 40 $\mathrm{mm}$ & 0.81 & 1.34 & 0.79 & 1.38 & $-2.70 \%$ & $2.91 \%$ \\
6 & 3 point 40 $\mathrm{mm}$ & 0.82 & 1.33 & 0.81 & 1.39 & $-4.66 \%$ & $1.35 \%$ \\
7 & 3 point 40 $\mathrm{mm}$ & 0.86 & 1.41 & 0.85 & 1.43 & $-1.70 \%$ & $0.69 \%$ \\
8 & 3 point 40 $\mathrm{mm}$ & 0.75 & 1.35 & 0.73 & 1.41 & $-4.21 \%$ & $3.06 \%$ \\
\hline
\end{tabular}

${ }^{*}$ Difference is defined as $\left(1-\left(d_{\mathrm{SEM}} / d_{\text {Caliper }}\right)\right) \times 100$ 


\subsection{Results and discussion}

Figure 5.2 shows a cross-sectional scanning electron micrograph of the $\mathrm{Al}_{2} \mathrm{O}_{3}$ fiber after sintering, where it is clear that the wall of the fiber exhibits an asymmetrical structure. Upon further magnification (Fig 5.2B and C) the macro-voids in the wall and the porous structure in between the sintered alumina grains can be seen. The fibers show an average pore diameter of $300 \mathrm{~nm}$ (Mercruy Intrusion), a porosity of approximately 50 percent (He and $\mathrm{Hg}$ density measurement) and a clean water permeability of approximately $500 \mathrm{~L} \mathrm{~m}^{-2} \mathrm{~h}^{-1}$ bar $^{-1}$.

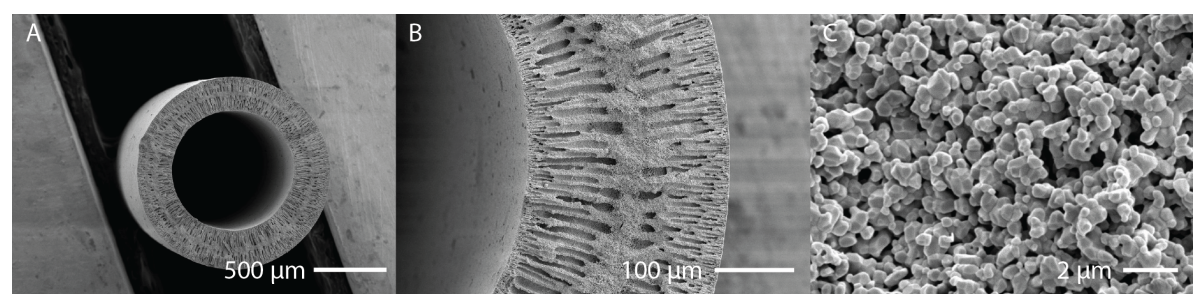

Figure 5.2: Cross-sectional scanning electron micrographs of a sintered aluminum oxide fiber used in mechanical testing. A: 50x magnification showing the roundness of the fiber B: close-up of fiber wall showing the asymmetrical wall structure with the presence of large macro-voids C: detail of individual grains in the fiber wall.

\subsubsection{Mechanical strength}

Figure 5.3 shows the observed mechanical strengths obtained by the 3 different methods; the 3-point bending test, the 4-point bending test and the diametrical compression. A detailed overview of all results, including inner and outer diameter, location of fracture, and load/extension can be found in the Supplementary Datafile [54]. In Figure 5.3 the lower and upper error bar denote the lowest and highest observed strength. The box indicates the inter quartile range $(I Q R)$ of the observed mechanical strengths, with the horizontal line representing the median value. For all experiments a large spread in the measured strength is observed. Furthermore, the difference between the 3-point and 4-point bending test and the effect of the outer span size $L_{o u t}$ is worth mentioning. 


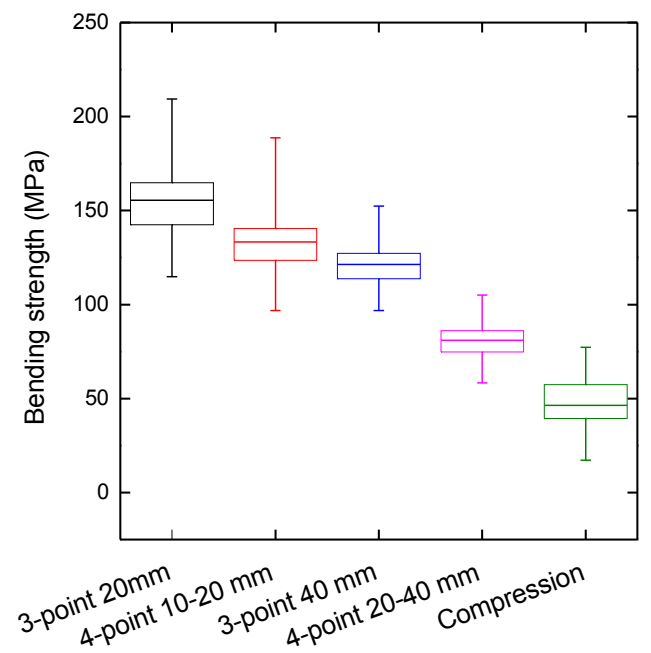

Figure 5.3: Summary of bending strengths measured using various methods. The lower and upper error bar denote the minimal and maximal observed mechanical strength, the boundaries of the box indicate the $I Q R$, whereas the horizontal line represents the median value.

For both outer spans, the 4-point bending test results in a significantly lower observed strength as compared to the 3 -point bending test. This effect is welldescribed in literature $[15,18,19]$, where it is indicated that results obtained by 4-point bending test will be lower as compared to 3-point bending test results. A larger span size (20 versus $40 \mathrm{~mm}$ ) results in a significantly lower mechanical strength, this effect is visible for both 4 and 3-point bending tests. The 3 -point bending test with an outer span of $20 \mathrm{~mm}$ results in a median strength of $\sim 155 \mathrm{MPa}$, the same experiment with $L_{\text {out }}=40 \mathrm{~mm}$ results in a median strength of approximately $120 \mathrm{MPa}$. This size effect is often described in literature, where an increased volume under stress (for example due to increased span size) will result in lower strength numbers [55].

The diametrical compression test shows the lowest mechanical strength values of all tests, however a comparison to the bending tests is complicated. The stress profile introduced in this method is rather different as compared to bending tests, and Figure 5.3 clearly shows that one should be extremely cautious 
when comparing results obtained by this method to the results of a bending test.

Matlab ${ }^{\circledR}$ is used to rank the measured strengths and to fit the three distributions to the data using maximum-likelihood methods. Table 5.3 displays the fitted parameters for all tests -bending and compression- obtained by fitting the measured strength to a Weibull, Normal or Log-normal distribution. Figure 5.4 visualizes the different probability models jointly with the measured and ranked data of the four different bending tests (empirical cumulative probability of failure estimated using the Kaplan-Meier method [56]). Figure 5.4 shows that the strength distributions tend to follow a normal or log-normal distribution. The Weibull distribution appears to be a lesser fit, especially at the lower end of the distribution.

As shown by the parameter estimates in Table 5.3, the difference between the mean value obtained from a normal distribution and the characteristic strength from a Weibull distribution can clearly be seen for all test geometries; the Weibull characteristic strength is always higher when compared to the mean value. The parameter that describes the shape of the probability distribution appears to independent of the span size of the test, with all shape parameters ( $m$ for Weibull, $\alpha$ for normal and $s^{*}$ for lognormal) being the same order of magnitude for the same type of test.

However, the shape values for a 3-point bending test are in disagreement with the 4-point bending test, where the 4-point bending test suggests a more narrow distribution. This might be explained by the fact that for a 4-point bending test the area under stress is larger, hence a larger probability a specimen will fail, possibly resulting in a more narrow distribution. This is also seen in the values that represent the mean and characteristic strength; the larger the volume subject to stress; the lower the observed strength value. For example, a 3-point bending test with a span size of $20 \mathrm{~mm}$ displays a significantly larger strength number as compared to a 3-point bending test with a span size of $40 \mathrm{~mm}$, albeit the shape factor is not strongly influenced by the span size. Table 5.3 again demonstrates that values obtained using a diametrical compression test are an order of magnitude smaller as compared to bending tests. This originates from the different stress profile in the fiber. 

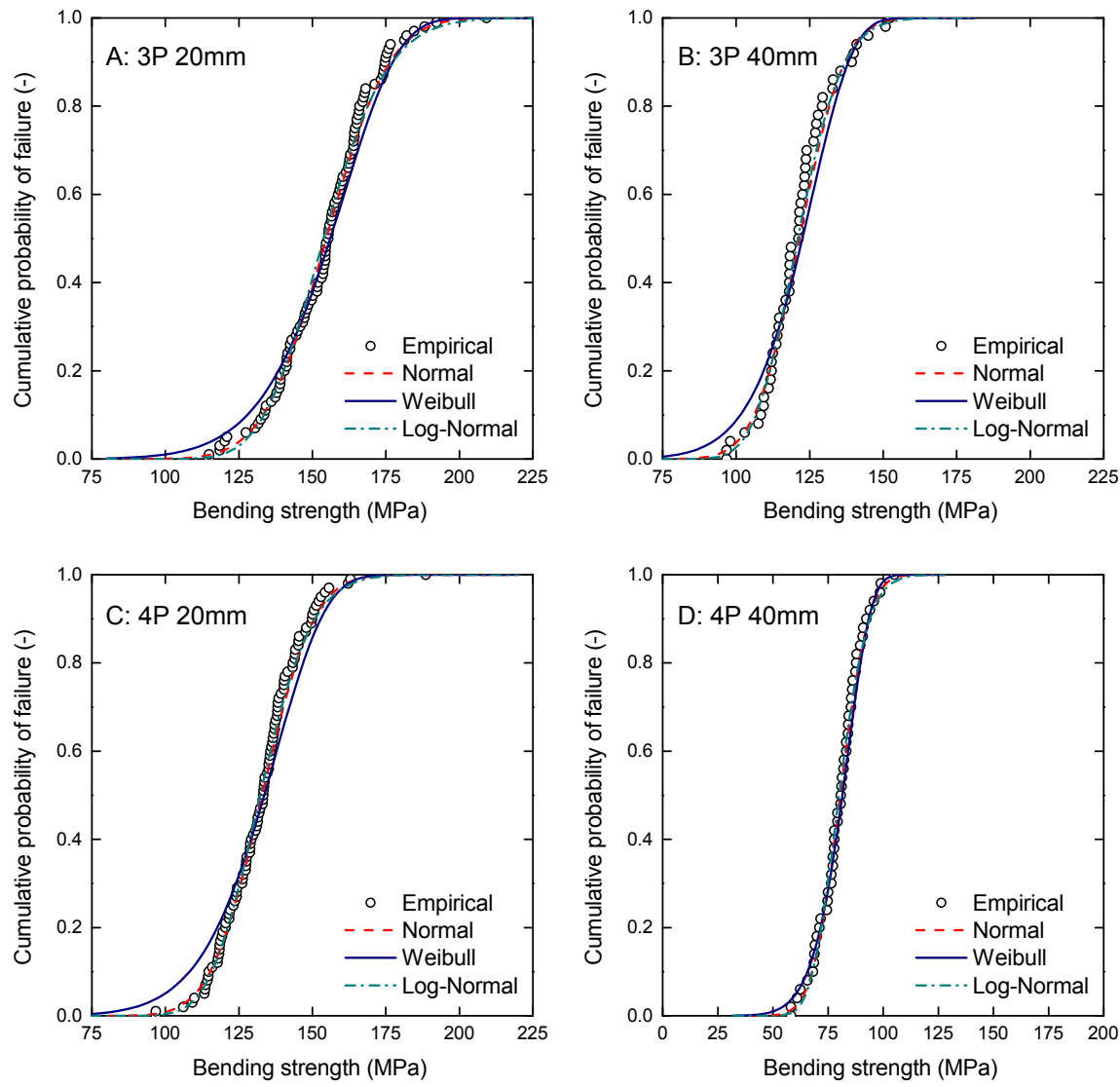

Figure 5.4: Cumulative probability of failure; empirical data (Kaplan-Meier estimate) and the 3 different distributions (parameters see Table 3). A: 3-point 20mm, B: 3-point 40mm, C: 4-point 10-20mm, D: 4-point 20-40mm 

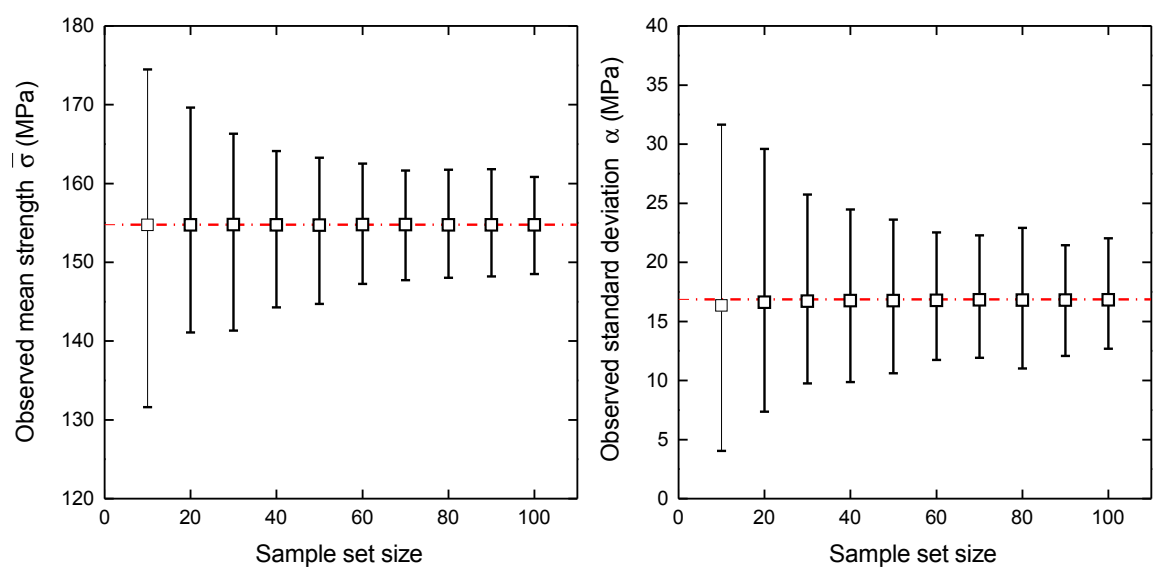

Figure 5.5: Effect of sample size on mean strength (a, left) and standard deviation (b, right) for 4-point bending, 20mm span, normal distribution. Error bars represent observed minimal and maximal values for mean (a) and standard deviation (b).

Table 5.4 shows the calculated $A I C$ values for all 3 distributions. For all bending tests the Weibull distribution is the least likely distribution $(\max A I C=$ Weibull). For example Danzer [26], or Lu [20] predicted this behavior for porous ceramics, as they state that a (log-) normal distribution can be expected. The results of the Anderson-Darling goodness of fit test are shown in Table 5.5, and indicate that the Weibull distribution appears to be the least likely distribution for the bending tests.

The differences in $A I C$ value between the Normal and Lognormal distribution are usually below 2, making it impossible to determine whether the preferred distribution is Normal or Lognormal [40, 41], as in certain cases the Lognormal distribution is converges to the Normal distribution [39]. The same holds for the diametrical compression test, where the difference in $A I C$ values or the results of the Anderson-Darling test are too small to state that any distribution is more likely. In general, it is difficult to accurately assess the distribution of these measurements, no specific distribution stands out nor is rejected. 


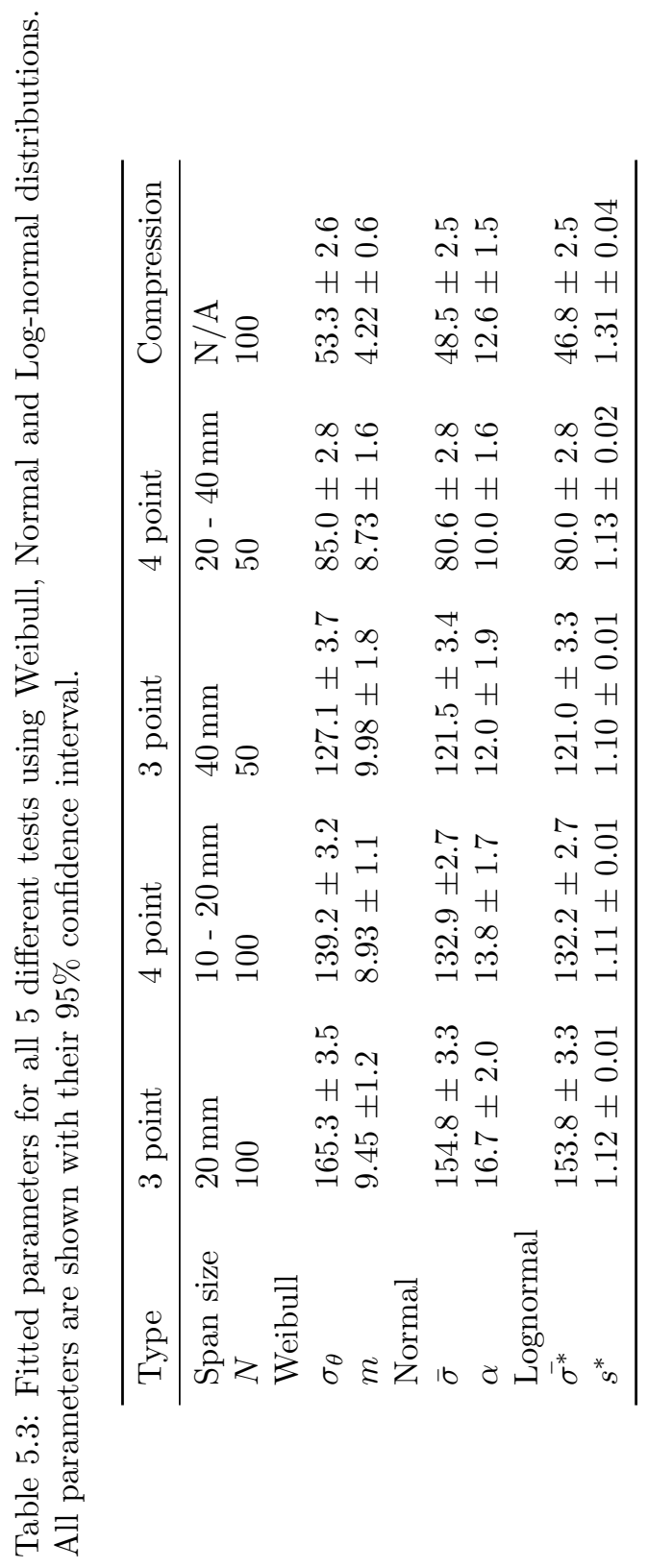


Table 5.4: The difference in $A I C$ values calculated for the three distributions, $\triangle A I C$ is defined as $\max (A I C)-\min (A I C)$

\begin{tabular}{lllll}
\hline Type & $N$ & $\min (A I C)$ & $\max (A I C)$ & $\Delta A I C$ \\
\hline 3-point $20 \mathrm{~mm}$ & 100 & Normal & Weibull & 11.23 \\
3-point $40 \mathrm{~mm}$ & 50 & LogNormal & Weibull & 11.12 \\
4 point 10-20 mm & 100 & LogNormal & Weibull & 26.00 \\
4 point 20-40mm & 50 & Normal & Weibull & 3.24 \\
Compression & 100 & Normal & LogNormal & 2.44 \\
\hline
\end{tabular}

\subsubsection{Influence of sample set size}

The parameters of the experimental data, which are estimated using maximum likelihood method, are considered to be the "true" parameters representing the distribution. These values were used to generate virtual strength data using Monte Carlo (MC) methods [21, 57]. This was done using Matlab ${ }^{\circledR}$.

Based on the parameter estimates in Table 5.3, virtual strength data was generated for a 4-point bending test $\left(L_{\text {out }}=20 \mathrm{~mm}\right)$, assuming a normal strength distribution. Out of the virtual strength data; sample sets are taken with a variable sample set size $N$. This is done 10.000 times, resulting in 10.000 sample sets of size $N$. These sample sets are used to determine new distribution parameters (mean strength and standard deviation) that describe this specific sample set of size $N$ shows the effect of sample set size on the mean strength (a) and standard deviation (b). The error bars represent the range of values observed in 10,000 MC simulations.

The observed mean and standard deviation in the 10.000 virtual sample sets varies substantially, especially for the lower sample set sizes. The variation on the observed mean would result in an over- or underestimation of the average strength of a fiber, however the variation of the observed standard deviation would result in a different shape of the probability distribution. At larger sample set sizes, the observed mean and standard deviation converge to the "true" parameters representing the distribution. Nonetheless, even at fair sample set sizes of $N=100$ the observed values differ significantly from the true parameters. This shows that the amount of samples measured is solely depending on what is economically/practically viable [21]. If one would use the parameters obtained by fitting 10 test specimens, Figure 5.6 shows the cumulative probability of failure a sample for two extreme cases, one where the lowest estimate 


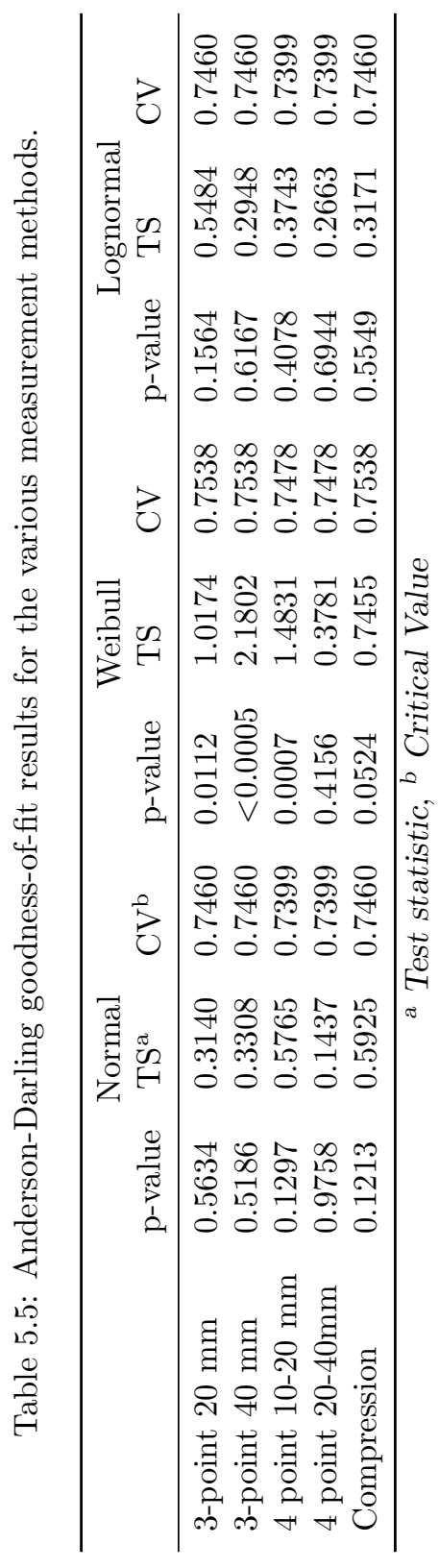




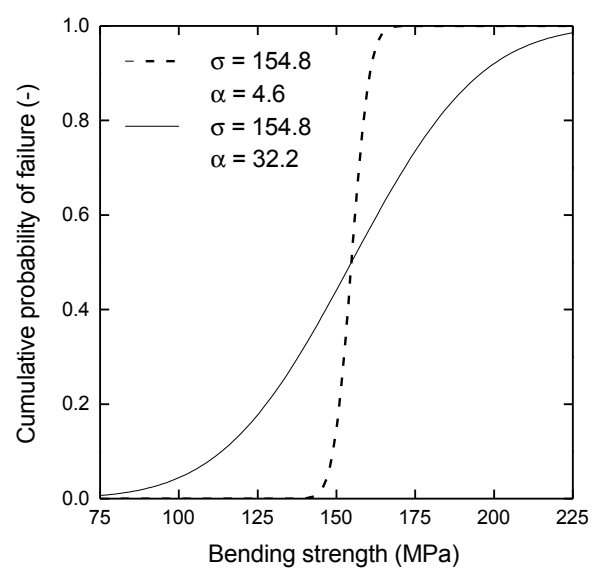

Figure 5.6: Cumulative probability of failure if the extreme values for the standard deviation are used to predict failure behaviour

for the standard deviation is used, whereas the second one uses the highest standard deviation estimate. The minimal and maximal values for the standard deviation are taken from Figure 5.5. For the mean strength the "true" mean strength is used. The large difference in standard deviation -which is a measure for the spread of the distribution- results in tremendous over- or underestimation of both the higher and lower end of the probability of failure. In the design of ceramic compounds an acceptable probability of failure is selected prior to design, depending on the specific application and possible consequences of failure. If one assumes an acceptable failure probability of 0.01 this would mean that at the corresponding stress, 1 out of 100 fibers is likely to fail. From Figure 5.6 it shows that with an allowable probability of failure of 0.01 , the stress would be $80 \mathrm{MPa}$ or $148 \mathrm{MPa}$, depending on the used standard deviation[24]. If one would erroneous estimate the type of distribution and its associated parameters; it would lead to wrong assumptions in design and possibly premature failure of, for example, a membrane module. This demonstrates that, especially for design, it is of key importance to measure sufficient samples in order to accurately describe the shape of the distribution. 


\subsection{Conclusion}

The mechanical strength of porous alumina hollow fiber membranes was measured using different measurement geometries. The resultant mechanical strength number is a direct result of the measurement method. Values obtained by 3point bending tests will be higher as compared to values obtained by 4-point bending test. Mechanical strength numbers obtained by diametrical compression are nearly a factor 2 lower as compared to the bending test numbers. All bending methods are suitable to characterize the mechanical strength of a ceramic hollow fiber, however to allow a direct comparison it is highly recommended to stick to span sizes and geometries mentioned in various standards, such as in the ASTM C1684-08 [18]. The utilized measurement method, span size and sample set size should be reported, combined with the mean strength and standard deviation. Only when these values are reported a comparison between different types of fibers can be made. The minimum required sample set size depends largely on the purpose of the measurements, in order to characterize the mechanical strength and to make a comparison to other fibers, 20 to 30 samples will give reasonable estimates of the average mechanical strength and standard deviation. If the values are used for design, detailed knowledge of the underlying probability distribution is required. In order to determine this, 100 or even more samples should be measured. Only at these large sample set sizes it is possible to determine the distribution type. Detailed knowledge about the distribution type and distribution parameters is required as the specific shape of this distribution largely affects the design strength. 


\subsection{References}

[1] I. Moch, Kirk-Othmer Encyclopedia of Chemical Technology, John Wiley \& Sons, Inc.

[2] X. Tan, N. Liu, B. Meng, S. Liu, Morphology control of the perovskite hollow fibre membranes for oxygen separation using different bore fluids, J. Membr. Sci. 378 (2011) 308-318.

[3] S. Liu, K. Li, R. Hughes, Preparation of porous aluminium oxide $\left(\mathrm{Al}_{2} \mathrm{O}_{3}\right)$ hollow fibre membranes by a combined phase-inversion and sintering method, Ceram. Int. 29 (2003) 875-881.

[4] D. Chen, M. Sixta, X. Zhang, L. De Jonghe, R. Ritchie, Role of the grainboundary phase on the elevated-temperature strength, toughness, fatigue and creep resistance of silicon carbide sintered with $\mathrm{Al}, \mathrm{B}$ and $\mathrm{C}$, Acta Mater. 48 (2000) 4599-4608.

[5] Z. Shi, Y. Zhang, C. Cai, C. Zhang, X. Gu, Preparation and characterization of $\alpha-\mathrm{Al}_{2} \mathrm{O}_{3}$ hollow fiber membranes with four-channel configuration, Ceram. Int. 41 (2015) 1333-1339.

[6] Y.-L. Elaine Fung, H. Wang, Investigation of reinforcement of porous alumina by nickel aluminate spinel for its use as ceramic membrane, J. Membr. Sci. 444 (2013) 252-258.

[7] M. W. J. Luiten-Olieman, M. J. T. Raaijmakers, L. Winnubst, T. C. Bor, M. Wessling, A. Nijmeijer, N. E. Benes, Towards a generic method for inorganic porous hollow fibers preparation with shrinkage-controlled small radial dimensions, applied to $\mathrm{Al}_{2} \mathrm{O}_{3}, \mathrm{Ni}, \mathrm{SiC}$, stainless steel, and YSZ, J. Membr. Sci. 407-408 (2012) 155-163.

[8] P. de Wit, E. J. Kappert, T. Lohaus, M. Wessling, A. Nijmeijer, N. E. Benes, Highly permeable and mechanically robust silicon carbide hollow fiber membranes, J. Membr. Sci. 475 (2015) 480-487.

[9] V. Middelkoop, H. Chen, B. Michielsen, M. Jacobs, G. Syvertsen-Wiig, M. Mertens, A. Buekenhoudt, F. Snijkers, Development and characterisation of dense lanthanum-based perovskite oxygen-separation capillary membranes for high-temperature applications, J. Membr. Sci. 468 (2014) $250-258$. 
[10] C. Buysse, A. Kovalevsky, F. Snijkers, A. Buekenhoudt, S. Mullens, J. Luyten, J. Kretzschmar, S. Lenaerts, Development, performance and stability of sulfur-free, macrovoid-free BSCF capillaries for high temperature oxygen separation from air, J. Membr. Sci. 372 (2011) 239-248.

[11] J. Smid, C. G. Avci, V. Günay, R. A. Terpstra, J. P. G. M. Van Eijk, Preparation and characterization of microporous ceramic hollow fibre membranes, J. Membr. Sci. 112 (1996) 85-90.

[12] I. Voigt, G. Fischer, P. Puhlfürß, M. Schleifenheimer, M. Stahn, $\mathrm{TiO}_{2}-\mathrm{NF}-$ membranes on capillary supports, Sep. Purif. Technol. 32 (2003) 87-91.

[13] M. Lee, Z. Wu, R. Wang, K. Li, Micro-structured alumina hollow fibre membranes: Potential applications in wastewater treatment, J. Membr. Sci. 461 (2014) 39-48.

[14] T. Byun, E. Lara-Curzio, R. Lowden, L. Snead, Y. Katoh, Miniaturized fracture stress tests for thin-walled tubular SiC specimens, J. Nucl. Mater. 367-370 (2007) 653-658.

[15] S. A. Rodrigues, J. L. Ferracane, A. Della Bona, Flexural strength and Weibull analysis of a microhybrid and a nanofill composite evaluated by 3- and 4-point bending tests., Dent. Mater. 24 (2008) 426-31.

[16] F. Mujika, On the difference between flexural moduli obtained by threepoint and four-point bending tests, Polym. Test. 25 (2006) 214-220.

[17] G. Quinn, R. Morrell, Design data for engineering ceramics: a review of the flexure test, J. Am. Ceram. Soc. 74 (1991).

[18] ASTM, C1684-08 Standard Test Method for Flexural Strength of Advanced Ceramics at Ambient Temperature, ASTM International, West Conshohocken, PA (2002) 1-21.

[19] P. Chitchumnong, S. Brooks, G. Stafford, Comparison of three-and fourpoint flexural strength testing of denture-base polymers, Dent. Mater. (1989) 3-6.

[20] C. Lu, A reassessment of the strength distributions of advanced ceramics, J. Aust. Cer. Soc. 44 (2008) 38-41.

[21] S. Nohut, Influence of sample size on strength distribution of advanced ceramics, Ceram. Int. 40 (2014) 4285-4295. 
[22] ASTM, C1239-13 Standard Practice for Reporting Uniaxial Strength Data and Estimating Weibull Distribution Parameters for Advanced Ceramics, ASTM International, West Conshohocken, PA (2014) 1-18.

[23] T. Hoshide, H. Sugiyama, Numerical Analysis of Sample-Size Effect on Strength of Alumina, J. Mater. Eng. Perform. 22 (2012) 1-8.

[24] R. Danzer, On the relationship between ceramic strength and the requirements for mechanical design, J. Eur. Ceram. Soc. 34 (2014) 3435-3460.

[25] R. Danzer, A general strength distribution function for brittle materials, J. Eur. Ceram. Soc. 10 (1992) 461-472.

[26] R. Danzer, P. Supancic, J. Pascual, T. Lube, Fracture statistics of ceramics: Weibull statistics and deviations from Weibull statistics, Eng. Fract. Mech. 74 (2007) 2919-2932.

[27] C. A. Klein, Characteristic strength, Weibull modulus, and failure probability of fused silica glass, Opt. Eng. 48 (2009) 113401.

[28] W. Weibull, A statistical distribution function of wide applicability, Int. J. Appl. Mech. 18 (1951) 293-297.

[29] G. D. Quinn, Weibull Effective Volumes and Surfaces for Cylindrical Rods Loaded in Flexure, J. Am. Ceram. Soc. 86 (2003) 475-479.

[30] R. Jain, J. Lock, S. Duffy, Effective area and effective volume calculations for ceramic test specimens, in: Volume 1: Aircraft Engine; Ceramics; Coal, Biomass and Alternative Fuels; Controls, Diagnostics and Instrumentation; Education; Electric Power; Awards and Honors, volume 1, ASME Turbo Expo 2009: Power for Land, Sea, and Air.

[31] DIN, Advanced technical ceramics - Mechanical properties of monolithic ceramics at room temperature - Part 5: Statistical analysis, 2007.

[32] R. Danzer, Some notes on the correlation between fracture and defect statistics: Are Weibull statistics valid for very small specimens?, J. Eur. Ceram. Soc. 26 (2006) 3043-3049.

[33] C. Lu, R. Danzer, F. Fischer, Fracture statistics of brittle materials: Weibull or normal distribution, Physical Review E 65 (2002) 067102. 
[34] F. Chen, R. Mourhatch, T. T. Tsotsis, M. Sahimi, Experimental studies and computer simulation of the preparation of nanoporous silicon-carbide membranes by chemical-vapor infiltration/chemical-vapor deposition techniques, Chem. Eng. Sci. 63 (2008) 1460-1470.

[35] B. Basu, D. Tiwari, D. Kundu, R. Prasad, Is Weibull distribution the most appropriate statistical strength distribution for brittle materials?, Ceram. Int. 35 (2009) 237-246.

[36] A. Zimmermann, J. Rödel, Fracture Statistics Based on Pore/Grain-Size Interaction, J. Am. Ceram. Soc. 82 (2004) 2279-2281.

[37] R. H. Doremus, Fracture statistics: A comparison of the normal, Weibull, and Type I extreme value distributions, J. Appl. Phys. 54 (1983) 193.

[38] B. Stawarczyk, M. Ozcan, C. H. F. Hämmerle, M. Roos, The fracture load and failure types of veneered anterior zirconia crowns: an analysis of normal and Weibull distribution of complete and censored data., Dent. Mater. 28 (2012) 478-87.

[39] E. Limpert, W. a. Stahel, M. Abbt, Log-normal Distributions across the Sciences: Keys and Clues, Bioscience 51 (2001) 341.

[40] H. Akaike, A new look at the statistical model identification, IEEE Trans. Automat. Contr. (1974).

[41] J. Frank, Electron Tomography: Methods for Three-Dimensional Visualization of Structures in the Cell, volume 40, 2nd edition, 2006.

[42] N. M. Razali, Y. B. Wah, Power comparisons of Shapiro-Wilk, Kolmogorov-Smirnov, Lilliefors and Anderson-Darling tests, J. Stat. Mod. Ana. 2 (2011) 21-33.

[43] T. Anderson, D. Darling, Asymptotic theory of certain goodness of fit criteria based on stochastic processes, Ann. Appl. Stat. 23 (1952) 193212.

[44] M. Stephens, Asymptotic results for goodness-of-fit statistics with unknown parameters, Ann. Stat. 4 (1976) 357-369.

[45] J. G. Bush, B. W. Woodruff, A. H. Moore, E. J. Dunne, Modified cramervon mises and anderson-darling tests for weibull distributions with unknown location and scale parameters, Communications in Statistics Theory and Methods 12 (1983) 2465-2476. 
[46] M. Luiten-Olieman, L. Winnubst, A. Nijmeijer, M. Wessling, N. E. Benes, Porous stainless steel hollow fiber membranes via dry-wet spinning, J. Membr. Sci. 370 (2011) 124-130.

[47] S. Husain, W. J. Koros, Macrovoids in Hybrid Organic/Inorganic Hollow Fiber Membranes, Ind. Eng. Chem. Res. 48 (2009) 2372-2379.

[48] X. Zhang, D. K. Wang, D. R. S. Lopez, J. C. Diniz da Costa, Fabrication of nanostructured $\mathrm{TiO}_{2}$ hollow fiber photocatalytic membrane and application for wastewater treatment, Chem. Eng. J. 236 (2014) 314-322.

[49] Z. Wu, R. Faiz, T. Li, B. F. Kingsbury, K. Li, A controlled sintering process for more permeable ceramic hollow fibre membranes, J. Membr. Sci. 446 (2013) 286-293.

[50] D. J. Green, An introduction to the mechanical properties of ceramics, Cambridge University Press, 1998.

[51] G. de With, Note on the use of the diametral compression test for the strength measurement of ceramics, J. Mater. Sci. Lett. 3 (1984) 6-8.

[52] R. Sedlacek, F. a. Halden, Method for Tensile Testing of Brittle Materials, Rev. Sci. Instrum. 33 (1962) 298.

[53] J. de Jong, N. Benes, G. Koops, M. Wessling, Towards single step production of multi-layer inorganic hollow fibers, J. Membr. Sci. 239 (2004) $265-269$.

[54] P. de Wit, Raw data, 2015.

[55] S.-D. Pang, Z. P. Bažant, J.-L. Le, Statistics of strength of ceramics: finite weakest-link model and necessity of zero threshold, Int. J. Fract. 154 (2009) 131-145.

[56] E. L. Kaplan, P. Meier, Nonparametric Estimation from Incomplete Observations, J. Am. Stat. Assoc. 53 (1958) 457-481.

[57] M. Ambrožič, Monte Carlo simulation of Weibull distribution of ceramic strength values, in: Society for Experimental Mechanics, volume 11, Society for Experimental Mechanics Inc, 2008. 


\section{Chapter 6}

\section{The mechanical strength of inorganic porous hollow fibers: A comparison between production methods}

This chapter is adapted from:

P. de Wit, F.S. van Daalen and N.E. Benes, The effect of the production method on the mechanical strength of an alumina porous hollow fiber, 2017, J. Eur. Ceram. Soc. 37 (10), pp 3453-3459

doi: 10.1016/j.jeurceramsoc.2017.03.062 


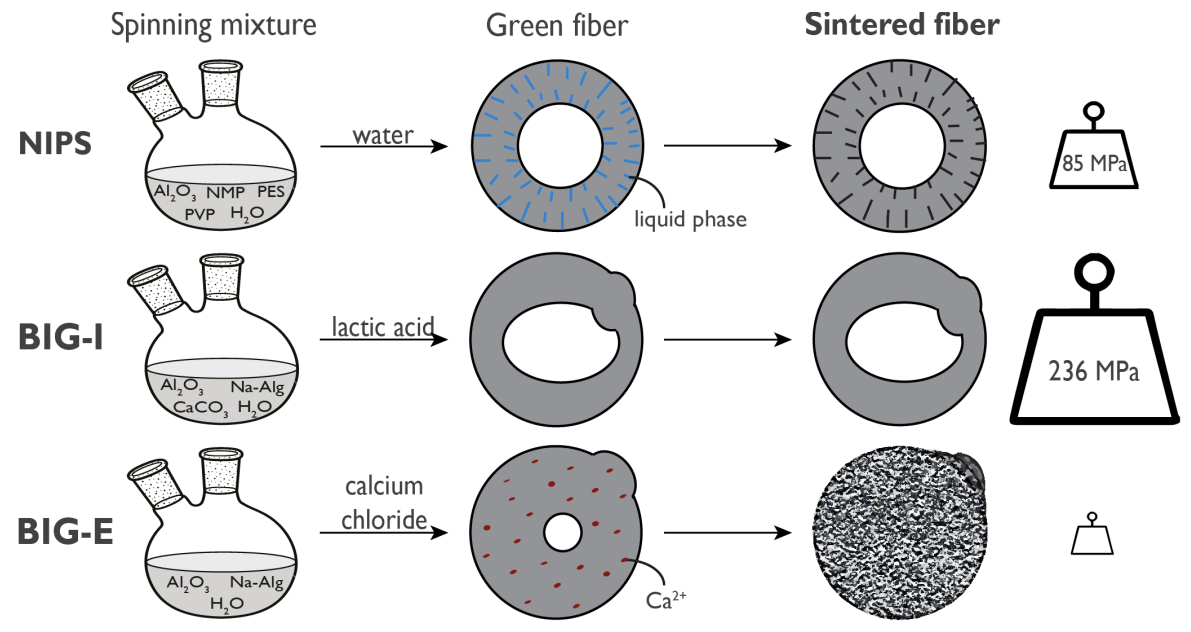

\section{Abstract}

The mechanical strength of inorganic porous hollow fibers is often discussed and measured and it impedes widespread application of these fibers. We show how the production method can alter the mechanical properties of the hollow fibers. Three different production methods are compared; non-solvent induced phase separation (NIPS), bio-ionic gelation with an internal multivalent ion source (BIG-I) and gelation with an external ion source (BIG-E). Fibers prepared using BIG-I seem to have a higher strength as compared to fibers prepared using NIPS or BIG-E. To predict failure behavior, statistical models are fitted to the strength data. All production methods result in a strength distribution that follows the Weibull model, in which failure occurs at the weakest-link. Fibers prepared by BIG-I methods are less reliable as compared to NIPS fibers. This is due to surface deformations present in the wall of the fibers, which can act as a weak link. If the strength data is re-analyzed with the surface-deformed fibers excluded, the BIG-I fibers do not longer follow the Weibull model, but start to follow a normal distribution. This shows that BIG-I based fibers have great potential with respect to their mechanical strength. At this moment, their strength is limited by deformations and is not limited by inherent macrovoids as is the case for the NIPS fibers. 


\subsection{Introduction}

Inorganic porous hollow fibers receive increasing attention due to their high surface to volume ratio combined with unique features such as chemical and thermal resistance, their porous structure or their catalytic and electrical properties [1]. Due to these properties, these fibers are used for applications such as; membrane separation in challenging environments [2-5], integrated electrode and/or catalyst [6-8], or as a micro reactor [9-11].

An important factor impeding the use of these fibers is their mechanical strength. The design stress used depends strongly on the measurement method and subsequent statistical analysis, as was recently demonstrated by our group [12]. The mechanical strength of porous ceramics often follows a Weibull model, which is based on a weakest-link hypothesis [13]. If a specimen fails, it is assumed to fail at its weakest link and by eliminating such a weaker link, one could improve the mechanical strength of the specimen $[14,15]$. Inorganic porous hollow fibers have many features that could be regarded as a weak link, examples are pores, macrovoids and surface scratches or deformations $[15,16]$.

When the amount of defects increases, the fibers might deviate from the weakest link theory, for example when defects interact and grow into larger defects, or when the amount of initial defects are large (such as pores). In this case the fiber starts to follow a normal distribution [17].

Various production methods are used to fabricate inorganic porous hollow fibers. The most common method is based on non-solvent induced phase separation, which results in a characteristic microstructure. This microstructure is the result of the phase inversion process, where polymer lean and polymer rich phases form, resulting in large macrovoids after sintering. Recently, methods based on internal [18] or external [19] gelation of a sodium alginate were used to fabricate inorganic porous hollow fibers. The alginate based method circumvents the formation of macrovoids completely, thus resulting in a different microstructure.

In this chapter, it is shown that the three different production methods result in different microstructures and how the three different microstructures affect the mechanical strength of the fibers. We also include a detailed statistical analysis of the underlying failure model and analyze the implications of these models for system design. 


\subsection{Experimental}

Alumina hollow fibers were prepared by non-solvent induced phase separation (NIPS) using a mixture of AKP30 $\alpha-\mathrm{Al}_{2} \mathrm{O}_{3}$ powder $\left(\mathrm{Al}_{2} \mathrm{O}_{3}\right.$, particle size of $0.3 \mu \mathrm{m}$, Sumitomo Chemicals Co. LTD. Japan), Polyethersulfone (PES, Ultrason, 6020P, BASF, Germany) and N-methylpyrrolidone (NMP, $99.5 \mathrm{wt} \%$, Sigma Aldrich, The Netherlands). Polyvinylpyrrolidone $\left(M_{w} 1,300,000\right.$, Sigma Aldrich, The Netherlands) was used as viscosity enhancer and de-ionized water (>18.2 $\mathrm{M} \Omega \mathrm{cm}^{-1}$, Milli-Q Advantage A10, Millipore) was used as non-solvent. Prior to use, PES and AKP-30 were dried overnight at $120^{\circ} \mathrm{C}$; all other chemicals were used as received. The fibers were prepared using a standard method as described by Luiten-olieman et al.. The recipe for fibers prepared using internal bio-ionic gelation (BIG-I) is based on earlier work [18]. A mixture of de-ionized water, AKP-30 $\alpha-\mathrm{Al}_{2} \mathrm{O}_{3}$ powder, $\mathrm{CaCO}_{3}$ (Sigma Aldrich, The Netherlands) and sodium alginate (From brown algae, medium viscosity, Sigma Aldrich, The Netherlands) is spun into a coagulation bath consisting of lactic acid (Sigma Aldrich, The Netherlands). The $\mathrm{pH}$ is adjusted to be below 1.5. Fibers prepared via external bio-ionic gelation (BIG-E) were based on the work of Shukla et al., in which a mixture of sodium alginate, AKP-30 $\alpha-\mathrm{Al}_{2} \mathrm{O}_{3}$ powder and demineralized water was spun into a coagulation bath of $\mathrm{CaCl}_{2} \quad 6 \mathrm{H}_{2} \mathrm{O}$ (Sigma Aldrich, The Netherlands). The full mixture composition and spinning conditions for all three recipes are given in Table 6.1

\subsubsection{Thermal treatment}

After drying under ambient conditions, the fibers were thermally treated under air $(100 \mathrm{~mL} / \mathrm{min})$ using a tubular furnace (STF16/610, Carbolite). The fibers prepared by NIPS were thermally treated at $300^{\circ} \mathrm{C}$ for 1 hour and at $1400^{\circ} \mathrm{C}$ for 2 hours. The fibers prepared by the two bio-ionic gelation methods were thermally treated at $110^{\circ} \mathrm{C}$ for 1 hour and at $1400^{\circ} \mathrm{C}$ for 2 hours. All heating and cooling rates were $5{ }^{\circ} \mathrm{Cmin}^{-1}$. After thermal treatment, the fibers were cut to the desired length required for mechanical testing. For each production method, various sintering batches were prepared from one single spinning batch.

\subsubsection{Mechanical testing}

The 4-point bending strength of fiber was measured at room temperature (20 \pm $3{ }^{\circ} \mathrm{C}$ ) and a relative humidity of $60 \% \pm 20 \%$ using a $5564 \mathrm{~A}$ mechanical testing bench (Instron) equipped with a $100 \mathrm{~N}$ load cell. All testing was carried out 
Table 6.1: Spinning conditions

\begin{tabular}{llll}
\hline Parameter & NIPS & BIG-I & BIG-E \\
\hline PES & $10.0 \%$ & - & - \\
NMP & $38.9 \%$ & - & - \\
PVP K-95 & $1.0 \%$ & - & - \\
AKP-30 & $49.1 \%$ & $12.4 \%$ & $12.6 \%$ \\
Na-Alg & - & $5.05 \%$ & $5.02 \%$ \\
CaCO & - & $0.15 \%$ & - \\
Water & $1.0 \%$ & $82.4 \%$ & $82.4 \%$ \\
Bore Liquid & $\mathrm{H}_{2} \mathrm{O}$ & $\mathrm{LA}^{*}$ & $\mathrm{CaCl}_{2}(10 \%)$ \\
Coagulation bath & $\mathrm{H}_{2} \mathrm{O}$ & $\mathrm{LA}^{*}$ & $\mathrm{CaCl}_{2}(10 \%)$ \\
Extrusion pressure & $2 \mathrm{bar}$ & $2 \mathrm{bar}^{*}$ & $2 \mathrm{bar}$ \\
Air gap & $3 \mathrm{~cm}$ & $1.5 \mathrm{~cm}$ & $1.5 \mathrm{~cm}^{-1}$ \\
Bore liquid flow rate & $7 \mathrm{~mL} \mathrm{~min}{ }^{-1}$ & $14 \mathrm{~mL} \mathrm{~min}$ & $17 \mathrm{~mL} \mathrm{~min}^{-1}$ \\
Outer diameter spinneret & $2.0 \mathrm{~mm}$ & $2.0 \mathrm{~mm}$ & $2.0 \mathrm{~mm}$ \\
Inner diameter spinneret & $0.8 \mathrm{~mm}$ & $0.8 \mathrm{~mm}$ & $0.8 \mathrm{~mm}^{-1}$ \\
Drying after spinning & $>24 \mathrm{~h}$ & $>24 \mathrm{~h}$ & $>24 \mathrm{~h}$ \\
\hline
\end{tabular}

${ }^{*}$ Lactic acid with a $\mathrm{pH}$ of 1.41 .

according to ASTM C1684-08 [21], which has been adapted as follows; 1) the rollers are not free to move laterally, 2) a tube is used instead of a rod, and 3) the material is porous instead of dense. The outer and inner span are 20 and $10 \mathrm{~mm}$ respectively. All fibers were tested as-fabricated and no surface treatment was carried out on the fibers. The load was measured at a constant compression rate of $0.5 \mathrm{~mm} \mathrm{~min}^{-1}$ and the maximum load at fracture was converted in the bending strength using:

$$
\sigma_{f, j}=\frac{16 F_{j} K d_{o u t, j}}{\pi\left(d_{o u t, j}^{4}-d_{i n, j}^{4}\right)}
$$

here, $F_{j}$ is the force at fracture for specimen $j, K$ being half the distance between the inner and outer roller $\left(K=0.5\left(L_{\text {out }}-L_{i n}\right)\right)$, and $d_{\text {out }, j}$ and $d_{i n, j}$ the outer and inner diameter of specimen $j$.

This equation is modified for elliptical fibers when the ratio of the major to minor diameter is less than 0.95 [21]. In that case, either the minor or the major axis of the sample is aligned with the direction of the load. In the equation below, the subscript $h$ and $v$ refer to the horizontal and vertical axis. 


$$
\sigma_{f, j}=\frac{16 F_{j} K d_{o u t, h, j}}{\pi\left(d_{\text {out }, h, j}^{2} d_{\text {out }, v, j}^{2}-d_{i n, h, j}^{2} d_{i n, v, j}^{2}\right)}
$$

The full details of the mechanical strength measurements and subsequent calculations is described in detail elsewhere [12, 21, 22].

\subsubsection{Fiber characterization}

The morphology of the fibers is investigated using a SM-6010 (JEOL) scanning electron microscope equipped with an EDS detector. Cross-sections of fibers were sputtered with a $5 \mathrm{~nm}$ chromium coating (Quorum Q150T ES). A Zeiss Axiovert 40 MAT optical microscope was used to analyze the roundness, inner and outer diameter of the fibers prepared using BIG-I. The pore size and porosity of the fibers were measured by mercury intrusion porosimetry with a Poremaster PM-33 (Quantachrome Instruments).

\subsection{Data analysis}

Three different probability distributions were used to describe the measured strength data. The data was fitted using a normal, lognormal and Weibull distribution, the rationale behind these specific distributions is based on other work $[12,17,23,24]$. In short; the Weibull distribution is often used for brittle ceramics and is based on the weakest link principle [13, 25]. The normal and lognormal distributions are often proposed for, for example, porous ceramics where defect interactions can occur. In that case the weakest-link assumption is not long valid $[15,16,26-28]$.

These three distributions all have 2 parameters that describe the shape and location of the distribution. The parameters describing the distributions were estimated using Matlabs fitdist function, which fits the Weibull function using maximum likelihood methods, whereas for the normal and lognormal distributions the parameter is the square root of the estimate of the variance or the square root of the log of the variance respectively. Based on the parameter estimates, a cumulative distribution function is plotted together with the empirical cumulative distribution function (using Matlabs ecdf) to allow visual comparison of the measured data and the proposed distribution.

An Anderson-darling (AD) test is used to test if the data fits any of the proposed distributions. The AD-test can be used to assess whether the data is likely to originate from a given distribution, but the downside is that it cannot 
be used to distinguish which distributions gives the best fit. This is assessed using the Akaike Information Criterion (AIC)[29]

$$
A I C=-2 \ln (\mathcal{L})+2 k
$$

The comparison of the three different production methods is done using a Mann-Whitney test, which is a non-parametric test of the null hypothesis that states that two samples come from the same population against an alternative hypothesis that states that a particular population tends to have larger values than the other. In addition to the Mann-Whitney test, where the two sample sets are normally distributed, a one sided two-sample $\mathrm{T}$ test is used. In order to assess the effect of different sintering batches on the mechanical strength, a Kruskal-Wallis H-test is used. In this non-parametric test, the null hypothesis is that the medians of all sintering groups are equal, whereas the alternative hypothesis is that at least one of the medians differs significantly from the others. For all tests, the significance threshold was set at 0.05 .

The roundness of the fibers was assessed by measuring the inner and outer diameter of the fiber multiple times. For NIPS fibers this was done using a digital caliper (Mitutoyo CD-15CPX, $\Delta d \pm 0.02 \mathrm{~mm}$ ), for BIG-I fibers this was done via image analysis of optical microscopy images (See full details and script in the supplementary information). The maximum and minimal measured diameter of the inside and the outside of the fiber are used to compute the inner and outer roundness respectively. A fiber was considered elliptical when the one of the ratios (inner or outer) was more than 0.95 .

\subsection{Results and discussion}

Figure 6.1 displays scanning electron micrographs of the fibers prepared via the various production methods. Figure $1 \mathrm{~A}$ and $\mathrm{B}$ show the fiber prepared by NIPS, showing a good roundness (Average inner ratio: $0.95 \pm 0.02$, outer ratio $0.99 \pm 0.06)$ and a microstructure which is very well known for this type of fiber. An a-symmetrical wall is obtained with large macrovoids near the inner and outer wall. The center of the wall consists of an approximately $80 \mu \mathrm{m}$ thick sponge like structure with an total wall thickness of approximately $300 \mu \mathrm{m}$. The outer diameter of the fiber is $1.5 \mathrm{~mm}$. All fibers prepared using NIPS were round and no surface deformations were observed.

Figure $6.1 \mathrm{~B}$ and $\mathrm{C}$ show the fiber prepared by internal bio-ionic gelation. It is shown that the fiber has a lower roundness compared to the NIPS fiber (Average inner ratio: $0.85 \pm 0.24$ ), outer ratio: $0.91 \pm 0.02$ ). A densely packed 
porous wall was obtained and due to the nature of the bio-ionic gelation process, no macrovoids were obtained $[18,19]$. The fiber has a thin $(\sim 240 \mu \mathrm{m})$ wall and an outer diameter of approximately $1 \mathrm{~mm}$. Overall, the total spinning batch had pieces of fiber that were round and homogenous, but also deformations of the inner and outer wall were observed, as Figure 5 displays. These deformations are likely to originate from instabilities during spinning and drying. Further optimization of the spinning process, including the drying step, is likely to remove these deformations. The fibers with surface deformations are included in the mechanical strength measurements.

In Figure 6.1D and $\mathrm{E}$ the result of the fibers prepared by external gelation are shown. Figure 6.1D shows that the obtained fiber is not hollow and that a very open, porous structure was obtained on the lumen side of the fiber. The detailed image of the microstructure reveals a network of sintered $\mathrm{Al}_{2} \mathrm{O}_{3}$ grains with large voids. Because of the open porous structure, we were unable to measure the mechanical strength of these fibers. This indicates the mechanical strength is very low. In addition, SEM-EDX measurements show calcium inclusions in the fiber originating from the very high calcium concentration of the gelation bath. Calcium will strongly affect $\mathrm{Al}_{2} \mathrm{O}_{3}$ sintering [30, 31], hence lowering the mechanical strength. Shukla et al. also prepared fibers via this method, but a higher sintering temperature $\left(>1500^{\circ} \mathrm{C}\right)$ was used to fully sinter these fibers [19]. In this study the sintering temperature was not adjusted to allow a fair comparison to the other production methods.

The prepared fibers are further characterized in terms of porosity and pore size, a summary of these results is given in Table 5, whereas the full details can be found in the supplementary information. The fibers prepared via the external bio-ionic gelation method are excluded from further analysis due to their low mechanical strength.

\subsubsection{Mechanical strength}

Figure 6.2 shows the mechanical strength for the two main methods; 228 pieces of fibers prepared by NIPS and 222 fiber pieces prepared by BIG-I. In this plot, the horizontal line in the box represents the median value, whereas the box itself represents the interquartile range (25th till 75 th percentile). The error bar represents the first and fourth quartile, the plus signs represent extreme values. All fibers per production method originate from one single spinning batch. These batches were thermally treated in three different sintering batches due to furnace size limitations. In order to verify that there is no significant influence on the mechanical strength and strength distribution by using different sin- 


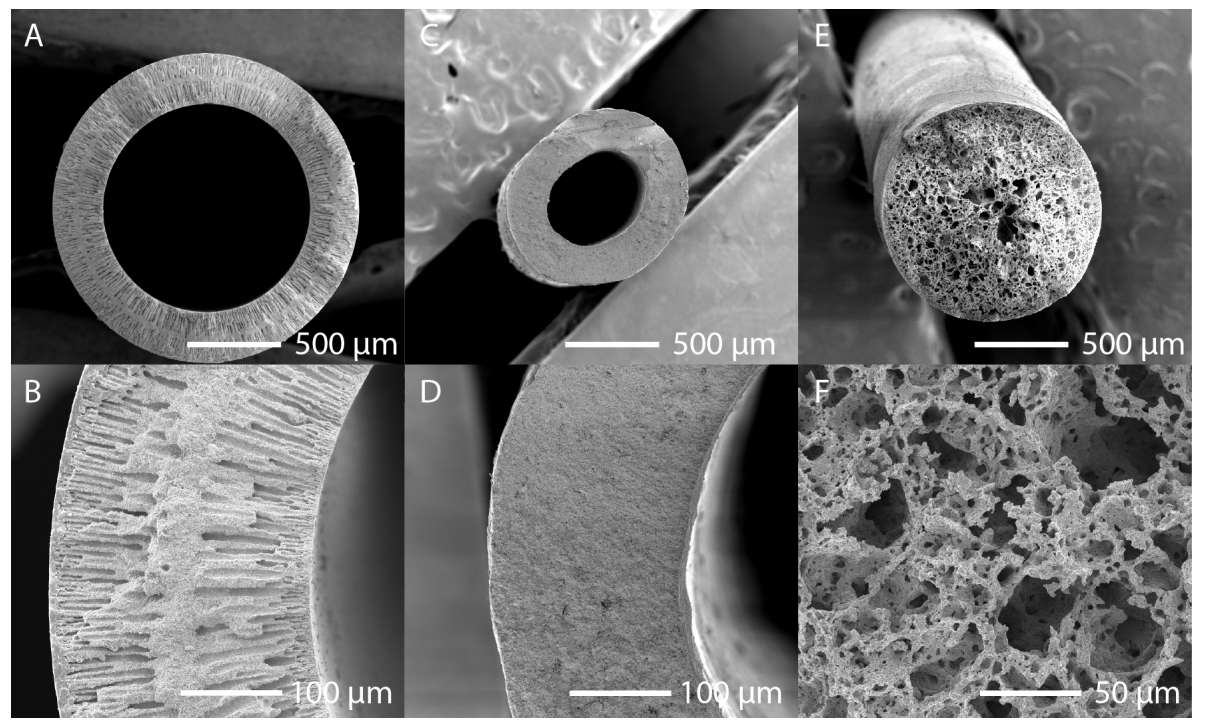

Figure 6.1: Post-fracture scanning electron micrograph of; A and B: NIPS based fiber showing its roundness and distinct microstructure, $\mathrm{C}$ and D: BIG-I fiber showing the non-roundness and macrovoid free wall, E and F: A nonhollow BIG-E fiber with large voids throughout the structure due to insufficient sintering and the presence of calcium.

tering batches, a non-parametric Kruskal-Wallis H-test was conducted. There was no significant difference between sintering batches (see the Supplementary information).

Figure 6.2 shows that there is a large difference between the median strength of the fibers prepared by NIPS (82.42 MPa) and BIG-I (215.01 MPa); the distribution of the fibers prepared by the two methods differ significantly (MannWhitney $U=523, P<0.001)$. In general, fibers prepared using BIG-I tend to be stronger but there is a large spread of the strength data, having a range of 73.4 to $384.5 \mathrm{MPa}$, whereas the range for the NIPS fibers is 52.7 to $103.9 \mathrm{MPa}$. This large spread might be the result of the wall defects that were described earlier. A large part of the BIG-I fibers show a homogenous and round structure whereas some parts have a large deformation on the outer wall, which might result in a lower or higher strength, thus creating a larger spread of the strength data. 


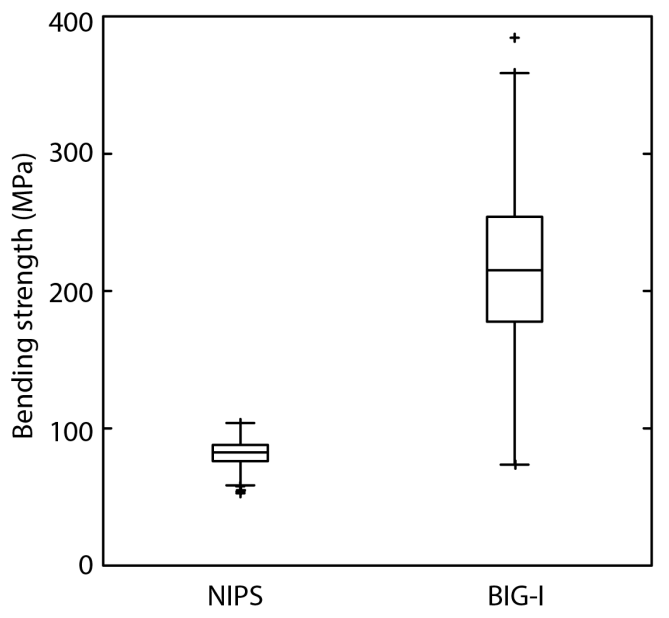

Figure 6.2: A box plot showing the main difference in mechanical strength for the two main production methods, NIPS and BIG-I. Note that the strength of fibers prepared using BIG-E is omitted as these fibers were too weak to measure.

\section{Statistical analysis NIPS fibers}

Figure 6.3 displays the empirical cumulative probability of failure for the fibers prepared using non-solvent induced phase separation with a normal, lognormal and Weibull distribution fitted to the measured strength data. As can be seen from Figure 6.3, the log-normal and normal distribution seem to deviate from the data, especially at the lower and upper end of the curve, whereas the Weibull distribution seems to have a reasonable fit.

Table 6.2 shows the results of the Anderson-Darling (AD) goodness-of-fit test and the Akaike Information Criterion (AIC). The AD-test has the null-hypothesis that the data comes from the given distribution, which results in the rejection of the normal and log-normal distribution as possible distributions that describe the data. The AIC values show the same outcome, the Weibull distribution has the lowest AIC value with a difference larger than 2 as compared to the other distributions [32, 33]. 


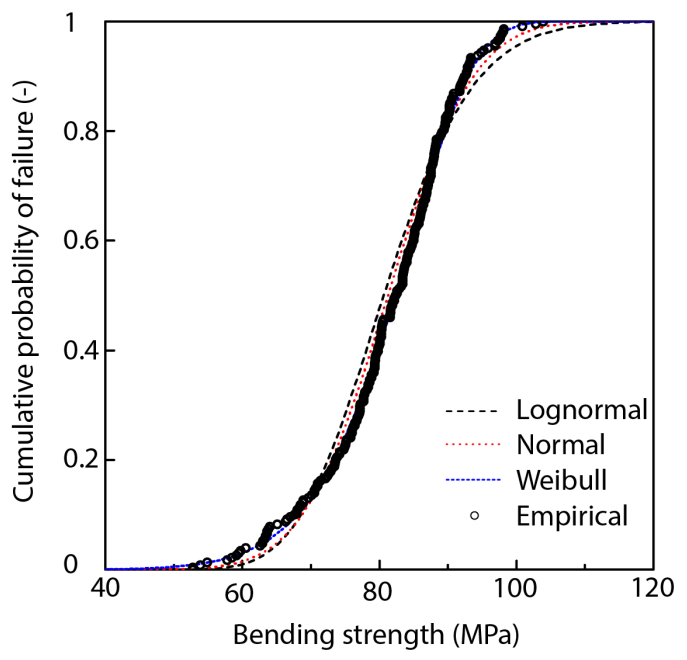

Figure 6.3: Empirical cumulative probability of failure for the NIPS prepared fibers, combined with the cumulative distribution function (cdf) for the normal, lognormal and the Weibull distribution. $N=228$.

Table 6.2: Goodness of fit test results for NIPS fibers, $N=228$.

\begin{tabular}{lrlllr}
\hline & \multicolumn{3}{c}{ Anderson-Darling } & \multicolumn{2}{c}{ AIC } \\
& P-value & $\mathrm{TS}^{a}$ & $\mathrm{CV}^{b}$ & $\mathrm{TS}^{a}$ & $\Delta$ AIC \\
\hline Normal & $<0.0005$ & 1.5783 & 0.7493 & 1689.1 & 11.6 \\
Weibull & 0.6730 & 0.2782 & 0.7587 & 1677.4 & 0 \\
Lognormal & $<0.0005$ & 3.3370 & 0.7493 & 1709.1 & 31.6 \\
\hline
\end{tabular}

${ }^{\mathrm{a}}$ Test statistic ${ }^{\mathrm{b}}$ Critical Value

The Weibull distribution [13] is the general applied distribution for strength characterization of brittle ceramics with a low amount of defects, whereas the lognormal distribution is proposed for porous ceramic with interacting defects [17]. Despite the porous nature of these NIPS, they still seem to follow the weakest-link principle described by Weibull. This means that the strength is determined by the weakest link, in this case the largest void. Hence, having 
larger macrovoids would reduce the mechanical strength of these fibers and eliminating these larger macrovoids could result in an improvement in mechanical strength.

\section{Statistical analysis BIG-I fibers}

The empirical cumulative distribution function (cdf) for the BIG-I fibers is shown in Figure 6.4. Here, the log-normal distribution shows the poorest fit to the measured data, but the normal and Weibull distribution seem to describe the data accurately.

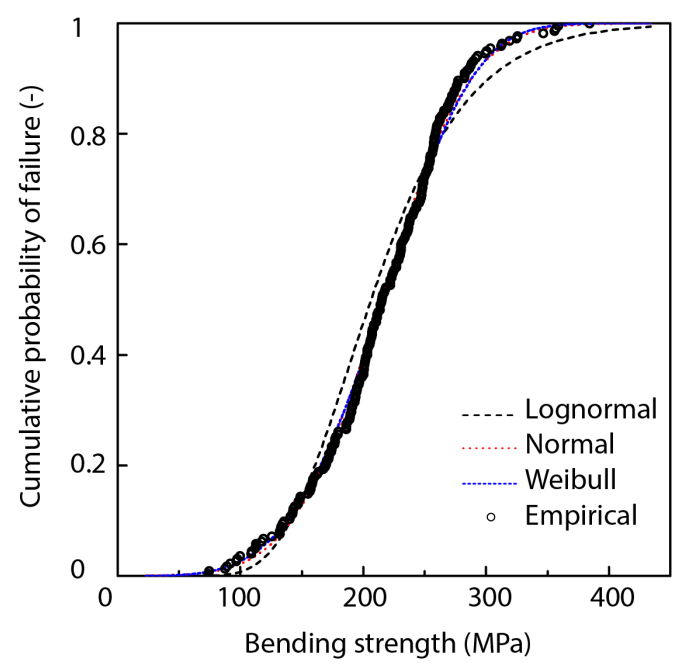

Figure 6.4: Empirical cumulative probability of failure for the BIG-I prepared fibers, combined with the cdfs for the normal, lognormal and the Weibull distribution. $N=222$.

This is also seen in the goodness-of-fit tests that are shown in Table 6.3, there the Anderson-Darling test rejects the lognormal distribution, but not the normal or Weibull distribution. Also the AIC is not able to distinguish between the normal or Weibull distribution.

During the bending tests large surface deformations are observed. If one would omit the 47 samples with a large surface deformation which were detected using 
Table 6.3: Goodness of fit test results for BIG-I fibers, $N=222$.

\begin{tabular}{lccccr}
\hline & \multicolumn{3}{c}{ Anderson-Darling } & \multicolumn{2}{c}{ AIC } \\
& P-value & $\mathrm{TS}^{a}$ & $\mathrm{CV}^{b}$ & $\mathrm{TS}^{a}$ & $\Delta$ AIC \\
\hline Normal & 0.1711 & 0.5349 & 0.7493 & 2428.7 & 0 \\
Weibull & 0.1968 & 0.5156 & 0.7586 & 2429.1 & 0.4 \\
Lognormal & $<0.0005$ & 3.7187 & 0.7493 & 2461.5 & 32.7 \\
\hline a Test statistic & ${ }^{\mathrm{b}}$ Critical Value & &
\end{tabular}

image analysis on post-fracture optical microscopy images (see the supplementary dataset for optical microscope images), the results change significantly. Figure 6.5 displays a box-plot of the mechanical strength of BIG-I fibers showing the difference for samples with or without a large surface deformation. The fibers with a flaw at the surface $(N=52$, Mean=161.9, $\mathrm{SD}=61.6)$ have a significantly lower bending strength as compared to the fibers where no visible deformation $(N=175$, Mean $=226.8, \mathrm{SD}=50.6)$ was present at the fracture site (One sided two-sample T test, $t(225)=7.7093, P<0.001$ ). This suggests that the large deformations at the outer side of the wall are associated with the lower mechanical strength values. Eliminating the deformed samples results in a dataset which has a smaller range.

Re-fitting the data with the surface deformed samples excluded, shows that the Weibull model is no longer the model of choice. Table 6.4 shows the results of the goodness-of-fit tests with the deformed samples excluded, both the AD-test and the AIC suggest that the data are normally distributed.

Table 6.4: Goodness of fit test results for BIG-I fibers, excluding fibers that where marked as having surface deformations, $N=175$.

\begin{tabular}{lrlllr}
\hline & \multicolumn{3}{c}{ Anderson-Darling } & \multicolumn{2}{c}{ AIC } \\
& P-value & $\mathrm{TS}^{a}$ & $\mathrm{CV}^{b}$ & $\mathrm{TS}^{a}$ & $\Delta \mathrm{AIC}$ \\
\hline Normal & 0.7065 & 0.2646 & 0.7485 & 1872.9 & 0 \\
Weibull & 0.0226 & 0.8982 & 0.7573 & 1881.0 & 8.11 \\
Lognormal & 0.0243 & 0.8741 & 0.7485 & 1877.0 & 4.11 \\
\hline
\end{tabular}

a Test statistic ${ }^{\mathrm{b}}$ Critical Value 


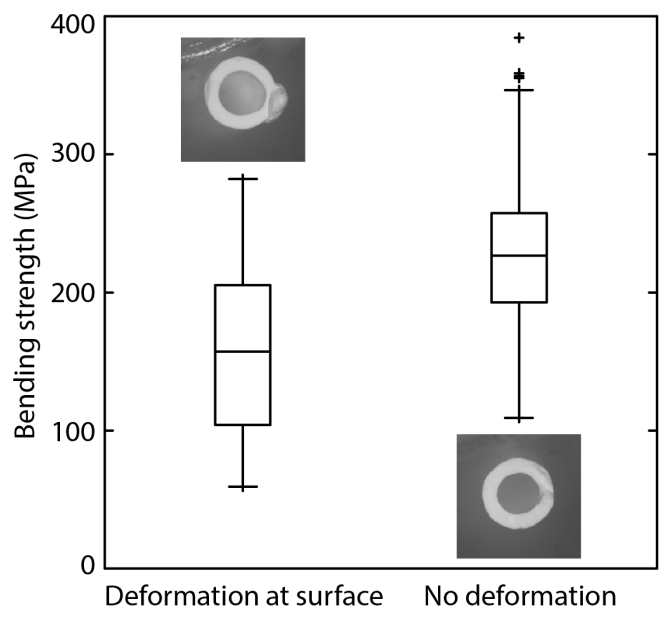

Figure 6.5: The effect of surface deformation on the mechanical strength of BIG-I prepared fibers.

Elimination of the fibers with a large deformations at the outer wall, results in normally distributed mechanical strength data of the fibers. This suggests that the weakest-link failure mechanism is no longer present. This can be the case in, for example, small specimens [34] or in specimens with porosity where defects can interact and grow into a crack $[15,35,36]$. In Figure 6.6 it is shown that crack formation could indeed be the case, but drawing conclusions about the exact failure mechanism would require more research on the BIG-I fibers, especially on optimized fibers with less deformations on the outer wall. The difference between the fibers with and without the surface deformation and the result of excluding the fibers with the surface deformation from the mechanical analysis shows that the BIG-I fibers have room for optimization. By optimizing the spinning and drying process, thus possibly eliminating the surface deformations, the strength will be solely dependent on the stacking of the inorganic particles. This is different as compared to the fibers prepared using NIPS, where the strength is limited by the intrinsic macrovoids. 


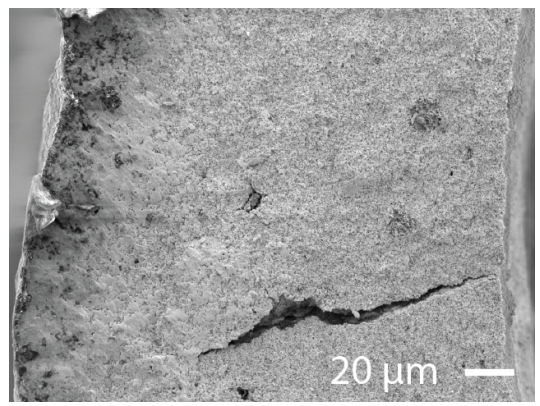

Figure 6.6: An example of a post fracture scanning electron micrograph showing crack formation.

\section{Implications of the statistical evaluation}

The mechanical strength of a ceramic component is described by a probability distribution function, where at a certain stress a "probability of failure" is given. This implies that at any given stress, there is always a (small) probability that the specimen would fail under this stress. This is a direct result of the Weibull weakest-link model, if a weak link is present in a given specimen, it might fail at a lower stress as compared to a specimen where this weak link is not present. Therefore, when designing a ceramic component one often selects an acceptable failure probability; the value of $10^{-6}$ is often used [24].

Table 6.5 summarizes the main findings of this study, showing the Weibull characteristic strength and modulus for fibers prepared using non-solvent induced phase separation and internal bio-ionic gelation. In addition, it shows the stress at a probability of $10^{-6}$, a value that could be used in the design of a component. Although the BIG-I fibers seem to be stronger as compared to the NIPS fibers at first glance, when comparing the design stress the NIPS fibers have a higher value. This is the result of the large scatter of the BIG-I fibers due to the surface deformations, which results in a lower Weibull modulus, hence it elongates the tail at the lower end of the distribution.

When the surface deformations with the BIG-I fibers are excluded, the mechanical strength no longer follows the Weibull distribution but appears to be normally distributed (See Table 6.4). This shows an increase in the stress at a probability of $10^{-6}$, which increases from $8.7 \mathrm{MPa}$ to $13.7 \mathrm{MPa}$. Further optimization of the BIG-I fiber might result in an increase of this value. In this study, the fibers with surface deformations were excluded from the analysis 
Table 6.5: Summary of key parameters describing the fibers prepared using the three different production methods.

\begin{tabular}{|c|c|c|c|}
\hline & NIPS & BIG-I & BIG-E \\
\hline Weibull characteristic strength (MPa) & 85.4 & 236.2 & $<10$ \\
\hline Weibull modulus & 9.9 & 4.2 & - \\
\hline Stress at probability of $10^{-6}(\mathrm{MPa})$ & 21.1 & 8.7 & - \\
\hline Min/Max outer diameter (mm) & 1.52 & $0.93 \quad 1.02$ & $1.0-1.1$ \\
\hline Min/Max inner diameter (mm) & $0.89 \quad 0.94$ & $0.46 \quad 0.54$ & - \\
\hline Wall thickness (mm) & 0.30 & 0.24 & - \\
\hline Roundness outer diameter & 0.99 & 0.91 & - \\
\hline Roundness inner diameter & 0.95 & 0.85 & - \\
\hline Porosity $(\%)$ & 54.5 & 30.0 & 76.7 \\
\hline Pore size $(\mathrm{nm})$ & $216,357^{*}$ & 130 & $200-1250$ \\
\hline
\end{tabular}

${ }^{*}$ Bi-modal pore size distribution

post-fracture by image analyses, hence it is likely that not all deformed fibers are removed, thus lowering this value even further. 


\subsection{Conclusion}

In this chapter the mechanical strength is measured and analyzed for $\mathrm{Al}_{2} \mathrm{O}_{3}$ hollow fibers prepared by three different preparation methods. In terms of absolute strength, bio-internal gelation with an internal ion source (BIG-I) results in the strongest fibers followed by the fibers prepared via non-solvent induced phase separation (NIPS). Bio-ionic gelation with an external ion source (BIG-E) produces the weakest fibers and is excluded from statistical analysis. Statistical analysis of these large datasets of strength data reveals that albeit the strength number of the BIG-I fibers is high, they are less reliable as compared to the NIPS fibers. Both production methods result in fibers that follow a Weibull model, which is based on a weakest-link theory. In the case of the NIPS fibers, these weaker links seem to originate from the macrovoids that are omnipresent in the structure result from the phase separation during production of these fibers. These macrovoids are hard to eliminate completely using NIPS-related methods.

The NIPS prepared fibers have an acceptable average mechanical strength, which is suitable for lab scale experiments were mechanical failure is inconvenient but acceptable. However, the design strength of these fibers is too low for practical applications where multiple fibers would be used in e.g. a membrane module. The BIG-I fibers show a homogenous wall without the presence of the macrovoids, but some fibers have large deformations at the outer wall of the fiber. These deformations are the result of instabilities during spinning and drying; further optimization of the spinning process is likely to remove these deformations. If the strength data is re-analyzed with the surface-deformed fibers excluded, the BIG-I fibers do not longer follow the Weibull model, as the weakest link is eliminated.

This shows that fibers prepared using internal bio-ionic gelation show great potential with respect to their mechanical strength. At this moment, the strength is limited by deformations that occur during their production, and is not limited by inherent macrovoids as it is for NIPS fibers. Elimination of these weaker links results in fibers with a higher mechanical strength, with also improved reliability which is a key factor in further upscaling and system design. 


\subsection{References}

[1] I. Moch, Kirk-Othmer Encyclopedia of Chemical Technology, Membranes, Hollow Fiber, John Wiley \& Sons, Inc.

[2] S. Dutczak, C. Tanardi, K. Kopeć, M. Wessling, D. Stamatialis, "Chemistry in a spinneret" to fabricate hollow fibers for organic solvent filtration, Sep. Purif. Technol. 86 (2012) 183-189.

[3] O. David, Y. Gendel, M. Wessling, Tubular macro-porous titanium membranes, J. Memb. Sci. 461 (2014) 139-145.

[4] B. Michielsen, H. Chen, M. Jacobs, V. Middelkoop, S. Mullens, I. Thijs, A. Buekenhoudt, F. Snijkers, Preparation of porous stainless steel hollow fibers by robotic fiber deposition, J. Memb. Sci. 437 (2013) 17-24.

[5] S. Shukla, N. Benes, I. Vankelecom, J. Méricq, M. Belleville, N. Hengl, J. S. Marcano, Sweep gas membrane distillation in a membrane contactor with metallic hollow-fibers, J. Memb. Sci. 493 (2015) 167-178.

[6] R. Kas, K. K. Hummadi, R. Kortlever, P. de Wit, A. Milbrat, M. W. J. Luiten-Olieman, N. E. Benes, M. T. M. Koper, G. Mul, Three-dimensional porous hollow fibre copper electrodes for efficient and high-rate electrochemical carbon dioxide reduction, Nat. Commun. 7 (2016) 10748.

[7] X. Zhang, D. K. Wang, D. R. S. Lopez, J. C. Diniz da Costa, Fabrication of nanostructured $\mathrm{TiO}_{2}$ hollow fiber photocatalytic membrane and application for wastewater treatment, Chem. Eng. J. 236 (2014) 314-322.

[8] T. Zhao, Z. Liu, K. Nakata, S. Nishimoto, T. Murakami, Y. Zhao, L. Jiang, A. Fujishima, Multichannel $\mathrm{TiO}_{2}$ hollow fibers with enhanced photocatalytic activity, J. Mater. Chem. 20 (2010) 5095.

[9] F. R. Garcia-Garcia, S. C. Tsang, K. Li, Hollow fibre based reactors for an enhanced $\mathrm{H}_{2}$ production by methanol steam reforming, J. Memb. Sci. 455 (2014) 92-102.

[10] A. Julbe, D. Farrusseng, C. Guizard, Porous ceramic membranes for catalytic reactors - Overview and new ideas, J. Memb. Sci. 181 (2001) 3-20.

[11] H. C. Aran, J. K. Chinthaginjala, R. Groote, T. Roelofs, L. Lefferts, M. Wessling, R. G. H. Lammertink, Porous ceramic mesoreactors: A new 
approach for gas-liquid contacting in multiphase microreaction technology, Chem. Eng. J. 169 (2011) 239-246.

[12] P. de Wit, F. S. Daalen, N. E. Benes, The mechanical strength of inorganic porous hollow fibers, J. Memb. Sci. 524 (2017) 721-728.

[13] W. Weibull, A statistical distribution function of wide applicability, J. Appl. Mech. 18 (1951) 293-297.

[14] S. van der Zwaag, The Concept of Filament Strength and the Weibull Modulus, J. Test. Eval. 17 (1989) 292-298.

[15] R. Danzer, P. Supancic, J. Pascual, T. Lube, Fracture statistics of ceramics: Weibull statistics and deviations from Weibull statistics, Eng. Fract. Mech. 74 (2007) 2919-2932.

[16] Ö. Kele, R. E. García, K. J. Bowman, Deviations from Weibull statistics in brittle porous materials, Acta Mater. 61 (2013) 7207-7215.

[17] C. Lu, A reassessment of the strength distributions of advanced ceramics, J. Aust. Ceram. Soc. 44 (2008) 38-41.

[18] H. Qasim Hussein, P. de Wit, E. J. Kappert, N. E. Benes, Sustainable Route to Inorganic Porous Hollow Fibers with Superior Properties, ACS Sustain. Chem. Eng. (2015) acssuschemeng.5b01248.

[19] S. Shukla, P. deWit, M. W. J. Luiten-Olieman, E. J. Kappert, A. Nijmeijer, N. E. Benes, Synthesis of Porous Inorganic Hollow Fibers without Harmful Solvents, ChemSusChem 8 (2015) 251-254.

[20] M. W. J. Luiten-olieman, M. J. T. Raaijmakers, L. Winnubst, T. C. Bor, M. Wessling, A. Nijmeijer, N. E. Benes, Towards a generic method for inorganic porous hollow fibers preparation with shrinkage-controlled small radial dimensions, applied to $\mathrm{Al}_{2} \mathrm{O}_{3}, \mathrm{Ni}, \mathrm{SiC}$, stainless steel, and ysz, J. Memb. Sci. 407-408 (2012) 155-163.

[21] ASTM, C1684-08 Standard Test Method for Flexural Strength of Advanced Ceramics at Ambient Temperature, ASTM Int. West Conshohocken, PA (2002) 1-21.

[22] ASTM, C1239-13 Standard Practice for Reporting Uniaxial Strength Data and Estimating Weibull Distribution Parameters for Advanced Ceramics, ASTM Int. West Conshohocken, PA (2014) 1-18. 
[23] R. Danzer, T. Lube, P. Supancic, Fracture statistics of ceramics: a short overview, in: Int. Conf. Fract.

[24] R. Danzer, On the relationship between ceramic strength and the requirements for mechanical design, J. Eur. Ceram. Soc. 34 (2014) 3435-3460.

[25] R. H. Doremus, Fracture statistics: A comparison of the normal, Weibull, and Type I extreme value distributions, J. Appl. Phys. 54 (1983) 193.

[26] C. Lu, R. Danzer, F. Fischer, Fracture statistics of brittle materials: Weibull or normal distribution, Phys. Rev. E 65 (2002) 067102.

[27] B. Basu, D. Tiwari, D. Kundu, R. Prasad, Is Weibull distribution the most appropriate statistical strength distribution for brittle materials?, Ceram. Int. 35 (2009) 237-246.

[28] M. Ambrožič, Monte Carlo simulation of Weibull distribution of ceramic strength values, in: Soc. Exp. Mech.

[29] H. Akaike, A new look at the statistical model identification, Autom. Control. IEEE Trans. (1974).

[30] T. Nagaoka, M. Yasuoka, K. Hirao, S. Kanzaki, Effects of cao addition on sintering and mechanical properties of $\mathrm{Al}_{2} \mathrm{O}_{3}$, J. Mater. Sci. Lett. 15 (1996) 1815-1817.

[31] J. Jung, S. Baik, Abnormal Grain Growth of Alumina: CaO Effect, J. Am. Ceram. Soc. 86 (2003) 644-649.

[32] S. Nohut, Influence of sample size on strength distribution of advanced ceramics, Ceram. Int. 40 (2014) 4285-4295.

[33] K. Burnham, D. Anderson, Model Selection and Multimodel Inference: A Practical Information-Theoretic Approach, 2nd edition, 2002.

[34] R. Danzer, Some notes on the correlation between fracture and defect statistics: Are Weibull statistics valid for very small specimens?, J. Eur. Ceram. Soc. 26 (2006) 3043-3049.

[35] L. Afferrante, M. Ciavarella, E. Valenza, Is Weibull's modulus really a material constant? Example case with interacting collinear cracks, Int. J. Solids Struct. 43 (2006) 5147-5157. 
[36] K. Tanaka, Y. Akiniwa, H. Kimachi, Y. Kita, R-curve behavior in fracture of notched porous ceramics, Eng. Fract. Mech. 70 (2003) 1101-1113. 



\section{Chapter 7}

\section{Tunable permeability and selectivity: Heatable ceramic membranes with thermo-responsive microgel coating}

This chapter is adapted from:

T. Lohaus, P. de Wit, M. Kather, D. Menne, N.E. Benes, A. Pich, M. Wessling. Tunable permeability and selectivity: Heatable ceramic membranes with thermo-responsive microgel coating, 2017, J. Membr. Sci doi: https://doi.org/10.1016/j.memsci.2017.05.052 


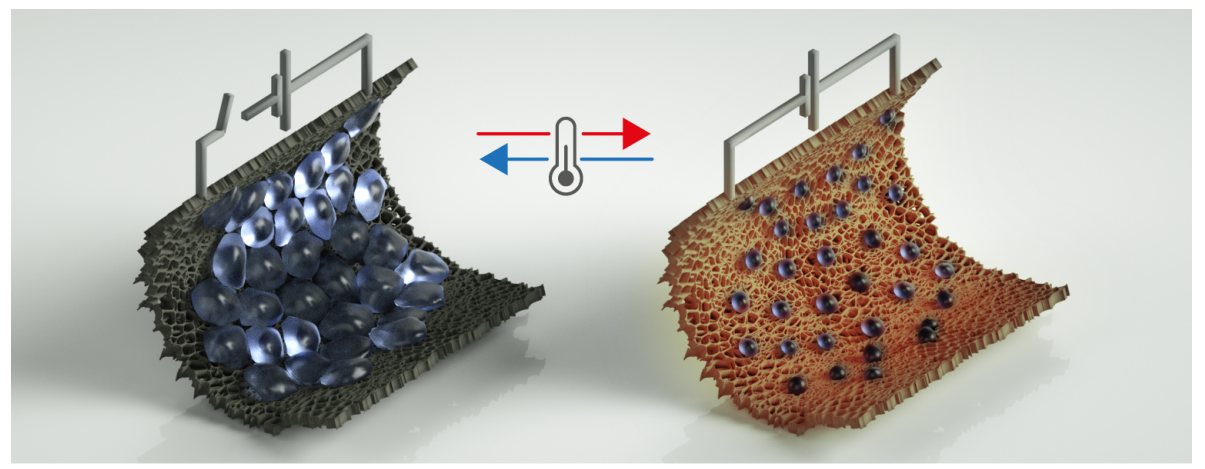

\section{Abstract}

In recent years, the interest in responsive materials to design membranes with tunable properties increased in order to customize membranes for adaptable process requirements. The majority of development methods require external adjustment of the feed stream temperature to achieve a responsiveness of the membrane. In this study, we propose a concept in which the temperature of the membrane itself can be directly controlled to initiate a response of the membrane surface. We use an electrically conductive membrane composed of silicon carbide and carbon on which thermo-responsive poly $(N$-vinylcaprolactam) $(\mathrm{P}$ VCL) microgels have been immobilized. By controlling the applied electrical power to the membrane, the permeability and selectivity of the membrane can be adjusted.

Immobilization of the microgels on the membrane has been realized via filtration coating. The microgel coating is stable with no change in permeability, hence no microgel loss, over time. Also during backwash, the permeability remains constant. Thermo-responsiveness remains reversible and stable in all conducted experiments. The controlled hydraulic resistance of the membrane behaves according to the hydrodynamic radius of the microgel, as a function of temperature. The electrical heating of the membrane shows to be more energy efficient compared to heating of the whole feed stream when operating in crossflow conditions, saving $14 \%$ of the consumed energy. 


\subsection{Introduction}

Our natural environment is a complex and highly efficient system of interacting structures. One of its most preeminent characteristics is the ability of biological materials to regenerate and reverse their behavior as a response to external stimuli. Over the last decades, research interest in synthesis of smart or stimuliresponsive materials has expanded vastly.

Stimuli-responsive polymers achieve attention for undergoing physico-chemical or structural changes when exposed to environmental changes such as temperature, $\mathrm{pH}$, ionic strength, magnetic, and electric field or light $[1,2]$.

The response of the polymers can be reversibly triggered as it is caused by changing interactions between solute and solvent without any chemical reaction. This results in a swollen, flexible polymer gel referred to as microgel $[3,4]$. In aqueous solutions, the solubility of responsive polymers plays a key role, because the polymer groups transit from hydrophobic to hydrophilic at a certain intensity of the stimuli, causing a switch in its solubility accompanied by a volumetric expansion [5]. Due to their exceptional physico-chemical functionality they find applicability in areas such as drug delivery systems [6-8], scavengers $[9,10]$, sensors [11-13], or as carrier systems for enzymes, metal nanoparticles or nanoreactors [14-17].

One of the most prevalent types of stimuli-responsiveness of microgels is their temperature sensitivity. When bonds between water and polymer are stronger than bonds between the polymers, polymer chains are arranged in a random cross-linked coil structure swollen with water molecules. When the temperature is raised above the volume phase transition temperature (VPTT), a transition takes place where bonds between water and polymer molecules break and polymer chains rearrange to a collapsed globule state [18]. Entrapped solvent molecules are expelled causing the particle to shrink. This process occurs over a very small temperature range, so that the transition is observed as a sudden shift in particle size [19].

Growing interest lies in developing membranes with tunable properties to customize membranes for adaptable process requirements. Membrane separation properties, such as permeability and selectivity, are to a large extent dependent on the micro-structure of the membranes. Functionalizing membranes with a microgel that change its size offers the potential to tune separation properties according to changing process conditions. Additionally, microgels offer a remarkably rapid response time to external stimuli in contrast to hydrogels or bulk systems, allowing for a quicker and more controlled switching of the pore size $[20-22]$. 
To functionalize membranes, most studies either include responsive materials during membrane synthesis or post-modify the surface with various graftingfrom methods [23-25]. Few studies use the "grafting-to" method such as physical adsorption in a coating process. Recently, Menne et al. [26] showed switchable permeability of membranes infiltrated with thermo-responsive microgels.
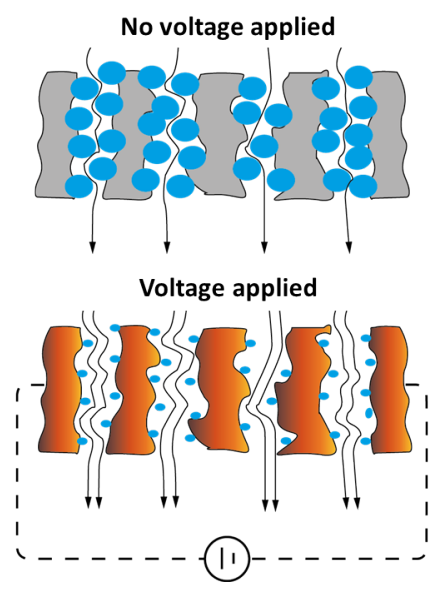

Figure 7.1: Schematic drawing of a P-VCL coated SiC-C membrane with microgels in the swollen state at room temperature (top) and collapsed microgels on an electrically heated membrane (bottom)

All of the developed thermo-responsive membranes depend on an external trigger, such as the feed stream temperature, to trigger responsiveness of the microgel size and thus permeability and selectivity. This limits the application to feed stream temperature and environmental temperature. In this study, we propose a concept in which the membrane itself can be controlled by electrical membrane heating. We use electrically conductive membranes composed of silicon carbide and carbon to electrically heat the membrane on which we immobilized thermo-responsive microgels.

The silicon carbide-carbon (SiC-C) fibers offer exceptionally high surface-tovolume ratio, anti-fouling behavior and electrical conductivity [27]. The heatable characteristics of the membrane enable responsiveness of permeability and selectivity of the membrane to not be driven by changes in feed temperature, but by the separate externally controlled applied voltage on the membrane. 
Table 7.1: Properties of the hybrid silicon carbide-carbon membrane used in this study.

\begin{tabular}{ll}
\hline Parameter & Value \\
\hline Pore diameter & $350 \mathrm{~nm}$ \\
Inner fiber diameter & $0.76 \mathrm{~mm}$ \\
Outer fiber diameter & $1.8 \mathrm{~mm}$ \\
Conductivity & $742 \mathrm{kS} \mathrm{m}^{-1}$ \\
4 point bending strength & $35 \mathrm{MPa}$ \\
Clean water permeability & $230 \mathrm{~L} \mathrm{~m}^{-2} \mathrm{~h}^{-1} \mathrm{bar}^{-1}$ \\
\hline
\end{tabular}

Figure 7.1 shows the schematic principle of a microgel coated SiC-C membrane, with microgels in the swollen state at room temperature where no voltage is applied to the membrane (top), and an electrically heated membrane with collapsed microgels (bottom). Promising applications arise from the possibility of tuning membrane resistance without pausing operation such as using different flows for filtration and backwash. An enhanced permeability during backwash might shorten backwash cycles or run backwashes more efficiently.

\section{$7.2 \quad$ Experimental}

\subsubsection{Membranes and membrane modules}

Hybrid SiC-C hollow fibers were prepared by dry-wet spinning of a PES, NMP, and $\mathrm{SiC}$ mixture followed by thermal treatment at $1000^{\circ} \mathrm{C}$ under an argon atmosphere. The details on the fabrication method and a full characterization of the fiber can be found elsewhere [27]. These fibers have a sufficient mechanical strength and suitable electrical conductivity to be used as a heatable membrane support. Table 7.1 provides an overview of the key properties of the membrane.

Copper wire (Conrad Electronics, Germany) with a diameter of $0.4 \mathrm{~mm}$ was soldered directly onto both membrane ends, allowing equal current flow within the membrane. The wire was wrapped around the complete outer wall of the fibers. Single-fibers were glued with two component epoxy resin into custommade modules made out of two separate perspex tubes connected by a four-way stainless steel connector that served as permeate outlet and connection to a thermocouple. These modules were used for dead-end, crossflow, and backwash 
filtration.

\subsubsection{Microgels}

$N$-vinylcaprolactam (VCL) (98\%, Sigma-Aldrich) was purified by distillation under vacuum and recrystallized in hexane (99\%, VWR). 2,2'-azobis(2-methylpropioamidine) dihydrochloride (AMPA) (97\%, Sigma-Aldrich) and $N, N^{\prime}$ methylenebis(acrylamide) (BIS) (99\%, Sigma-Aldrich) were used as received.

Aqueous microgels consisting of VCL as monomer, BIS as cross-linker, and AMPA as initiator were synthesized using a $\mathrm{RC} 1$ su reaction calorimeter with a triple-walled $500 \mathrm{~mL}$ RTCAL glass reactor (Mettler-Toledo), equipped with a mechanical stirrer, temperature sensor and a baffle. For the synthesis $3.6919 \mathrm{~g}$ (26.52 mmol) monomer (VCL) and $0.1000 \mathrm{~g}(0.65 \mathrm{mmol})$ cross-linker (BIS) were dissolved in $250 \mathrm{~mL}$ deionized water, then stirred at $300 \mathrm{rpm}$ for $30 \mathrm{~min}$ while heating to $70^{\circ} \mathrm{C}$ and purged with nitrogen to remove oxygen from the system. Afterwards, the reaction mixture was stirred for 90 min under nitrogen atmosphere and then $0.0833 \mathrm{~g}(0.31 \mathrm{mmol})$ of the initiator (AMPA) dissolved in $1 \mathrm{~mL}$ deionized water was added. The polymerization lasted for $1 \mathrm{~h}$ and the P-VCL microgel was cleaned by dialysis in deionized water with a regenerated cellulose dialysis tube with a cut-off between $12 \mathrm{kDa}$ to $14 \mathrm{kDa}$ (Carl Roth) from monomers and side products. The polymerization was based on publications by Boyko et al. [28] and Pich et al. [29].

\subsubsection{Analysis}

The temperature dependent hydrodynamic radii $\left(R_{h}\right)$ were calculated from second order cumulant fits via the Stokes-Einstein equation using dynamic light scattering (DLS) measurements with a laser light scattering spectrometer (ALV/DLS/SLS-5004, ALV-GmbH, Germany) with an ALV-5004/EPP multiple digital $\tau$ correlator and laser goniometry system ALV/CGS-3 with a helium-neon laser (Uniphase 1145P, output power of $22 \mathrm{~mW}$ and wavelength of $632.8 \mathrm{~nm}$ ) as a light source.

Scanning electron micrographs were taken using a Hitachi S4800. The fibers were freeze dried by putting water immersed fibers in liquid nitrogen and then dried overnight under vacuum with an Alpha 1-4 LD plus (Martin Christ Gefriertrocknungsanlagen GmbH, Germany) and sputtered with tungsten. 


\subsubsection{Membrane coating}

The microgel solution was mixed with deionized water until a concentration of $2 \mathrm{~g} \mathrm{~L}^{-1}$ was reached. Membrane coating was performed using an OSMO Inspector 2 (Convergence B.V., the Netherlands). The fibers were flushed with demineralized water in crossflow and dead-end mode before coating of the microgels. Flushing was done for 5 min per operating mode. The membranes were coated with an inside-out filtration at a constant flux of $1350 \mathrm{~L} \mathrm{~m}^{-2} \mathrm{~h}^{-1}$ in dead-end until a trans-membrane pressure (TMP) of 3 bar is reached. Assuming full retention of filtrated microgels, the specific mass of adsorbed microgels $m^{\prime \prime}$ is calculated with

$$
m^{\prime \prime}=\dot{J}^{\prime \prime} \cdot c \cdot t
$$

where $\dot{J}^{\prime \prime}$ denotes the flow rate per area, $t$ the coating time, and c feed concentration of the microgels. After coating, the membranes were cleaned by a crossflow of pure water to wash out the residual microgel solution. The modules were filled with ultra pure water to prevent drying of the microgels during storage.

\subsubsection{Experimental set-up and procedure}

A constant pressure set-up was used that allows to measure in dead-end, crossflow and backwash mode. Constant pressure was supplied by a nitrogen gas bottle and was regulated with a MET cell (Evonik, Germany). In crossflow, a MCP-Z pump (Ismatec, Germany) was used to adjust the crossflow rate. The measured data of temperature, weight and pressure were recorded every second with Daisylab (Measurement Computing Corporation, USA). The membranes were connected via the copper wire to a voltage source (Manson HCS-3404, Reichelt, Germany) to electrically heat the membrane. A k-type thermocouple (PeakTech, Germany) is placed in the 4-way connector of the module to measure the temperature in the middle of the module.

Before a coated fiber was used in an experiment the fiber was flushed with ultrapure water three times for ten minutes both with voltage applied and not applied to wash the fiber. To measure pure water permeability of coated membranes, a constant trans membrane pressure of 1 bar, 2 bar and 3 bar was applied stepwise and the flux was measured for $15 \mathrm{~min}$ at each pressure step. The measurements with increasing temperatures and backwash experiments were all performed at a TMP of 2 bar and recorded for 10 min at every temperature step. For retention measurements a mixture of $2 \mathrm{~g} \mathrm{~L}^{-1}$ dextrane (PSS Polymer Standard Service, Germany) in water and $0.2 \mathrm{~g} \mathrm{~L}^{-1}$ sodium azide (Sigma- 
Aldrich) was used. The dextrane standard has a molecular size of $2.18 \mathrm{MDa}$ with a poly dispersity index (PDI) of 4.2. Retention measurements were obtained with a crossflow of $5.1 \mathrm{~mL} \mathrm{~min}^{-1}$. The temperature was kept constant for four minutes before taking a sample. Samples have been analyzed using size exclusion chromatography (SEC) with water as the eluent.

\subsection{Results and discussion}

\subsubsection{Characteristics of the coated membrane}

The synthesis of the gel resulted in a size of $360 \mathrm{~nm}$ at $20^{\circ} \mathrm{C}$ with a volume phase transition temperature (VPTT) at $32^{\circ} \mathrm{C}$. The aqueous polymer microgels were immobilized onto the SiC-C membranes via dead-end filtration. During the coating the trans-membrane pressure (TMP) increases exponentially indicating a deposition of microgels on the membrane and within its pores similar to the coating procedure presented in Menne et al. [26]. The membrane permeability decreases strongly during the coating processes due to adsorption of microgels. The final permeability is $(29 \pm 6) \mathrm{L} \mathrm{m}^{-2} \mathrm{~h}^{-1} \mathrm{bar}^{-1}$. The immobilized mass of microgels onto the membrane is $(112.0 \pm 3.5) \mathrm{g} \mathrm{m}^{-2}$.

Figure 7.2a displays a scanning electron micrograph of a SiC-C hollow fiber membrane with deposited polymer microgels, the picture was taken from a membrane directly after coating. Due to their softness, the microgels form a film on the membrane, seen as the dark area on top op the brighter membrane. Figure $7.2 \mathrm{~b}$ shows the adsorption of microgels on the surface of the membrane after usage. Microgels were also observed within the pores of the membrane, which can be attributed to the softness of the particles that allows them to penetrate pores up to 10 times smaller than the actual size of the gel, depending on their deformability $[30,31]$.

The size of the microgel is a function of temperature, with a decreasing diameter for an increasing temperature. To tune the microgel size on the heated membrane, reliable measurement and control of the temperature is necessary, as well as knowledge on the evolving temperature distribution over the length of the membrane at varying flow conditions. The temperature of the fiber is tuned by the applied power, which results in a the correlation between temperature and applied power. Figure 7.3 shows the temperature distribution over the length of the hollow fiber for measurements in dead-end (black symbols) and crossflow mode (white symbols) for different specific energy inputs. The temperature increases along the membrane since the residence time of the water increases and water volume inside the hollow fiber decreases with per- 


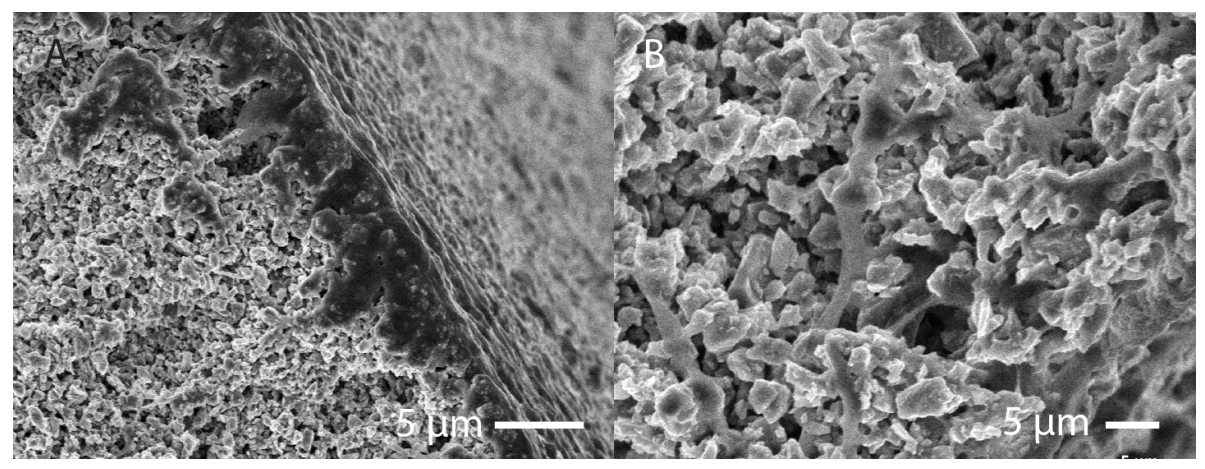

Figure 7.2: Scanning electron micrographs of the cross-section of a SiC-C hollow fiber coated with P-VCL microgels. (A) shows the fiber after the microgel coating process and (B) shows the fiber after permeation tests. Images have been adapted in brightness.

meation. The temperature gradient along the length of the module is more pronounced in dead-end as compared to crossflow mode, due to additional removal of heat by convective transport in axial direction. Higher temperatures evolve in dead-end at respective energy inputs, hence more energy is needed in crossflow mode to exceed the volume phase transition temperature (VPTT) due to enhanced heat loss. Using crossflow a nearly constant temperature profile along the length of the module forms. The nearly constant temperature profile enables good control of the microgel size and a suitable temperature estimate, when only measuring in the middle of the membrane module.

\subsubsection{Tunable permeability}

Figure 7.4 and Figure 7.5 display the switching characteristics of the membranes for dead-end and crossflow measurements, respectively. Each figure includes two diagrams, the top one plotting the permeability and the bottom one the corresponding temperature over time. A power of $30 \mathrm{~W} \mathrm{~m}^{-1}$ is applied in dead-end experiments and $100 \mathrm{~W} \mathrm{~m}^{-1}$ in crossflow experiment for 10 minutes in each cycle. The power is switched off for 10 minutes to let the membrane cool and observe reversible behavior of the permeability and temperature.

In both diagrams, the correlation between temperature and permeability is 


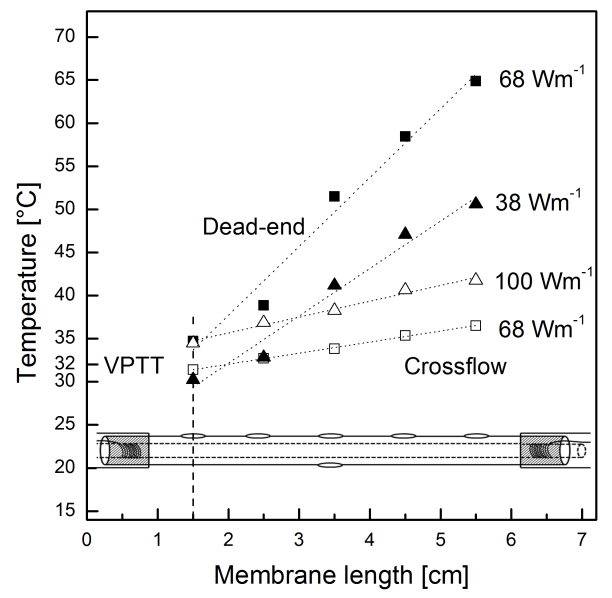

Figure 7.3: Temperature distribution along the length of the fiber in dead-end (black symbols) and crossflow (white symbols) clean water permeation for two distinct power inputs. The membrane module visualizes the measuring spots. The feed enters the module at distance $0 \mathrm{~cm}$ at room temperature $\left(25^{\circ} \mathrm{C}\right)$.

evitable with elevated permeabilities at higher temperatures. When power is applied onto the membrane the temperature rises to its final level within two minutes. The temperature increase causes the microgels to collapse, increasing the pore size for water permeation. Permeability is around 5-10 times greater in the heated state than without applied voltage.

Both permeability and temperature reach an almost constant value during an applied power sequence where they stay stable during the time of heating. Temperature and permeability return to their untuned state after removing the applied voltage. During heating, temperature and permeability rise to the same level with each cycle showing a reversible and stable switch of the modified membrane. It should be mentioned, that the permeability reacts without any delay on temperature changes since thermal switching of microgels is immediate [20]. However, the whole microgel-membrane assembly needs two minutes reaction time to react on the applied power and to increase its temperature to its final value. The changes from applied power to no power occur faster in crossflow than in dead-end filtration due to the intense cooling effect of the crossflow. The resulting switching curve for crossflow is sharper 
in the cool down period, while permeability and temperature level off more slowly in dead-end cycles. Comparing the energy needed to fulfill the tuning of the membrane in the crossflow mode to the energy that would have been needed to heat up the whole feed stream, the electrical heating of the membrane is significantly more power-saving. Computing a simple energy balance with the data from Figure 7.5 the electrical heating with $100 \mathrm{~W} \mathrm{~m}^{-1}$ consumes only $86 \%$ of the energy that would have been consumed heating up a water stream by $21.5^{\circ} \mathrm{C}$. Membrane permeability is influenced by the permeating fluid viscosity. As the viscosity of water decreases with increasing temperature, the increase in permeability is at least partially caused by the decrease in viscosity of the water surrounding the membrane. In order to examine how strong the switching characteristic is due to the decrease in viscosity, and to put measurements into perspective, the hydraulic resistance of the membrane is a more reliable parameter to assess the influence of temperature on the membrane performance. Figure 7.6 examines the hydraulic resistance switch of the membrane between the swollen and collapsed state of the microgel in a broad range of temperatures. In $6 \mathrm{~min}$ intervals, the applied voltage was increased stepwise which is enough time for the coated membrane to reach steady state. Black triangles in Figure 7.6 illustrate the hydrodynamic radius of the micro-
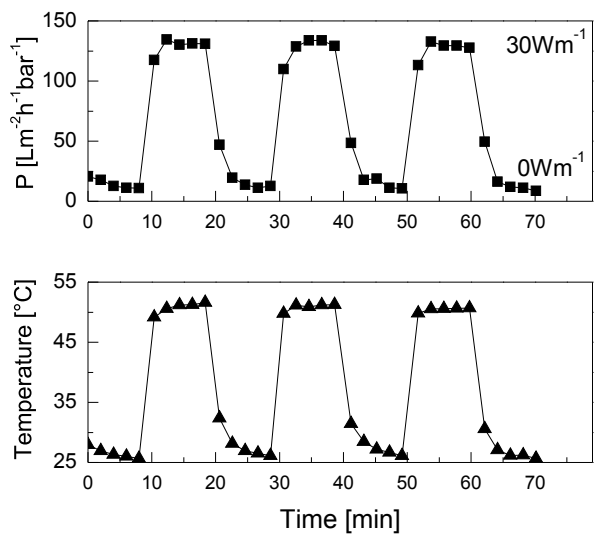

Figure 7.4: Dead-end permeability over time for each 10 minutes cycles of heating with $30 \mathrm{~W} \mathrm{~m}^{-1}$ and no applied voltage. The temperature was measured in the middle of the module. 
gels dispersed in aqueous solution as a function of temperature measured by dynamic light scattering (DLS). At temperatures below the VPTT $\left(32{ }^{\circ} \mathrm{C}\right)$, the polymer chains are well solvated by water molecules and microgels are in swollen state with a radius of about $360 \mathrm{~nm}$. At temperatures close to the VPTT, the disruption of the hydrogen bonds leads to partial dehydration of the polymer chains, and the microgels start to collapse and their radii decrease. After exceeding the VPTT, the microgels are almost totally collapsed and the decrease in size levels off and approaches a constant value of about $120 \mathrm{~nm}$. Figure 7.6 correlates the decrease of the hydrodynamic radius of the microgels to the hydraulic resistance of the membrane over temperature over a range of temperatures. The white triangles show crossflow measurements and white squares dead-end measurements. The course of both decreasing radius and resistance is in astonishingly good agreement. The resistance measured in crossflow agrees well with the hydrodynamic radius showing a switch of membrane resistance and radius at the VPTT of $32^{\circ} \mathrm{C}$. The dead-end measurement has an off-set of around $5{ }^{\circ} \mathrm{C}$ to lower temperatures, showing a slight underestimation of the measured temperature to the switch of the gels. The underestimation might be attributed to different flow conditions on the inside of the membrane and the more inhomogeneous temperature distribution shown in Figure 7.3. Under crossflow conditions, the more homogeneous temperature distribution leads to
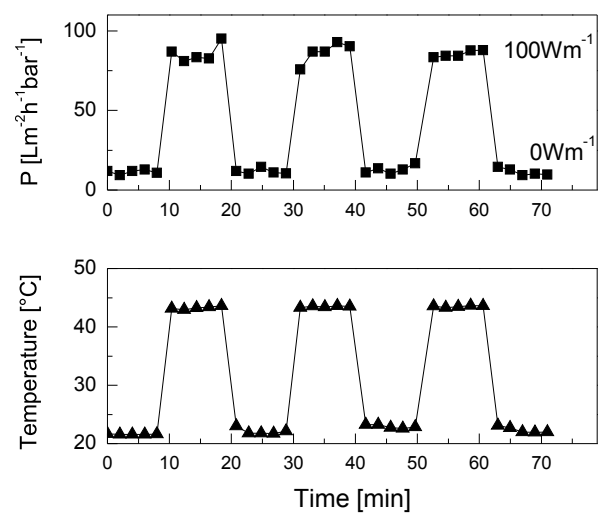

Figure 7.5: Crossflow permeability over time for each 10 minutes cycles of heating with $100 \mathrm{~W} \mathrm{~m}^{-1}$ and no applied voltage. The temperature was measured in the middle of the module. 


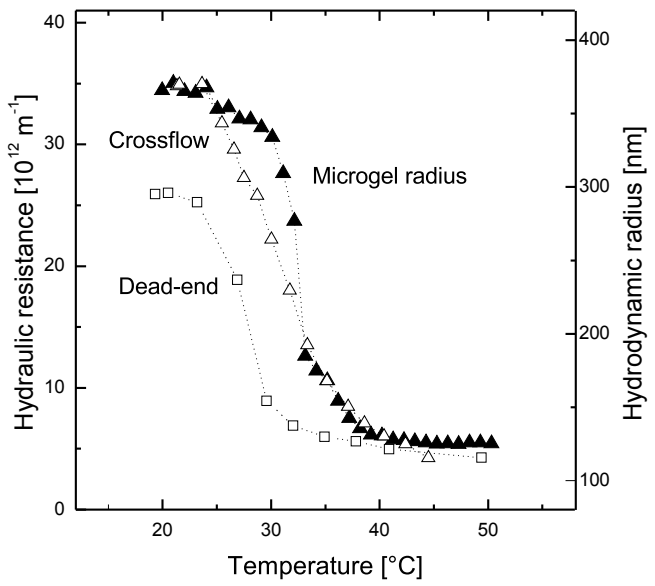

Figure 7.6: Membrane resistance as a function of measured temperature and compared with the hydrodynamic radius of the microgel. Black triangles denote the decrease of hydrodynamic radius with temperature, while white symbols present the hydraulic resistance of the membrane. White squares and triangles denote measurements in dead-end and crossflow, respectively.

a better temperature estimation when only measuring the temperature in the middle of the membrane module. It is still surprising to see how well also measurements in dead-end mode fit to the hydrodynamic radius although the temperature gradient along the membrane is large making a good temperature estimation difficult (see Figure 7.3). The difference in base resistance at $20^{\circ} \mathrm{C}$ between both measurements comes from fiber-to-fiber differences as the membrane permeability varies with different sintering batches.

\subsubsection{Tunable selectivity}

To analyze the retention characteristics of macromolecules, filtration experiments are conducted using a dextrane solution. Uncoated membranes let all dextranes pass, resulting in a zero retention rate. Figure 7.7 displays the retention rate of the $200 \mathrm{kDa}$ dextrane as a function of membrane temperature. The microgel coating causes a significant increase in retention. While the uncoated membrane allows all dextrane molecules to permeate, the membrane coated 
with larger microgels reaches a retention rate of $83 \%$ at room temperatures. A $90 \%$ cut-off was not reached with the coating. With increasing membrane temperature, the hydrodynamic radius of the microgel decreases, allowing an increased amount of dextrane molecules to permeate. After reaching the final temperature of $50{ }^{\circ} \mathrm{C}$, electric power was turned off. When the temperature decreases to room temperature, the retention rate reverts to $83 \%$, showing the selectivity behavior of the membrane to be switchable. The curve of the decrease of retention over temperature shows a similar shape as the decrease of hydraulic resistance.

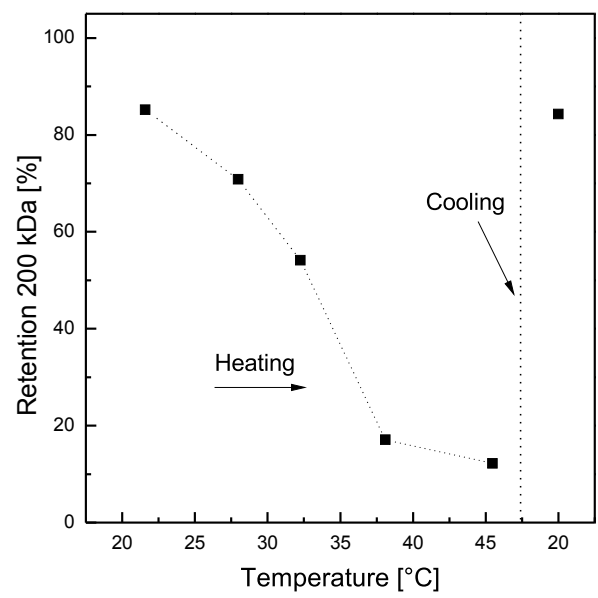

Figure 7.7: Retention of $200 \mathrm{kDa}$ dextrane as a function of applied temperature on the membrane. Temperature was increased stepwise after $10 \mathrm{~mL}$ filtrated volume was collected at each step in steady state. The temperature was increased up to $50{ }^{\circ} \mathrm{C}$ and then cooled back to room temperature.

\subsubsection{Stability of the coated membrane}

The results presented in the previous sections show that coating heatable membranes with microgels enables reproducible tunability of permeability and selectivity. Since microgels are attached to the membrane only adsorptively and not through chemical bonds, it is important to check for the stability of the coating. We assume that the adsorption of the microgels on the membrane 
is a cooperative effect of electrostatic attraction forces and hydrophobic interactions. Weak electrostatic attraction forces may be expected because $\mathrm{SiC}-\mathrm{C}$ posseses weak negative surface charge and microgels exhibit weak positive surface charge due to the initiator fragments integrated into polymer chains during precipitation polymerisation process. Hydrophobic attraction forces may originate from interactions between aliphatic segments of lactam rings of VCL and carbon rich SiC-C surface. In addition, ability of microgels to deform and spread at solid surfaces increases the adsorption strength due to the multiple interactions and large contact area. The physical bonds between membrane and microgel might be sensitive towards shear forces at the membrane surface causing possible desorption and rinsing out of microgels during permeation or backwashing.

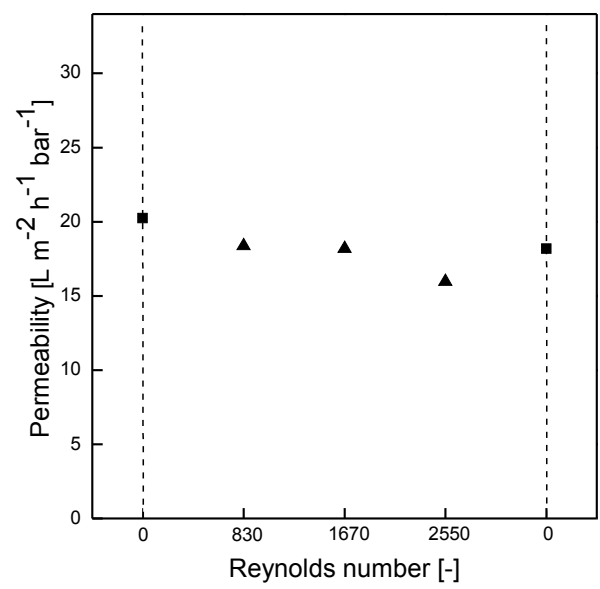

Figure 7.8: Permeability of a microgel coated membrane as a function of Reynolds number applied as crossflow.

Figure 7.8 displays the permeability as a function of the Reynolds number Re calculated from the applied crossflow velocity. The permeability is measured in dead-end mode before and after applying crossflow. The permeability at a Reynolds number of 830 and 1670 with the respective shear rates $\tau=17.000 \mathrm{~s}^{-1}$ and $\tau=33.000 \mathrm{~s}^{-1}$ stays constant compared with the final one measured in dead-end mode. The constant permeability implies that no microgels get washed off the membrane, otherwise the final permeability would 
be enhanced. At a Reynolds number of $2550 \tau=50.000 \mathrm{~s}^{-1}$ the permeability is slightly lower, probably because the crossflow in the hollow fiber is turbulent and the permeability value is not corrected against pressure loss in the fiber. To test the long term stability of the coating membrane modules they were repeatedly permeated with ultrapure water without applied power over the course of almost 30 days. Within measurements the membrane modules were kept wet to prevent the microgels from drying. Figure 7.9 shows no increase in permeability with increasing time which confirms that microgels are not released from the membrane surface.

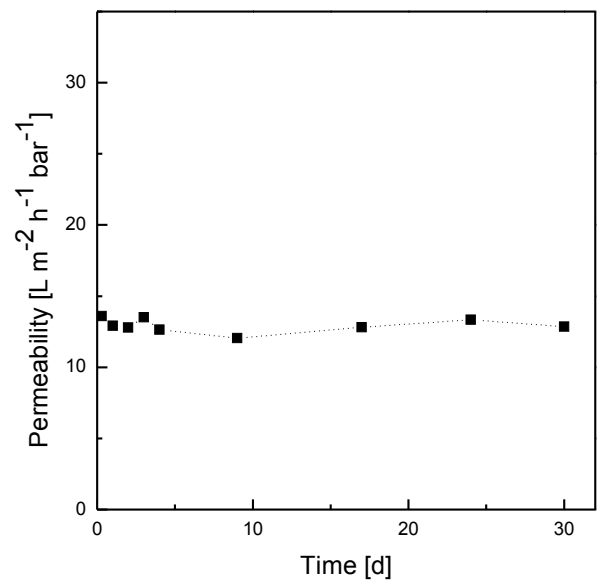

Figure 7.9: Permeability of a microgel coated membrane measured over a period of 30 days.

To analyze a possible influence of the direction of permeation, the permeability during backwashing cycles has been observed and is displayed in Figure 7.10. Black squares are used for measurements where the membrane has been heated with $35 \mathrm{~W} \mathrm{~m}^{-1}$ only during the backwashing cycles, while in regular filtration no power was applied and permeation took place at room temperature. White squares are used for measurements where both backwash and regular filtration took place at room temperature. Visible is the enhanced permeability in backwash filtration due to the enhanced temperature. Microgels are stable in backwash filtration even when power is applied. Some loss in permeability must be considered, similarly to loss in permeability during the wash-in process. 


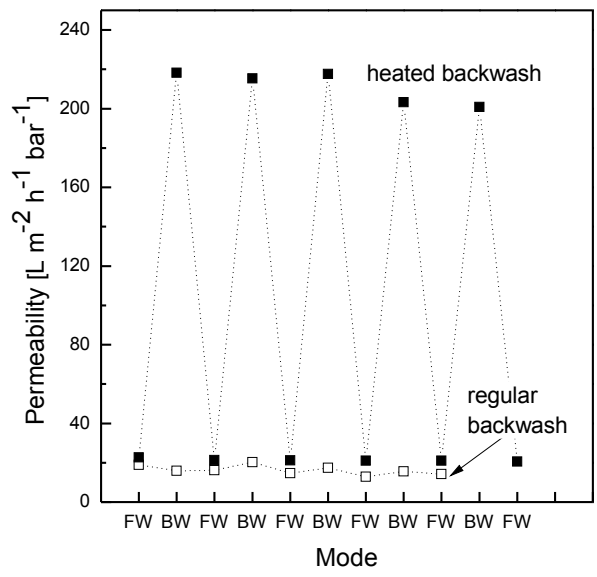

Figure 7.10: Stability of a microgel coated membrane for backwash and filtration cycles (white squares) and cycles where the membrane is heated during backwashing cycles (black squares). FW denotes forward filtration and BW backwash filtration.

\subsection{Conclusion}

In the present work, we designed thermo-responsive membranes by coating heatable ceramic membranes with P-VCL microgels, allowing a switch in resistance and retention during operation. The microgel coated SiC-C membranes are heatable due to their electrical conductivity, which allows tuning of their permeability and selectivity. The developed membrane modification has advantages over existing tunable membranes. The membrane coating presents an effective and feasible way to functionalize membranes. The properties of the modified fiber can be tailored by the direct heating of the fibers independent of the feed temperature. The tuning behaviour of the modified membrane was proven to be stable and reproducible. The thermo-responsive size of the single microgels in water translates surprisingly well into a thermo-resposive behavior of the hydraulic resistance of the fiber. Crossflow measurements result in more accurate temperature profiles and more reliable measurements as compared to dead-end experiments. Electrical heating of the fiber shows to be $14 \%$ more energy efficient compared to heating of the feed stream in crossflow mode. The microgel coating was tested to be stable without a loss in permeability 
for more than 30 days and up to Reynolds numbers of 2550. Also, during backwash and backwash with heating, the modified membrane keeps a stable, switchable behavior. Promising applications arise from the possibility of tuning membrane resistance without pausing operation. Variations of fluxes might induce hydraulic instabilities, which in turn could prevent fouling. Also, tuning selectivity is interesting to incorporate, for example in varying purification tasks with a membrane that can directly adapt to changing process conditions. The variable permeability during backwash could be directly applied to filtration processes that are prone to fouling, with a more efficient cleaning cycle when backwashing at higher permeabilities, which might decrease the necessary cleaning duration while increasing cleaning results.

\subsection{Acknowledgements}

This work has been funded within the "Inorganic porous hollow fibers for intensified fractionation and filtration" project and the Collaborative Research Center SFB 985 "Functional Microgels and Microgel Systems" by the German Research Foundation (Deutsche Forschungsgemeinschaft - DFG) and the Volkswagen Stiftung. The authors thank S. Hanisch SEC analysis, K. Faensen for the high quality SEM images, and M. Müller, T. Harhues, S. Lohmann for their support in the lab. A part of this work was performed at the Centre for Chemical Polymer Technology CPT, which was supported by the EU and the federal state of North Rhine-Westphalia (grant EFRE 3000883 02). 


\subsection{References}

[1] M. A. C. Stuart, W. T. S. Huck, J. Genzer, M. Müller, C. Ober, M. Stamm, G. B. Sukhorukov, I. Szleifer, V. V. Tsukruk, M. Urban, F. Winnik, S. Zauscher, I. Luzinov, S. Minko, Emerging applications of stimuliresponsive polymer materials, Nat. Mater. 9 (2010) 101-113.

[2] D. Wandera, S. R. Wickramasinghe, S. M. Husson, Stimuli-responsive membranes, J. Membr. Sci. 357 (2010) 6-35.

[3] A. Fernandez-Nieves, H. M. Wyss, J. Mattsson, D. A. Weitz (Eds.), Microgel Suspensions, Wiley-Blackwell, 2011.

[4] S.-K. Ahn, R. M. Kasi, S.-C. Kim, N. Sharma, Y. Zhou, Stimuli-responsive polymer gels, Soft Matter 4 (2008) 1151.

[5] N. Nath, A. Chilkoti, Creating smart surfaces using stimuli responsive polymers, Adv. Mat. Res. 14 (2002) 1243-1247.

[6] O. L. J. Virtanen, M. Brugnoni, M. Kather, A. Pich, W. Richtering, The next step in precipitation polymerization of $\mathrm{N}$-isopropylacrylamide: particle number density control by monochain globule surface charge modulation, Polym. Chem. 7 (2016) 5123-5131.

[7] J. Dubbert, T. Honold, J. S. Pedersen, A. Radulescu, M. Drechsler, M. Karg, W. Richtering, How hollow are thermoresponsive hollow nanogels?, Macromolecules 47 (2014) 8700-8708.

[8] B. Özkahraman, I. Acar, M. K. Gök, G. Güçlü, N-vinylcaprolactam-based microgels: synthesis, characterization and drug release applications, Res. Chem. Intermed. 42 (2016) 6013-6024.

[9] X. Huang, Y. Yin, Y. Tang, X. Bai, Z. Zhang, J. Xu, J. Liu, J. Shen, Smart microgel catalyst with modulatory glutathione peroxidase activity, Soft Matter 5 (2009) 1905.

[10] S. Berger, R. Singh, J. D. Sudha, H.-J. Adler, A. Pich, Microgel/clay nanohybrids as responsive scavenger systems, Polymer 51 (2010) 38293835 .

[11] J. Zhang, J. Lei, H. Ju, C. Wang, Electrochemical sensor based on chlorohemin modified molecularly imprinted microgel for determination of 2,4dichlorophenol, Anal. Chim. Acta 786 (2013) 16-21. 
[12] Y. Gao, X. Li, M. J. Serpe, Stimuli-responsive microgel-based etalons for optical sensing, RSC Adv. 5 (2015) 44074-44087.

[13] M. A. Lifson, J. A. Carter, B. L. Miller, Functionalized Polymer Microgel Particles Enable Customizable Production of Label-Free Sensor Arrays, Anal. Chem. 87 (2015) 7887-7893.

[14] M. Karg, T. Hellweg, Smart inorganic/organic hybrid microgels: Synthesis and characterisation, J. Mater. Chem. 19 (2009) 8714.

[15] N. Welsch, A. L. Becker, J. Dzubiella, M. Ballauff, Core-shell microgels as "smart" carriers for enzymes, Soft Matter 8 (2012) 1428-1436.

[16] G. Agrawal, M. Schürings, X. Zhu, A. Pich, Microgel/ $/ \mathrm{SiO}_{2}$ hybrid colloids prepared using a water soluble silica precursor, Polymer 53 (2012) 11891197.

[17] H. Jia, D. Schmitz, A. Ott, A. Pich, Y. Lu, Cyclodextrin modified microgels as "nanoreactor" for the generation of Au nanoparticles with enhanced catalytic activity, J. Mater. Chem. A 3 (2015) 6187-6195.

[18] A. Pich, W. Richtering, Microgels by precipitation polymerization: Synthesis, characterization, and functionalization, Adv. Polym. Sci. 234 (2010) 1-37.

[19] R. Pelton, Temperature-sensitive aqueous microgels, Adv. Colloid Interface Sci. 85 (2000) 1-33.

[20] E. C. Cho, J.-W. Kim, A. Fernández-Nieves, D. A. Weitz, Highly Responsive Hydrogel Scaffolds Formed by Three-Dimensional Organization of Microgel Nanoparticles, Nano Lett. 8 (2008) 168-172.

[21] T. Tanaka, D. J. Fillmore, Kinetics of swelling of gels, J. Chem. Phys. 70 (1979) 1214.

[22] E. Sato Matsuo, T. Tanaka, Kinetics of discontinuous volume-phase transition of gels, J. Chem. Phys. 89 (1988) 1695.

[23] L. Liang, X. Feng, L. Peurrung, V. Viswanathan, Temperature-sensitive membranes prepared by uv photopolymerization of n-isopropylacrylamide on a surface of porous hydrophilic polypropylene membranes, J. Membr. Sci. 162 (1999) 235-246. 
[24] Y.-J. Choi, T. Yamaguchi, S.-i. Nakao, A novel separation system using porous thermosensitive membranes, Ind. Eng. Chem. Res. 39 (2000) $2491-$ 2495.

[25] N. Shtanko, V. Y. Kabanov, P. Y. Apel, M. Yoshida, A. Vilenskii, Preparation of permeability-controlled track membranes on the basis of "smart" polymers, J. Membr. Sci. 179 (2000) 155-161.

[26] D. Menne, F. Pitsch, J. Wong, A. Pich, M. Wessling, Temperaturemodulated water filtration using microgel-functionalized hollow-fiber membranes, Angew. Chem., Int. Ed. 53 (2014) 5706-5710.

[27] P. de Wit, E. J. Kappert, T. Lohaus, M. Wessling, A. Nijmeijer, N. E. Benes, Highly permeable and mechanically robust silicon carbide hollow fiber membranes, J. Membr. Sci. 475 (2015) 480-487.

[28] V. Boyko, A. Pich, Y. Lu, S. Richter, K.-F. Arndt, H.-J. P. Adler, Thermosensitive poly (n-vinylcaprolactam-co-acetoacetoxyethyl methacrylate) microgels: 1 - synthesis and characterization, Polymer 44 (2003) 78217827 .

[29] A. Pich, A. Tessier, V. Boyko, Y. Lu, H.-J. P. Adler, Synthesis and characterization of poly (vinylcaprolactam)-based microgels exhibiting temperature and ph-sensitive properties, Macromolecules 39 (2006) 7701-7707.

[30] G. R. Hendrickson, L. A. Lyon, Microgel Translocation through Pores under Confinement, Angew. Chem., Int. Ed. 49 (2010) 2193-2197.

[31] S. Saxena, C. E. Hansen, L. A. Lyon, Microgel Mechanics in Biomaterial Design, Acc. Chem. Res. 47 (2014) 2426-2434. 



\section{Chapter 8}

\section{Inorganic porous hollow fibers as support material for thin layers by interfacial polymerization}




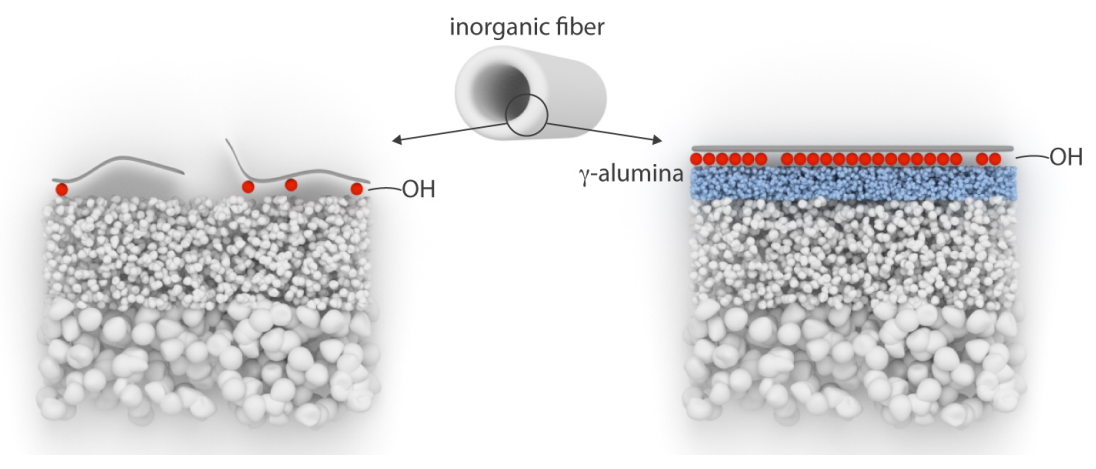

\begin{abstract}
Membrane separation under harsh conditions, such as high- $p, T$ or in the presence of aggressive chemicals, requires a robust membrane support. In academia commonly ceramic disks are used for this purpose, but these disks provide a too low surface-area-to-volume ratio for practical applications. Ceramic hollow fibers potentially provide a much larger specific surface area, but applying a defect free thin selective layer on such structures is more intricate. Here we show the successful preparation of a thin poly(amide) layer on a porous hollow $\alpha$-alumina fiber by interfacial polymerization of piperazine with trimesoyl chloride. Two aspects of the fabrication method are identified as particularly crucial for obtaining a high quality selective layer: in order to avoid delamination of the layer the ceramic surface should have a sufficient amount of hydroxyl groups for covalent attachment, and controlled drying steps are necessary to avoid local surplus or lack of liquid on the outer surface of the ceramic. To increase the hydroxyl group concentration and to facilitate the presence of sufficient reactants, the fibers have been coated with a layer of $\gamma$-alumina. Sufficiently long drying steps (20 min) have been employed to avoid uneven drying over the length of the fiber. The obtained fibers show clean water fluxes in the range of $2-5 \mathrm{~L} \mathrm{~m}^{-2}$ bar $^{-1} \mathrm{~h}^{-1}$ combined with retention of Rose Bengal above $99 \%$.
\end{abstract}




\subsection{Introduction}

Interfacial polymerization (IP) is a well-known technique to fabricate extremely thin separation layers on porous supporting structures and has been extensively studied over the past decades $[1,2]$. Research has been done on preparing thin selective films on porous polymeric supports, such as poly(ethersulfone) or poly(etherimide) [3-7]. The use of such membranes in harsh conditions can be limited by the stability of the thin selective layer as well as by the stability of the porous support. In applications involving high- $p, T$, or in the presence of aggressive chemicals, polymer supports can suffer from plasticization, swelling, or thermal degradation. The thermo-chemical stability of an inorganic porous support evades such problems. Ceramics have been successfully used as support for thin IP films, for example for hypercrosslinked networks that require an thermal imidization step [8], or for pervaporation where the mechanical and thermal stability of the ceramic is required $[9,10]$

Commonly, in academia ceramic supports have the geometry of a flat disk, with a far too low surface-area-to-volume ratio for viable industrial application. Hollow fibers provide a much larger surface-area-to-volume ratio [7, 11, 12] allowing for industrial application [13]. Inorganic porous hollow fibers can be prepared from various materials, for example $\mathrm{Al}_{2} \mathrm{O}_{3}$ [14], $\mathrm{TiO}_{2}$ [15] or $\mathrm{SiC}$ [16]. The diameters of such fibers can be as small as $\sim 200 \mu \mathrm{m}$ [17]. Limited research is reported on IP films prepared directly atop of porous inorganic hollow fibers. Nearly all IP films on inorganic porous hollow fibers involve the use of a polymeric intermediate layer. For example, a poly(ethersulfon) repair layer was coated onto a commercially available ceramic tube prior to the IP fabrication of a PVA-Pip-TMC layer [18]. A polymeric coating of PDA or PEI was applied onto an $\mathrm{Al}_{2} \mathrm{O}_{3}$ fiber with a relatively large outer diameter of $3.7 \mathrm{~mm}$ in order to facilitate the IP fabrication of an MDP-TMC layer [9]. The use of a polymeric repair layer inherently reduces the overall thermo-chemical stability of the final membrane. Peters et al. coated ceramic fibers with an inorganic $\left(\gamma-\mathrm{Al}_{2} \mathrm{O}_{3}\right)$ intermediate layer, prior to applying a micro porous silica layer [19] or poly(vinylalcohol) layer [20] via dip-coating.

To our knowledge, entirely inorganic thin porous hollow fiber supports, without polymeric intermediate layers, have never been modified by interfacial polymerization. In this work, we show that it is possible to fabricate a defect free layer by interfacial polymerization onto an $\mathrm{Al}_{2} \mathrm{O}_{3}$ hollow fiber with an outer diameter of $1.5 \mathrm{~mm}$, using an inorganic intermediate layer. 


\subsection{Experimental}

\subsubsection{Chemicals}

AKP-30 $\alpha-\mathrm{Al}_{2} \mathrm{O}_{3}$ powder $\left(99.9 \% \mathrm{Al}_{2} \mathrm{O}_{3}\right.$, particle size of $0.3 \mu \mathrm{m}$, Sumitomo Chemicals Co. LTD. Japan), poly(ethersulfone) (PES, Ultrason ${ }^{\circledR}$ E6020 P, BASF), and de-ionized water $\left(>18.2 \mathrm{M} \Omega \mathrm{cm}^{-1}\right.$, Milli-Q Advantage A10, Millipore) were used for fiber preparation. Prior to use, PES was dried overnight at $80^{\circ} \mathrm{C}$. Piperazine (Pip, 99\%), n-hexane (anhydrous, 95\%), trimesoyl chloride (TMC, 98\%), Rose Bengal (RB, 95\%), poly(vinyl alcohol) (PVA, Mowiol $\left.8-88, M_{W} 67000 \mathrm{~g} \mathrm{~mol}^{-1}\right)$, poly(vinyl pyrrolidone) $\left(M_{W} \sim 1,300,000\right)$, and $N$ methyl-2-pyrrolidone (NMP, <99.5\%) were obtained from Sigma-Aldrich (the Netherlands) and used as received. Nitric acid (1M) was obtained from Merck and diluted to $0.05 \mathrm{M}$ for further use. Ethanol (99\%) was obtained from Assink Chemie (the Netherlands).

\subsubsection{Fiber fabrication}

Alumina hollow fiber membranes were prepared by dry-wet spinning based on non-solvent induced phase separation (NIPS) using a well-established method [17]. In short, a mixture of AKP-30 $\alpha-\mathrm{Al}_{2} \mathrm{O}_{3}$ powder, polyethersulfone, $\mathrm{N}$ methylpyrrolidone and polyvinylpyrrolidone was spun into a de-ionized water bath functioning as non-solvent. The mixture composition and spinning parameters are listed in Table 8.1. After thermal treatment $\left(300^{\circ} \mathrm{C}\right.$ for $1 \mathrm{~h}, 1400^{\circ} \mathrm{C}$ for $2 \mathrm{~h}$, rate of $5^{\circ} \mathrm{C} \mathrm{min}^{-1}$ ) the fibers were coated with an AKP-30 $\mathrm{Al}_{2} \mathrm{O}_{3}$ layer in order to lower the surface roughness. A $50 \mathrm{wt} \%$ suspension of AKP-30 in $0.05 \mathrm{wt} \% \mathrm{PVA}$ in $0.02 \mathrm{~mol} \mathrm{HNO}_{3}$ solution is ultrasonic treated to disperse the AKP-30 particles. Prior to coating, one end of the fiber was sealed with hot melt adhesive (Dremel) and the fibers were vertically dip coated with a rate of $2.4 \mathrm{~cm} \mathrm{~min}^{-1}$ and a holding time of $30 \mathrm{~s}$. After drying (1h, 25C, REL 50-80\%) the fibers are sintered for $1 \mathrm{~h}$ at $1000^{\circ} \mathrm{C}$ with a heating rate of $5{ }^{\circ} \mathrm{C} \mathrm{min}{ }^{-1}$. Two layers of $\gamma$-alumina were applied on top of the $\alpha$-alumina fiber to provide enough hydroxyl-groups for covalent attachment of the poly(amide) layer to the support. For each layer of $\gamma$-alumina, $20 \mathrm{~mL}$ of PVA solution $(2.25 \mathrm{~g}$ PVA in $75 \mathrm{~mL} 0.05 \mathrm{M} \mathrm{HNO}_{3}$ ) and $30 \mathrm{~mL}$ of boehmite sol were mixed. The details of the boehmite synthesis and coating procedure are described elsewhere [21]. 
Table 8.1: Spinning conditions

\begin{tabular}{ll}
\hline Condition & Value \\
\hline PES & $9.40 \mathrm{wt} \%$ \\
NMP & $40.0 \mathrm{wt} \%$ \\
AKP-30 & $48.9 \mathrm{wt} \%$ \\
PVP K95 & $0.70 \mathrm{wt} \%$ \\
Water & $1.00 \mathrm{wt} \%$ \\
Bore Liquid & $\mathrm{H}_{2} \mathrm{O}$ \\
Coagulation bath & $\mathrm{H}_{2} \mathrm{O}$ \\
Extrusion pressure & $2 \mathrm{bar}$ \\
Air gap & $3 \mathrm{~cm}$ \\
Bore liquid flow rate & $7 \mathrm{~mL} \mathrm{m^{-1 }}$ \\
Diameter spinneret & $\mathrm{OD} / \mathrm{ID}=2.0 \mathrm{~mm} / 0.8 \mathrm{~mm}$ \\
Drying after spinning & $>24 \mathrm{~h}$ \\
\hline
\end{tabular}

The lower end of the fiber was sealed with hot melt adhesive and the fibers were vertically dip coated with a rate of $9 \mathrm{~cm} \mathrm{~min}^{-1}$. After drying $\left(2 \mathrm{~h}, 25^{\circ} \mathrm{C}\right.$, REL $50-80 \%)$ and removal of the hot melt adhesive, the $\gamma$-alumina layer is sintered for $1 \mathrm{~h}$ at $600^{\circ} \mathrm{C}$ with a heating rate of $5^{\circ} \mathrm{C} \mathrm{min}^{-1}$.

\subsubsection{Interfacial polymerization}

Prior to dipcoating, the fibers were sealed at the lower end with a $1.5 \mathrm{~cm}$ long glass tube filled with Araldite 2014-1 (Huntsman) and cured for $24 \mathrm{~h}$. There was no further pretreatment applied to the fibers. The fibers were inserted in the aqueous phase containing $2 \mathrm{wt} \%$ piperazine for 1 minute, and withdrawn with a vertical dipcoater $\left(9 \mathrm{~m} \mathrm{~min}^{-1}\right)$. The fibers were dried at ambient conditions for $20 \mathrm{~min}$, and inserted for 10 seconds in the organic phase $(0.15 \mathrm{wt} \% \mathrm{TMC}$ in n-hexane). The fibers were withdrawn with a speed of $897 \mathrm{~mm} \mathrm{~min}^{-1}$ and rinsed with acetone to remove any unreacted monomers. All fibers were stored under ambient conditions until further use. 


\subsubsection{Module fabrication}

The final fiber was glued (Araldite 2014, Huntsman) in a 1/4" piece of metal tubing that acts as the membrane outlet, whereas the other side of the fiber was already glued using an Araldite filled glass cap. The fiber is enclosed with a metal tube and connected to a T-piece for permeate/retentate streams. Figure 8.1 shows a schematic overview of the potted fiber and how the module assembly is connected to the setup for permeation experiments.

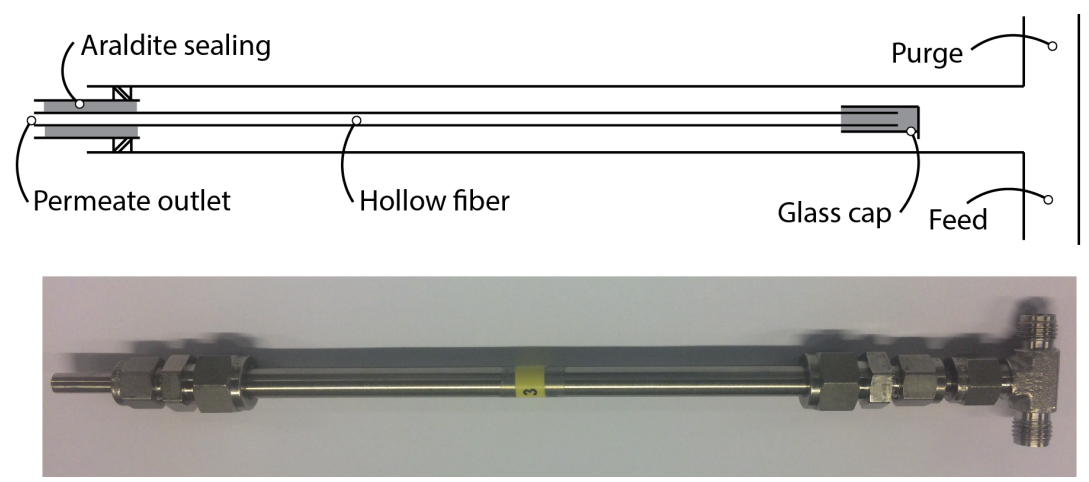

Figure 8.1: Schematic overview of membrane potting and assembly of the module

\subsubsection{Characterization methods}

Scanning electron micrographs of the cross-section and top view morphology of green, sintered, and TFC fibers were obtained with a Zeiss Merlin FE-SEM or JEOL-JSM6010 scanning electron microscope. Samples were coated with a $10 \mathrm{~nm}$ chromium layer (Quorum Q150T ES). The outer diameter of the fibers was measured using a Nikon V-12 profile projector with a 50x objective lens (Nippon Kogaku, Japan). 18 samples originating from 3 different fibers were analyzed and the average diameter was taken for flux calculations. Clean water fluxes were measured on a custom-build setup (Convergence, the Netherlands) in dead-end operation, the permeate volume was measured over time volumetrically. 


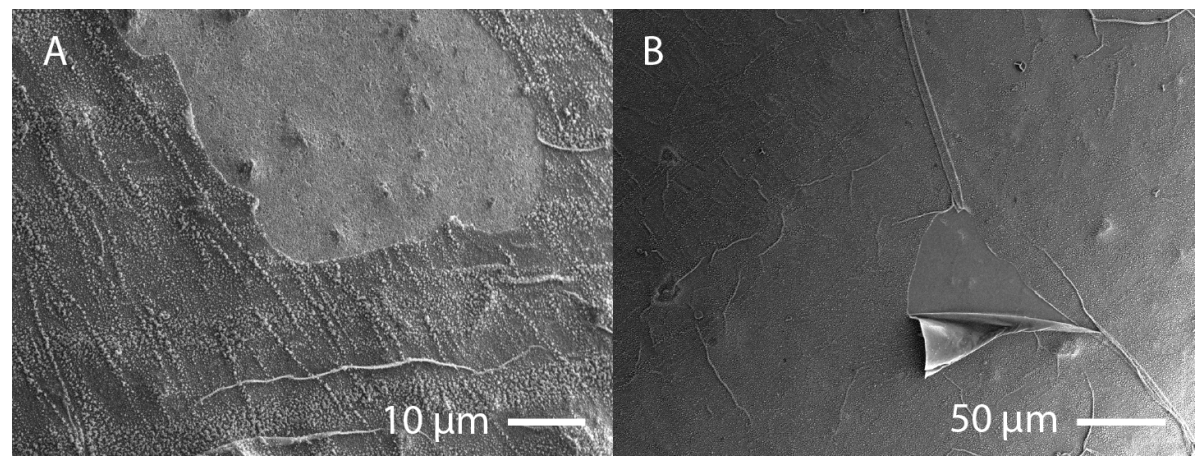

Figure 8.2: Scanning electron micrographs (top view) of a TMC-Pip film on an AKP-30 smoothed fiber. A poly(amide) film is present covering parts of the surface, but also clear patches of the ceramic support are visible.

Rose Bengal retention ( $35 \mu \mathrm{mol}$ in water or ethanol) was measured at a custommade dead-end filtration setup. The feed was pressurized with nitrogen to 18 bar applied to an outside-in geometry. Solute concentrations of the feed and permeate streams were measured with an UV-VIS spectrophotometer at $549 \mathrm{~nm}$ (Varian Cary 300 scan). The retention was calculated using:

$$
R=\frac{c_{f}-c_{p}}{c_{f}} \cdot 100
$$

\subsection{Results and discussion}

\subsubsection{Fiber fabrication and coating}

The $\mathrm{Al}_{2} \mathrm{O}_{3}$ fibers have pores in the range of $350 \mathrm{~nm}$ (not shown here, see [22]). The surface smoothing via coating with AKP-30 reduces the pore size to approximately $100 \mathrm{~nm}$. This pore size is sufficiently small to allow the formation of a defect free TMC-Pip layer by interfacial polymerization [23].

Figure 8.2A and B show top-view scanning electron micrographs of a layer prepared directly on the AKP-30 smoothing layer. A poly(amide) film is present covering parts of the surface, but also clear patches of the ceramic support are visible. Two main factors are hypothesized to contribute to this delamination; the lack of sufficient hydroxyl groups and insufficient drying of the fiber after being in contact with the aqueous phase. 
A sufficiently long drying time is required to avoid that excess aqueous solution is present on the outer surface of the fiber. This excess of aqueous solution may shield of the fiber surface from the reactant in the organic phase, causing film formation to occur at a slight distance from the fiber surface and prohibiting the surface hydroxyl groups to partake in the polymerization reaction. The relative large pores $(100 \mathrm{~nm})$ and low porosity $(30 \%)$ of the AKP-30 intermediate layer complicate controlled vertical drying of the outer surface of the fiber without affecting the aqueous phase inside the porous structure. The capillary forces in the pores are too small to disestablish the gravitational force. To increase the amount of hydroxyl groups, and to allow for a large reactant reservoir in $\sim 5 \mathrm{~nm}$ small pores, the fibers were coated with two layers of $\gamma$-alumina [24].

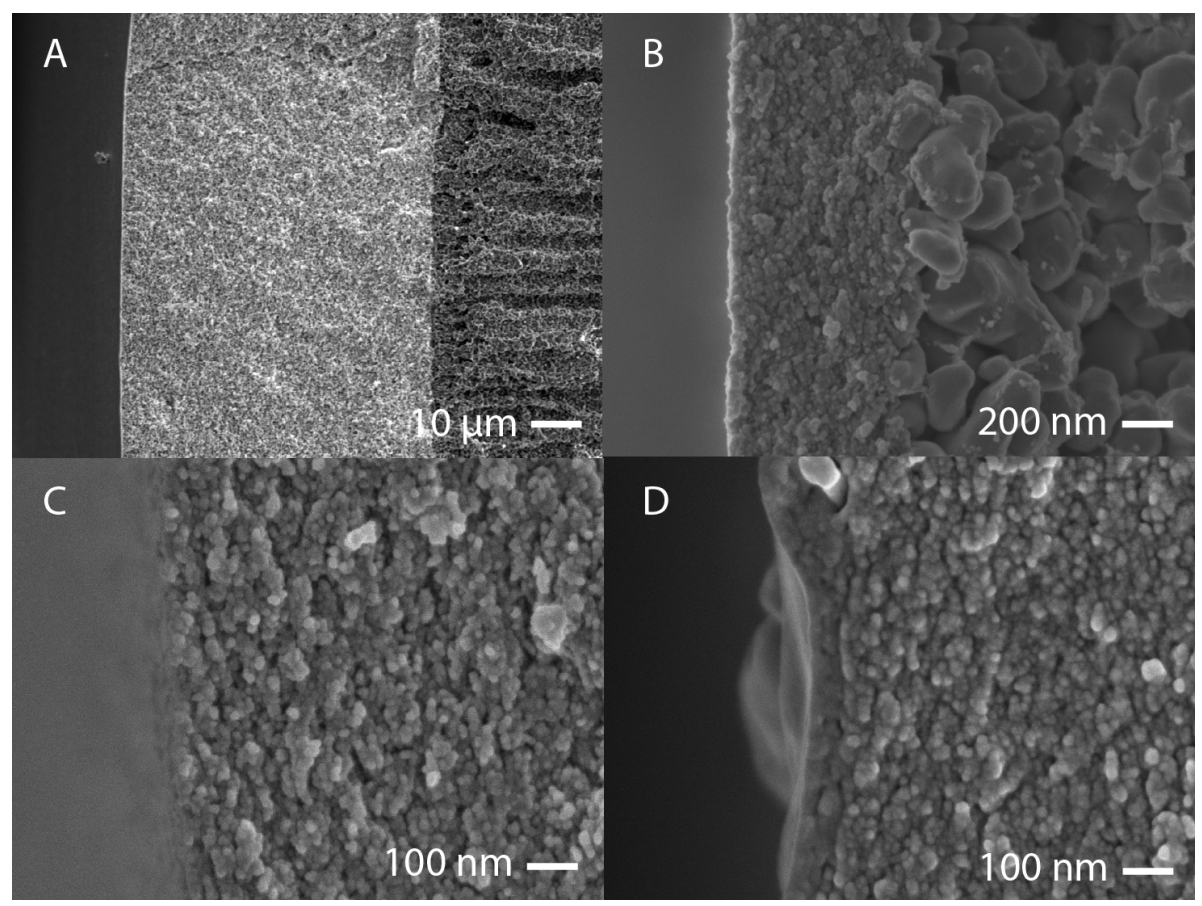

Figure 8.3: Cross-section scanning electron micrographs of the wall of an $\alpha$ alumina fiber coated with the AKP-30 smoothing layer (A). Panel B shows the $\gamma$-alumina layer. Panel $\mathrm{C}$ and $\mathrm{D}$ show the $\gamma$-alumina layer with (D) and without (C) TMC-Pip film 
Figure 8.3A to D show the successful coating of a ceramic NIPS hollow fiber. Panel A shows the outside of the fiber wall on which the AKP-30 smoothing layer is coated. Panel B shows a detail of the $\gamma$-alumina layer on the smoothing layer, where can be seen that the thickness is in the order of $200 \mathrm{~nm}$. The layer is found not to be defect free, possibly due to the non-clean room conditions of the coating. Figure $8.3 \mathrm{C}$ and $\mathrm{D}$ show a high resolution image of the $\gamma$-alumina layer, without (Panel C) and with (Panel D) the TMC-Pip layer present.

The $\gamma$-alumina coated fibers were submerged in the aqueous phase to fill the porous structure with piperazine monomer. The drying procedure after this step appears to be an important factor for successful preparation of membranes. Figure 8.4 shows the influence of the drying time at ambient conditions on the adhesion of the TMC-Pip layer to the support. Scanning electron micrographs were taken at the top and bottom of the fiber. Because the fibers were vertically dried, the amount of residual water is expected to be higher at the bottom of the fiber. It can be clearly seen that there is a water film present on the outer surface of the fiber after 10 minutes of drying, resulting in an unattached freestanding TMC-Pip film. However, 20 minutes of drying results in a wellattached film on both the top and bottom side of the fiber.

\subsubsection{Retention and Permeation}

Using the optimized synthesis parameters, 13 fibers have been fabricated and used for performance testing. Table 8.3.2 shows the results of these measurements. Out of 13 fibers, one of the fibers broke during potting. The remaining 12 fibers have been tested for their Rose Bengal retention. During these tests, 3 fibers showed such a poor retention and high flux that they were omitted from further analysis. This indicates that even due to careful surface pre-treatment, still minor defects can bee present. These defects might not necessarily be in the TMC-Pip layer itself, but could also arise from fiber handling during the coating steps, or from handling during potting of the fiber.

The clean water permeability and Rose Bengal retention have been measured for the 9 fibers that showed acceptable fluxes. The clean water permeability is in the order of $2-5 \mathrm{~L} \mathrm{~m}^{-2} \mathrm{~h}^{-1} \mathrm{bar}^{-1}$. This is in good agreement with previously measured TMC-pip membranes that have been prepared on flat-sheet PAN supports using a slightly different recipe [25]. All measured fibers show excellent retention $(>99 \%)$ for Rose Bengal in water, as compared to a retention of 61 $\%$ for a fiber with only the $\gamma$-alumina layer. 


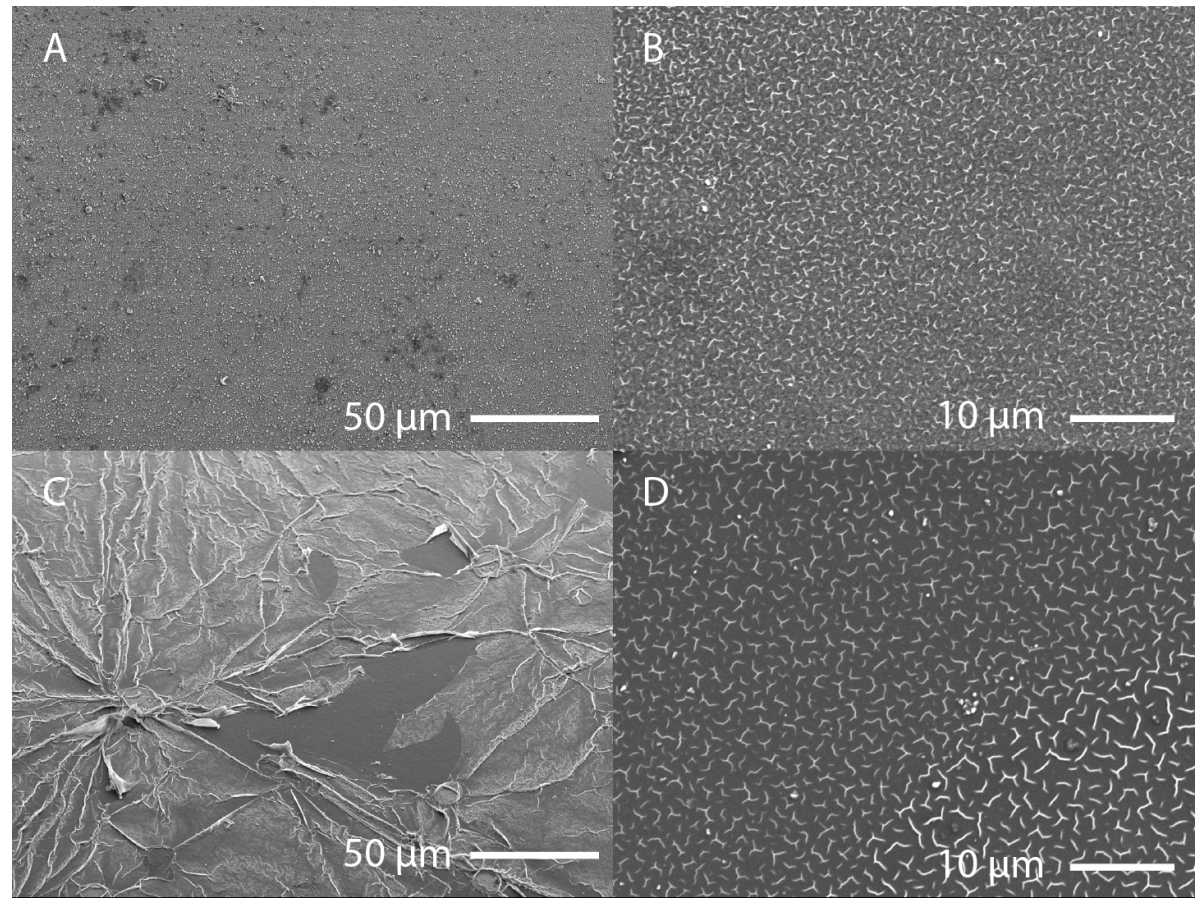

Figure 8.4: Top-view scanning electron micrographs of the TMC-Pip poly(amide) films. Micrographs were taken on the top (A and B) of the bottom $(\mathrm{C}$ and $\mathrm{D})$ of the hollow fiber. The fiber shown in $\mathrm{A}$ and $\mathrm{C}$ was dried for 10 minutes, the fiber in $\mathrm{B}$ and $\mathrm{D}$ for 20 minutes. 
Table 8.2: Summary of the results for 13 fibers prepared using the optimized recipe. For comparison also the results of an $\gamma-\mathrm{Al}_{2} \mathrm{O}_{3}$ fiber are shown.

\begin{tabular}{llll}
\hline$\#$ & Length $(\mathrm{cm})$ & Retention $(\%)$ & $\mathrm{CWP}^{a}\left(\mathrm{~L} \mathrm{~m}^{-2} \mathrm{~h}^{-1} \mathrm{bar}^{-1}\right)$ \\
\hline$\gamma$ & 10.2 & $61 \pm 1$ & $17.41 \pm 0.75$ \\
1 & 14.1 & $\mathrm{n} / \mathrm{m}^{c}$ & $\mathrm{n} / \mathrm{m}^{c}$ \\
2 & 13.7 & $99.8 \pm 1$ & $3.88 \pm 0.13$ \\
3 & 13.6 & $97.9 \pm 1$ & $3.84 \pm 0.31$ \\
4 & 13.9 & $\mathrm{n} / \mathrm{m}^{c}$ & $\mathrm{n} / \mathrm{m}^{c}$ \\
5 & broken $^{b}$ & & \\
6 & 13.7 & $99.8 \pm 1$ & $3.20 \pm 0.25$ \\
7 & 13.1 & $99.7 \pm 1$ & $2.32 \pm 0.18$ \\
8 & 13.2 & $99.9 \pm 1$ & $5.02 \pm 0.29$ \\
9 & 14.7 & $99.8 \pm 1$ & $4.08 \pm 0.45$ \\
10 & 13.0 & $\mathrm{n} / \mathrm{m}^{c}$ & $\mathrm{n} / \mathrm{m}^{c}$ \\
11 & 12.8 & $99.9 \pm 1$ & $3.31 \pm 0.26$ \\
12 & 14.7 & $100.0 \pm 1$ & $4.70 \pm 0.72$ \\
13 & 12.9 & $99.6 \pm 1$ & $4.03 \pm 0.23$ \\
\hline
\end{tabular}

${ }^{\text {a }}$ Clean Water Permeance with $95 \%$ confidence interval

$\mathrm{b}$ This fiber broke during potting.

${ }^{c}$ Flux was in the order of an unmodified fiber, omitted from further analysis. 


\subsection{Conclusion}

By modification of an AKP-30 $\mathrm{Al}_{2} \mathrm{O}_{3}$ fiber, prepared by dry-wet spinning with an AKP-30 repair layer using dip coating, a sufficiently smooth surface is obtained to allow the formation of TMC-pip thin films. In order to improve the chemical bonding to the support, sufficient hydroxyl-groups are required that can be obtained by coating two layers of $\gamma$-alumina onto the fiber. This, combined with appropriate drying of the fiber, after it has been soaked with the aqueous phase, allows for defect free thin films to be obtained. The TFC fibers show promising water permeance values (average $3.82 \mathrm{~L} \mathrm{~m}^{-2} \mathrm{~h}^{-1} \mathrm{bar}^{-1}$ ) with acceptable retention of Rose Bengal $\left(1017 \mathrm{~g} \mathrm{~mol}^{-1}\right)$.

Out of 12 tested fibers with a length over $12 \mathrm{~cm}, 9$ fibers were completely defect free, whereas other fibers showed a lower retention or high fluxes. Even due to careful surface pre-treatment, still minor defects can be present. These defects might not necessarily be in the TMC-Pip layer itself, but could also arise from fiber handling or fiber potting and sealing.

To conclude, this study shows that thin inorganic porous hollow fibers can indeed be a suitable support for layers prepared by interfacial polymerization, but it also shows that the pre-treatment of the fiber is of key importance to allow proper adhesion of the layer. The results obtained in this study could be used to fabricate thin films on inorganic porous hollow fibers with more advanced chemistries. By doing so, it would open the road for industrial application of these layers on a larger scale. 


\subsection{References}

[1] M. J. T. Raaijmakers, N. E. Benes, Current trends in interfacial polymerization chemistry, Prog. Polym. Sci. 63 (2015) 86-142.

[2] W. Lau, A. Ismail, N. Misdan, M. Kassim, A recent progress in thin film composite membrane: A review, Desalination 287 (2012) 190 - 199. Special Issue in honour of Professor Takeshi Matsuura on his 75th Birthday.

[3] W. Fang, L. Shi, R. Wang, Mixed polyamide-based composite nanofiltration hollow fiber membranes with improved low-pressure water softening capability, J. Memb. Sci. 468 (2014) 52-61.

[4] R.-X. Zhang, T. Liu, L. Braeken, Z. Liu, X.-L. Wang, B. Van der Bruggen, A design of composite hollow fiber membranes with tunable performance and reinforced mechanical strength, J. Appl. Polym. Sci. 132 (2015).

[5] X. Wei, S. Wang, Y. Shi, H. Xiang, J. Chen, B. Zhu, Characterization of a positively charged composite nanofiltration hollow fiber membrane prepared by a simplified process, Desalination 350 (2014) $44-52$.

[6] D. Hua, Y. K. Ong, P. Wang, T.-S. Chung, Thin-film composite tribore hollow fiber (tfc tbhf) membranes for isopropanol dehydration by pervaporation, J. Memb. Sci. 471 (2014) 155-167.

[7] S. Verssimo, K.-V. Peinemann, J. Bordado, New composite hollow fiber membrane for nanofiltration, Desalination 184 (2005) 1 - 11. Desalination and the EnvironmentDesalination and the Environment.

[8] M. J. T. Raaijmakers, M. A. Hempenius, P. M. Schön, G. J. Vancso, A. Nijmeijer, M. Wessling, N. E. Benes, Sieving of hot gases by hypercross-linked nanoscale-hybrid membranes., J. Am. Chem. Soc. 136 (2014) $330-5$.

[9] G. M. Shi, T.-S. Chung, Thin film composite membranes on ceramic for pervaporation dehydration of isopropanol, J. Memb. Sci. 448 (2013) 34-43.

[10] J. Zuo, Y. Wang, T.-S. Chung, Novel organic-inorganic thin film composite membranes with separation performance surpassing ceramic membranes for isopropanol dehydration, J. Memb. Sci. 433 (2013) 60-71. 
[11] P. Kosaraju, K. Sirkar, Interfacially polymerized thin film composite membranes on microporous polypropylene supports for solvent-resistant nanofiltration, J. Memb. Sci. 321 (2008) 155-161.

[12] S. Dutczak, C. Tanardi, K. Kopeć, M. Wessling, D. Stamatialis, "Chemistry in a spinneret" to fabricate hollow fibers for organic solvent filtration, Sep. Purif. Technol. 86 (2012) 183-189.

[13] I. Moch, Membranes, Hollow-Fiber, in: Kirk-Othmer Encycl. Chem. Technol., John Wiley \& Sons, Inc., 2000.

[14] B. Kingsbury, K. Li, A morphological study of ceramic hollow fibre membranes, J. Memb. Sci. 328 (2009) 134-140.

[15] T. Zhao, Z. Liu, K. Nakata, S. Nishimoto, T. Murakami, Y. Zhao, L. Jiang, A. Fujishima, Multichannel $\mathrm{TiO}_{2}$ hollow fibers with enhanced photocatalytic activity, J. Mater. Chem. 20 (2010) 5095.

[16] P. de Wit, E. J. Kappert, T. Lohaus, M. Wessling, A. Nijmeijer, N. E. Benes, Highly permeable and mechanically robust silicon carbide hollow fiber membranes, J. Memb. Sci. 475 (2015) 480-487.

[17] M. W. J. Luiten-olieman, M. J. T. Raaijmakers, L. Winnubst, T. C. Bor, M. Wessling, A. Nijmeijer, N. E. Benes, Towards a generic method for inorganic porous hollow fibers preparation with shrinkage-controlled small radial dimensions, applied to $\mathrm{Al}_{2} \mathrm{O}_{3}, \mathrm{Ni}, \mathrm{SiC}$, stainless steel, and YSZ, J. Memb. Sci. 407-408 (2012) 155-163.

[18] L.-Y. Chu, S. Wang, W.-M. Chen, Surface modification of ceramicsupported polyethersulfone membranes by interfacial polymerization for reduced membrane fouling, Macromol. Chem. Phys. 206 (2005) 19341940.

[19] T. A. Peters, J. Fontalvo, M. A. G. Vorstman, N. E. Benes, R. A. Van Dam, Z. A. E. P. Vroon, E. L. J. Van Soest-Vercammen, J. T. F. Keurentjes, Hollow fibre microporous silica membranes for gas separation and pervaporation: Synthesis, performance and stability, J. Memb. Sci. 248 (2005) 73-80.

[20] T. Peters, N. Benes, H. Buijs, F. Vercauteren, J. Keurentjes, Thin high flux ceramic-supported PVA membranes, Desalination 200 (2006) 37-39. 
[21] R. Uhlhorn, M. Huis in't Veld, K. Keizer, A. Burggraaf, Synthesis of ceramic membranes, J. Mater. Sci. Lett. 27 (1992) 527-537.

[22] P. de Wit, F. S. Daalen, N. E. Benes, The mechanical strength of inorganic porous hollow fibers, J. Memb. Sci. 524 (2017) 721-728.

[23] Y. Zhang, N. E. Benes, R. G. H. Lammertink, Visualization and characterization of interfacial polymerization layer formation, Lab. Chip 15 (2015) 575-580.

[24] M. Zamora, A. Cordoba, A study of surface hydroxyl groups on $\gamma$-alumina, J. Phys. Chem. 82 (1978) 584-588.

[25] M. Dalwani, N. E. Benes, G. Bargeman, D. Stamatialis, M. Wessling, Effect of ph on the performance of polyamide/polyacrylonitrile based thin film composite membranes, J. Memb. Sci. 372 (2011) 228-238. 

Chapter 9

\section{Reflections and perspectives}





\subsection{Reflections}

This thesis presents various topics related to the fabrication and utilization of inorganic porous hollow fibers (IPHF). This chapter reflects on the new materials and methods that have been used to prepare these fibers, the surface modifications that have been conducted to alter their separation performance, and the investigation of their mechanical strength.

\subsubsection{Reflections on new hollow fiber materials}

Current developments in the field of chemical engineering call for porous hollow fibers with additional functionality, for example to be used as microreactors, catalyst supports, or electrodes. For membrane applications, most studies focus on alumina or titania hollow fibers, but some applications can benefit from the use of other materials. An example of a promising material is silicon carbide ( $\mathrm{SiC})$, due to the low fouling tendency this material shows in oil/water separations [1].

Chapter 2 describes a method for the fabrication of silicon carbide hollow fibers. Via a two-step thermal treatment in argon, one is able to produce $\mathrm{SiC}$ fibers that have sufficient mechanical strength to be used in a single fiber membrane module. Although the mechanical strength of these fibers is acceptable, further optimization of the mechanical strength is required to allow the construction of larger, multi-fiber modules. By tuning the thermal treatment procedure, and therefore regulating the amount of residual carbon, it is possible to tune the electrical properties of $\mathrm{SiC}$ fibers. Fibers with a high amount of residual carbon have been used as heatable membrane support in chapter 7. Depending on the application, the residual carbon can either be advantageous, as it boosts the electrical conductivity [2], or can be undesirable, for example when a true $\mathrm{SiC}$ fiber is required because of its properties [1, 3-5].

\subsubsection{Reflections on polymer/solvent systems}

Major limitations of current polymer/solvent systems used to fabricate inorganic hollow fibers include the presence of sulfur in the polymer and the prerequisite of using organic solvents. The use of sulfur containing polymers can be avoided by selecting polymers such as CA, PEI, or PS. These polymers allow phase separation induced by a non-solvent. One of the downsides of these polymers can be the mismatch between the temperature of polymer decomposition and the required temperature for particle sintering. Most of these 
polymers decompose before initial sintering occurs. As a result, the structure might collapse.

The sulfur free polymers still require the use of an organic solvent. These solvents can be completely omitted by using a water-soluble polymer. Chapter 3 and chapter 4 describe two approaches of a new method that is based on ionic cross-linking of a water soluble sodium alginate with multivalent ions. In the first approach, referred to as external bio-ionic gelation (BIG-E), the multivalent ions are supplied from the solution in the coagulation bath. In the second method, referred to as internal bio-ionic gelation (BIG-I), the multivalent ions are present in the spinning mixture in the form of an insoluble carbonate salt. The carbonate salt is decomposed by protons supplied from the coagulation bath. The bio-ionic gelation avoids the use organic solvents and also prevents the formation of macro voids that are typical for fibers prepared via NIPS. Such macro voids are attributed to the formation of the polymer-lean phase during the NIPS process. These macro voids can persist in the structure of the fiber after thermal treatment and can have a significant impact on both the mechanical properties and the pore size distribution of the fiber. During bio-ionic gelation no polymer lean phase is formed and a symmetric fiber wall is obtained. As such, the bio-ionic crosslinking allows for a narrow pore size distribution and enhanced mechanical properties, as explained in chapter 6 . By selection of the multivalent ion, one can incorporate metal(oxide)s on the pore surface of the fibers (chapter 3). For example, by incorporating cobalt, catalytically active fibers can be prepared in a single step production process. A major challenge in the production of fibers by ionic gelation is the emergence of deformations during the drying step. The highly-swollen alginate gels contain large amounts of water. Removal of this water induces shrinkage in both longitudinal as well as radial direction. The contraction in longitudinal direction can be prevented, to a certain extent, by stretching the fibers during drying. Due to the high capillary forces and thin fiber wall, collapse of the fibers into a "flat" structure occurs quite readily. A possible solution to prevent this collapse would involve replacing the water by a more volatile solvent $[6,7]$.

\subsubsection{Reflections on multi-layer systems}

In this thesis two multi-layer systems are discussed; the first is a silicon carbide support on which thermally responsive microgels are coated, the second consists of an $\mathrm{Al}_{2} \mathrm{O}_{3}$ fiber on which a polymeric separation layer is deposited via interfacial polymerization. 
A electro-heatable membrane support allows for the fabrication of responsive membranes with a permeability and a selectivity that can be tuned via an electrical current supplied to the fiber. Such functionality is obtained by coating the silicon carbide fibers with poly $(N$-vinylcaprolactam $)(\mathrm{P}-\mathrm{VCL})$ microgels. Switchable membranes can be beneficial for applications where, for example, the feed stock might change from batch to batch, or when the product specifications might change. In addition, the temperature switch can allow for a more efficient backwash. One of the major concerns of these responsive membranes is their stability in acidic or non-aqueous environments; such conditions have been demonstrated to be detrimental for the microgel [8]. So far, the temperature switchable membranes have only been studied in single-fiber modules. Design and construction of multi-fiber modules will be challenging, in particular with respect to the required electrical connections.

The second discussed surface modification is based on interfacial polymerization (IP), an approach that is generally considered facile. At a stable interface two reactants meet and polymerize to form a thin layer. The thin layer is often supported by a porous organic or inorganic substrate. For applications involving demanding conditions the support material should provide sufficient stability. In this respect, ceramic substrates are often considered superior. Generally, flat ceramic substrates are used for interfacial polymerization [9] and scale-up to tubular geometries has received only limited attention [10-13]. Several factors are key to obtaining a high-quality thin layer on a large surface area ceramic support. The surface of support should be smooth, it should allow for wetting by one of the phases, it should have a sufficiently large pore volume to act as reactant reservoir, and its surface should allow for covalent attachment of the IP layer. In this thesis it is shown that for the fabrication of high-quality thin film composite poly(amide)/alumina porous hollow fibers an intermediate $\gamma$-alumina layer complies with these requirements; it is smooth and hydrophilic, it has a high porosity $(\sim 60 \%)$, and provides a large concentration of surface hydroxyl groups that can participate in the interfacial polymerization reaction. In addition to the properties of the hollow fibers that are requisite for obtaining a high-quality TFC membrane, a drying step in the fabrication process is identified as crucial as well. After a fiber has been in contact with the aqueous phase, a sufficiently long drying time is required to avoid that excess aqueous solution is present on the outer surface of the fiber. This excess of aqueous solution may shield the fiber surface from the reactant in the organic phase. This will cause film formation to occur at a slight distance from the fiber surface, prohibiting the surface hydroxyl groups to partake in the polymerization reaction. This problem is further amplified by the vertical orientation of the 
fibers during the drying step, allowing gravity to generate a gradient in the amount of solution over the length of the fiber. This results in distinct film formation characteristics at the top and bottom of the fiber. The small pores in the $\gamma$-alumina layer provide high capillary forces that, combined with the large number of surface hydroxyl groups, helps to negate these problems.

\subsubsection{Reflections on measurement of the mechanical strength}

Mechanical characterization of inorganic porous fibers is not straightforward. Generally, the mechanical characteristics of inorganic fibers are expressed in terms of their bending strength, and this bending strength is determined from measuring the force at failure for multiple samples in a 3-point or 4-point bending test. The results obtained by such tests should be treated with caution because they are strongly dependent on the specifics of the test (type of bending test, exact geometry of the set-up, the size of sample, the amount of samples measured, the method of data processing, etc.). Direct comparison between strength data found in literature is therefore not justifiable. It is strongly recommended to stick to published guidelines of, for example, the standards of ASTM $[14,15]$. Such a standard specifies many measurement parameters and give guidelines on the measurement protocol and data processing. Conforming to standards aids direct comparison of reported strength data.

Brittle failure processes in inorganic hollow fibers originate at weak points or critical defects. Consequently, the type of test and the sample size are crucial. A 4-point bending test is considered more appropriate than a 3-point bending test because the volume of the sample under stress is larger in a 4-point bending test there is a higher probability of finding a critical defect. Inherently, the strength values obtained from a 4-point bending test are lower as compared to a 3-point bending test. The distribution of weak points and defects is best captured when a large number of samples is measured.

The minimum amount of samples measured depends on the purpose of the measurement. A quick quantification of the average bending strength, within a $95 \%$ confidence interval, requires a minimum of 10 samples [15]. To describe the underlying probability distribution function, a minimum amount of 30 measurements is proposed if the distribution is known. Typically, the mechanical strength of inorganic hollow fibers is considered to follow a Weibull type distribution (with shape parameter $m$ and characteristic strength $\sigma_{\theta}$ ), or a Normal distribution (with mean $\mu$ and standard deviation $s$ ) $[15,16]$. Obviously, the accuracy and usability of the derived values greatly improves by 
measuring larger amounts of samples [17]. When the underlying distribution is not known, one has to measure many samples $(\sim 300)$ in order to accurately determine the type of distribution and to make reliable parameter estimates [17].

\subsubsection{Reflections on module design}

In this thesis all characterization and application tests are carried out on single fiber modules. In most cases, a single fiber is glued into a piece of tubing and operated in a dead-end or semi cross-flow operating mode. This allows for quick screening of hollow fiber properties. Such an approach is appropriate when focus is on the properties of the fiber itself, rather than on the performance of a module. Further scale up would not only require the conversion from dead-end operation to cross-flow mode, but would also require the design of multi-fiber modules. 


\subsection{Perspectives}

This chapter gives perspectives for future research in the field of inorganic porous hollow fibers, mainly focusing on novel fiber materials and the gaps that impede industrial application.

\subsubsection{Perspectives on functional fibers}

A wide range of materials is used to fabricate inorganic fibers. Extending this range of materials is only required when a specific application calls for a certain material. Many materials are suitable to act as high surface-area-to-volume support or membrane, but only little materials are used that actively promote reaction or separation. Extension of the array of fiber materials should be based on materials that do incorporate additional functionality. If one wants to optimize current fibers, one should focus on their mechanical properties, pore size, or conductivity. Optimizing these parameters will result in more versatile fibers that are easier to apply to many fields.

\section{Aluminum}

The use of aluminum as hollow fiber material could be a solution for the brittle nature of the fiber, that often hampers module building involving ceramic fibers. A large number of fibers is currently produced out of $\mathrm{Al}_{2} \mathrm{O}_{3}$, but the brittleness of this material makes the mechanical behavior of the fibers hard to predict. Aluminum would be a good alternative due to its ductile behavior, low weight, and with surface properties that resemble aluminum oxide.

Fabrication of these fibers is possible via the standard dry-wet spinning approach, using a mixture of aluminum particles, NMP and poly(EtherImide) (PEI) is dissolved in NMP, and water is used as non-solvent. After dry-wet spinning a PEI fiber loaded with aluminum particles is obtained [18, 19]. Figure $9.1 \mathrm{~A}$ shows a scanning electron micro graph of such a fiber.

The main challenge in fabricating aluminum porous hollow fibers is the thermal treatment, where the decomposition of PEI $\left(550^{\circ} \mathrm{C}\right.$ to $\left.650{ }^{\circ} \mathrm{C}\right)$ is close to the melting point $\left(660^{\circ} \mathrm{C}\right)$ of the aluminum. In order to fully remove the PEI, an oxidative environment is required, as thermal treatment in argon results in $40 \%$ char residue. Obviously, this results in oxidation of the aluminum to aluminum oxide, which can partially be overcome by using a reductive atmosphere such as $4 \% \mathrm{H}_{2}$ in $\mathrm{Ar}[20,21]$. By adjusting the thermal treatment program, we were able to sinter aluminum pellets with little amount of polymeric binder. 


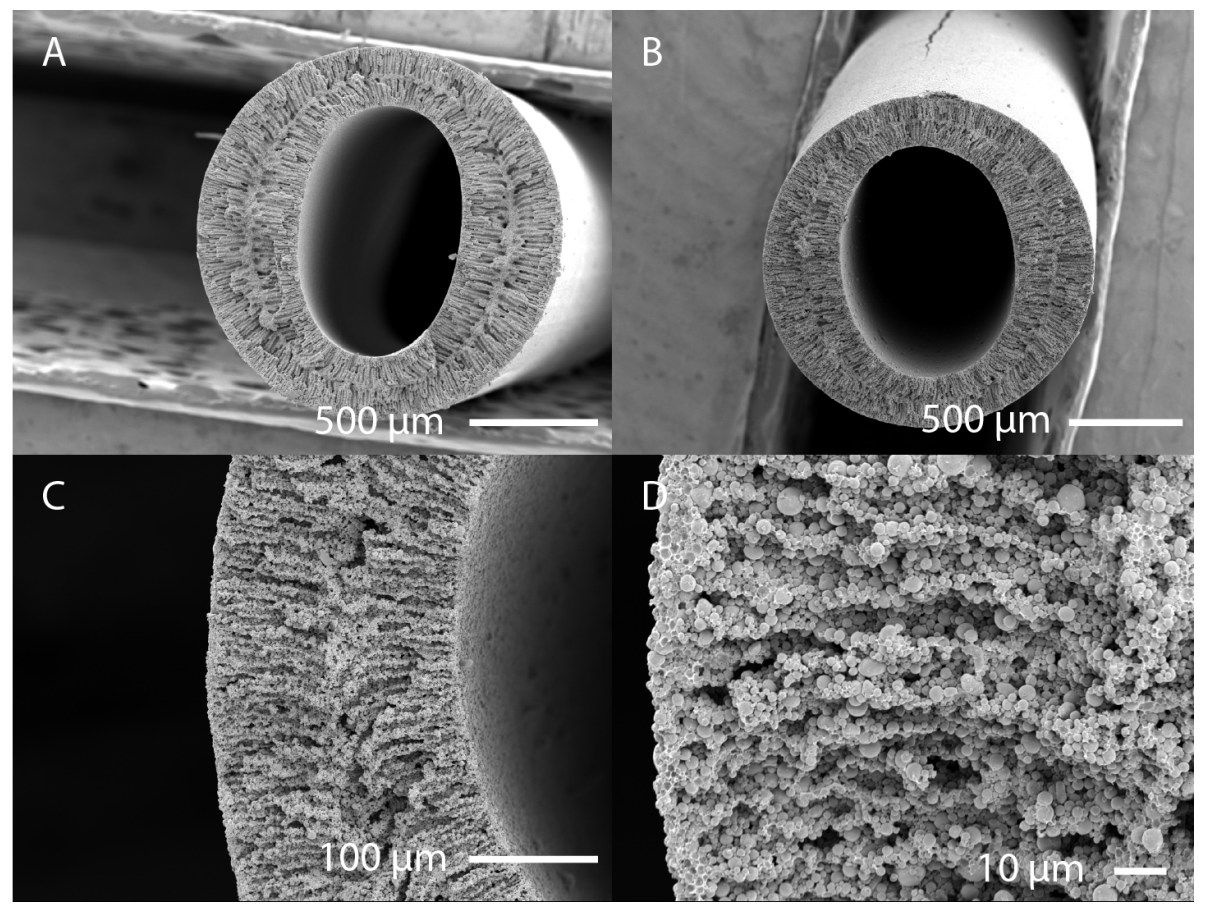

Figure 9.1: Scanning electron micrographs of aluminum hollow fibers before (A) and after (B, C and D) thermal treatment. (C) and (D) show a cross-section of the fiber wall, in which the individual aluminum particles are visible

Fibers, on the other hand, suffered from insufficient sintering, as Figure 9.1B, C and $\mathrm{D}$ shows. This is mainly due to the residual carbon and the low sintering temperature of $660^{\circ} \mathrm{C}$. As a result, the mechanical strength of these fibers was low. Possible routes to overcome this would include the use of a polymer with a lower decomposition temperature, or using a lower amount of polymer. Bio-ionic gelation methods allow for lower polymer concentrations, down to 2.5 wt $\%[22]$. 


\section{Copper}

Large scale aqueous phase electrochemical conversion of carbon dioxide to carbon monoxide requires an active, earth abundant electrocatalyst. A porous hollow fiber copper electrode with a compact 3-D geometry provides a large area, three-phase boundary for gas-liquid reactions and is a promising candidate for carbon dioxide reduction. This concept is schematically depicted in Figure 9.2, in which $\mathrm{CO}_{2}$ is forced to flow through the wall of a porous hollow copper fiber. Such a fiber can easily be prepared by dry-wet spinning of a $\mathrm{PEI} / \mathrm{NMP} /$ Copper mixture.

Figure 9.2: Artist impression of a copper hollow fiber which acts as gas diffusing electro-catalyst for the conversion of $\mathrm{CO}_{2}$ into $\mathrm{CO}$

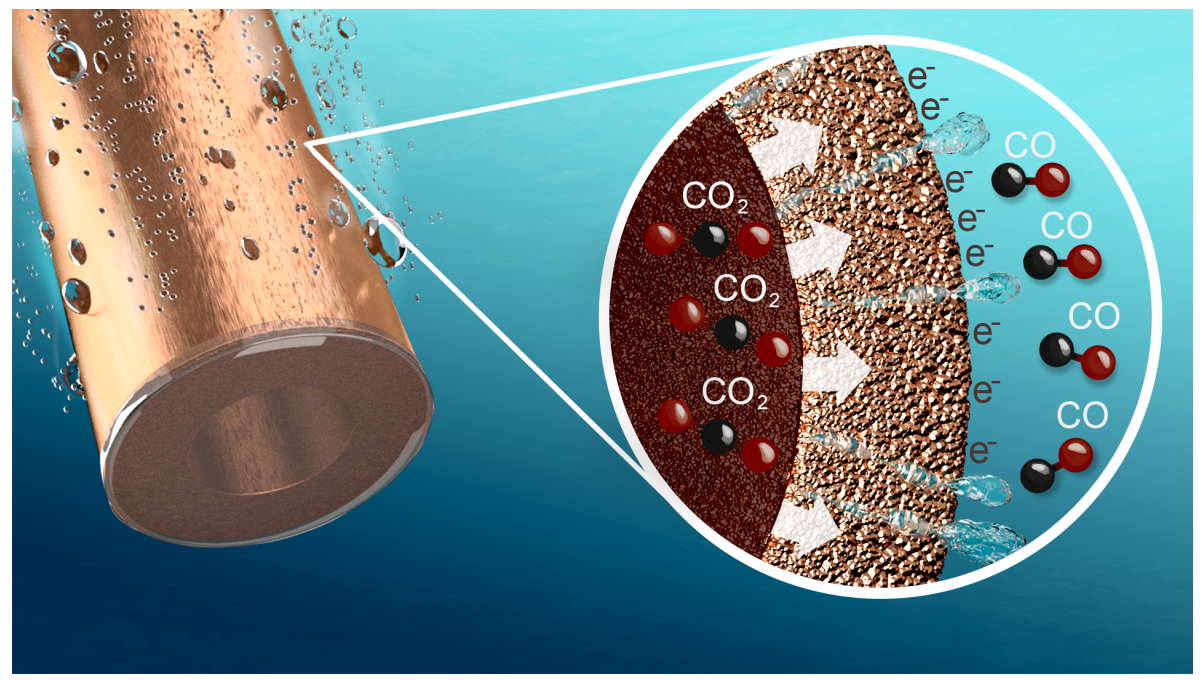

After drying, the fiber is thermally treated in a two-step process. In the first step, the PEI is removed under air at $600{ }^{\circ} \mathrm{C}$. As a result, the copper particles are sintered and converted into copper oxide. In order to obtain a catalytically active fiber, the copper oxide fiber is reduced to copper under a reducing $(4 \%$ $\mathrm{H}_{2}$ in $\mathrm{Ar}$ ) atmosphere. The porous copper hollow fiber is subsequently tested for its catalytic conversion of $\mathrm{CO}_{2}$ in $\mathrm{CO}$

The performance of the copper electrode is unprecedented; at over-potentials between $200 \mathrm{mV}$ and $400 \mathrm{mV}$, faradaic efficiencies for $\mathrm{CO}_{2}$ reduction of up to $85 \%$ have been obtained. Moreover, the $\mathrm{CO}$ formation rate is at least one order 
of magnitude larger when compared to state-of-the-art nano-crystalline copper electrodes.

Copper hollow fiber electrodes can be prepared via a facile method that is compatible with existing large-scale production processes. The results of this study may inspire the development of new types of hollow fiber electrodes for electrochemical processes in which at least one gas phase reactant is involved, such as in fuel cell technology [23].

\section{Metal coated}

For many applications, it is not necessary to use a fully metal fiber. For catalytic or electrical applications, a (conductive) outer shell layer would be sufficient. Post-modification of $\mathrm{Al}_{2} \mathrm{O}_{3}$ fibers with electroless deposition allows for the fabrication of such a fiber.

\section{Nickel on $\mathrm{Al}_{2} \mathrm{O}_{3}$}

Electroless deposition of nickel/phosphorus or boron alloys is used for a number of applications, such as in automotive, aircraft/aerospace, and chemical industry to improve wear resistance or corrosion protection. Furthermore, nickel benefits from good electrical and thermal properties. The electroless deposition of nickel on non-conductive substrates has been extensively studied [24-26]. The method is based on electrochemical reduction of a metal complex using a strong reductor. In order to allow electron transport on a non-conductive support, such as a ceramic fiber, pre-treatment of the surface is required. The most common method is based on seeding the surface with $\mathrm{PdCl}_{2}$, followed by reduction with sodium hypophosphite [25].

Using a system based on propionic acid and lactic acid used as complexing agents, nickel(II) sulfate as nickel source, thiourea as stabilizer and sodium hypophosphite as a reducing agent nickel layers were deposited on porous alumina hollow fibers. The $\mathrm{pH}$ of the plating bath was adjusted using sodium hydroxide and hydrochloric acid [27]. Figure 9.3A shows the wall of an $\mathrm{Al}_{2} \mathrm{O}_{3}$ fiber that has been plated with a nickel layer. The fiber was in contact with the plating bath for 5 minutes. In B, a close-up of the wall is depicted, which shows that the nickel deposition also occurs in the porous wall structure of the fiber. By increasing the plating time, the nickel layer can be adjusted in terms of porosity. After a plating time of 40 minutes, a dense nickel layer is obtained on the wall of the fiber [22]. 
Figure 9.3: $\mathrm{An} \mathrm{Al}_{2} \mathrm{O}_{3}$ porous hollow fiber with a nickel inner and outer layer. The layer is obtained by 5 min electroless deposition. (B) shows a magnification where the growth inside the porous structure is visible.

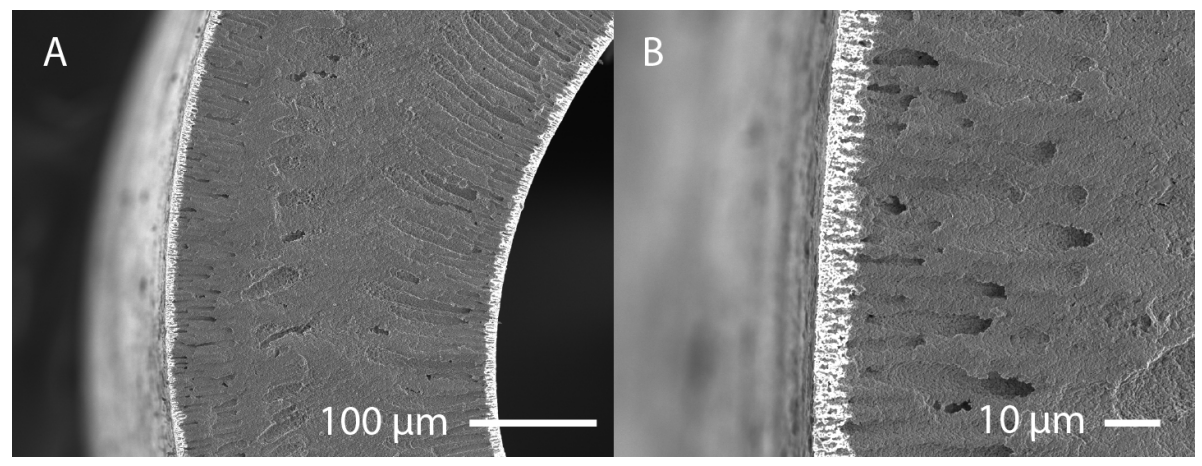

Nickel is often used as a catalyst, for example in hydrogenation of organic compounds [28]. The high surface-to-volume ratio of the $\mathrm{Al}_{2} \mathrm{O}_{3}$ fiber and its excellent resistance to elevated temperature and pressure make this an interesting assembly for, for example, the construction of a microreactor. However, the catalytic activity of the deposited nickel was not investigated and impurities of the plating bath might be affecting its performance. Secondly, a dense nickel layer could help in the sealing of inorganic hollow fibers, in which the nickelcoated part of the fiber is soldered into a module. Thirdly, a nickel coated layer could be used to incorporate electrical functionality in the fiber, such as the use as electrode or as heating element.

\section{$\mathrm{Cu}$ on $\mathrm{Al}_{2} \mathrm{O}_{3}$}

Copper can be deposited in a similar way as nickel, using electroless decomposition of a copper complex and a suitable reducing agent. Using EDTA and triethanolamine as complexing agents, copper sulfate as copper source and formaldehyde as reducing agent, a layer of copper can be deposited on a $\mathrm{Al}_{2} \mathrm{O}_{3}$ support [29].

In order to use copper coated $\mathrm{Al}_{2} \mathrm{O}_{3}$ fibers for the conversion of $\mathrm{CO}_{2}$ in $\mathrm{CO}$, a highly porous copper layer is required. This is obtained by purging argon through the fiber during electroless plating, which often results in a unstable plating bath. It is hypothesized that small particles present in the fiber' structure are forced into the plating bath. These particles result as nucleus for 
rapid deposition of the copper plating bath. Fibers with a copper layer were subsequently tested for their efficiency in $\mathrm{CO}_{2}$ reduction, but were found to perform poorly. One of the main reasons is the lower poresize of the $\mathrm{Al}_{2} \mathrm{O}_{3}$ support $(100 \mathrm{~nm})$ as compared to the fully copper fibers $(1 \mu \mathrm{m}$ to $3 \mu \mathrm{m})$. As a result of this, only little $\mathrm{CO}_{2}$ is available for the reaction [30].

\subsubsection{Perspectives on bio-ionic gelation}

Bio-ionic gelation of a sodium alginate results in thin-walled fibers with a symmetrical wall, without the presence of large voids that are often present in fibers derived from non-solvent induced phase separation.

As chapter 6 shows, BIG-I derived fibers suffer from deformations in present in the outer wall of the fibers. These deformations could originate from agglomerates that are not fully removed during the preparation of the spinning mixture, in which a mixture of water and inorganic particles is ultrasonically treated for 30 minutes prior to alginate dosage. An alternative method that might prevent the formation of these agglomerates could be ball-milling, which is frequently used to fabricate spinning mixtures involving inorganic particles [31-35].

A second hypothesis is that these deformations occur during drying of the water swollen alginate gels. After spinning, the BIG-I fibers are stored in an acid bath to allow full liberation of the $\mathrm{M}^{2+} \mathrm{CO}_{3}$ salt, followed by rinsing with deionized water and drying under ambient conditions. Upon further drying, large stresses develop in the fiber that might result in deformation of the outer wall. The degree of shrinkage depends on how well these fibers are dried. In turn, the drying rate depends on the ambient conditions, as Figure 9.4 shows. In this figure, the normalized longitudinal shrinkage is shown as function of the time on the left-hand $y$-axis, whereas on the right-hand $y$-axis the relative humidity is plotted over time. It is clear that after a short period the water content of the fiber is in equilibrium with the surrounding air. Upon increase of the ambient humidity, the dilation of the fiber suggests that it takes up water. In the case of drying shrinkage would be expected. Up to now the fibers have not been dried in a controlled environment, and conditions might vary from experiment to experiment. Homogeneous drying under a controlled environment might reduce the shrinkage observed during this step. 


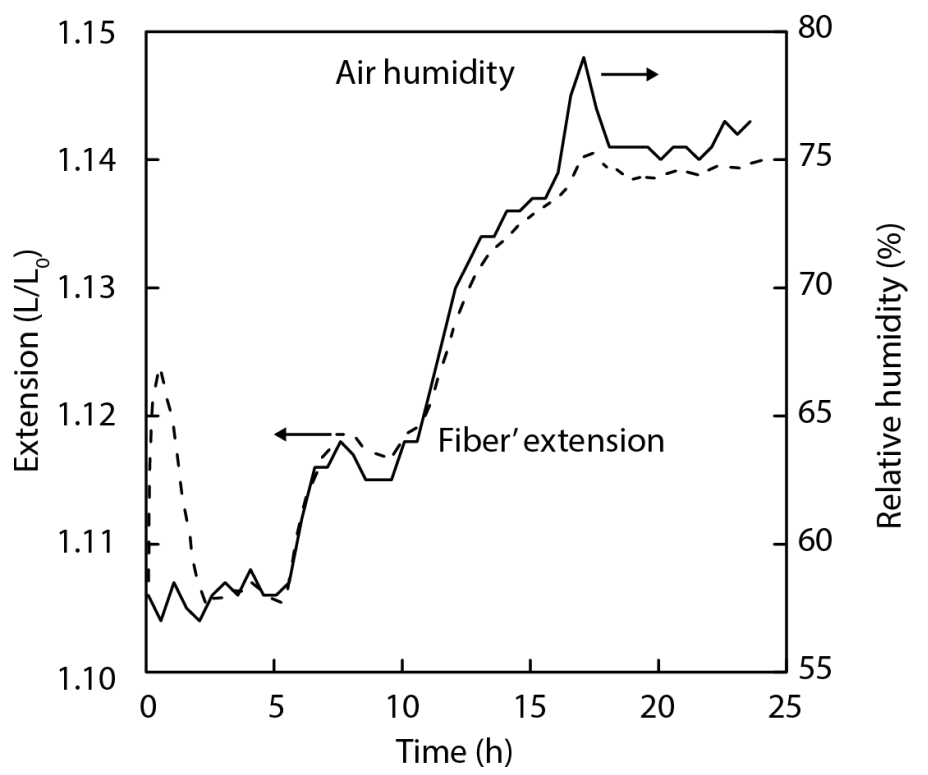

Figure 9.4: Normalized length of a sodium alginate fiber (solid line) and the relative humidity of the drying atmosphere (dashed line) over time.

The sodium alginate gel contains large amounts of water, and drying will cause large changes in the dimensions of the fibers. If the changes in geometry are too large or too fast, the structure might even deform or collapse. The structural collapse upon drying has been studied extensively for alginate-gel based microspheres [7, 31, 36-48]. A method to fully dry the fiber, without inducing large stresses in the fiber wall, can be based on exchanging the water for a less bound solvent. This approach has been used previously in the drying of sodium alginate microspheres.

Figure 9.5 shows a scanning electron micrograph of an alginate derived fiber before thermal treatment. Figure A shows a fiber dried after a brief rinse with deionized water after the gelation bath, figure B shows a fiber that was rinsed with deionized water, stored in ethanol for 24 hours, and dried under comparable conditions [49]. The difference in wall thickness is likely not the result of the ethanol immersion, but could be a local variation in the fiber's wall thickness. 
Figure 9.5: A sodium alginate fiber dried directly after the gelation bath (A) versus a fiber that was immersed in ethanol for $24 \mathrm{~h}$ prior to drying (B)

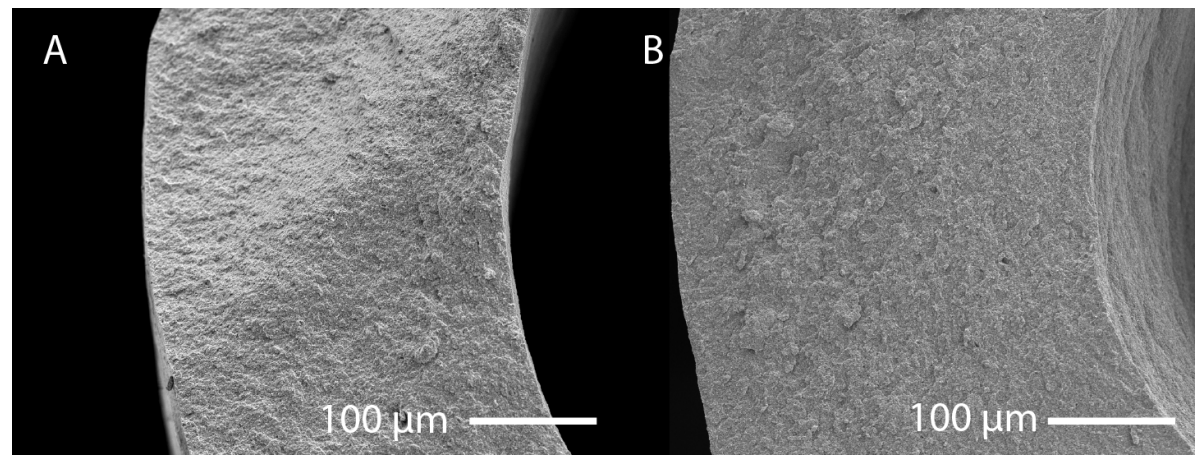

Fibers stored in ethanol prior to sintering show less deformations and do not collapse that often. This suggests that solvent exchange prior to sintering could overcome the deformations induced during drying. Another approach could involve ethanol as co-solvent during spinning, which might limit the swelling of the sodium alginate gel [6].

\subsubsection{Perspectives on module design}

At present, the quality of inorganic porous hollow fibers has advanced to a level where further optimization of the fiber itself might not be beneficial. Major factors that impede industrial application, such as lack of mechanical strength and large pore sizes, have been eliminated. Ensuing challenges are the design and construction of fiber systems/modules for large scale operation. Several hollow fiber modules are identified:

- A single fiber, sealed with glue on one side for dead-end operation

- A single fiber, sealed with glue on two sides for cross-flow operation

- A single fiber, sealed with O-rings for dead-end or cross-flow operation

- Multiple fibers sealed with glue on both sides 


\section{Single fiber glued on one side}

Currently, the majority of modules is based on a single fiber with one end glued into a tube, and the other end glued shut. The tube acts as inlet or outlet, depending whether inside-out or outside-in tests are carried out. section 9.2.3 schematically shows such a module, which is operated in an inside-out fashion. For outside-in, the inlet and outlet connections are reversed.

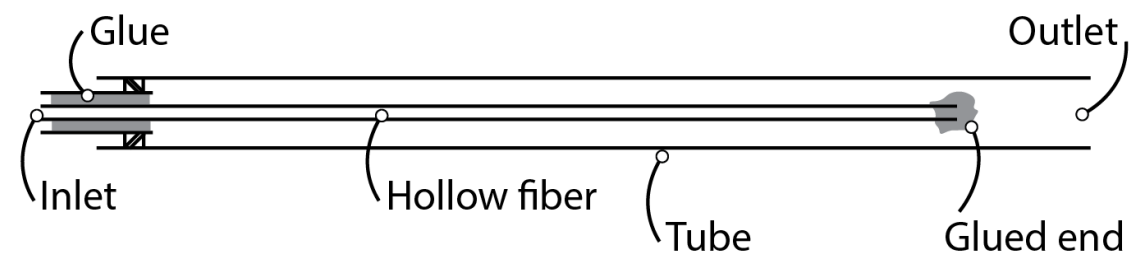

Figure 9.6: A schematic drawing of a single fiber module glued on one side. The depicted module is operated in inside-out dead-end mode. For outside-in operation, the inlet and outlet can be reversed.

In our labs, the fiber is generally potted in a $3 \mathrm{~cm}$ long $1 / 4$ inch stainless steel tube using a suitable glue. As outer tube, often a $1 / 2$ inch metal tubing is used and the fiber is inserted in the outer tube using a Swagelock connection (Part no SS-810-6-4). The assembled module offers reasonable protection to the brittle fiber and allows for quick connection of the module to, for example, a clean water setup. These single fiber modules are excellent for quick screening of fiber properties such as porometry, clean water fluxes or molecular weight cutoff measurements. The major downside is the lack of support on one end of the fiber, which might result in failure of the fiber upon rough handling. In addition, the dead-end operation with its associated susceptibility for fouling makes these modules impractical to study practical separations.

\section{Single fiber glued on two sides}

The method of putting a single fiber into a module has been extended by gluing the fiber on both ends, which results in a module that is schematically shown in Figure 9.7. A feed, permeate and retentate stream can be connected to the module, and the module can be operated in inside-out cross-flow mode. Variations of such a module exist, for example to allow outside-in cross-flow 
mode. In that case, a second T-piece is used to allow a feed and retentate to flow along the membrane.

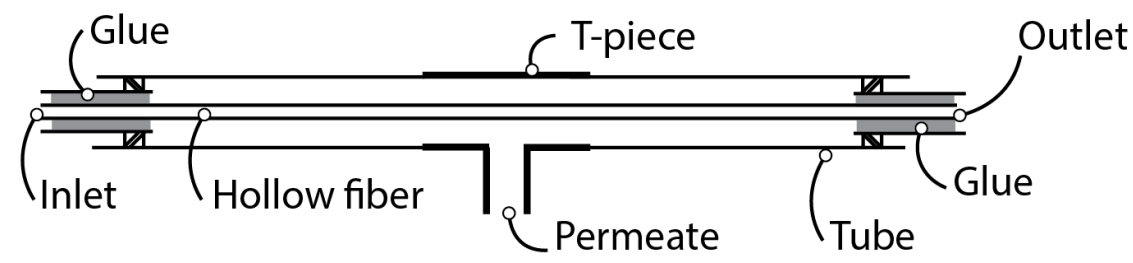

Figure 9.7: A schematic drawing of a single fiber module glued on two sides. The depicted module can be operated in inside-out cross-flow mode.

The module is constructed in a similar way as the one-side-glued module, but requires more care in assembling as the two ends of the fiber are easily rotated. This results in a torsional force on the fiber which will lead to failure of the fiber. Once assembled, the fiber is well protected and supported on both sides and the module allows for easy connection to a membrane setup. By closing the outlet the module can also be used in dead-end mode. Yet, the success rate of assembling such a module is low, as fibers often break during module assembly due to torsional forces. Circumventing the use of glue, for example by an o-ring, would allow for fiber replacement upon failure.

\section{Single fiber sealed with an O-ring}

Gluing a fiber on both ends results in good support of the fiber on both ends, but also limits the movement of the fiber during module assembly. In addition, many glues have undesirable properties that result in a loss of sealing, for instance swelling or embrittlement. Furthermore, a fiber glued into a module is permanently fixed inside the module and can not be removed or replaced when broken. A module has been designed based on a single o-ring sealing on the outer side of the fiber, in such a way that torsional forces on the fiber would be as low as possible. The module can be seen in section 9.2.3. By uni-axially clamping the two parts together the fiber is well sealed and torsion is avoided. The module is tested with an inorganic fiber with a pore size of $300 \mathrm{~nm}$ and measuring a molecular weight cutoff for an aqueous Dextrane solution. The MWCO value $(26000 \mathrm{kDa})$ of the system suggests that all Dextranes are retained by the fiber and that there is leakage from the feed side to the permeate side of the module. 

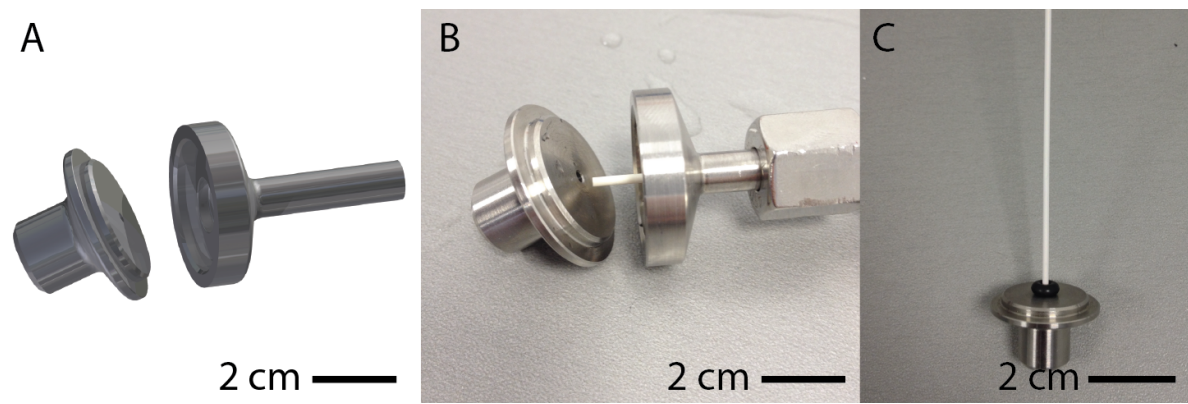

Figure 9.8: (A) shows a schematic drawing with the concept of sealing the fiber with an o-ring. (B) and (C) show the constructed module with the fiber inserted into the module, in (C) the o-ring is clearly visible

\section{Multiple fibers sealed with glue}

In order to house multiple fibers into a single module the techniques used for polymeric hollow fibers can serve as inspiration. Aligning multiple fibers and gluing these into a piece of tubing is frequently done for polymeric fibers, for example for the fabrication of dialysis modules [50-52]. This approach is also used for inorganic fibers, Figure $9.9 \mathrm{~A}$ shows 5 inorganic fibers glued into a stainless steel tube, which are used for separation of olefin/parafin gas mixtures. This shows the feasibility of the approach, but drawbacks remain. Firstly, further scale-up is limited. When more fibers are stacked into the bundle it becomes increasingly difficult for the glue to reach the core of the bundle. This is seen in figure $\mathrm{B}$ and $\mathrm{C}$, where $10+$ silicon carbide fibers are glued into a silicon carbide (Figure 9.9B) or in a PVC (Figure 9.9C) tube. A possible solution would be the use of spacers to keep the fibers slightly separated, but this would strongly complicate bundle fabrication.

Secondly, stacking many fibers into a closely packed bundle will inevitable result to fracture of one or more fibers. As these fibers are not always completely straight, and adjacent fibers might touch resulting in a point load on the fiber. A local high force on the fiber might result in failure of the fiber, rendering the entire bundle useless. 


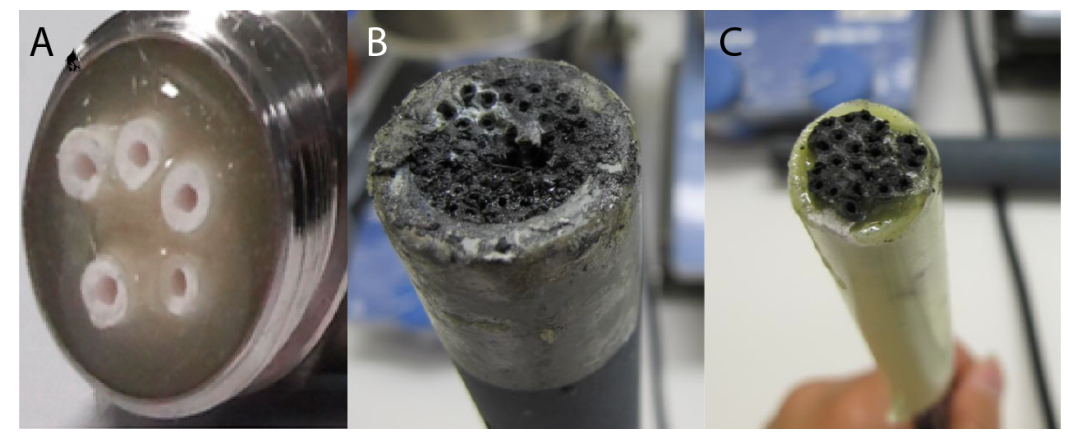

Figure 9.9: Multiple ceramic fibers potted using glue into a stainless steel tubing (A), a silion carbide tube (B), or PVC tube (C). Panel (A) is reprinted (adapted) with permission from Faiz et al..

Thirdly, it is difficult to create a smooth cross-section after sealing of the fibers. For polymeric fibers these glued bundles are usually cut, using a sharp knife, to their desired length, leaving a smooth cross-section. When ceramic fibers are used, cutting required more work often resulting in fragmentation of the fibers used.

Fourthly, a bundle of fibers glued into a tube is not a module yet. Inserting the module into a casing and ensuring sealing of the bundle itself into the casing is not straightforward, as manipulation of the bundle poses a high risk of fracturing the fibers.

Lastly, by gluing these fibers into a piece of tubing, the glue becomes the weak link of the module, which might result in a module that is not suitable for its intended use. Inorganic fibers are excellent in terms of thermal and chemical resistance, contrary to most polymeric glues used to seal these bundles. 


\section{Glue stability}

Even though inorganic fibers have a high thermal and chemical stability, this is often not the case for the glues used to pot these fibers, making this one of the weak points of the system. There are several factors of importance in selecting a suitable glue;

1. The glue should be stable under operating conditions ( $T, P$, solvents);

2. The glue should adhere properly to the material to ensure sealing;

3. The glue should be of appropriate viscosity.

With respect to the first item, most glues fail. Most polymer based glues are unsuitable for use at temperatures in excess of $200{ }^{\circ} \mathrm{C}$ or elevated pressures. In addition, a large range of glues shows swelling upon contact with various solvents, such as toluene, acetone, or hexane. Table 9.1 shows the stability of several commercial glues used in this thesis. The second item seems trivial, but some glues do not completely adhere to the surface, possibly due to wetting problems and the porous nature of the fiber. The third item can be explained in multiple ways. A low viscosity is required for the glue to reach the core of a bundle of fibers, but a too low viscosity results in flow of the glue. A too high viscosity makes dispensing glue, e.g. from a syringe, impossible.

Out of the glues mentioned in Table 9.1, hot melt adhesive is used in our laboratory to temporarily seal fibers to prevent the penetration of liquids into the bore of the fiber, e.g. during dipcoating of an aquous solution. The major downside of the hot melt adhesive is its lack of solvent resistance. Therefore, when dipcoating in solvents such as hexane, often Araldite 2014-1 is used for its better solvent resistance. The sealing capacity of Araldite 2014-1 is acceptable, with good adhesion to porous $\mathrm{Al}_{2} \mathrm{O}_{3}$ fibers.

The used poly(urethane) has a too low viscosity to be practical, as the glue simply flows away from the interface. DW30 is a commercial cement which as acceptable solvent resistance and is thermally resistant up to $400^{\circ} \mathrm{C}$. The major downside is the low sealing capacity of the cement, which is attributed to non-wetting of the pores, leaving a large percolative pathway along the sealing. 


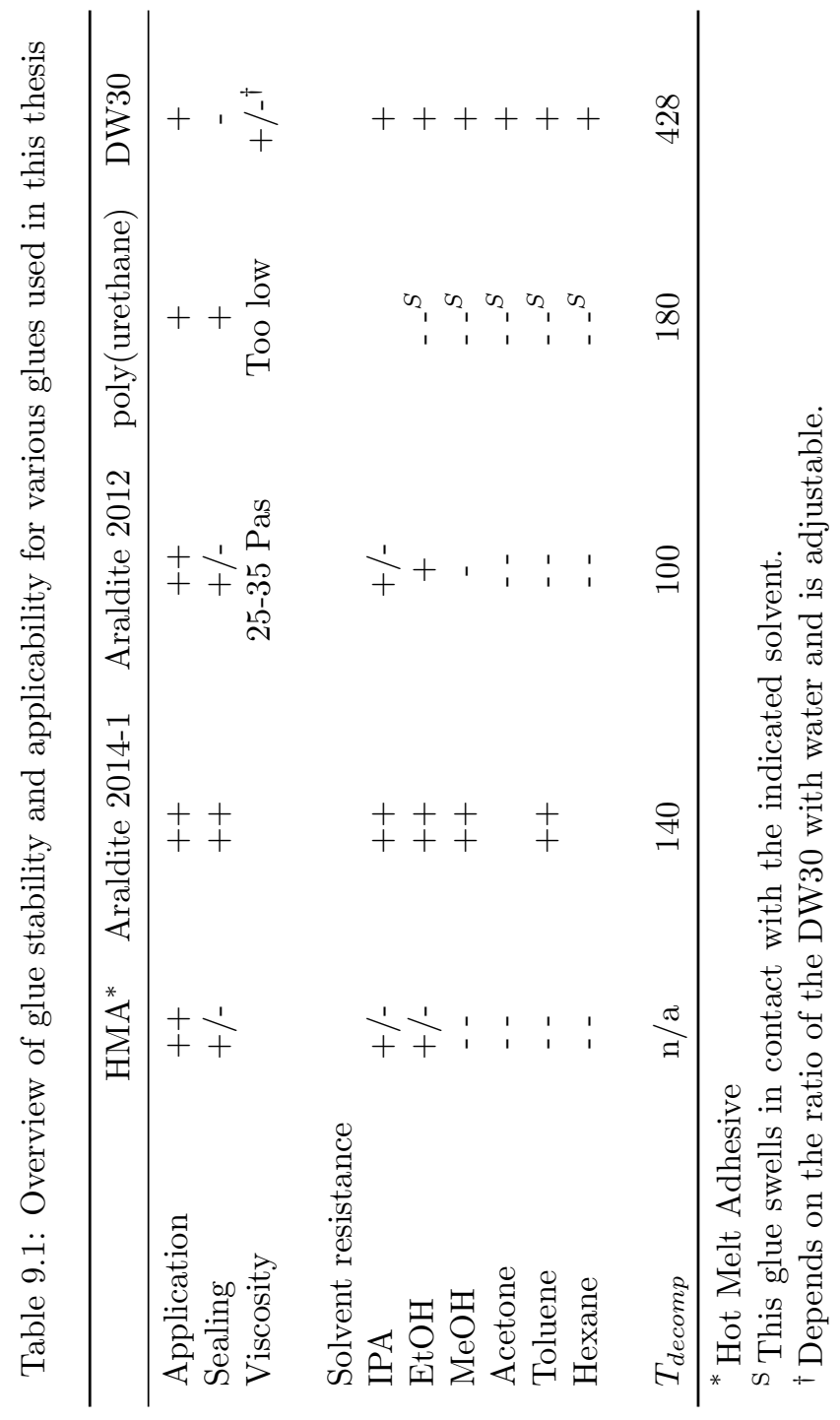




\section{Other sealing concepts}

To add to fiber sealing by glue and o-ring, several alternative methods were identified. To overcome the limitations of most, polymer based, glues the use of ceramic sealants is considered. One strategy could involve using an inorganic particle loaded polymer slurry as sealing, which is thermally treated to remove the polymer and to sinter the inorganic particles. The main challenge is shrinkage of the seal, which is inevitable upon removal of the polymer and during densification of the inorganic material [54]. This would work for systems that are thermally stable, e.g., that consist only out of inorganic materials that sinter at elevated temperatures.

A second alternative would be to use a low temperature sinterable glass that could be used to integrate the fibers in, for example, a glass module. Glass modules comprising multiple fibers have been reported recently, but the production of these modules is cumbersome and requires multiple steps. Also, the fragility of the glass module could be a concern for industrial application [55]. Close stacking of the fibers could lead to failure of individual fibers, due to forces exerted by one fiber to another. This can be circumvented by the use of spacers at the glue-site. A small spacer separating the fibers, e.g., $1 \mathrm{~mm}$, might be sufficient to keep the fibers separated throughout the entire module. Another option could be based on 3D printing of a holder, which would also allow the fibers to be stacked into a certain orientation. Additionally, the holder could be tailored in such a way that it could simplify enclosing the bundle of fibers by a module. Recently, solvent resistant polymers such as PEEK were 3D printed, which could also facilitate usage of such a holder under harsh conditions [56].

Finally, for metal, or metal coated fibers, soldering of welding could be promising options in order to construct a module out of multiple fibers. Especially for fibers that also require an electrical connection between the fiber and the (outside) of the module this would be of interest. 


\subsubsection{Perspectives on mechanical strength measurements}

Detailed knowledge on the mechanical properties of inorganic porous hollow fibers is of utmost important in the design of multi-fiber modules. Currently, most research on mechanical properties focuses on the flexural strength of these fibers, which gives reasonable estimates of the fiber's mechanical integrity for comparative purposes. In order to design a module, a more detailed mechanical investigation is required.

During two-sided potting of a fiber, the fiber is subject to many more stresses. Not only forces exerted on the fiber in the radial direction are importance, but also torsional forces, pressure gradients with their resultant hoop stresses, and the effect of flow along the fiber. Some of these forces are difficult to measure on a fiber, whereas others are already used to quantify the strength of a fiber. Torsional forces are found to be the largest contributing factor on potted fiber failure.

Upon operation as a membrane, a pressure gradient over the wall of the fiber is often used as a driving force. This gradient results in radial stresses in the fiber that are not accounted for during, for example, a bending test. It is therefore difficult to translate results obtained during a bending test to, for example, the burst pressure of the fiber. Measurement of the burst pressure of these fibers requires a high-pressure setup which is not easily accessible, but could reveal valuable information on the mechanical properties that are relevant in operation. On the contrary, in chapter 2 no failure was observed in $\mathrm{SiC}$ fibers upon rapid pressurization up to pressures of 18 bar. This suggests that the burst pressure of these fibers will probably be higher than what normally would be required for most membrane processes.

What currently lacks are well-defined criteria on which the fiber's mechanical properties should be evaluated. This does not only depend on the specific design of the module or the sealing method used, but also strongly depends on the acceptable probability of failure. The latter depends on the underlying statistical model, which can only be determined by testing a large amount of fibers for their mechanical properties. Based on an acceptable failure rate, a design stress can be calculated which could be used for module design. Obviously, one should attempt to keep the stresses exhibited on the fiber below this design value. 


\subsection{References}

[1] B. Hofs, J. Ogier, D. Vries, E. F. Beerendonk, E. R. Cornelissen, Comparison of ceramic and polymeric membrane permeability and fouling using surface water, Sep. Purif. Technol. 79 (2011) 365-374.

[2] G. Wei, S. Chen, X. Fan, X. Quan, H. Yu, Carbon nanotube hollow fiber membranes: High-throughput fabrication, structural control and electrochemically improved selectivity, J. Memb. Sci. 493 (2015) 97-105.

[3] W. Deng, X. Yu, M. Sahimi, T. T. Tsotsis, Highly permeable porous silicon carbide support tubes for the preparation of nanoporous inorganic membranes, J. Memb. Sci. 451 (2014) 192-204.

[4] V. Suwanmethanond, E. Goo, P. K. T. Liu, G. Johnston, M. Sahimi, T. T. Tsotsis, Porous silicon carbide sintered substrates for high-temperature membranes, Ind. Eng. Chem. Res. 39 (2000) 3264-3271.

[5] B. Elyassi, M. Sahimi, T. T. Tsotsis, Silicon carbide membranes for gas separation applications, J. Memb. Sci. 288 (2007) 290-297.

[6] J. Li, J. He, Y. Huang, D. Li, X. Chen, Improving surface and mechanical properties of alginate films by using ethanol as a co-solvent during external gelation, Carbohydr. Polym. 123 (2015) 208-216.

[7] R. Vreeker, L. Li, Y. Fang, I. Appelqvist, E. Mendes, Drying and rehydration of calcium alginate gels, Food Biophys. 3 (2008) 361-369.

[8] Y. Wang, J. Nie, B. Chang, Y. Sun, W. Yang, Poly(vinylcaprolactam)based biodegradable multiresponsive microgels for drug delivery, Biomacromolecules 14 (2013) 3034-3046.

[9] M. J. T. Raaijmakers, N. E. Benes, Current trends in interfacial polymerization chemistry, Prog. Polym. Sci. 63 (2015) 86-142.

[10] L. Y. Chu, S. Wang, W. M. Chen, Surface modification of ceramicsupported polyethersulfone membranes by interfacial polymerization for reduced membrane fouling, Macromol. Chem. Phys. 206 (2005) 19341940.

[11] G. M. Shi, T. S. Chung, Thin film composite membranes on ceramic for pervaporation dehydration of isopropanol, J. Memb. Sci. 448 (2013) 34-43. 
[12] M. J. T. Raaijmakers, M. A. Hempenius, P. M. Schön, G. J. Vancso, A. Nijmeijer, M. Wessling, N. E. Benes, Sieving of hot gases by hypercross-linked nanoscale-hybrid membranes., J. Am. Chem. Soc. 136 (2014) $330-5$.

[13] M. Raaijmakers, Hyper-cross-linked, hybrid membranes via interfacial polymerization, Phd thesis, University of Twente, 2013.

[14] ASTM, C1239-13 Standard Practice for Reporting Uniaxial Strength Data and Estimating Weibull Distribution Parameters for Advanced Ceramics, 2014 .

[15] ASTM, C1684-08 Standard Test Method for Flexural Strength of Advanced Ceramics at Ambient Temperature, ASTM Int. West Conshohocken, PA (2002) 1-21.

[16] C. Lu, A reassessment of the strength distributions of advanced ceramics, J. Aust. Ceram. Soc. 44 (2008) 38-41.

[17] S. Nohut, Influence of sample size on strength distribution of advanced ceramics, Ceram. Int. 40 (2014) 4285-4295.

[18] E. Smeets, Aluminium hollow fibers, Bachelor thesis, University of Twente, 2014.

[19] W. Lensing, The preparation and characterization of aluminium hollow fiber membranes, Bachelor thesis, University of Twente, 2015.

[20] S. Okuma, The Sintering Mechanism of Aluminium and the Anodization of Aluminium Sintered Bodies, Act. Passiv. Electron. Components 6 (1979) $23-29$.

[21] T. Schubert, T. Pieczonka, S. Baunack, B. Kieback, The Influence of the Atmosphere and Impurities on the Sintering Behaviour of Aluminium, in: Euro PM, pp. 3-8.

[22] G. A. Kerga, Polymer and Solvent Free Inorganic Hollow Fiber Membranes, Master thesis, University of Twente, 2015.

[23] R. Kas, K. K. Hummadi, R. Kortlever, P. de Wit, A. Milbrat, M. W. J. Luiten-Olieman, N. E. Benes, M. T. M. Koper, G. Mul, Three-dimensional porous hollow fibre copper electrodes for efficient and high-rate electrochemical carbon dioxide reduction, Nat. Commun. 7 (2016) 10748. 
[24] R. C. Agarwala, V. Agarwala, Electroless alloy/composite coatings: A review, Sadhana 28 (2003) 475-493.

[25] J. R. Henry, Electroless (autocatalytic) plating, Met. Finish. 97 (1999) 431-442.

[26] J. Sudagar, J. Lian, W. Sha, Electroless nickel, alloy, composite and nano coatings - A critical review, J. Alloys Compd. 571 (2013) 183-204.

[27] I. Baskaran, T. S. N. S. Narayanan, A. Stephen, Effect of accelerators and stabilizers on the formation and characteristics of electroless Ni-P deposits, Mater. Chem. Phys. 99 (2006) 117-126.

[28] H. Adkins, H. Cramer, The use of nickel as a catalyst for hydrogenation, J. Am. Chem. Soc. 52 (1930) 4349-4358.

[29] G. Venkatachalam, S. Karthikeyan, M. Hitharth, K. Sumanjeet, S. Narayanan, Formulation of novel electroless plating process for $\mathrm{Cu}$ and Cu-P alloys, Int. J. ChemTech Res. 5 (2013) 237-245.

[30] C. Keijzers, Electrochemical reduction of $\mathrm{CO}_{2}$ to $\mathrm{CO}$ with a copper catalyst deposited on an alumina hollow fiber, Bachelor thesis, University of Twente, 2016.

[31] Y. Jia, Y. Kanno, Z. P. Xie, Fabrication of alumina green body through gelcasting process using alginate, Mater. Lett. 57 (2003) 2530-2534.

[32] N. Abdullah, M. A. Rahman, M. H. D. Othman, A. Ismail, J. Jaafar, A. A. Aziz, Preparation and characterization of self-cleaning alumina hollow fiber membrane using the phase inversion and sintering technique, Ceram. Int. 42 (2016) 12312-12322.

[33] J. Ma, Z. Xie, H. Miao, B. Zhang, X. Lin, Y. Cheng, Gelcasting of alumina ceramic components in nontoxic Na-alginate-CaIO3-PVP systems, Mater. Des. 26 (2005) 291-296.

[34] J.-W. Zhang, H. Fang, J.-W. Wang, L.-Y. Hao, X. Xu, C.-S. Chen, Preparation and characterization of silicon nitride hollow fiber membranes for seawater desalination, J. Memb. Sci. 450 (2014) 197-206.

[35] J.-W. Wang, L. Li, J.-W. Zhang, X. Xu, C.-S. Chen, $\beta$-Sialon ceramic hollow fiber membranes with high strength and low thermal conductivity for membrane distillation, J. Eur. Ceram. Soc. 36 (2015) 59-65. 
[36] Q. Xiao, X. Gu, S. Tan, Drying process of sodium alginate films studied by two-dimensional correlation ATR-FTIR spectroscopy, Food Chem. 164 (2014) 179-184.

[37] N. C. Whyte, J. Englar, M. Kung, Alginate degradation in situ accompanying thermal drying of the marine algae Nereocystis luetkeana and and Macrocystis integrifolia, Technical Report, Canada fisheries and marine service, 1976.

[38] L. W. Chan, H. Y. Lee, P. W. S. Heng, Production of alginate microspheres by internal gelation using an emulsification method, Int. J. Pharm. 242 (2002) 259-262.

[39] C. Soukoulis, L. Yonekura, H. H. Gan, S. Behboudi-Jobbehdar, C. Parmenter, I. Fisk, Probiotic edible films as a new strategy for developing functional bakery products: The case of pan bread, Food Hydrocoll. 39 (2014) 231-242.

[40] K. Kilan, P. Warszyński, Thickness and permeability of multilayers containing alginate cross-linked by calcium ions, Electrochim. Acta 144 (2014) $254-262$.

[41] S. Alkoy, H. Yanik, B. Yapar, Fabrication of lead zirconate titanate ceramic fibers by gelation of sodium alginate, Ceram. Int. 33 (2007) 389-394.

[42] V. F. T. Teixeira, N. R. Pereira, W. R. Waldman, A. L. C. D. Ávila, V. H. Pérez, R. J. S. Rodríguez, Ion exchange kinetics of magnetic alginate ferrogel beads produced by external gelation, Carbohydr. Polym. 111 (2014) 198-205.

[43] C. K. Kuo, P. X. Ma, Ionically crosslinked alginate hydrogels as scaffolds for tissue engineering: Part 1. Structure, gelation rate and mechanical properties, Biomaterials 22 (2001) 511-521.

[44] X. D. Liu, W. Y. Yu, Y. Zhang, W. M. Xue, W. T. Yu, Y. Xiong, X. J. Ma, Y. Chen, Q. Yuan, Characterization of structure and diffusion behaviour of Ca-alginate beads prepared with external or internal calcium sources., J. Microencapsul. 19 (2002) 775-782.

[45] L. W. Chan, H. Y. Lee, P. W. S. Heng, Mechanisms of external and internal gelation and their impact on the functions of alginate as a coat and delivery system, Carbohydr. Polym. 63 (2006) 176-187. 
[46] B. Y. Choi, H. J. Park, S. J. Hwang, J. B. Park, Preparation of alginate beads for floating drug delivery system: Effects of $\mathrm{CO}_{2}$ gas-forming agents, Int. J. Pharm. 239 (2002) 81-91.

[47] T. Andersen, J. E. Melvik, O. Gåserød, E. Alsberg, B. E. Christensen, Ionically gelled alginate foams: Physical properties controlled by type, amount and source of gelling ions, Carbohydr. Polym. 99 (2014) 249-256.

[48] C. J. E. Santos, T. S. Wei, B. Cho, W. M. Kriven, A forming technique to produce spherical ceramic beads using sodium alginate as a precursor binder phase, J. Am. Ceram. Soc. 96 (2013) 3379-3388.

[49] S. van den Berg, Improving the drying process of alginate hollow fibers, Bachelor thesis, University of Twente, 2016.

[50] I. Moch, Membranes, Hollow-Fiber, in: Kirk-Othmer Encycl. Chem. Technol., John Wiley \& Sons, Inc., 2000.

[51] R. W. Baker, Membrane Technology and Applications, 2012.

[52] S. Nunes, K. Peinemann, Membrane technology, 2001.

[53] R. Faiz, M. Fallanza, I. Ortiz, K. Li, Separation of Olefin/Paraffin Gas Mixtures Using Ceramic Hollow Fiber Membrane Contactors, Ind. Eng. Chem. Res. 52 (2013) 7918-7929.

[54] M. N. Rahaman, Ceramic processing, Taylor \& Francis Group, 2007.

[55] P. Peeters, Inorganic Hollow Fiber Module, 2016.

[56] W. Wu, P. Geng, G. Li, D. Zhao, H. Zhang, J. Zhao, Influence of layer thickness and raster angle on the mechanical properties of 3D-printed PEEK and a comparative mechanical study between PEEK and ABS, Materials (Basel). 8 (2015) 5834-5846. 


\section{Dankwoord}

Aan alles komt een einde, niet alleen aan een 4.5 jaar durende promotie, maar ook aan dit boekwerk. Ik realiseer memijzelf dat dit wellicht het meest gelezen deel van mijn thesis is, dus ik zal het kort houden...

Nieck, als dagelijks begeleider en promotor ben ik je een groot dankjewel schuldig. In het begin van mijn promotie had ik soms mijn bedenkingen of "Fibers" wel helemaal je ding waren, tussen alle ellipsometers, iPOSS en dunne lagen. Gelukkig is dat helemaal goed gekomen en ik ben blij dat de vezels nu weer helemaal terug zijn. Het meest waardeer ik hoe je als alles tegen zit er toch nog een positieve draai aan kunt geven. Ik denk nog steeds dat FiF niet de afkorting is van "Films in Fluids", maar van "Fabricating Inorganic Fibers".

Arian, als promotor en begeleider heb je mij heel erg vrij gelaten. De halfjaarlijkse voortgangsmeeting was vooral een bijpraatmoment tussen jou en Nieck. Ik ken weinig mensen die sneller antwoorden op emails dan hun eigen out-ofoffice reply dat kan. Dankjewel voor alle hulp en input tijdens mijn promotie.

Working on an industrially based project means many project meetings, visits and discussions. I am grateful to all industrial partners for their contributions; Eirini and Johnny from Liqtech, Cristoph and Ülrich from Wyatt/Superon, Gerrald and later Michiel from AkzoNobel, Petrus from Solsep, Frans and Martin from Pervatech, Erik from DSM, Arian as representative from Shell, and Marcel and Henk from ECN.

Matthias, thanks for always asking the right questions at the right time. It's been great to have you involved, especially when it comes to generating new ideas. One of the benefits of a transnational project were the frequent visits to the RWTH Aachen. 
Theresa, from day one of the project I enjoyed your approach to all the problems we encountered with the fibers. Even though some of our side projects did not work out, I am happy that we managed to do so many awesome things with our fibers.

Emiel, eigenlijk is het allemaal jouw schuld... Van studeren in Enschede, tot uiteindelijk promoveren bij IM, om een of andere reden was jij daar vaak bij betrokken. De 4 jaar die we samen in het lab hebben gewerkt waren fantastisch, al was het maar omdat jouw experimenten altijd voor spannende situaties zorgen. Evelien, ik denk dat mijn bijdrage aan de polymeerchemie beperkt zal blijven tot het NH-hotel. Ik weet zeker dat jouw bijdrage belangrijker zal zijn. Dankjulliewel dat jullie mijn paranimfen willen zijn.

I would like to thank the students who had the courage to do their bachelor assignment (Wouter, Frederique, Cas, Tim, Suzanne) or master assignment (Ying, Wilhelm, Annemiek and Gize) with me. Your work, in some way or another, contributed to this thesis. Thanks! Frederique, jouw bachelor onderzoek heeft significant bijgedragen aan de hoofdstukken 5 en 6 . Ik durf wel te stellen dat er weinig studenten zijn die zo productief zijn geweest tijdens hun bachelor met zo weinig begeleiding. Dankjewel daarvoor!

Hussein, your stay in Twente had a huge impact on all of us, thanks for the interesting time working together on the internal gelation of sodium alginate gels. We made some super fibers. Khalid, your enthusiasm and persistence helped a lot in the synthesis of copper fibers; without you I would not have known all possible ways to the labs of PCS.

Kristianne, dankjewel voor je relativerende woorden als ik weer eens aan het klagen was over alles. Heel veel succes met je BDS Measurements en ik hoop dat je ooit de afkorting durft te googlen. Frank, Cindy en Mieke; lang geleden begon ik als student-assistent bij IM, zittend bij jullie op de kamer. Over de jaren heb ik daar het nodige geleerd, dankjulliewel daarvoor. Frank, ik ben blij dat je me het vertrouwen gaf om zelf opstellingen in elkaar te knutselen, maar ze vallen in het niet vergeleken met hoe jij ze in elkaar zet.

Timon, als BHV maatje ben ik blij dat we tegen het einde van mijn promotie nog een gezamenlijk vrijdagmiddagexperiment hebben gedaan. Dat het allemaal niet zo lukte kwam vast omdat we ons niet strikt aan het protocol hebben gehouden. 
Özlem, thanks for the fun during our Friday afternoon experiments, who were never really on a Friday anyway.

I'd like to thank the (former) office mates for joining me in my complaints about anything; Michiel, Emiel, Evelien, Kristianne, Marcel, Bas, Rian, Renaud, Jason, Zainab, Pelin and Mariël. To Renaud, Pelin, Jeff and Evelien, I can only say that Charlie is with the rainbows over Hirschegg. As our cluster grown so big of the years, it is impossible to mention all of you by name. I would like to thank all the current and past members of the Membrane Science and Technology cluster for making awesome memories.

Als ik mijn promotie even niet meer zag zitten waren er gelukkig een hele groep toffe mensen die daar verandering in konden brengen; Xavier, Hanna, Tom, Ester, Erik, Saskia, Rob, Evelien, Kim, Kenneth, Peter, Fokke, René, Brink, Wendy en iedereen die ik vergeet, dankjewel! Een belangrijke vermelding voor het "oud" bestuur der ZPV Piranha "Aqua Vitae" (Tom, Eline, Inge, Fokke en Max) waarmee we ook tijdens mijn promotie nog enkele memorabele momenten hebben meegemaakt. Het codewoord is...

Lieve Claire, dankjewel voor al je liefde en support als het even tegen zat. Dit boekje was niet gelukt zonder jouw hulp. 



\section{Curriculum Vitae}

Patrick de Wit was born on the 30th of June 1988 in Dordrecht, The Netherlands. In 2004, he obtained is havo-diploma cum laude at Develsteincollege, Zwijndrecht. In the same year he started a bachelor of applied science in chemical engineering at The Hague University of Applied Science in The Hague. During these years he was active as a board member of SV ProXcess. In total three half-year internships were conducted at Kerry Bio-Science, Zwijndrecht, The Netherlands; The North-West University in Potchefstroom, South Africa; and a final graduation project at Esterol SDN BHD, Shah Alam, Malaysia.

In 2009 he finished his bachelor studies cum laude and continued with a master in Chemical Engineering at the University of Twente, in the track Process Engineering. During his masters studies he remained active in student life by being a board member of student swim club ZPV Piranha. In 2012, he graduated from the University of Twente on a master thesis entitled: "Silicon carbide membranes for produced water treatment".

Starting from February 2013, he has been working as a $\mathrm{PhD}$ candidate at the Films in Fluids group at the University of Twente, under the supervision of prof.dr.ir. Nieck E. Benes on the fabrication of inorganic porous hollow fibers. His research was presented at multiple international conferences and workshops, including the International Conference on Inorganic Membranes (2014, Brisbane, Australia), the Euromembrane conference (2015, Aachen, Germany) and the 9th International Membrane Science and Technology conference (2016, Adelaide, Australia). 



\section{List of publications}

\section{Peer-reviewed journals}

Per May 2017

P. de Wit, E.J. Kappert, T. Lohaus, M. Wessling, A. Nijmeijer, N.E. Benes, 2015, Highly permeable and mechanically robust silicon carbide hollow fiber membranes, J. Membr. Sci., 475, pp. 480-487.

http://dx.doi.org/10.1016/j.memsci.2014.10.045

S. Shukla, P. de Wit, M.W.J. Luiten-Olieman, E.J. Kappert, A. Nijmeijer, N.E. Benes, 2015, Synthesis of Porous Inorganic Hollow Fibers without Harmful Solvents, ChemSusChem 8 pp. 251-254.

http://dx.doi.org/10.1002/cssc.201402483

H.Q. Hussein, P. de Wit, E.J. Kappert, A. Nijmeijer, N.E. Benes, 2015, A sustainable route to inorganic porous hollow fibers with superior properties, ACS Sustainable Chem. Eng. 3 (12) pp. 3454-3460.

http://dx.doi.org/10.1021/acssuschemeng.5b01248

R. Kas, K. Khazzal Hummadi, R. Kortlever, P. de Wit, A. Milbrat, M.W.J. Luiten-Olieman, N.E. Benes, M.T.M. Koper and G. Mul, 2016, Three-dimensional porous hollow fibre copper electrodes for efficient and high-rate electrochemical carbon dioxide reduction, Nat. Commun. 7:10748

http://dx.doi.org/10.1038/ncomms10748

P. de Wit, F.S. van Daalen and N.E. Benes, 2017, The mechanical strength of a ceramic porous hollow fiber, J. Membr. Sci., 524, pp. 721-728.

http://dx.doi.org/10.1016/j.memsci.2016.11.047 
P. de Wit, F.S. van Daalen and N.E. Benes, 2017, The effect of the production method on the mechanical strength of an alumina porous hollow fiber, J. Eur. Ceram. Soc., 37 (10), pp. 3453-3459.

http://doi.org/10.1016/j.jeurceramsoc.2017.03.062

T. Lohaus, P. de Wit, M. Kather, D. Menne, N.E. Benes, A. Pich, M. Wessling, Tunable permeability and selectivity: Heatable inorganic porous hollow fiber membrane with a thermo-responsive microgel coating, J. Membr. Sci. https://doi.org/10.1016/j.memsci.2017.05.052

\section{Selected oral presentations}

P. de Wit, A. Nijmeijer, N.E. Benes, Highly permeable and mechanically robust silicon carbide hollow fiber membranes, International Conference on Inorganic Membranes (ICIM), 2014, Brisbane, Australia

P. de Wit, N.E. Benes, Breaking with traditions: Do porous inorganic hollow fibers follow the Weibull model? European Ceramic Society (ECerS), 2015, Toledo, Spain

P. de Wit, S. Shukla, H.Q. Hussein, E.J. Kappert, M.W.J. Luiten, A. Nijmeijer, N.E. Benes, An organic-solvent-free route to inorganic porous hollow fibers, EuroMembrane, 2015, Aachen, Germany

P. de Wit, F.S. van Daalen, S. Shukla, H.Q. Hussein and N.E. Benes, An organic-solvent-free route to inorganic porous hollow fibers, IMSTEC, 2016, Adelaide, Australia 

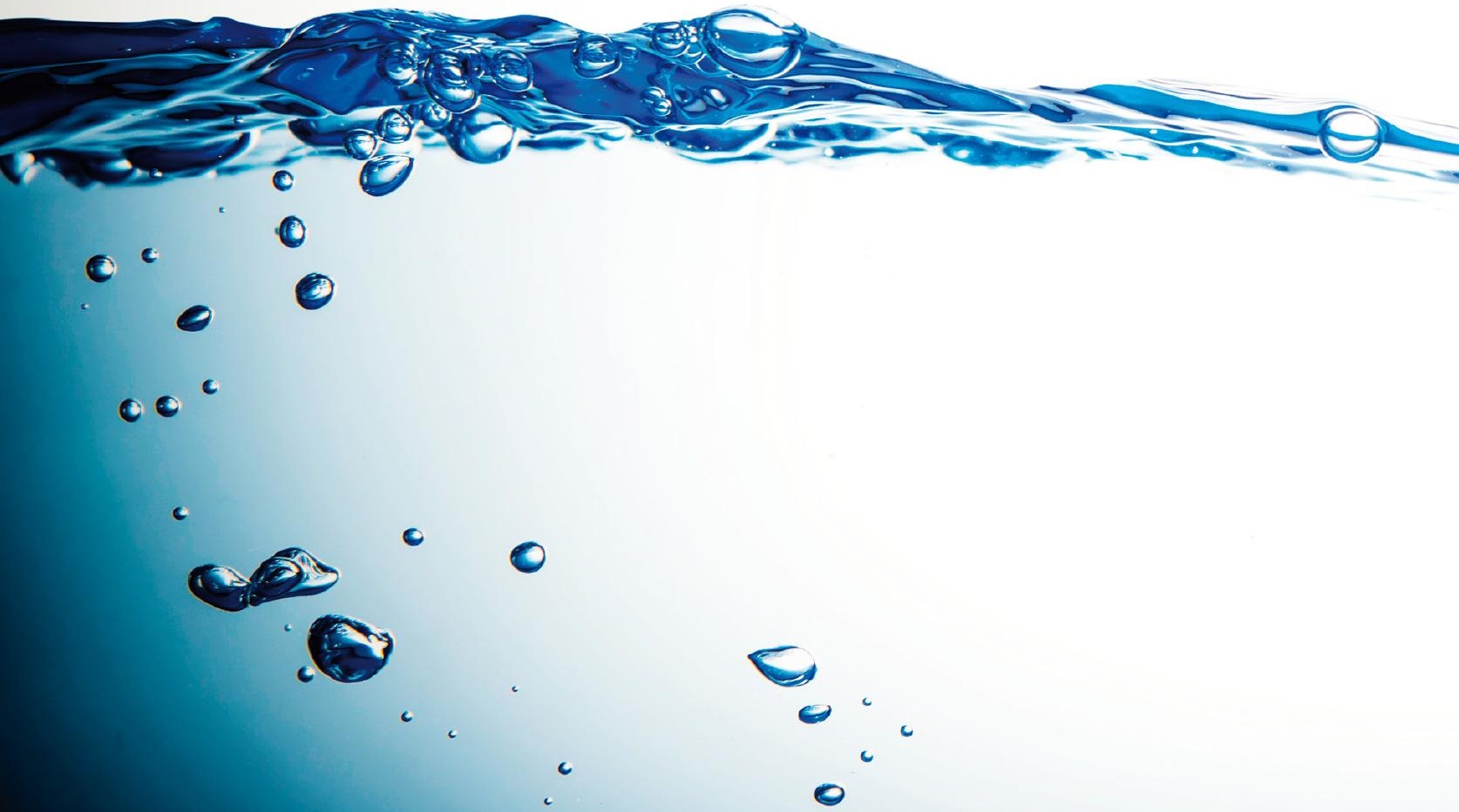

ISBN: 978-90-365-4327-9

0 